FRANCISCO XAVIER SEVEGNANI

ANÁLISE DA ASSINATURA MAGNÉTICA RESULTANTE DE FALTAS EM SISTEMAS ELÉTRICOS VIA WAVELETS 
FRANCISCO XAVIER SEVEGNANI

\title{
ANÁLISE DA ASSINATURA MAGNÉTICA RESULTANTE DE FALTAS EM SISTEMAS ELÉTRICOS VIA WAVELETS
}

\author{
Tese apresentada à Escola Politécnica da \\ Universidade de São Paulo para obtenção \\ do título de Doutor em Engenharia de \\ Eletricidade.
}


FRANCISCO XAVIER SEVEGNANI

\title{
ANÁLISE DA ASSINATURA MAGNÉTICA RESULTANTE DE FALTAS EM SISTEMAS ELÉTRICOS VIA WAVELETS
}

\author{
Tese apresentada à Escola Politécnica \\ da Universidade de São Paulo para \\ obtenção do título de Doutor em \\ Engenharia de Eletricidade. \\ Área de Concentração: \\ Sistemas de Potência \\ Engenharia de Energia e Automação \\ Elétricas \\ Orientador: \\ Prof. Dr. Carlos Antonio França Sartori
}


Este exemplar foi revisado e alterado em relação à versão original, sob responsabilidade única do autor e com a anuência de seu orientador.

São Paulo, 17 de Setembro de 2009

Assinatura do autor

Assinatura do orientador

FICHA CATALOGRÁFICA

Sevegnani, Francisco Xavier

Análise da assinatura magnética resultante de faltas em sistemas elétricos via wavelets / F.X. Sevegnani. -- ed.rev. --São

Paulo, 2009.

$157 \mathrm{p}$.

Tese (Doutorado) - Escola Politécnica da Universidade de São Paulo. Departamento de Engenharia de Energia e Automação Elétricas.

1. Sistemas elétricos de potência (Monitoramento) 2. Campo eletromagnético (Identificação) 3. Análise de ondaletas-wavelets (Análise de séries temporias) 4. Energia elétrica (Qualidade) 5. Métodos numéricos 6 . Compatibilidade eletromagnética I. Uni versidade de São Paulo. Escola Politécnica. Departamento de Engenharia de Energia e Automação Elétricas II. t. 
DEDICATÓRIA

Dedico este trabalho à minha esposa Isabel, aos meus filhos Fábio e Ana Luisa e à minha neta Yara. 


\section{AGRADECIMENTOS}

Ao Prof. Dr. Carlos Antonio França Sartori, pela valiosa orientação na elaboração deste trabalho, bem como pela grande atenção e amizade demonstrada ao longo deste período.

Ao Laboratório de Eletromagnetismo Aplicado: LMAG-PEA-USP.

Ao Instituto de Pesquisas Energéticas e Nucleares (IPEN/CNEN-SP), e ao Centro de Tecnologia da Marinha em São Paulo (CTMSP) pela colaboração nas avaliações experimentais. Em especial ao Tarcio, Cleomir, Aparecida e Mário Alves.

Ao Centro Universitário da FEI pelo suporte que permitiu obter os dados da bancada experimental.

Ao Centro de Ciências Exatas e Tecnologia da Pontifícia Universidade Católica de São Paulo pelas condições que possibilitaram a realização de testes e calibração dos sensores desenvolvidos neste trabalho.

À Universidade Paulista, UNIP, pelo apoio e colaboração.

Ao Eng. Matheus Garcia Pellegrina e ao colega M.Sc. Marco Antonio Arouca pelo assessoramento no desenvolvimento da bancada experimental, pelas discussões técnicas e pelo apoio constante.

Ao Dr.Carlos Shiniti Muranaka pelas sugestões no desenvolvimento do sensor magnético.

Ao M.Sc. Edval Delbone pelo incentivo e informações técnicas.

Ao M.Sc. Arduino Francesco Lauricella pelas discussões e sugestões nos testes do sensor magnético.

Ao Dr. Fábio Romeu de Carvalho pela amizade e estímulo para o desenvolvimento deste trabalho.

Ao M.Sc. Darcio Ribeiro de Araújo pelas sugestões e trocas de informações que auxiliaram na realização deste trabalho, além da amizade e companheirismo.

Ao Dr. Sílvio Xavier Duarte pelas sugestões na montagem da bancada experimental ,auxílio na calibração,testes do sensor magnético e simulações do ATP.

Ao Dr. Elcio Franklin Arruda pelas sugestões e fornecimento dos dados simulados da rede de distribuição via ATP.

À minha esposa e filhos, pelo estímulo e compreensão.

A todos que, direta ou indiretamente, colaboraram durante o desenvolvimento deste trabalho. 


\section{RESUMO}

Apresenta-se uma metodologia que tem como base a análise de campos magnéticos no monitoramento da qualidade da energia de sistemas elétricos. Em particular, são avaliados os aspectos referentes à detecção de faltas em sistemas elétricos. Diferente do processo de monitoração tradicional, cujos sensores precisam estar fisicamente conectados aos circuitos analisados, propõe-se estudar a viabilidade da utilização dos sinais provenientes da assinatura magnética resultante no exame do desempenho dos sistemas elétricos. Ressalta-se, assim, a característica não invasiva deste processo. Em uma primeira instância, simulações numéricas e medidas experimentais são usadas para estimar a validade deste método. Com base em valores das correntes de falta fase-terra, relacionados a configurações reais de sistemas de distribuição, provenientes de simulações numéricas e disponibilizadas na literatura, são calculados os campos magnéticos em regiões pré-selecionadas próximas às linhas. A seguir, aplicam-se os conceitos relacionados a wavelets no tratamento dos sinais resultantes. É nesta etapa que, por meio da decomposição da assinatura magnética correspondente, serão obtidos os dados necessários para se correlacionar os componentes dos sinais ao diagnóstico das faltas, nos sistemas elétricos. A Análise de múltirresolução é aplicada. Além destes resultados teóricos, aqueles provenientes de uma bancada experimental são examinados. Algumas configurações canônicas foram pré-selecionadas, visando estudar a eventual influência dos aspectos geométricos nos resultados relacionados à decomposição do sinal em análise. Embora métodos analíticos pudessem ser empregados na determinação da assinatura magnética resultante, os métodos numéricos, tais como o método dos elementos finitos, foram utilizados visando agilizar a obtenção de resultados teóricos a serem avaliados. Da mesma forma, aplicativos já disponibilizados comercialmente foram utilizados na decomposição dos sinais. Esta metodologia foi aplicada, também, para identificar faltas, aplicando-se a análise da variância para os diversos níveis do detalhe wavelet.

A validação da metodologia foi feita pela comparação entre os resultados simulados e obtidos experimentalmente. 
Palavras- chaves: Detecção e classificação de faltas em Sistemas Elétricos, Assinatura magnética, Análise de sinais, Transformada Wavelet, Qualidade de energia, Compatibilidade eletromagnética. 


\begin{abstract}
A methodology based on the analysis of magnetic fields for monitoring the quality of energy in electrical systems is presented herein. Aspects referring to fault detection in electrical systems in particular are evaluated. Contrary to the traditional monitoring process, in which sensors must be physically linked to the circuits under analysis, the results are presented from a feasibility study on the use of signals arising from the resulting magnetic signature by means of the electrical systems analysis. Thus the non-invasive characteristic of this process should be pointed out. First, numerical simulations and experimental measures were used to estimate the validity of this method. Based on values of the current of phase-earth fault related to actual features of the distribution systems and derived from numeric simulations found in the literature, the magnetic fields, in pre-established regions, were calculated. Following this, the concepts related to wavelets in the treatment of resulting signals were applied. It is in this phase that, by means of the decomposition of the corresponding magnetic signature, the data necessary to correlate the signal components for the diagnosis of faults in electrical systems were obtained. A Multiresolution Analysis (MRA) was applied. In addition to these theoretical results, the results from a laboratory workbench were also examined. Some canonical features were pre-selected, aiming to study the influence of geometric aspects on the results related to the signal decomposition analyzed. Although analytical methods could be employed to determine the resulting magnetic signature, numerical methods, such as the finite element method, were used to expedite obtaining the theoretical results to be analyzed. Likewise, commercial software was also used for the decomposition of signals. This methodology was validated by comparing the measured and simulated magnetic flux density. This methodology was also applied to identify and classify faults by means of the variance curve towards the wavelet detail.
\end{abstract}

Keywords - Detection and classification of faults in Electric Systems, Magnetic signature, Signal analysis, Wavelet Transform, Energy quality, Electromagnetic compatibility. 


\section{LISTAS}

\section{LISTA DE FIGURAS}

Figura 1 - Fator de escala "a" da Wavelet Mãe Chapéu Mexicano[80]............. 36

Figura 2 - Translação da Wavelet Mãe Chapéu Mexicano [80]......................... 37

Figura 3 - Função Wavelet de Haar [18] …………................................... 38

Figura 4 - Função Wavelet db4 [18] ...................................................... 38

Figura 5 - Função Wavelet db-6 [18] ...................................................... 39

Figura 6 - Função Wavelet - sym3 [18] ................................................. 39

Figura 7 - Wavelet mãe "chapéu mexicano" [80]......................................... 40

Figura 8 - Espectro de energia da wavelet mãe "chapéu mexicano" [80].......... 41

Figura 9 - Análise de Multirresolução.......................................................... 48

Figura 10 - Processo de reconstrução de um sinal ......................................... 50

Figura 11- Fluxo de dados da metodologia proposta - Avaliação teórica ......... 52

Figura 12 - Fluxo de dados da metodologia proposta - Avaliação experimental via sensor de densidade de fluxo magnético ................................... 53

Figura 13 - Linha trifásica experimental para simulação de faltas ………........... 53

Figura 14- Linha experimental trifásica e medição das correntes por "probes"... 54

Figura 15 - Dimensões do Sensor magnético ……….................................. 55

Figura 16 - Foto do sensor magnético ……............................................... 56

Figura 17 - Wavelet mãe db4 ……................................................ 58

Figura 18 - Exemplo de decomposição da densidade de fluxo magnético $B$ através da Transformada Discreta Wavelet db4 - nível 10, em função do número de amostras .............................................. 58

Figura 19 - Espectro wavelet. Detalhes característicos das zonas de frequência, utilizados na classificação dos diferentes tipos de distúrbios [6], [84] ................................................................ 60

Figura 20 - Formas de ondas das correntes para curto F1T simulado ............ 62

Figura 21 - Corrente $\mathrm{I}_{1}$ curto monofásico F1T - simulado .............................. 62 
Figura 22- Espectro de frequências da corrente $I_{1}$ para curto F1T simulado.

Figura 23 - Espectro de frequências em $\mathrm{dB}_{\mathrm{A}}$ de 11 - simulado.

Figura 24 - Corrente 11 em função das amostras no intervalo da falta simulado

Figura 25 - Espectro de frequências do detalhe de $l_{1}$ usando FFT- simulado ....

Figura 26 - TW Daubechies 4- nível 10 (db4-10) aplicada á corrente $\mathrm{I}_{1}$ simulado

Figura 27 - Detalhe d1 da corrente $I_{1}$

Figura 28 - Curva da variância em função do nível do detalhe

Figura 29 - Circuito elétrico utilizado no Flux-2D para modelagem do problema.

Figura 30 - Componente na direção "x" do campo magnético resultante $\mathrm{P}(500$, -500) $\mathrm{mm}$

Figura 31 - Decomposição através da $T W$ do componente " $x$ " da densidade de fluxo magnético

Figura 32 - Detalhe $d_{1}$ da densidade de fluxo magnético .................................. 70

Figura 33 - Detalhe $d_{2}$ da densidade de fluxo magnético ................................. 71

Figura 34 - Sistema de coordenadas utilizado …………………………..... 72

Figura 35- Correntes $I_{1}, I_{2}$ e $I_{3}$ para curto F1T. Valores experimentais …........ 73

Figura 36- Corrente $\mathrm{I}_{1}$ - curto F1T - Valores experimentais .......................... 74

Figura 37- Espectro de frequências da corrente $\mathrm{I}_{1}$ (FFT) Valores experimentais

Figura 38- Espectro de frequências da corrente $l_{1}$ em $d_{B}$. Valores experimentais

Figura 39- Decomposição da corrente $I_{1}$ através da Transformada Discreta Wavelet db4 - nível 10 , em função do número de amostras.

Valores experimentais

Figura 40 - Decomposição da corrente $\mathrm{I}_{1}$ através da Transformada Discreta Wavelet db4 - nível 4, em função do número de amostras. 
Figura 41 - Densidade de fluxo magnético. Curto F1T no ponto $\mathrm{P}(-500$,

- 250)mm - Valores simulados [58]

Figura 42- Espectro de frequências da densidade de fluxo magnético $\mathrm{B}(\mu T)$. Curto F1T no ponto $\mathrm{P}(-500,-250) \mathrm{mm}$. Valores simulados

Figura 43- Espectro de frequências em $\mathrm{dB}_{\text {ut }}$ da densidade de fluxo magnético. Curto $\mathrm{F} 1 \mathrm{~T}$ no ponto $\mathrm{P}(-500,-250) \mathrm{mm}$. Valores simulados

Figura 44 - TW da Densidade de fluxo magnético. Curto- circuito F1T no ponto $\mathrm{P}(-500,-250) \mathrm{mm}$. Valores simulados.

Figura 45 - Detalhe 4 reconstruído da $T W$ da Densidade de fluxo magnético. Curto-circuito F1T no ponto $\mathrm{P}(-500,-250) \mathrm{mm}$. Valores simulados

Figura 46 - Variância para o ponto $\mathrm{P}(-500,-250) \mathrm{mm}$, curto F1T. Valores simulados

Figura 47 - Densidade de fluxo magnético para curto F1T no ponto $\mathrm{P}(-500$, -250) $\mathrm{mm}$. Valores experimentais

Figura 48 - Espectro de frequências da densidade de fluxo magnético obtido através da aplicação da FFT com amplitude em B $(\mu \mathrm{T})$.. Valores experimentais

Figura 49 - Espectro de frequências da densidade de fluxo magnético obtido aravés da aplicação da FFT, com amplitude em dB $\mathrm{d}_{\text {uт. Valores }}$ experimentais

Figura 50- $T W$ da Discreta db4, nível 10, aplicada para . curto F1T, medido no ponto $\mathrm{P}(-500,-250) \mathrm{mm}$. Valores experimentais

Figura 51- TW Discreta db4, nível 10, aplicada para curto F1T, medido no ponto $\mathrm{P}(-500,-250) \mathrm{mm}$. 
Figura 52 - Variância em função do nível de detalhe. Valores Experimentais ..... 90

Figura 53 - Ruído de fundo no laboratório - valores experimentais .................. 91

Figura 54- Densidade de fluxo magnético bruto para curto-circuito F1T no ponto $\mathrm{P}(-500,-950) \mathrm{mm}$ - Valores experimentais

Figura 55- Comparação entre as densidades de fluxo magnético, medido e simulado, para curto $\mathrm{F} 1 \mathrm{~T}$, no ponto $\mathrm{P}(-500,-250) \mathrm{mm}$

Figura 56 - Comparação entre as densidade de fluxo magnético, medido e simulado, para curto $\mathrm{F} 1 \mathrm{~T}$, no ponto $\mathrm{P}(-500,-450) \mathrm{mm}$

Figura 57- Comparação entre as densidades de fluxo magnético, medido e simulado, para curto F1T no ponto $\mathrm{P}(-550,-650) \mathrm{mm}$

Figura 58- Densidades de fluxo magnético, simulado e medido, para curto F1T no ponto $\mathrm{P}(-950,-740) \mathrm{mm}$

Figura 59- Densidades de fluxo magnético, simulado e medido, para curto F2T, no ponto $\mathrm{P}(0,-450) \mathrm{mm}$,

Figura 60- Densidades de fluxo magnético, simulado e medido, para curto F3T, no ponto $\mathrm{P}(500,-650) \mathrm{mm}$

Figura 61 - Densidades de fluxo magnético, simulado e medido, para curto F3T, no ponto $P(1500,-650) \mathrm{mm}$

Figura 62- Densidades de fluxo magnético, simulado e medido, para curto, F3T, no ponto $\mathrm{P}(500,-1450) \mathrm{mm}$

Figura 63- Densidades de fluxo magnético, simulado e medido, para curto bifásico, F1F3, no ponto $P(500,-250) \mathrm{mm}$

Figura 64 - Variância da densidade de fluxo magnético, no ponto $P(-500,-650)$ $\mathrm{mm}$, em função do nível de detalhe wavelet, para todos os tipos de curto-circuitos. Valores experimentais

Figura 65 - Detalhe das curvas de variância da densidade de fluxo magnético, no ponto $P(-500,-650) \mathrm{mm}$, em função do nível de detalhe wavelet, para todos os tipos curtos-circuitos. Valores experimentais 
Figura 66 - Variância da densidade de fluxo magnético, no ponto $P(-500,-650)$ $\mathrm{mm}$, em função do nível de detalhe wavelet, para curtos-circuitos monofásicos. Valores experimentais

Figura 67 - Variância da densidade de fluxo magnético, no ponto $P(-500,-650)$ $\mathrm{mm}$, em função do nível de detalhe wavelet, para curtos-circuitos bifásicos-terra. Valores experimentais

Figura 68 - Variância da densidade de fluxo magnético no ponto $P(-500,-650)$ $\mathrm{mm}$, em função do nível de detalhe wavelet, para curtos bifásicos. Valores experimentais

Figura 69 - Variância da densidade de fluxo magnético, no ponto $P(-500,-650)$ $\mathrm{mm}$, em função do nível de detalhe wavelet, para curto-circuito trifásico. Valores experimentais

Figura 70 - Variância da densidade de fluxo magnético, no ponto $P(1500,-650)$ $\mathrm{mm}$, em função do nível de detalhe wavelet, para curtos-circuitos monofásicos Valores experimentais

Figura 71 - Comparação entre as amplitudes da densidade de fluxo magnético medido para curtos-circuitos monofásicos e em regime permanente (normal) no ponto $\mathrm{P}(500,-650) \mathrm{mm}$

Figura 72 - Detalhe da comparação entre as amplitudes das densidades de fluxo magnético medidos para curtos-circuitos monofásicos e em regime permanente, no ponto $\mathrm{P}(500,-650) \mathrm{mm}$

Figura 73 - Variância da densidade de fluxo magnético medido no ponto $P(500$, -650)mm, para curtos-circuitos monofásicos e em regime permanente 
LISTA DE TABELAS

Tabela 1 Pontos onde foram realizadas as medições, em milímetros ..... 72

Tabela 2 Valores simulados via FLUX 2D ............................................ 108

Tabela 3 Valores simulados e medidos ............................................... 111

Tabela 4 Comparação entre as Variâncias .............................................. 112

\section{LISTA DE SÍMBOLOS}

a Fator de escala: contração ou dilatação da função wavelet

A Aproximação, componentes de baixa frequência

AMR Análise Multi-Resolução

ANEEL Agência Nacional de Energia Elétrica

ATP Alternative Transient Program

b Fator de translação da função wavelet

cA Coeficientes wavelet da aproximação - baixas frequência

cD Coeficientes wavelet do detalhe - altas frequências

D Detalhe, componentes de alta frequência

$\mathrm{db} \quad$ Nome resumido da familia Daubechies

$\mathrm{dB} \quad$ deciBel

E Energia de uma função ou sinal

$E(a, b) \quad$ Função bidimensional de densidade de energia da wavelet

EMTP Electromagnetic Transient Program

$\mathrm{H} \quad$ Filtro passa altas

H' $\quad$ Filtro passa altas de reconstrução

IEC International Electrotechnical Commission

IEEE Institute of Electrical and Electronics Engineer

L Filtro passa baixas

L' $\quad$ Filtro passa baixas de reconstrução

MEF Método dos Elementos Finitos 
QEE Qualidade de Energia Elétrica

RNA Redes Neurais Artificiais

$S \quad$ Sinal original

$\mathrm{T}(\mathrm{a}, \mathrm{b}) \quad$ Transformada Wavelet - bidimensional

TC Transformadores de Corrente

TDF Transformada Discreta de Fourier

TDFJ Transformada Discreta de Fourier Janelada

TJF Transformada Janelada de Fourier

TF Transformada de Fourier

TRF Transformada Rápida de Fourier

TP Transformadores de Potencial

TQ Transformada Quadrática

TW Transformada Wavelet

TWC Transformada Wavelet Contínua

TWD Transformada Wavelet Discreta

TWDI Transformada Wavelet Discreta Inversa

$\sigma^{2}(a) \quad$ Variância wavelet para uma Transformada Wavelet Contínua

$2 \downarrow \quad$ Operador "downsampling"

$2 \uparrow \quad$ Operador "upsampling"

IEC International Electrotechnical Commission

DEC Duração Equivalente de Interrupção por Unidade Consumidora

FEC Frequência Equivalente de Interrupção por Unidade Consumidora

FIC Frequência de Interrupção individual por Unidade Consumidora ou por Ponto de Conexão

DIC Duração de Interrupção Individual por Unidade Consumidora ou Ponto de Conexão 


\section{SUMÁRIO}

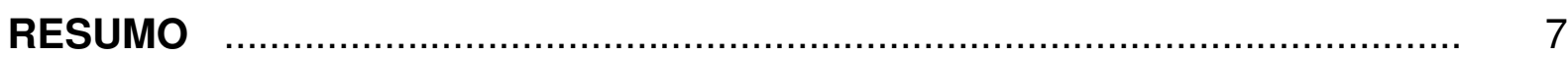

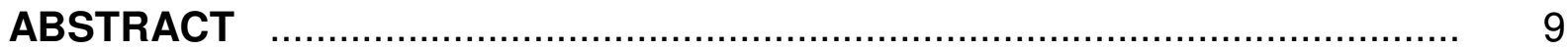

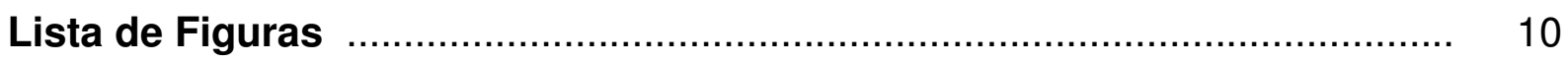

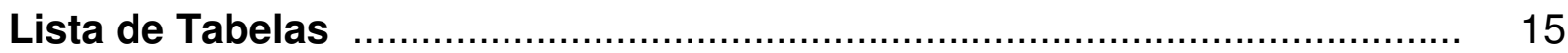

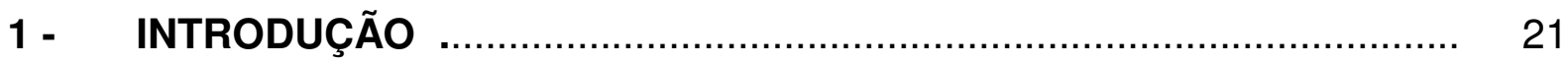

2 - O ESTADO DA ARTE …….......................................................... 24

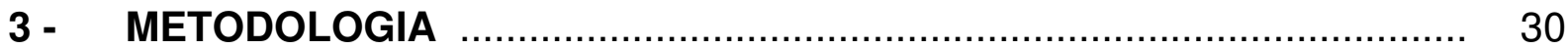

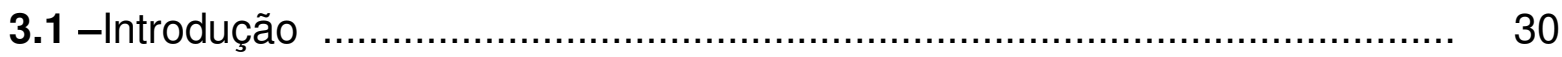

3.2 - Aspectos teóricos …................................................................. 30

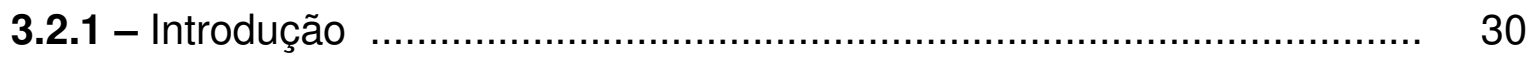

3.2.2 - Transformada de Fourier ..................................................... 31

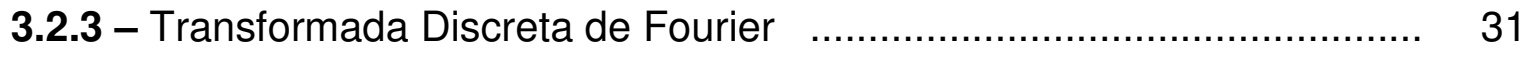

3.2.4 - Transformada Janelada de Fourier ……...................................... 32

3.2.5 - Transformada Wavelet ........................................................... 33

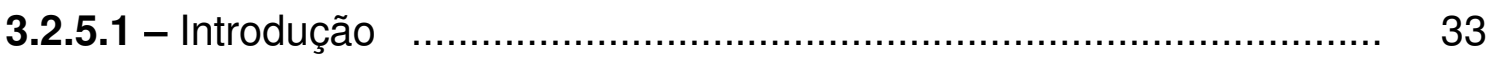

3.2.5.2 - Transformada Wavelet Contínua . .......................................... 34

3.2.5.2.1 - Dilação ou Fator de Escala ................................................. 36

3.2.5.2.2 - Translação ...................................................................... 37

3.2.5.2.3 - Famílias Wavelets ................................................ $\quad 37$

3.2.5.2.3.1 - Família Haar ............................................................. 37

3.2.5.2.3.2 - Família Daubechies ................................................. 38

3.2.5.2.3.3 - Família Symlets ...................................................... 39

3.2.5.3 - A Transformada Wavelet Inversa …….................................... 40

3.2.5.4 - Espectro de energia da wavelet ............................................ 40

3.2.5.5 - A energia wavelet do sinal e o espectro de potência ................. 42 
3.2.5.6 - A Transformada Wavelet Discreta

3.2.5.6.1 - Escala de grade diádica e Transformada Wavelet Ortogonal 46

3.2.5.7 - Análise de Multirresolução 47

3.2.5.8 - Reconstrução Wavelet 50

3.3 - Metodologia proposta para detecção de Faltas 51

3.3.1 - Introdução 51

3.3.2 - Metodologia aplicada à análise dos sinais 57

3.4 - Metodologia de classificação dos sinais

4 - RESULTADOS

4.1 - Introdução 61

4.2 - Aplicação da metodologia em simulações numéricas

4.2.1 - Aplicação da metodologia em simulações numéricas utilizando dados teóricos

4.2.1.1 - Análise das correntes na linha

4.2.1.1.1 - Análise espectral da corrente $l_{1}$ simulada, através da Transformada Rápida de Fourier

4.2.1.1.2 - Transformada Wavelet aplicada à forma de onda da corrente $\mathrm{I}_{1}$ e curva da variância 65

4.2.1.1.3 - Densidade de fluxo magnético e Transformada Wavelet 68

4.2.2 - Aplicação da metodologia em simulações numéricas com dados experimentais

4.2.2.1 - Medições das correntes na linha para curto $F 1 T$

4.2.2.2 - Análise espectral da corrente $I_{1}$ usando a Transformada Rápida de Fourier 74

4.2.2.3 - Transformada Wavelet aplicada á forma de onda da corrente $I_{1} .76$

4.2.2.4 - Densidade de fluxo magnético 78

4.2.2.4.1 - Forma de onda do curto fase-terra 78

4.2.2.4.2 - Espectro de freqüências da forma de onda da densidade de fluxo magnético 
4.2.2.4.3 - Transformada wavelet da forma de onda da densidade de fluxo magnético

4.2.2.4.4 - Variância do sinal simulado no ponto $\mathrm{P}(-500,-250) \mathrm{mm}$

4.3.1 - Medições das densidades de fluxo magnético através de sensor de campo magnético

4.3.1.1 - Forma de onda da densidade de fluxo magnético em um ponto $\mathrm{P}(-500,-250) \mathrm{mm}$ para curto

4.3.1.1.1 - Análise espectral da densidade de fluxo magnético usando a Transformada Rápida de Fourier

4.3.1.1.2 - Transformada Wavelet aplicada à forma de onda da densidade de fluxo magnético para curto F1T no ponto $\mathrm{P}(-500,-250) \mathrm{mm}$

4.3.1.1.3 - Variância do sinal em função do nível de detalhe wavelet para curto F1T no ponto $\mathrm{P}(-500,-250) \mathrm{mm}$

4.3.2 - Influência da densidade de fluxo magnético presente no laboratório

4.3.2.1 - Densidade de fluxo magnético no laboratório

4.3.2.2 - Densidade de fluxo magnético bruto

4.4 - Comparação entre densidade de fluxo magnético simulado e medido para vários pontos

4.4.1 - Introdução

4.5 - Determinação da fase com falta por meio da comparação entre as curvas de variâncias para vários tipos de curtos.

4.5.1 - Introdução

4.6 - Determinação da fase com falta através da amplitude da densidade de fluxo magnético em função do tempo 
5.1 - Análise dos resultados................................................................... 107

5.1.1 - Resultados simulados ................................................................ 107

5.1.2 - Resultados experimentais......................................................... 109

5.1.3 -.Comparação entre valores simulados e medidos ............................. 110

5.1.4 - Determinação da fase com falta através das curvas de variância e por meio da amplitude da densidade de fluxo magnético em função do tempo

5.1.5 - Determinação da fase com falta através da densidade de fluxo magnético em função do tempo

5.1.6 - Resultados adicionais

6 - CONCLUSÕES

7 - REFERÊNCIAS.

8 - APÊNDICE - A

9 - APÊNDICE - B

10 - APÊNDICE - C 


\section{1- INTRODUÇÃO}

Os sistemas de potência estão sujeitos a fenômenos transitórios que podem ser ocasionados, por exemplo, por descargas atmosféricas, acionamento de cargas indutivas (motores, transformadores), chaveamentos de capacitores, faltas sustentadas etc.

Assim, em função das características destes fenômenos e do nível de imunidade dos equipamentos atuais, nota-se que diversos eventos indesejáveis podem ocorrer, tais como acionamentos indevidos de relés, mau funcionamento de equipamentos eletro-eletrônicos, distorções harmônicas e interrupções do fornecimento de energia elétrica.

Ressaltam-se, desta forma, além dos aspectos técnicos indesejáveis, aqueles que poderão resultar em prejuízos econômicos de grande vulto, tanto para as concessionárias como para os consumidores.

Por outro lado, menciona-se, no nosso cenário atual, a crescente evolução e introdução de produtores descentralizados e da desregulamentação do mercado de energia elétrica mundial, gerando problemas na qualidade de energia.

Com relação aos aspectos técnicos, pode-se citar, por exemplo, a presença de múltiplas fontes geradoras de energia e, consequentemente, sentidos diversos de fluxo de energia elétrica. Neste cenário, regulamentações bastante rígidas devem ser seguidas, visando atender os critérios de qualidade de fornecimento de energia.

Existem várias normas internacionais e nacionais relacionadas à supervisão e controle da qualidade de energia. Entre as normas internacionais ressalta-se a IEC 61000-4-30 (2003-02) [1] . No Brasil, destaca-se a resolução no 24 (2000-01) da ANEEL [2]. Estas abordam, basicamente, métodos de medidas para qualidade de energia e as disposições relativas à continuidade da distribuição de Energia Elétrica às unidades consumidoras. Diversos índices são recomendados visando atender aos requisitos de qualidade de energia, destacando-se o DEC(Duração Equivalente de Interrupção por Unidade Consumidora) e o FEC(Frequência Equivalente de Interrupção por Unidade Consumidora), além dos indicadores de Continuidades Individuais tais como o FIC ( Frequência de Interrupção individual 
por Unidade Consumidora ou por Ponto de Conexão) e o DIC (Duração de Interrupção Individual por Unidade Consumidora ou Ponto de Conexão).

No que diz respeito ao cenário da gestão de redes de distribuição, observa-se que existe uma tendência em alguns países a não recomendar a adoção de processos invasivos, tais como a instalação de dispositivos nos condutores, e a restringir processos que demandem equipes numerosas e altamente qualificadas para atividades de supervisão das linhas de energia elétrica.

Desta forma, entre os diversos aspectos relacionados aos tópicos de qualidade de energia, a adoção de processos clássicos de deteç̧ão e localização de faltas poderá apresentar-se, em um futuro próximo, como técnica obsoleta.

Faz-se, assim, necessária uma reflexão sobre o desenvolvimento e o aprimoramento de aparelhos e técnicas não invasivas para a monitoração de redes de energia.

Diversas técnicas, adequadas à análise no plano tempo-frequência, aplicáveis no diagnóstico e na análise de fenômenos relacionados à qualidade de energia elétrica, têm sido desenvolvidas. Dentre estas, destaca-se a Transformada Wavelet (TW). Nota-se que esta tem sido destacada na literatura atual como uma ferramenta apropriada e de grande potencialidade para a análise de sinais dos eventos resultantes dos fenômenos eletromagnéticos anteriormente mencionados [3]-[5]. De uma maneira simplificada, pode-se dizer que a análise de sinais via TW permite a obtenção de informações simultâneas nos domínio do plano tempo-frequência. Esta decomposição do sinal via TW é realizada por meio de filtros, aplicando-se o que se denomina Análise de Multirresolução (AMR), possibilitando o diagnóstico e localização de distúrbios. Isto é, os distúrbios podem ser detectados no tempo, em função do seu conteúdo de freqüência [6],[7]. A possibilidade de se utilizar dispositivos não invasivos, tais como sensores de campos magnéticos, atende aos requisitos anteriormente descritos, no que tange à análise de qualidade de energia de sistemas elétricos.

Neste contexto, propõe-se o desenvolvimento detalhado da metodologia de deteç̧ão de faltas em redes de energia elétrica, tendo como modelo teórico a aplicação da TW no tratamento das ondas que representam as variações ocorridas 
no campo magnético, resultantes de fenômenos que possam gerar índices de qualidades de energia não adequados. 


\section{2 - O ESTADO DA ARTE}

Os eventos relacionados a falhas nos sistemas elétricos são bastante diversificados e podem ser provocados pela ocorrência de vários tipos de fenômenos eletromagnéticos que afetam diretamente os consumidores de energia elétrica. Note-se que estes eventos podem estar relacionados à qualidade de energia elétrica, fator muito importante, atualmente, na competitividade dos setores industriais e comerciais. Entre os principais eventos relacionados com a qualidade de energia elétrica (QEE) mencionam-se os transitórios, variações de tensão de curta duração, variações de tensão de longa duração, distorções da forma de onda, flutuações ou oscilações de tensão e variações na frequência do sistema elétrico [8], [9].

Dentre as normas relacionadas a estes aspectos, destacam-se as da International Electrotechnical Commission - IEC 61000-4-30: 2003 [1], IEC 61000-411: 2004 [10], IEC 61000-4-13: 2002 [11], EN 50160: 2000 [12]. Estas tratam dos métodos de medições, índices de mérito e recomendações relativas a este importante tópico.

As normas americanas do Institute of Electrical and Electronics Engineer IEEE 519 (1992-05) [13] e IEEE 1159 (1995-11) [14], também, podem ser destacadas.

Com relação aos organismos reguladores nacionais enfatiza-se que, compete à Agência Nacional de Energia Elétrica (ANEEL), regulamentar os aspectos relativos à qualidade de energia elétrica. Através das Resoluções da ANEEL № 24 de 27 de janeiro de 2000 [2] e № 505 de 26 de novembro de 2001, foram criados diversos indicadores específicos para avaliar a qualidade de energia elétrica fornecida pelas concessionárias [15].

Observa-se que a proteção dos sistemas elétricos é complexa e envolve diversos procedimentos para que se possa garantir o fornecimento de energia com qualidade. Assim, ressalta-se que para analisar as faltas é necessário detectar, localizar e classificar os eventos relacionados.

Note-se que a ocorrência de distúrbios no sistema elétrico acarreta mudanças nas formas de ondas da tensão e da corrente. Para que estudos e análises destas 
formas de ondas possam ser feitos, utilizam-se simulações computacionais, através de softwares, por exemplo, EMTP (Electromagnetic Transient Program) [16], ATP (Alternative Transient Program) [17], Matlab [18], PSCAD/EMTDC [19] e processos de avaliação de sinais com medidas realizadas através de sistemas computacionais de aquisição de dados e instrumentos de medições. Para esta finalidade, utilizam-se osciloscópios, oscilógrafos de dados, analisadores de espectro e outros. As análises das formas de ondas podem fornecer informações para detecção, localização e classificação dos distúrbios. De uma maneira geral, estas análises podem ser feitas através de diversas técnicas de tratamento de sinais [20]-[23] .

Ressaltam-se, atualmente, as técnicas relacionadas à TW Discreta (TWD), que, juntamente com a técnica Análise de Multirresolução (AMR), permite analisar as formas de ondas dos eventos, detectar, localizar no tempo e classificar diversos distúrbios. Observe-se, porém, a importância da escolha da wavelet mãe e sua dependência do tipo de distúrbio analisado, devendo-se levar em conta a semelhança entre o sinal e a função wavelet. Verifica-se que existem vários tipos de wavelets que podem ser utilizados. A wavelet mãe Daubechies é largamente utilizada nos eventos sobre QEE [24], [25]. Outras famílias, como Coiflets e Symlets, são também utilizadas nos problemas de qualidade de energia [8]. Quanto à classificação dos distúrbios, diversos índices de mérito são aplicados, tais como os coeficientes quadrados da TW que permitem extrair as características necessárias para diferenciá-los [7]. Nota-se que, por exemplo, componentes de frequência, tais como $60 \mathrm{~Hz}$ e $600 \mathrm{~Hz}$ do sinal, são obtidos através da AMR e utilizados para classificação de faltas. Neste caso, o componente de frequência em $60 \mathrm{~Hz}$ indica variações de amplitude no sinal, permitindo classificar os distúrbios entre afundamento de tensão, elevação e interrupção momentânea de tensão. Por outro lado, o componente de $600 \mathrm{~Hz}$ indica a presença de variações, classificando os distúrbios como oscilações transitórias [26]. Destaca-se, também, a metodologia que relaciona a energia do sinal distorcido com a energia de cada componente da decomposição AMR, usando o teorema de Parseval. Comparando a curva de desvio padrão dos detalhes referentes ao sistema em regime permanente com a curva de desvio padrão para um determinado distúrbio, é possível classificar os diferentes distúrbios pelas faixas de frequências correspondentes [6]. Outro método 
relacionado à identificação e classificação de distúrbios utiliza um procedimento que é composto de quatro blocos, sendo o primeiro relacionado ao sinal de erro, onde o sinal é obtido pela diferença entre o sinal em regime permanente e o sinal com distúrbio. O segundo bloco é composto pela $T W$, constituindo-se na análise do sinal. O terceiro bloco é acionado, por exemplo, quando o sinal de erro for superior a $10 \%$ da tensão em regime permanente. O quarto bloco faz a classificação do distúrbio, usando o critério de máxima verossimilhança [27]-[33].

Uma segunda abordagem para detecção de faltas é aquela que utiliza método híbrido Wavelet e Fourier para detectar distúrbios harmônicos, inter-harmônicos, transitórios e notching [34], [35].

A Transformada Wavelet Contínua (TWC) também é utilizada para detectar e analisar afundamentos de tensão e transitórios. As características do sinal estudado são medidas no plano tempo-frequência. Comparando-se os valores de um banco de dados com os medidos é possível caracterizar cada tipo de distúrbio. Neste caso, analisa-se a amplitude e a duração do afundamento de tensão. Quanto aos transitórios estes são localizados pela largura do sinal [36].

A quarta abordagem é a comparação entre quatro técnicas de processamento de sinais, TWC, Transformada Wavelet Discreta (TWD) com Análise de Multirresolução (TWD e AMR), Transformada Quadrática (TQ) e a Transformada de Fourier (TF). A TQ é uma ferramenta de processamento de sinais que representa um sinal em um plano tempo-frequência levando em conta considerações de energia do sinal [37].

Os distúrbios afundamento de tensão, transitórios oscilatórios e distorções harmônicas são analisados através de cada uma das ferramentas de representação tempo-frequência. Uma comparação qualitativa dos resultados mostra as vantagens e desvantagens de cada técnica de processamento de sinais aplicados na análise de distúrbios de tensão [37].

A aplicação de Redes Neurais Artificiais (RNAs) é muitas vezes utilizada, conjuntamente com a TW, para detectar e classificar os distúrbios [38], [39]. Em [40] é apresentada uma técnica diferenciada que permite identificar as condições de falta (curto-circuito ou circuito aberto) nos terminais de uma linha de transmissão, através da avaliação da tensão induzida em outra linha (Crosstalk). A TW é usada para filtrar 
o sinal e decompô-lo para obter a assinatura da falta. São usadas duas Redes Neurais diferentes para validar os resultados e o resultado global é testado em um arranjo experimental.

Em [8], é proposto um algoritmo para detecção, localização e classificação de distúrbios na QEE, utilizando a TW. O algoritmo proposto compreende sete módulos: módulo de detecção e localização no tempo, módulo de conteúdo espectral, módulo de classificação via Transformada Rápida de Fourier, módulo de classificação via TW, módulo de classificação via Redes Neurais Artificiais, módulo de estimação da amplitude e módulo de estimação da duração do distúrbio. Já em [23], foi feito um estudo comparativo de ferramentas modernas de análise aplicadas à qualidade de energia. As ferramentas são a Transformada Janelada de Fourier (TJF), TW e Redes Neurais Artificiais (RNAs). A TW e TJF são adequadas para detectar, localizar e classificar distúrbios agregados às formas de ondas de tensão em sistemas elétricos. Os distúrbios também podem ser classificados alternativamente pelas Redes Neurais Artificiais [41].

Em [42] é desenvolvido um algoritmo digital para a implementação da proteção da interface concessionária - indústria operando em sistemas de cogeração. A decisão de abrir o paralelo entre estes dois sistemas é difícil, pois implica em riscos técnicos e econômicos para ambos. É proposta uma proteção multi-função com uma visão sistêmica das principais condições operativas, entre as quais se destacam o religamento automático decorrente do curto-circuito na concessionária, a oscilação de potência seguida ao déficit de energia entre os dois sistemas e o ilhamento que é a condição de uma parte das cargas da concessionária serem alimentadas pelo gerador da indústria quando da perda parcial ou total de sua própria alimentação.

Para a análise dos três fenômenos e sua classificação que possuem freqüências altas e baixas, usou-se o conceito de energia, TW e o desvio padrão dos coeficientes de seus níveis.

Quanto à identificação e localização de faltas destaca-se o princípio das ondas viajantes de tensão geradas por uma situação de falta. Através da análise do sinal e conhecendo-se a velocidade de propagação da falta e o tempo para percorrer a distância entre o ponto de falta e o final da linha, calcula-se a distância da falta. A 
Transformada Wavelet Discreta (TWD) e AMR são também usadas como ferramentas de análise de sinais em relés de proteção de linhas de transmissão, visando identificar e localizar faltas. Ressalta-se que, na literatura atual, são usados diversos algoritmos de localização usando o princípio das ondas viajantes [43]-[50].

Deve-se ressaltar que os métodos de detecção, classificação, localização de faltas utilizadas no sistema elétrico são majoritariamente invasivos, pois utilizam Transformadores de Corrente (TCs) e Transformadores de Potencial (TPs) para obtenção das medidas dos sinais.

Neste trabalho propõe-se uma metodologia inovadora que consiste em monitorar o sistema elétrico de modo não invasivo, à distância, diretamente através da análise do sinal correspondente do campo magnético resultante. Note-se que, nas situações de falta, a corrente elétrica assume valores elevados em relação à corrente de regime permanente, o mesmo acontecendo com o campo magnético. Assim, a aplicação da TW e seus algoritmos classificatórios podem ser úteis nesta metodologia proposta. Estudos teóricos e experimentais são propostos. Há na literatura diversos trabalhos relacionando a avaliação teórica de campos, tanto analiticamente quanto por meio de métodos numéricos [51]-[56]. Neste trabalho, o campo magnético será obtido por medidas experimentais e simulações numéricas.

Ressalta-se que a monitoração do sistema elétrico pela medição do campo magnético de forma não invasiva começa a despertar interesse nos pesquisadores. Em [57] uma metodologia é apresentada na qual, através do campo irradiado pelas linhas aéreas, procura-se, por um processo inverso, obter as correntes da linha utilizando-as para análise do sistema elétrico. A influência da corrente de terra e a presença de materiais ferro- magnéticos (postes) e condutores ao redor da linha são mencionados neste estudo. Softwares comerciais tais como Flux 2D [58], EMTP [16] são utilizados nesses estudos teóricos. Outros trabalhos sobre o assunto foram recentemente apresentados [59]-[61].

Nota-se, no que se refere a sensores de campo magnético para monitorar as correntes das linhas aéreas, que há, no mercado, um indicador utilizado para linhas aéreas de alta tensão 6-66 kV. Neste, segundo informações do fabricante, o sensor magnético é utilizado na detecção de corrente e o sensor de campo elétrico monitora a tensão da linha. Os sinais dos sensores são processados e comparados com um 
critério de alarme. Uma lâmpada de xenônio indica a passagem da corrente de falta, emitindo pulsos de luz de alta intensidade em todas as direções. Eles são instalados nos postes [62].

Em [63] e [64] apresenta-se uma metodologia que tem como base a análise de campos magnéticos no monitoramento da qualidade da energia de sistemas elétricos. Em particular, são avaliados os aspectos referentes à detecção de falhas em sistemas elétricos. Diferentemente do processo de monitoração tradicional, cujos sensores precisam estar fisicamente conectados aos circuitos analisados, propõe-se avaliar a viabilidade da análise da assinatura magnética resultante na avaliação de desempenho destes. Simulações numéricas e medidas experimentais são utilizadas na determinação dos campos magnéticos. Por outro lado, os conceitos relacionados a Wavelets são aplicados na avaliação e identificação das faltas. Alguns resultados relacionados a faltas fase-terra são apresentados. Assim, neste trabalho apresentase o desenvolvimento deste método que tem, como ponto de partida, a decomposição dos sinais do campo magnético, resultantes dos distúrbios decorrentes de faltas. No que tange aos aspectos referentes às simulações numéricas, necessárias à determinação das correntes de falta, dos valores dos campos magnéticos resultantes e decomposição e análise destes via Wavelets, softwares comerciais são utilizados. Assim, este trabalho mostra-se inovador, pois, além de tratar de um problema atual que é a qualidade de energia elétrica, propõe uma nova solução para o monitoramento desta, que é a avaliação do campo magnético gerado por uma linha de distribuição, associada a uma ferramenta matemática com características adequadas à análise de fenômenos transitórios, a $T W$, via um processo não invasivo. 


\section{3 - METODOLOGIA}

\section{1 - INTRODUÇÃO}

Neste capítulo serão abordados vários tópicos relacionados à metodologia utilizada na detecção de falhas. Inicialmente serão apresentados os aspectos teóricos que justificam a aplicação das ferramentas usadas no processamento dos sinais. Dentre estas se destacam a TF e a TW. Em seguida, serão descritos os procedimentos diretamente relacionados à metodologia proposta. Descreve-se, assim, a obtenção das formas de onda da corrente elétrica e da densidade de fluxo magnético relativos aos transitórios. Apresentam-se os procedimentos para a obtenção de formas de onda via simulação numérica e via bancada experimental. Menciona-se, assim, como possíveis aplicações desta metodologia, a detecção, a avaliação do intervalo de tempo de ocorrência de faltas e a classificação destas.

\section{2 - Aspectos Teóricos}

\subsection{1 - Introdução}

Atualmente diversas técnicas podem ser utilizadas para tratamento de sinais. Com relação à $T F$, nota-se que este método tem, como característica, fornecer a decomposição do sinal no domínio da freqüência [65]. Menciona-se, também, a Transformada Janelada de Fourier (TJF), que pode decompor o sinal no domínio tempo-frequência, porém, utilizando uma janela de análise com tamanho fixo [66]. Por outro lado, a utilização da TW tem sido bastante utilizada na análise de fenômenos transitórios, apresentando, como grande vantagem, a possibilidade de transformar um sinal para o plano tempo-frequência e variar o tamanho da janela de análise, de acordo com a frequência do sinal [67], [68]. Pode-se dizer que a TW comporta-se como janelas, que proporcionam a visualização do sinal no tempo, para intervalos de frequência determinados pela função base (wavelet mãe) e suas decomposições (wavelets filhas).

Nota-se, que a TW decompõe o sinal a ser estudado em função de sua similaridade com uma determinada wavelet mãe, pré-estabelecida. Esta função é transladada por todo o sinal, sendo atribuídos coeficientes que significam o quão 
próximos estão o sinal e a função base ou suas variações (filhas). Assim, deve-se escolher a função que melhor se adequar ao sinal a ser estudado. Ressalta-se, portanto, que as TW encontram-se amplamente divulgadas na literatura atual, sendo escolhidas, preponderantemente neste trabalho, devido às suas características intrínsecas, apropriadas à análise de fenômenos transitórios. As variações existentes no sinal, para um determinado intervalo de frequências, podem ser obtidas com a precisão de tempo necessária à analise deste tipo de fenômeno [21] e [69], [70].

Uma breve descrição das técnicas de processamento de sinais, anteriormente mencionadas, é apresentada a seguir:

\subsection{2 - Transformada de Fourier}

A TF é uma ferramenta matemática tradicional que fornece o espectro de frequências de um sinal contínuo no tempo.

A TF X(f) de um sinal contínuo x(t) é definido por [ 44]:

$$
X(f)=\int_{-\infty}^{\infty} x(t) e^{-j 2 \pi f t} d t
$$

Na equação (1), a função contínua $X(f)$ é a TF de um sinal contínuo no tempo x(t), no domínio da frequência. $O$ sinal $x(t)$ é dado por:

$$
x(t)=\int_{-\infty}^{\infty} X(f) e^{j 2 \pi f t} d t
$$

A TF não tem a propriedade de localização no tempo

\subsection{3 - Transformada Discreta de Fourier}

A Transformada Discreta de Fourier (TDF) é aplicada em processamento digital de sinais, conduzindo a muitos algoritmos eficientes que podem ser implementados em computadores ou em processadores digitais [22].

A TDF de um sinal amostrado é definida como [45]:

$$
X(k)=\sum_{n=0}^{N-1} x(n) e^{-j \frac{2 \pi k n}{N}}
$$


Onde $x(n)$ é uma sequência discreta que, para aplicações particulares, deve ser obtida pela amostragem do sinal contínuo $x(t)$ a cada $T_{s}$ segundos: $x(n)=x\left(n \cdot T_{s}\right)$ para $\mathrm{n}=0,1,2,3 \ldots ., \mathrm{N}-1$ [45].

A TDF produz uma sequência de valores complexos $X(k)$, cujas amplitudes correspondem aos componentes discretos de frequência de $x(n)$. Menciona-se que a TDF é aplicável a sinais periódicos [20], [21], [69], [70].

\subsection{4- Transformada Janelada de Fourier}

$\mathrm{Na}$ Transformada Janelada de Fourier(TJF) escolhe-se uma função janela w(t) e translada-se esta janela Contínuamente sobre o sinal a ser analisado. Desta forma, pode-se representar a TJF por:

$$
\operatorname{TJF}(f, \tau)=\int_{-\infty}^{\infty} x(t) w(t-\tau) e^{-j 2 \pi f t} d t
$$

A TJF é similar à transformada de Fourier, exceto pelo fato de que o sinal $x(t)$ está multiplicado por uma função janela representada por $w(t-\tau)$ na eq. (4). Desta maneira, a Transformada Discreta de Fourier Janelada de uma entrada discreta é definida como:

$$
\operatorname{TJFD}(k, m)=\sum_{n} x(n) w(n-m) e^{-j \frac{2 \pi k n}{N}}
$$

Onde a seqüência w(n-m), na sua forma mais simples, é uma janela retangular.

$$
w(n-m)=\left\{\begin{array}{l}
1 \quad \text { se } 0 \leq(n-m) \leq(N-1) \\
0 \quad \text { outros valores }
\end{array}\right.
$$

Para cada janela $w(n-m)$, a TJFD produz uma sequência de valores complexos, cuja amplitude representa o conteúdo espectral associado às frequências discretas do sinal $x(n)$ [45].

Dependendo da análise que se deseja fazer, diversos outros tipos de função janela podem ser utilizados, tais como janela de Hanning e janela de Kaiser [23]. Nota-se que o tamanho da janela escolhido influi na resolução tempo-frequência. A resolução de tempo - frequência cresce em sentido inverso. Uma janela larga, por exemplo, permite boa resolução em frequência, mas baixa resolução no tempo, 
enquanto que, uma janela estreita fornece boa resolução no tempo e baixa resolução na frequência.

O problema da TJFD é igual ao Princípio da Incerteza de Heisenberg, originalmente aplicado ao movimento e localização de partículas móveis e pode ser aplicado à informação tempo - frequência de um sinal [45]. Assim, a priori, não se pode saber quais são os intervalos de tempo em que certa faixa de frequência ocorre. Tal problema está relacionado à largura da janela [21].

Para algumas aplicações em sinais de energia, tais como no caso de fenômenos transitórios, isto representa sérios problemas, já que a definição do tamanho ótimo da janela representa uma dificuldade adicional.

Dentre as alternativas propostas na literatura para superar tais dificuldades, destaca-se a TW, cuja aplicação mostra-se adequada à análise dos problemas de resolução tempo-frequência, encontrados na TJFD [67], [68], [70], [71].

\subsection{5 - Transformada Wavelet}

\subsubsection{1 - Introdução}

O termo wavelet foi usado por Alfréd Haar, em 1909, para designar a função que assim passou a ser nomeada [72]. As wavelets são funções de curta duração, energia finita e valor médio zero [73].

A partir de 1980 as pesquisas envolvendo a TW se intensificam, e no começo da década de 90, expandem-se para as diversas áreas da engenharia e outras áreas do conhecimento [74]. Assim, pode-se citar Stephane Mallat, no processamento digital de imagens, Meyer com as wavelets Contínuamente deriváveis e Ingrid Daubechies, entre outros [75], [79].

De uma maneira geral, a wavelet pode ser manipulada de dois modos: movendo-se para várias posições sobre o sinal (translação) e dilatando-se ou comprimindo-se (escala). Assim, pode-se mencionar que elas funcionam como uma janela que diminui para os componentes de altas frequências e aumenta para os de baixas freqüências, ou seja, a TW é uma técnica que utiliza janelas variáveis [79]. 


\subsubsection{2 - Transformada Wavelet Contínua}

A Transformada Wavelet de um sinal contínuo em relação à função Wavelet é definida por [80], [81]:

$$
T(a, b)=w(a) \int_{-\infty}^{\infty} x(t) \psi^{*}\left(\frac{t-b}{a}\right) d t
$$

Onde w(a) é uma função peso e o asterisco indica o complexo conjugado da função wavelet. O parâmetro "a" corresponde à contração ou dilatação da função wavelet e é chamado de dilação ou fator de escala. O parâmetro "b" corresponde à translação da função wavelet.

Observa-se que a Transformada Wavelet Contínua (TWC) pode ser pensada como uma correlação de um sinal $x(t)$ com um conjunto de wavelets de várias larguras.

O fator $w(a)=1 / \sqrt{a}$ é usado por conveniência para que todas as funções da classe wavelet tenham a mesma norma (energia); de fato, está convenção não é obrigatória e permite-se que outras normalizações sejam usadas, como exemplo, o fator $1 / a[45]$.

Desta forma, a TWC pode ser escrita como:

$$
T(a, b)=\frac{1}{\sqrt{a}} \int_{-\infty}^{\infty} x(t) \psi^{*}\left(\frac{t-b}{a}\right) d t \quad a \neq 0
$$

Onde $\psi^{*}\left(\frac{t-b}{a}\right)$ é a wavelet em função dos parâmetros "a" e "b" e x(t) é o sinal investigado. Na equação, o produto da wavelet pelo sinal é integrado sobre o intervalo do sinal, observando-se que esta integral se denomina, matematicamente, convolução.

Nesta equação, "a" e "b" variam Contínuamente em $R$, sendo que a função denominada wavelet mãe é definida por :

$$
\psi^{*}{ }_{a, b}(t)=\frac{1}{\sqrt{a}} \psi^{*}\left(\frac{t-b}{a}\right)
$$

Desta forma, o sinal $x(t)$, de uma dimensão, "ganha" uma representação bidimensional $\mathrm{T}(\mathrm{a}, \mathrm{b})$, permitindo uma análise tempo- frequência do sinal.

Assim, a Transformada integral pode ser escrita como: 


$$
T(a, b)=\int_{-\infty}^{\infty} x(t) \psi_{a, b}^{*}(t) d t
$$

Pode-se, também, expressar a TW de forma mais compacta, como um produto interno [76].

$$
T(a, b)=<x, \psi_{a, b}>
$$

Observando-se as características anteriormente mencionadas, uma função $\psi(t)$ para ser classificada como wavelet deve satisfazer os seguintes critérios matemáticos [80],[81]:

a) a wavelet deve ter energia finita, assim:

$$
E=\int_{-\infty}^{\infty}|\psi(t)|^{2} d t<\infty
$$

Onde E é a energia de uma função igual à integral do quadrado do módulo da amplitude de $\psi(t)$.

b) se $X(f)$ for a $T F d e ~ \psi(t)$, isto é,

$$
X(f)=\int_{-\infty}^{\infty} \psi(t) e^{-j(2 \pi f) t} d t
$$

Então a seguinte propriedade deve ser obedecida [80]:

$$
C_{g}=\int_{0}^{\infty} \frac{|X(f)|^{2}}{f} d f<\infty
$$

onde $\mathrm{C}_{\mathrm{g}}$ é chamada de condição de admissibilidade e depende da wavelet escolhida [80]. Observa-se, então, que $\psi(t)$ deve ter valor médio zero.

Os itens seguintes apresentam as propriedades relacionadas à dilação e à translação das funções wavelets. 


\subsubsection{1 - Dilação ou Fator de Escala}

A função wavelet pode ser dilatada ou comprimida. A dilatação e a compressão são regidas pelo parâmetro "a", anteriormente apresentado na equação (7). Um exemplo relacionado à wavelet, denominada "chapéu mexicano", é apresentado na Figura 1.

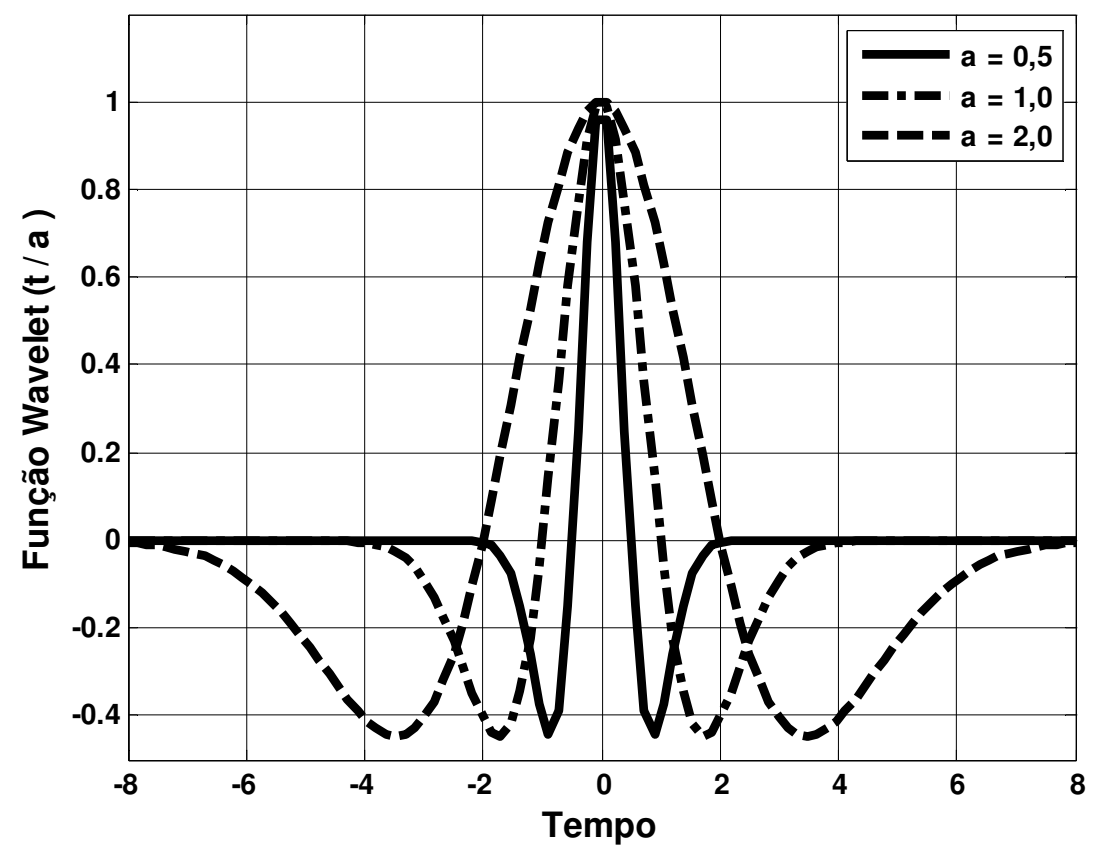

Figura 1 - Fator de escala "a" da wavelet Mãe Chapéu Mexicano[80]

O fator de escala "a" indica o comportamento da wavelet em relação à dilatação ou compressão. Para valores baixos de "a" $(0<a<1)$, tem-se wavelet comprimida e para valores elevados de "a" $(\mathrm{a}>1)$, tem-se a wavelet dilatada.

Observando-se a Figura 1, nota-se que, ao se adotar "a" = 1, a função wavelet mãe está no seu estado natural. Para "a" $=0,5$ a wavelet mãe está comprimida, permitindo identificar melhor os detalhes de alta frequência do sinal. Já para "a" $=2$, a função dilata-se e permite identificar os detalhes em baixa frequência. 


\subsection{Translação}

O movimento da wavelet ao longo do eixo do tempo é governado pelo parâmetro de translação "b". Um exemplo é apresentado na Figura 2.

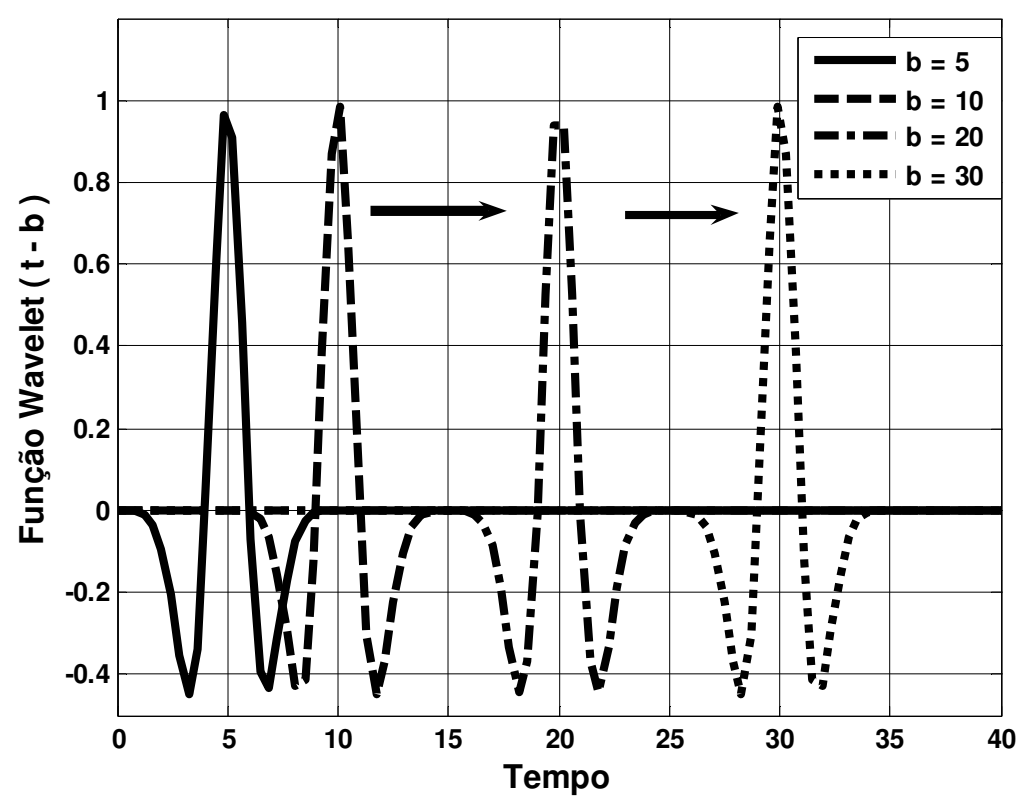

Figura 2 - Translação da wavelet Mãe Chapéu Mexicano [80]

A Figura 2 mostra a translação da wavelet em quatro posições diferentes "b" $=(5,10,20$ e 30). A translação permite amostrar o sinal.

\subsubsection{3 - Famílias Wavelets}

Existem várias famílias wavelets que são utilizadas nas análises de sinais. Serão citadas algumas delas, como exemplo.

\subsection{1- Família Haar}

A wavelet de Haar é a mais antiga e mais simples das wavelets. Sua característica geral é ter suporte compacto, isto é, toda energia da wavelet está restrita a um intervalo finito. A wavelet de Haar também é conhecida como Daubechies 1 ou db1. É uma função que possui simetria e não é contínua [73], [80]. 
A Figura 3 mostra a função wavelet de Haar.

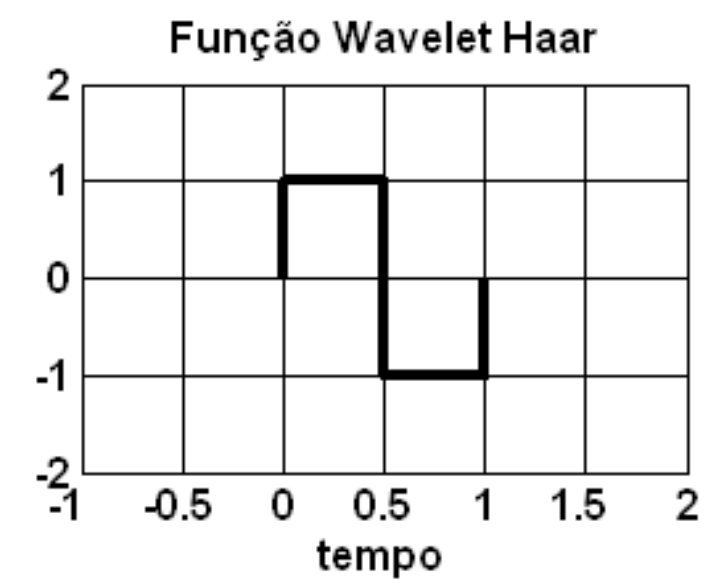

Figura 3- Função wavelet de Haar [18]

\subsection{2 - Família Daubechies}

As wavelets da família Daubechies são funções com suporte compacto. $O$ nome resumido das wavelets da família Daubechies é $\mathrm{dbN}$, sendo $\mathrm{N}$ um número inteiro e positivo. Por exemplo, db1 ou Haar, db4, db6, db15. Estas wavelets não possuem expressão analítica, exceto db1 ou Haar e são assimétricas [73]. A Figura 4 mostra a função wavelet $\mathrm{db} 4$.

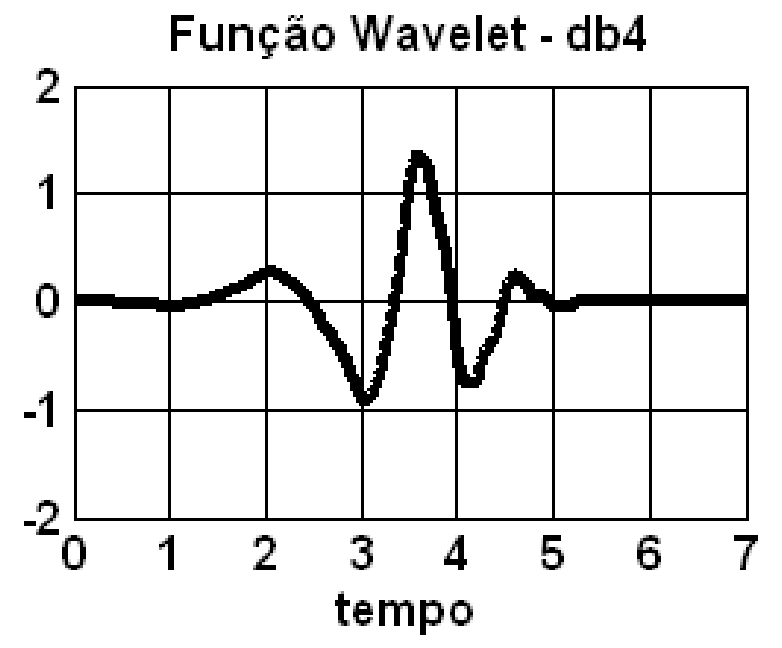

Figura 4 - Função Wavelet db4 [18] 
Na Figura 5 tem-se a função wavelet db6.

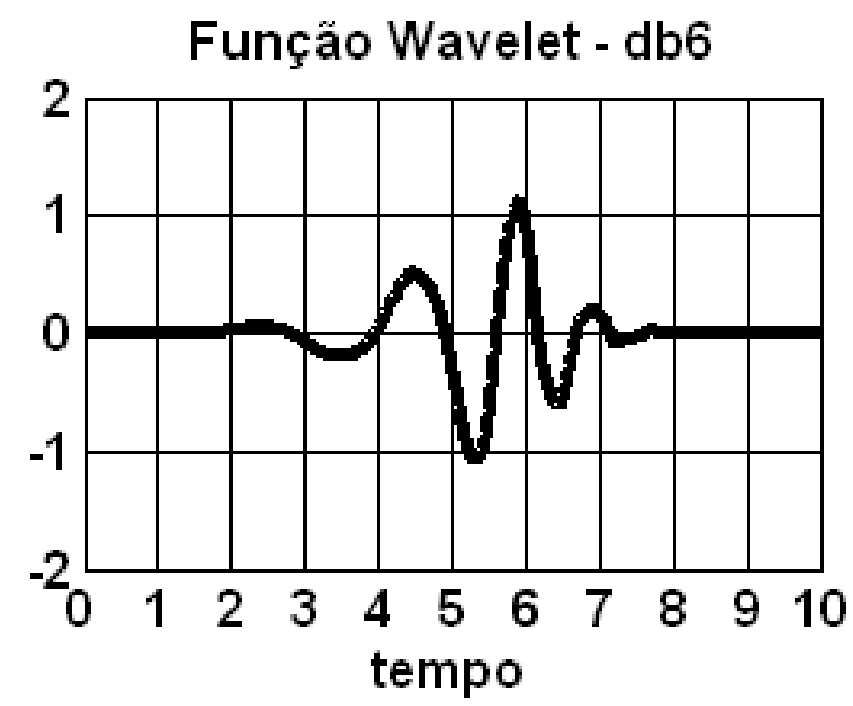

Figura 5 - Função Wavelet db-6 [18]

\subsection{3 - Família Symlets}

As wavelets da família Symlet são funções com suporte compacto. O nome resumido das wavelets da família Symlet é sym, sendo $\mathrm{N}=2,3, .$. número inteiro e positivo. Por exemplo, sym2, sym3 [73]. A Figura 6 mostra a função wavelet sym3.

Função wavelet Symlet3-sym3

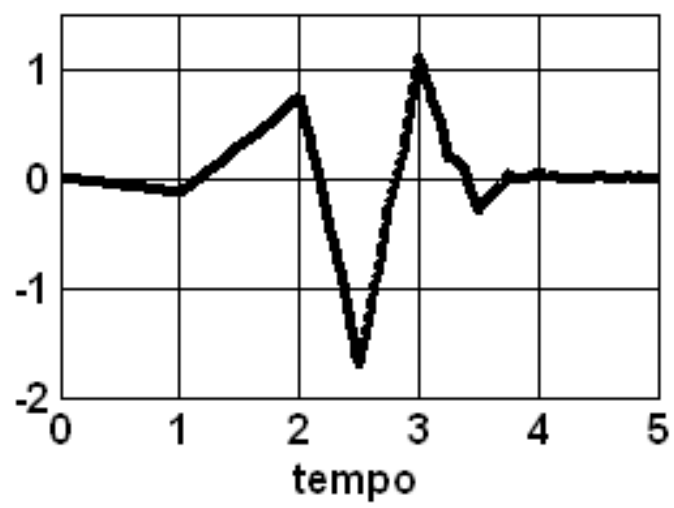

Figura 6 - Função Wavelet - sym3 [18] 


\subsubsection{3 - A Transformada Wavelet Inversa}

A $T W$ inversa é definida como [81]:

$$
x(t)=\frac{1}{C_{g}} \int_{-\infty}^{\infty} \int_{0}^{\infty} T(a, b) \psi_{a, b}(t) \frac{d a d b}{a^{2}}
$$

Onde, $x(\mathrm{t})$ é o sinal, $\mathrm{T}(\mathrm{a}, \mathrm{b})$, a $T W, \psi_{a, b}(t)$, a função wavelet, $\mathrm{C}_{\mathrm{g}}$, a constante de admissibilidade, "a", parâmetro de dilação e "b", parâmetro de translação.

Ela permite recuperar o sinal original a partir da TW pela integração de todas as dilações e translações "a" e "b".

\subsubsection{4 - Espectro de Energia da wavelet}

As wavelets que satisfazem a condição de admissibilidade, eq. (14), são filtros passa faixa, pois deixam passar somente os componentes do sinal, dentro de um intervalo finito de frequências e nas proporções caracterizadas pelo espectro de energia da wavelet. O quadrado da amplitude da TF da Wavelet, em função da freqüência, fornece o gráfico da função densidade espectral de energia (DEE). Como exemplo, pode-se citar a wavelet mãe "chapéu mexicano", Figura 7, que é a segunda derivada da função Gaussiana, sendo dada por [80]:

$$
\psi(t)=\left(1-t^{2}\right) e^{-t^{2} / 2}
$$

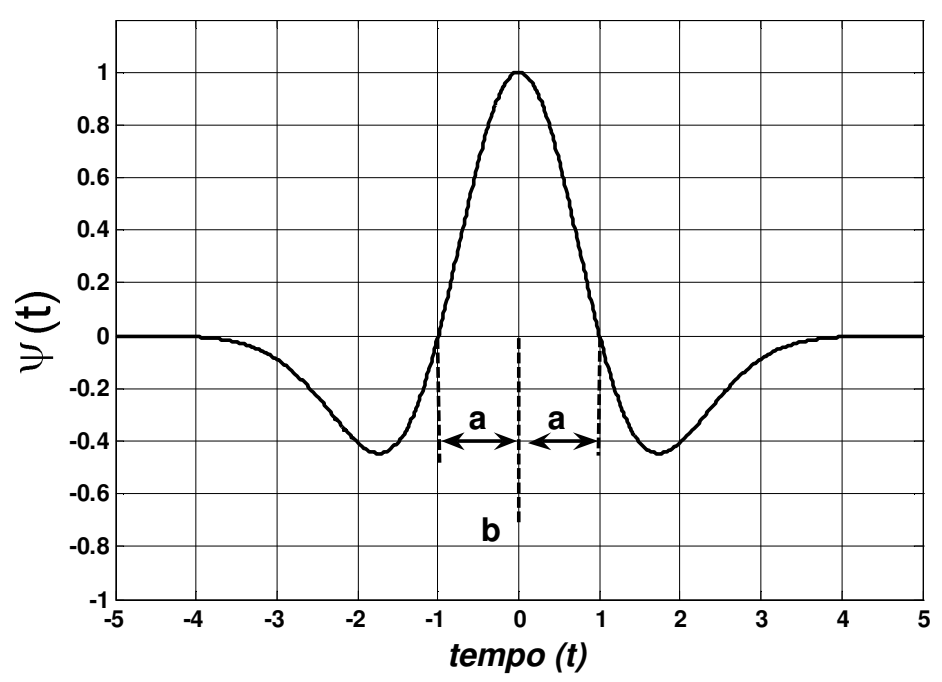

Figura 7 - Wavelet mãe "chapéu mexicano" [80] 
O espectro de energia de Fourier da wavelet "chapéu mexicano" é [80] :

$$
E_{F}(f)=|X(f)|^{2}=32 \pi^{5} f^{4} e^{-4 \pi^{2} f^{2}}
$$

onde o subscrito $\mathrm{F}$ significa o espectro de Fourier. $\mathrm{O}$ gráfico do espectro de energia da wavelet "chapéu mexicano" está mostrado na Figura 8. Como a wavelet "chapéu mexicano" é uma função real, seu espectro de Fourier é simétrico em relação ao zero. O pico do espectro de energia ocorre no domínio da frequência para $f_{p}= \pm \sqrt{2} / 2 \pi$. A segunda parte da área do espectro de energia é usada para definir o centro da banda passante do espectro de energia, $f_{c}$, ou desvio padrão em relação ao eixo vertical,como segue:

$$
f_{c}=\sqrt{\frac{\int_{0}^{\infty} f^{2}|X(f)|^{2} d f}{\int_{0}^{\infty}|X(f)|^{2} d f}}
$$

Para a wavelet mãe "chapéu mexicano, $\mathrm{f}_{\mathrm{c}}$ é igual a $\sqrt{2,5} / 2 \pi$ ou $0,251 \mathrm{~Hz}$. Na prática é necessário conhecer as frequências características da wavelet mãe , $\mathrm{f}_{\mathrm{p}}, \mathrm{f}_{\mathrm{c}}$ ou outra, para comparar os espectros de frequência obtidos usando a TFcom a TW.

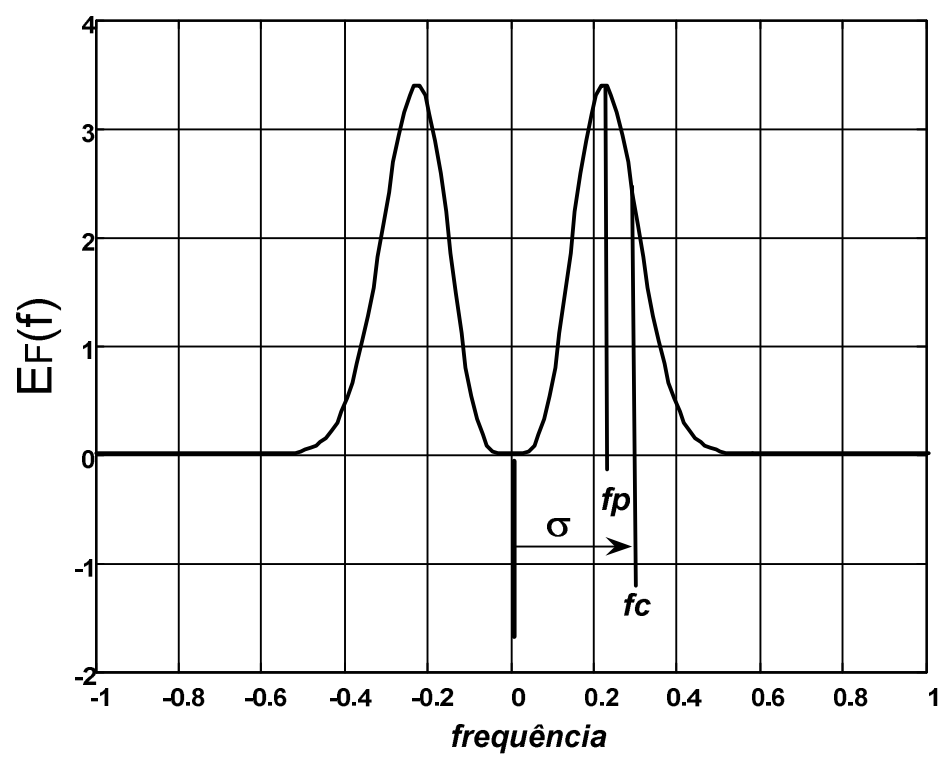

Figura 8 - Espectro de energia da wavelet mãe "chapéu mexicano" [80] 
Pelas eq. (16) e (12) observa-se que a energia total da wavelet mãe "chapéu mexicano" é finita e é expressa por [80]:

$$
E=\int_{-\infty}^{\infty} \psi(t)^{2} d t=\int_{-\infty}^{\infty}\left|\left(1-t^{2}\right) e^{-t^{2} / 2}\right|^{2} d t=\frac{3}{4} \sqrt{\pi}
$$

A energia da função, também, é dada pela área sob seu espectro de energia,

$$
E=\int_{-\infty}^{\infty}|X(f)|^{2} d f=\int_{-\infty}^{\infty} 32 \pi^{5} f^{4} e^{-4 \pi^{2} f^{2}} d f=\frac{3}{4} \sqrt{\pi}
$$

Portanto

$$
\int_{-\infty}^{\infty}|\psi(t)|^{2} d t=\int_{-\infty}^{\infty}|X(f)|^{2} d f
$$

O resultado obtido pela eq.(21) é uma versão do teorema de Parseval.

Muitas vezes, a função wavelet é normalizada para que tenha energia unitária. Este resultado é obtido, no caso da função "chapéu mexicano", dividindose a eq.(16) por $\left(\frac{3 \sqrt{\pi}}{4}\right)^{1 / 2}$,resultando na eq.(22), a seguir.

$$
\psi(t)=\frac{2}{\sqrt{3} \sqrt[4]{\pi}}\left(1-t^{2}\right) e^{-t^{2} / 2}
$$

As eq. (16) e (22) são igualmente utilizadas na literatura [80].

\subsubsection{5- A energia wavelet do sinal e o espectro de potência}

A energia total contida em um sinal, $x(t)$, é definida como a integral do quadrado da amplitude.

$$
E=\int_{-\infty}^{\infty}|x(t)|^{2} d t=\|x(t)\|^{2}
$$

Para esta equação ser utilizada, o sinal deve ter energia finita.

Se, por exemplo, $x(t)$ for uma tensão aplicada a uma resistência ôhmica, a energia convertida em calor, por efeito Joule, é proporcional à integral do quadrado 
da tensão. A utilização do quadrado da amplitude permite a utilização de sinais complexos [82], [83].

A contribuição relativa do sinal de energia contida para um fator de escala "a" e translação "b", específico, é dada pela função bidimensional de densidade de energia da wavelet [80]:

$$
E(a, b)=|T(a, b)|^{2}
$$

O gráfico de $E(a, b)$ é conhecido como escalograma (análogo ao espectrograma) e pode ser integrado através de "a" e "b" para recuperar a energia total do sinal, usando a constante de admissibilidade, $\mathrm{C}_{\mathrm{g}}$, como segue:

$$
E=\frac{1}{C_{g}} \int_{-\infty}^{\infty} \int_{0}^{\infty}|T(a, b)|^{2} \frac{d a}{a^{2}} d b
$$

A distribuição de energia para dado fator de escala "a" é dada por:

$$
E(a)=\frac{1}{C_{g}} \int_{-\infty}^{\infty}|T(a, b)|^{2} d b
$$

Através das eq.(25) e (26) obtém-se a energia total do sinal dada por:

$$
E=\int_{0}^{\infty} E(a) \frac{d a}{a^{2}}
$$

A eq. (27) pode ser expressa em termos da banda passante, fazendo-se $\mathrm{da} / \mathrm{a}^{2}=-\mathrm{df} / \mathrm{f}_{\mathrm{c}}, f=\mathrm{f}_{\mathrm{c}} / \mathrm{a}$ e $\mathrm{E}_{\mathrm{W}}(\mathrm{f})=\mathrm{E}(\mathrm{a}) / \mathrm{f}_{\mathrm{c}}$, onde $\mathrm{w}$ significa wavelet. Tem-se, então [80]:

$$
E=\int_{0}^{\infty} E_{W}(f) d f
$$

Um gráfico da energia wavelet, $E_{W}(f)$ em função de $f$ (espectro de energia wavelet) tem a área sob a curva igual à energia total e que pode ser comparada diretamente com o espectro de energia de Fourier $E_{F}(f)$ do sinal. 
$\mathrm{Na}$ eq. 26, pode-se ver que a energia total do sinal é dada por:

$$
E=\frac{1}{C_{g} f_{c}} \int_{-\infty}^{\infty} \int_{0}^{\infty}|T(f, b)|^{2} d f d b
$$

Onde se define $T(f, b)=T(a, b)$ para $f=f_{c} / a$.

O espectro de potência é o espectro de energia dividido pelo período do sinal sob investigação. Para um sinal de duração $\tau$, o espectro de potência de Fourier e wavelet são, respectivamente,

$$
\begin{gathered}
P_{F}(f)=\frac{1}{\tau} E_{F}(f) \\
P_{w}(f)=\frac{1}{\tau} E_{w}(f)=\frac{1}{\tau f_{c} C_{g}} \int_{0}^{\tau}|T(f, b)|^{2} d b
\end{gathered}
$$

A variância wavelet para uma TW Contínua é dada por [80], [81]:

$$
\sigma^{2}(a)=\frac{1}{\tau} \int_{0}^{\tau}|T(a, b)|^{2} d b
$$

Ela é usada, na prática, para determinar as escalas dominantes do sinal. A eq.(32) é muito semelhante à eq. (24) que dá a distribuição de energia em função da escala e à eq. (31) que fornece a função densidade espectral de energia.

\subsubsection{6 - A Transformada Wavelet Discreta}

Se os parâmetros de escala "a" e translação "b" forem discretos, tem-se a TW Discreta (TWD). Este tipo de discretização da Wavelet tem a forma [80], [81]:

$$
\psi_{m, n}(t)=\frac{1}{\sqrt{a_{0}^{m}}} \psi\left(\frac{t-n b_{0} a_{0}^{m}}{a_{0}^{m}}\right)
$$


Onde $\psi$ é a Wavelet mãe e os parâmetros de escala e translação "a" e "b" são funções de parâmetros inteiros m e n, $a=a_{o}^{m}$ e $b=n b_{o} a_{o}^{m}$, que permite uma expansão da família originada pela Wavelet mãe, gerando as Wavelets filhas, com $a_{0}>1$ e $b_{0}>0$.

A $T W$ de um sinal contínuo $x(\mathrm{t})$, usando Wavelets discretas, tem a forma:

$$
T_{m, n}=\int_{-\infty}^{\infty} x(t) \frac{1}{a_{0}^{m / 2}} \psi\left(a_{0}^{-m} t-n b_{0}\right) d t
$$

que pode também ser expressa como o produto interno

$$
T_{m, n}=<x, \psi_{m, n}>
$$

A família de funções Wavelets, que constituem um frame, é tal que a energia dos coeficientes Wavelets resultantes permanece dentro de certo intervalo de energia do sinal original [80], [81]. A condição de frame é dada por:

$$
A E \leq \sum_{m=-\infty}^{\infty} \sum_{n=-\infty}^{\infty}\left|T_{m, n}\right|^{2} \leq B E
$$

$T_{m, n}$ são os coeficientes Wavelets discretos, A e B são as fronteiras do sistema, isto é, frame bounds e $\mathrm{E}$ a energia do sinal original dado pela equação (19).

O sinal $x(t)$ tem energia finita. Os frame bounds $A$ e $B$ dependem dos parâmetros $a_{0}$ e $b_{0}$ escolhidos para a análise e da função Wavelet usada [67], [80], [81].

Se $A=B$, a fórmula de reconstrução é dada pela série infinita

$$
x(t)=\frac{1}{A} \sum_{m=-\infty}^{\infty} \sum_{n=-\infty}^{\infty} T_{m, n} \psi_{m, n}(t)
$$

Se $A=B=1$, a família definida pelo frame forma uma base ortogonal. Para se obter uma representação não redundante na AMR e uma reconstrução perfeita do sinal original, são exigidos bancos de filtros ortogonais e, consequentemente, uso de wavelets ortogonais [20 ] e [46]. Se $A \neq B$ a fórmula de reconstrução é dada por:

$$
x^{\prime}(t)=\frac{2}{A+B} \sum_{m=-\infty}^{\infty} \sum_{n=-\infty}^{\infty} T_{m, n} \psi_{m, n}(t)
$$


Sendo que $x^{\prime}(\mathrm{t})$, é a reconstrução do sinal que difere do sinal original $x(t)$ por um erro que depende dos valores limites do sistema .

\subsubsection{1 - Escala de grade diádica e Transformada Wavelet ortogonal}

Uma escolha comum para os parâmetros discretos são: $\mathrm{a}_{0}=2$ e $\mathrm{b}_{0}=1$. Este arranjo é chamado grade diádica e é usado para construir uma base wavelet ortogonal. Substituindo-se $a_{0}=2$ e $b_{0}=1$ na equação (33), a grade wavelet diádica pode ser escrita como [80]:

$$
\psi_{m, n}(t)=\frac{1}{\sqrt{2^{m}}} \psi\left(\frac{t-n 2^{m}}{2^{m}}\right)
$$

Ou, mais compactamente, como

$$
\psi_{m, n}(t)=2^{-m / 2} \psi\left(2^{-m} t-n\right)
$$

Estas wavelets são ortogonais e normalizadas por terem energia unitária, apresentando as seguintes características [81],[82]:

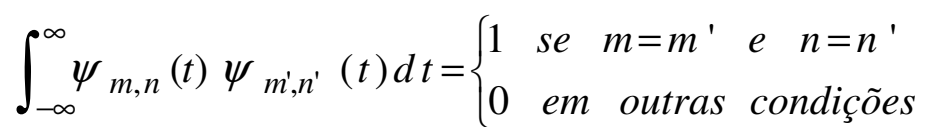

Usando a wavelet de grade diádica da equação (39), a TW Discreta (TWD) pode ser escrita como:

$$
T_{m, n}=\int_{-\infty}^{\infty} x(t) \psi_{m, n}(t) d t
$$


Escolhendo-se uma base wavelet ortogonal, $\psi_{m, n}(t)$, pode-se reconstruir 0 sinal original em termos dos coeficientes wavelets, $\mathrm{T}_{\mathrm{m}, \mathrm{n}}$, usando a $T W$ Discreta Inversa .

$$
x(t)=\sum_{m=-\infty}^{\infty} \sum_{n=-\infty}^{\infty} T_{m, n} \psi_{m, n}(t)
$$

A equação (43) pode ser escrita em termos do produto interno.

$$
x(t)=\sum_{m=-\infty}^{\infty} \sum_{n=-\infty}^{\infty}<x, \psi_{m, n}>\psi_{m, n}(t)
$$

A TWD pode ser implementada com o algoritmo $A M R$, que será descrito a seguir.

\subsubsection{7 - Análise de Multirresolução (AMR)}

A $A M R$ é uma técnica que permite tratar um sinal através de filtros passabaixa e passa-alta, dividindo-o em sub-bandas. Cada sub-banda é analisada individualmente. Realizando a AMR através da TW, pode-se estabelecer uma dependência tempo-frequência que permite extrair detalhes contidos no sinal.

O processo de filtragem elimina determinadas frequências ou bandas de frequências de um sinal, fornecendo "versões do sinal original" relativas aos coeficientes de funções wavelets e funções escalas em aproximações e detalhes. As aproximações são os componentes em baixa frequência do sinal e os detalhes são os componentes em alta frequência do sinal [79]. Aproximações e detalhes são obtidos através de uma sucessão de processos de convolução. O sinal original é dividido, então, em diferentes escalas de resolução. O Algoritmo de decomposição Multirresolução (AMR), ou algoritmo da pirâmide é ilustrado na Figura 9, onde três níveis de decomposição são tomados como exemplo. 
$O$ sinal original $S$ é introduzido em dois filtros, um passa-baixa $L$ e outro passa-alta $\mathrm{H}$ e, na saída dos filtros, o sinal é subamostrado por um fator de 2 , através do operador "downsampling" $\downarrow$. A cada estágio da pirâmide de análise, temse como saídas, sequências de coeficientes wavelets e de aproximação (ou escala).

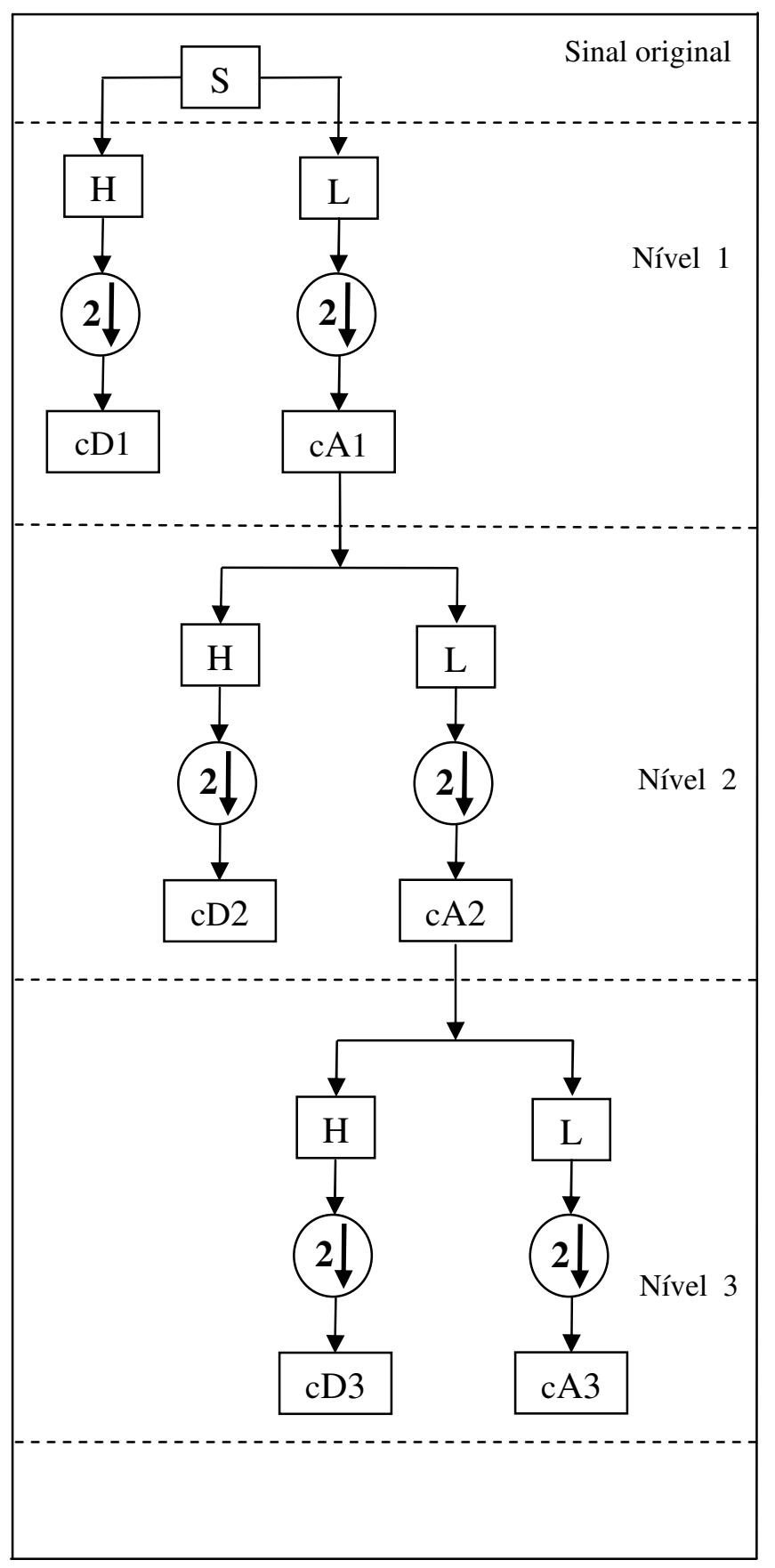

Figura 9 - Análise de Multirresolução 
Em seguida, a aproximação A1 passa, novamente, através dos filtros e do operador "downsampling" $2 \downarrow$, decompondo-se os coeficientes de detalhe (ou wavelet) (alta frequência) e coeficientes de aproximação ou escala A2 ( baixa frequência), nela contidos, com seus com seus respectivos coeficientes wavelets, cD2 e cA2. Este processo é repetido diversas vezes até que seja atingido o nível de decomposição desejado [21].

Em relação à Figura 9, os procedimentos da decomposição Multirresolução são definidos como:

$$
\begin{aligned}
& D_{j}(n)=\sum_{k} h(k) A_{j-1}(n-k) \\
& A_{j}(n)=\sum_{k} L(k) A_{j-1}(n-k)
\end{aligned}
$$

Onde $L$ e $h$ são os vetores dos filtros passa baixa e passa alta respectivamente e $D_{j}$ e $A_{j}$ são os detalhes e aproximações para a resolução $j$, sendo $\mathrm{j}=1,2,3, \ldots . ., \mathrm{J}$, respectivamente [21].

$A_{j-1}$ é a aproximação do nível imediatamente acima do nível j.

Sendo $\mathrm{K}=1,2, \ldots \ldots, \mathrm{K}$, onde $\mathrm{K}$ é o comprimento do vetor filtro.

Para se ter uma representação não redundante e reconstrução única do sinal original são necessários bancos de filtros em quadratura (Quadrature Mirror Filters QMF). A $T W$ e a decomposição Multirresolução estão intimamente relacionadas. Também, como é mostrada na Figura 9, a decomposição wavelet é acompanhada pela inclusão da operação "down-sampling" dentro da $A M R$, que divide o número de amostras por 2 na saída de cada filtro. Isto é feito levando em conta os dados associados a índices ímpares e rejeitando os de índice par. Caso contrário, estaríamos obtendo duas vezes mais dados do que no início [8].

Os filtros passa baixa e passa alta são determinados pela função escala e pela função wavelet, respectivamente. $O$ processamento de sinais usa exclusivamente wavelets ortogonais e de suporte compacto.

Algumas wavelets que são frequentemente usadas para processamento de sinais são Daubechies, Morlets, Coiflets e Symlets. Estas wavelets apresentam diferentes atributos e desempenho, quando usadas em aplicações específicas, tais como a deteç̧ão de transitórios, compressão de sinais e ruídos. Por outro lado, não 
há critérios definidos para a seleção das wavelets. A melhor escolha é uma wavelet que melhor interrogue o fenômeno a ser estudado. Neste trabalho será usada a Wavelet Daubechies nível 4. Neste caso assumiu-se esta em função de suas propriedades e utilização ampla, conforme apresentado na literatura atual [21],[84]. Foram testadas várias wavelets, sendo que algumas delas, também, poderiam ter sido utilizadas.

\subsubsection{8- Reconstrução wavelet}

Para reconstruir ou sintetizar um sinal original, sem perder informações, usase a TW Discreta Inversa (TWDI). Para este fim, o número de amostras deve ser aumentado e isto pode ser feito pela inserção de zeros entre as amostras, já que o processo de decomposição do sinal, pela diminuição das amostras, introduziu distorções "aliasing". Estas distorções podem ser corrigidas por uma escolha adequada dos filtros [79] e [81].

Pode-se também reconstruir as aproximações e detalhes partindo dos vetores de coeficientes e, em seguida, combinando-os. A Figura 10 ilustra a reconstrução de um único nível do sinal original, onde H' é o filtro passa-alta de reconstrução, L' o filtro passa-baixa de reconstrução e $2 \uparrow$ o operador "upsampling".

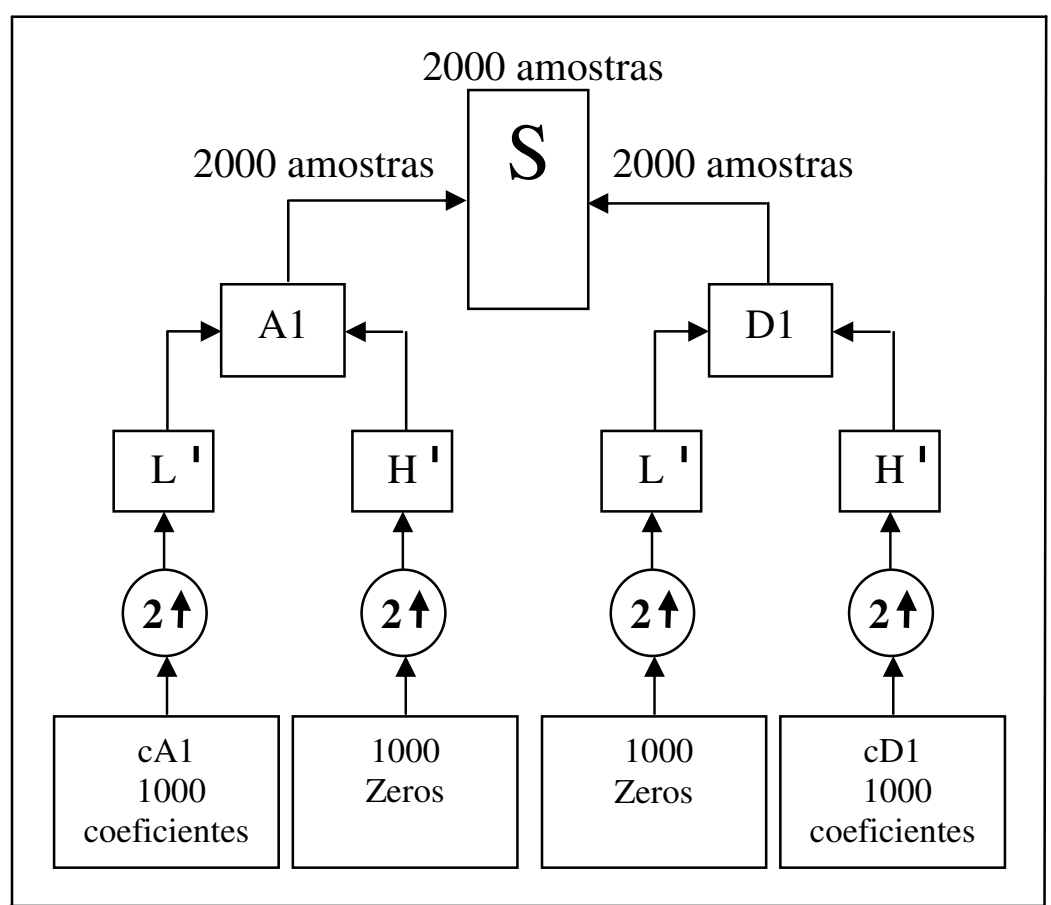

Figura 10- Processo de reconstrução de um sinal 


\section{3 - Metodologia proposta para detecção de faltas}

\subsection{1 - Introdução}

A metodologia proposta para detecção de faltas é constituída por várias etapas, tendo como ponto de partida a determinação das formas de onda da corrente nos circuitos elétricos. Na etapa 1, utilizam-se como dados, as formas de ondas de correntes de curto-circuito de um sistema elétrico, obtidas por simulação numérica e, também, através de bancada experimental. A etapa 2 , constitui-se na inclusão desses dados como fonte de corrente de falta na configuração do circuito considerado, para a avaliação das densidades de fluxo magnético resultantes nas regiões de interesse. Estas regiões correspondem àquelas onde, na prática, ocorreriam as medições da densidade de fluxo magnético. Desta forma, esta situação simula a avaliação da densidade de fluxo magnético resultante dos eventuais distúrbios nos circuitos de distribuição de energia elétrica.

Estas duas primeiras etapas utilizam os recursos disponíveis em softwares, ATP, Matlab e Flux 2D , cuja transferência de dados é realizada através de arquivos pós-processados [17], [18], [58] e [84].

O Método dos Elementos Finitos (MEF) é utilizado na determinação da densidade de fluxo magnético. Realizadas estas etapas, os dados do campo magnético obtidos são, também, pós-processados, visando obter a decomposição deste através da TW (TW) [18]. A Figura 11 apresenta o fluxograma correspondente à metodologia proposta nestas etapas do trabalho. 


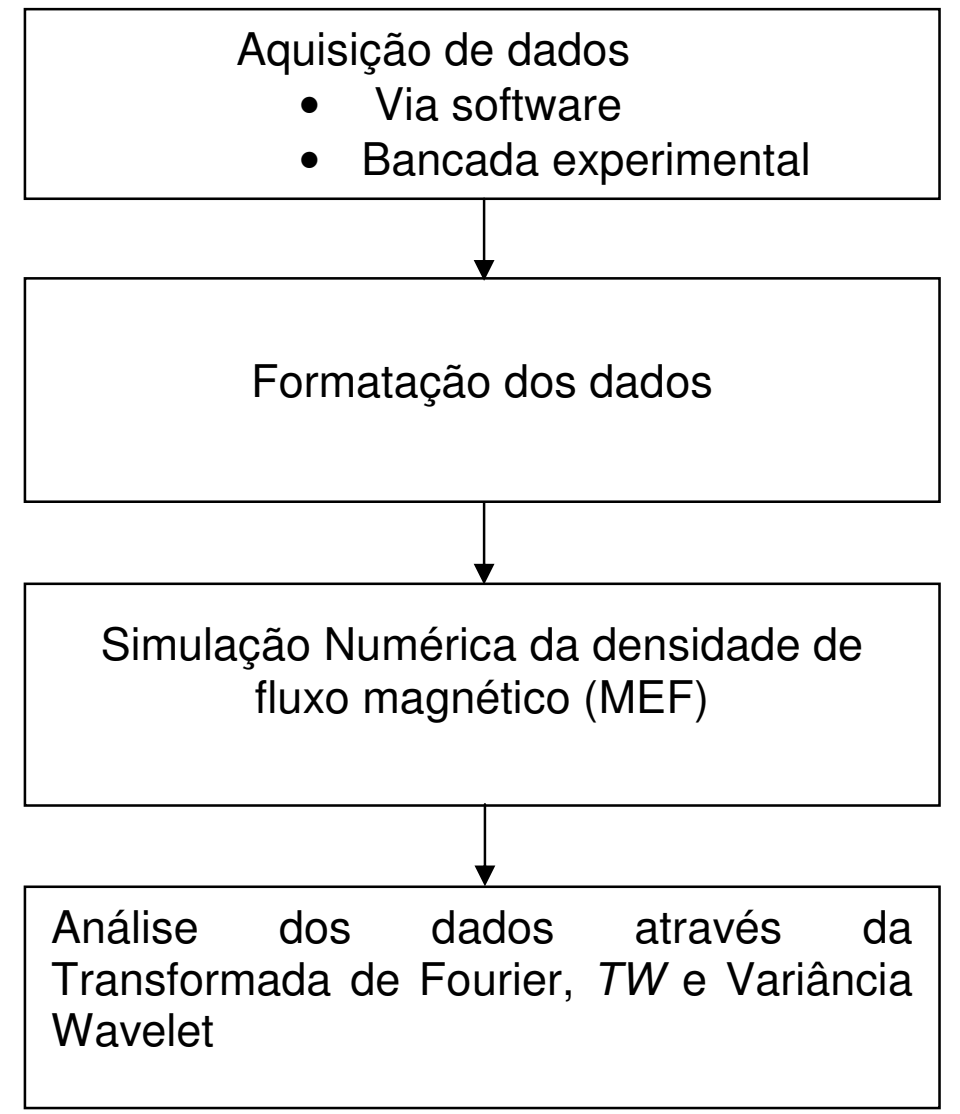

Fig. 11 - Fluxo de dados da metodologia proposta-Avaliação teórica

A etapa 3 consiste em obter as formas de onda da densidade de fluxo magnético, diretamente de uma bancada experimental, usando um sensor magnético. O fluxograma da metodologia proposta está representado na Figura 12. 


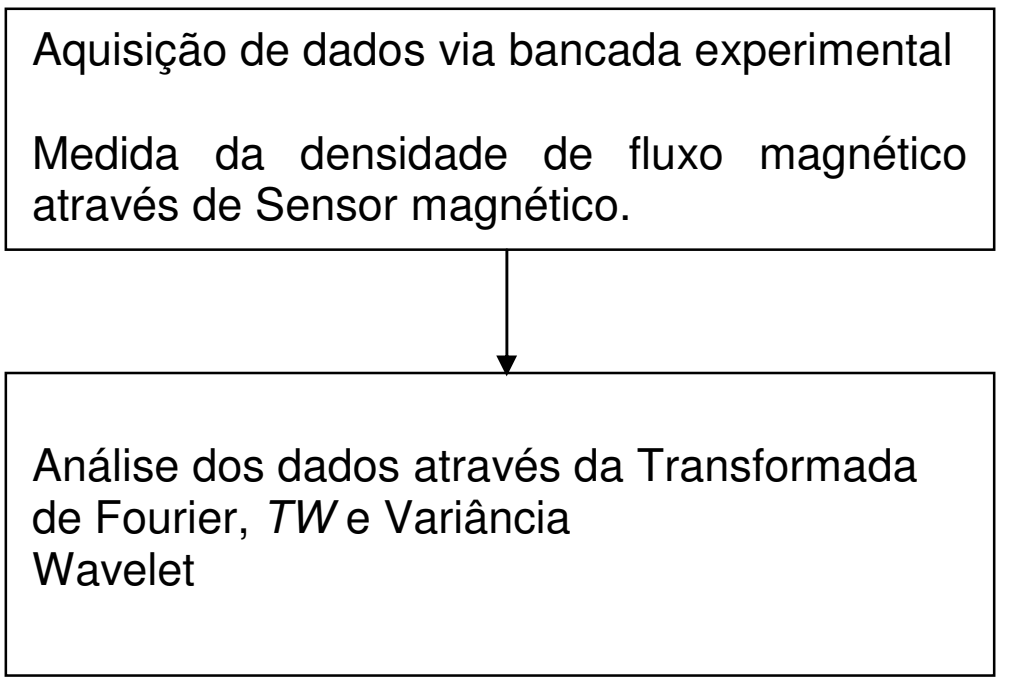

Figura 12 - Fluxo de dados da metodologia proposta - Avaliação experimental via sensor de densidade de fluxo magnético

O diagrama elétrico da bancada experimental utilizada está representado na Figura 13.

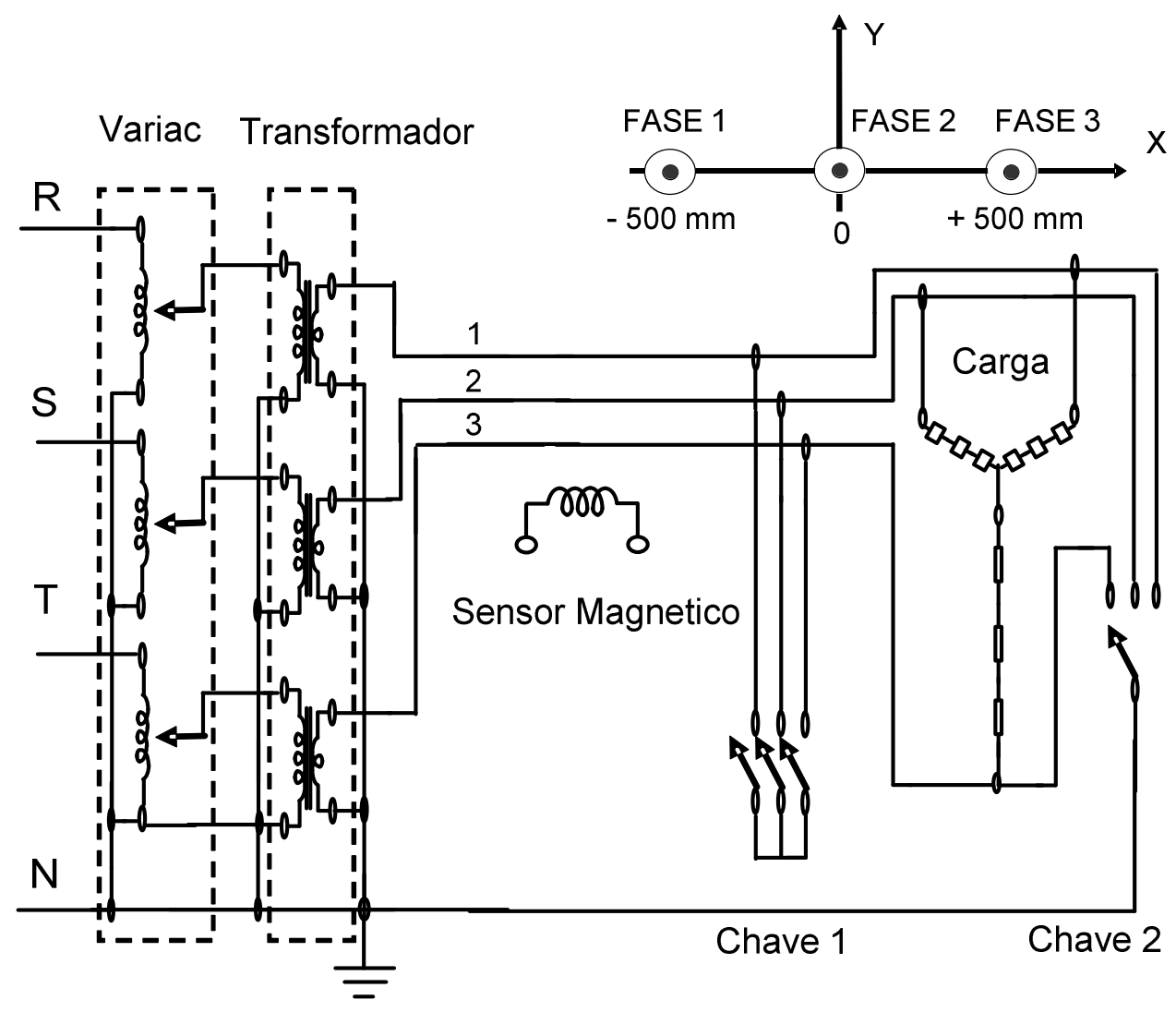

Figura 13 - Linha trifásica experimental para simulação de faltas 
A rede trifásica de 220 VCA alimenta um Variac trifásico, ligado em estrela, cuja saída é conectada ao primário de um transformador trifásico, ligado em estrela. O secundário, ligado em estrela, foi construído visando obter tensão de linha da ordem de um volt eficaz; as correntes obtidas na linha atingiram algumas dezenas de ampères. As características físicas e elétricas são descritas a abaixo:

A linha trifásica que constitui a bancada experimental, possui 4 metros de comprimento, utilizando-se três cabos de $16 \mathrm{~mm}^{2}$, distantes entre si 50 centímetros e mantidos a uma altura de $1,70 \mathrm{~m}$ em relação ao piso. A carga resistiva utilizada apresenta $0,8 \Omega$ ligada em estrela. Nestas condições a corrente na linha é da ordem de 1 ampère eficaz.

O condutor neutro, com a mesma secção dos cabos da linha, foi ligado entre o secundário do transformador e a carga, sendo posicionado no piso, paralelamente à fase central.

A Figura 14 ilustra a linha experimental utilizada.

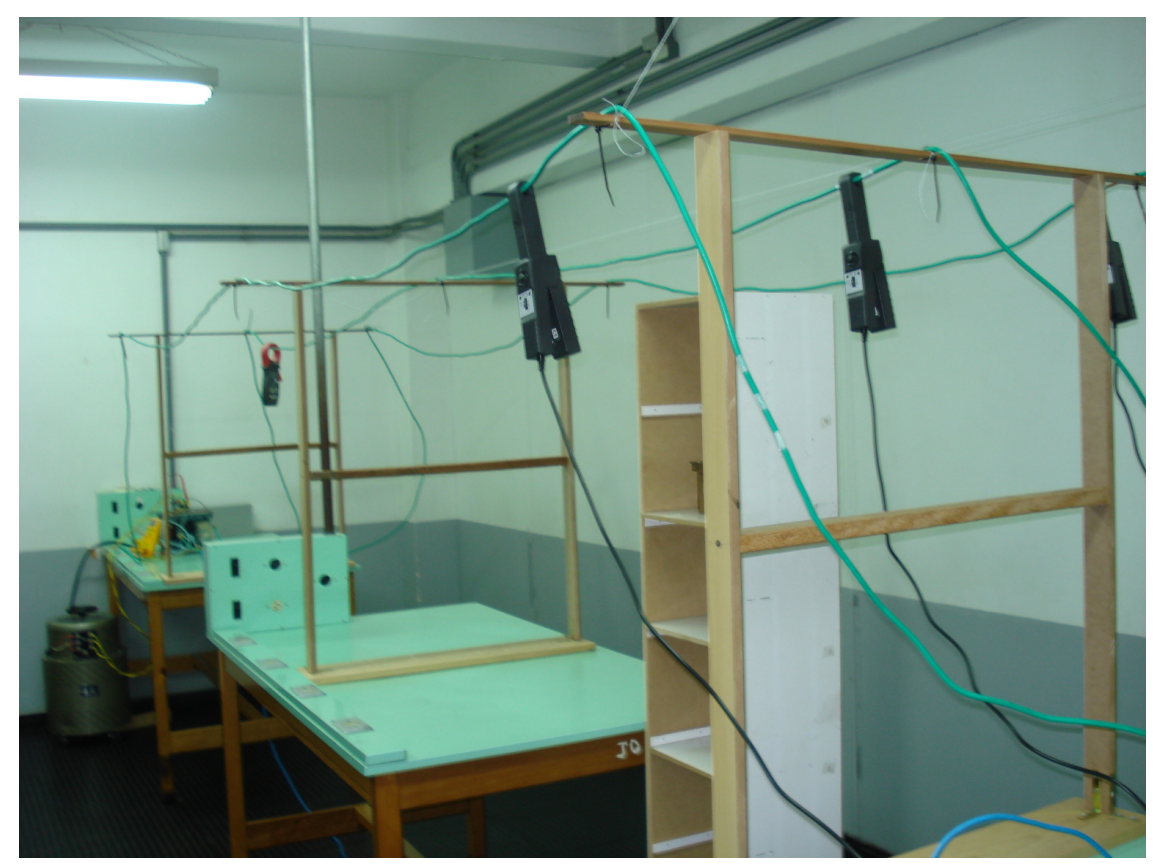

Figura 14 - Linha experimental trifásica e medição das correntes por "probes" 
Os equipamentos utilizados estão apresentados a seguir:

- Variac Trifásico

Transformador Variador de Voltagem -VARIVOLT -Sociedade Técnica

Paulista Ltda -VT - 290- Entrada $220 \mathrm{~V}$, frequência $60 \mathrm{~Hz}$, fases 3 -

Saída 0 a 240 V- Corrente máxima 22 A- Potência máxima 9 kVA.

- Transformador de Potencial

Tensão primária 220 VCA - Transformador trifásico de 1kVA.

- Osciloscópio AGILENT 4 canais

modelo № $54624 \mathrm{~A}-100 \mathrm{MHz}-200 \mathrm{MSa} / \mathrm{s}$

- Amperímetro Alicate.

Minipa ET 4050

- Multímetros MINIPA

ET 2700

- "Probe" - Pontas de prova para medida de corrente $-100 \mathrm{kHz}$ -

Tecktronix - Current Probe 100 Amp- Model A622

- Sensor magnético

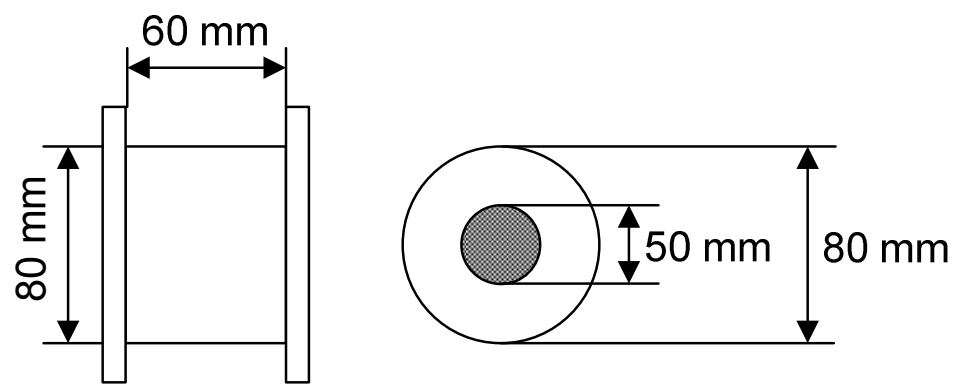

Figura 15 - Dimensões do sensor magnético

Número de espiras

1724

Secção do fio

$0,28 \mathrm{~mm}^{2}$

Resistência

$19,7 \Omega$

Indutância

$123,2 \mathrm{mH}(\mathrm{f}=1 \mathrm{kHz})$

Capacitância

$213,5 \mathrm{nF}(\mathrm{f}=1 \mathrm{kHz})$ 


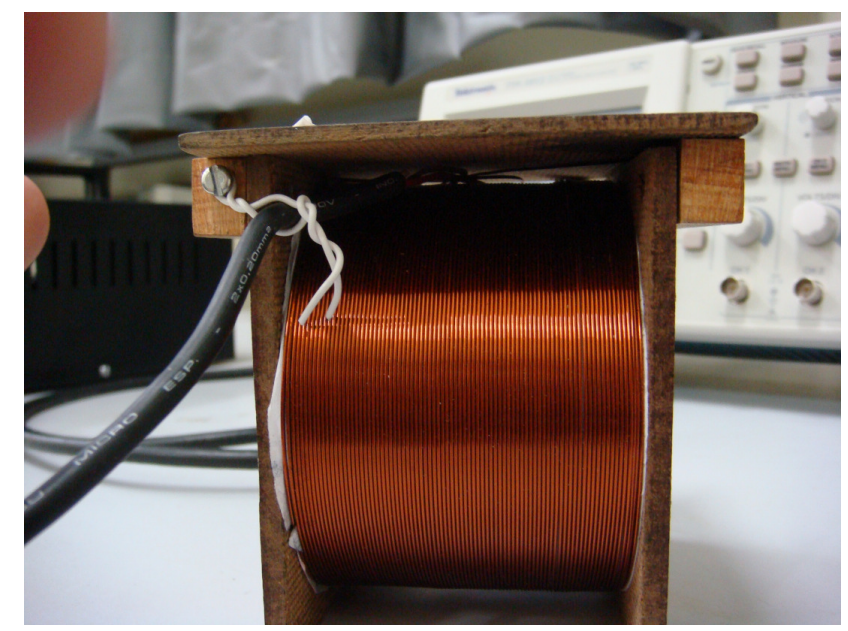

Figura 16 - Foto do sensor magnético

As formas de onda da densidade de fluxo magnético, geradas por diversos tipos de curtos-circuitos, foram obtidas através de um sensor unidirecional, cujas características são apresentadas no apêndice A. O sensor foi posicionado debaixo da linha e fora desta, de modo a captar diferentes características da intensidade de fluxo magnético, tanto em regime permanente quanto durante os transitórios. Um osciloscópio foi utilizado na obtenção das formas de ondas e armazenamento dos dados correspondentes.

Inicialmente, com a linha desligada, mediu-se a densidade de fluxo magnético do ambiente. Em seguida, mediu-se a densidade de fluxo magnético, em regime permanente (normal) para corrente de um ampère eficaz, em vários pontos debaixo e fora da linha. Na sequência, por meio do fechamento adequado das chaves indicadas na Figura 13, foram produzidos e registrados dez tipos de curtos-circuitos para vários posicionamentos do sensor.

As densidades de fluxo magnético obtidas por simulação numérica foram, também, contempladas. A simulação numérica foi feita utilizando-se o software Flux 2D, considerando as correntes de curto-circuito medidas por "probes" na bancada experimental. 
A análise dos sinais de corrente e densidade de fluxo magnético foi realizada usando as ferramentas de análise de sinais tais como, TF e TW, descritas anteriormente.

\subsection{2 - Metodologia aplicada à análise dos sinais}

Realizou-se a análise do sinal, inicialmente, através da comparação das formas de onda da corrente e da densidade de fluxo magnético, obtida via pós-processamento [18]. Como as formas de ondas de curtos-circuitos são típicas, a diferença de amplitudes entre a condição permanente e o estado perturbado permite detectar, mesmo via análise visual, o distúrbio. Estes valores de amplitude podem ser medidos, por exemplo, utilizando-se os cursores do software. Pode-se, também, medir, da mesma forma, o instante de início e fim do curto-circuito, isto é, sua duração.

Nesta etapa a Transformada Rápida de Fourier (TRF) pode ser aplicada, para detectar o conteúdo espectral do sinal. Isto é, pode-se, nesta etapa, avaliar o espectro de frequências, correspondente à frequência fundamental do transitório e seus harmônicos.

A seguir, aplica-se a TW Discreta, que através da $A M R$, fornece informações no plano tempo-frequência. Assim, o sinal original será decomposto em dois outros sinais. Conforme descrito anteriormente, estes sinais resultam da filtragem do sinal que fornece um componente em alta frequência, "o detalhe d1", e um componente em baixa frequência, "a aproximação a1". Por outro lado, a aproximação é decomposta em novo detalhe d2, e uma nova aproximação a2. Este processo é então repetido, até que o nível de decomposição desejado seja atingido. A função Daubechies ( $\mathrm{dbN}, \mathrm{N}=2,3,4, \ldots, 8$ ) foi utilizada como wavelet mãe, sendo adotada a função db4 e nível de decomposição 10, como mostram as Figuras 17 e 18. Uma análise detalhada sobre a utilização desta é apresentada em [24]. Basicamente, a semelhança entre a função mãe e o sinal é critério utilizado para essa decisão. 


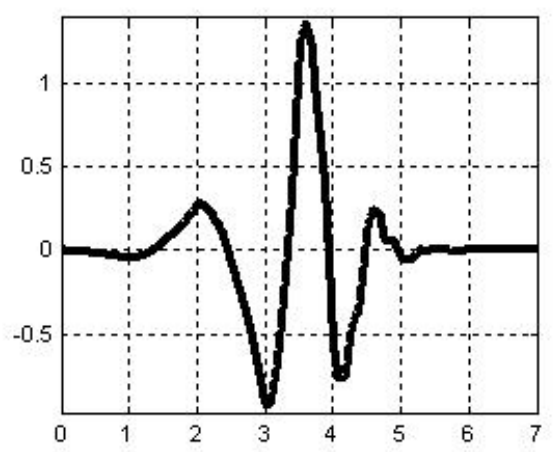

Função Wavelet Daubechies 4 - db 4

Figura 17 - Wavelet mãe db4

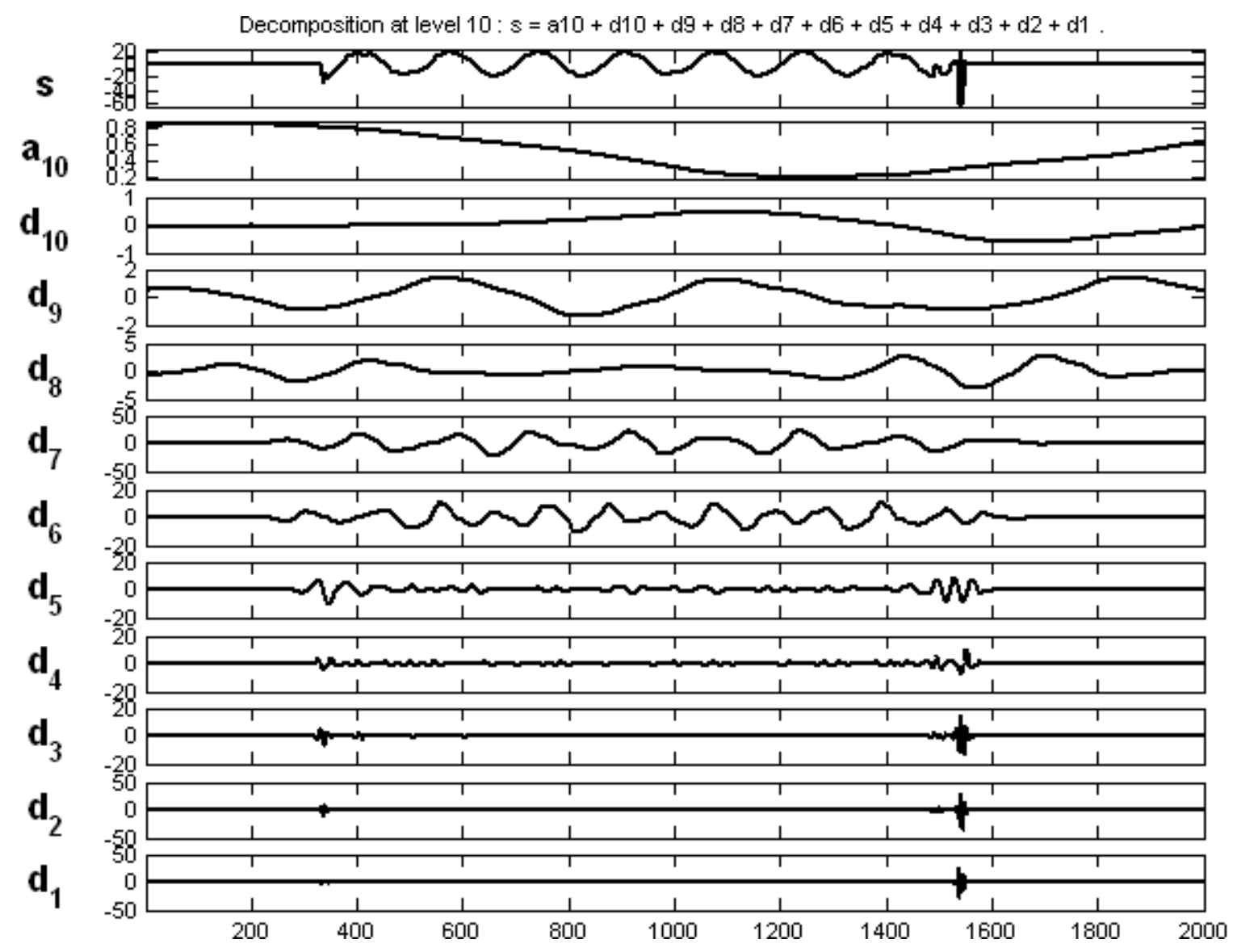

Figura18 - Exemplo de decomposição da densidade de fluxo magnético $B$ através da Transformada Discreta Wavelet db4 - nível 10, em função do número de amostras 


\section{4 - Metodologia de classificação dos sinais}

A metodologia de classificação está baseado no Teorema de Parseval, anteriormente apresentado, o qual afirma que a energia do sinal distorcido pode ser obtida em termos de seus coeficientes wavelets [6] .

$$
\int_{-\infty}^{\infty} x^{2}(t) d t=\sum_{k=-\infty}^{\infty} c_{j, k}^{2}+\sum_{l=1}^{j} \sum_{k=-\infty}^{\infty} d_{j, k}^{2}
$$

onde $c_{j, k}=\left\langle x(t), \phi_{j, k}(t)>\right.$ e $d_{j, k}=\left\langle x(t), \psi_{j, k}(t)>\right.$

Por outro lado, observa-se que a variância pode ser considerada como uma medida da energia de um sinal com média zero. Assim, a variância do sinal decomposto, em seus diferentes níveis de resolução, é proposta como índice de mérito a ser utilizada na classificação de faltas.

Usando-se a $A M R$, decompõe-se o sinal em diferentes níveis de resolução (detalhes), sendo que o número de níveis selecionado visa cobrir a faixa de alta frequência de interesse. Em seguida, obtém-se a variância de cada versão de detalhe para diferentes níveis de resolução do sinal distorcido, a fim de construir a curva da variância em função dos níveis de detalhe.

A Figura 19 apresenta uma curva da energia em função dos níveis de detalhes e em função das zonas características de frequência [6],[84]. Nota-se que esta curva é dividida em 3 zonas de frequências. A primeira zona com níveis de detalhe de 2 a 5 mostra a região característica em altas frequências. A segunda zona com níveis de detalhe de 5 a 8 mostra a região de afundamento e elevação de tensão. A terceira zona, com níveis de detalhes de 8 a 10, mostra região de baixas frequências. A classificação é feita pela diferença entre a curva de um determinado distúrbio e a curva referente ao sistema em regime permanente [6], [84]. 
Ressalte-se que a curva apresentada refere-se às características de um sinal de tensão. Neste trabalho, análises semelhantes são realizadas, aplicadas às correntes de faltas e às densidades de fluxo magnético resultantes. Em vez do desvio padrão, será utilizada a curva da variância em função do nível do detalhe.

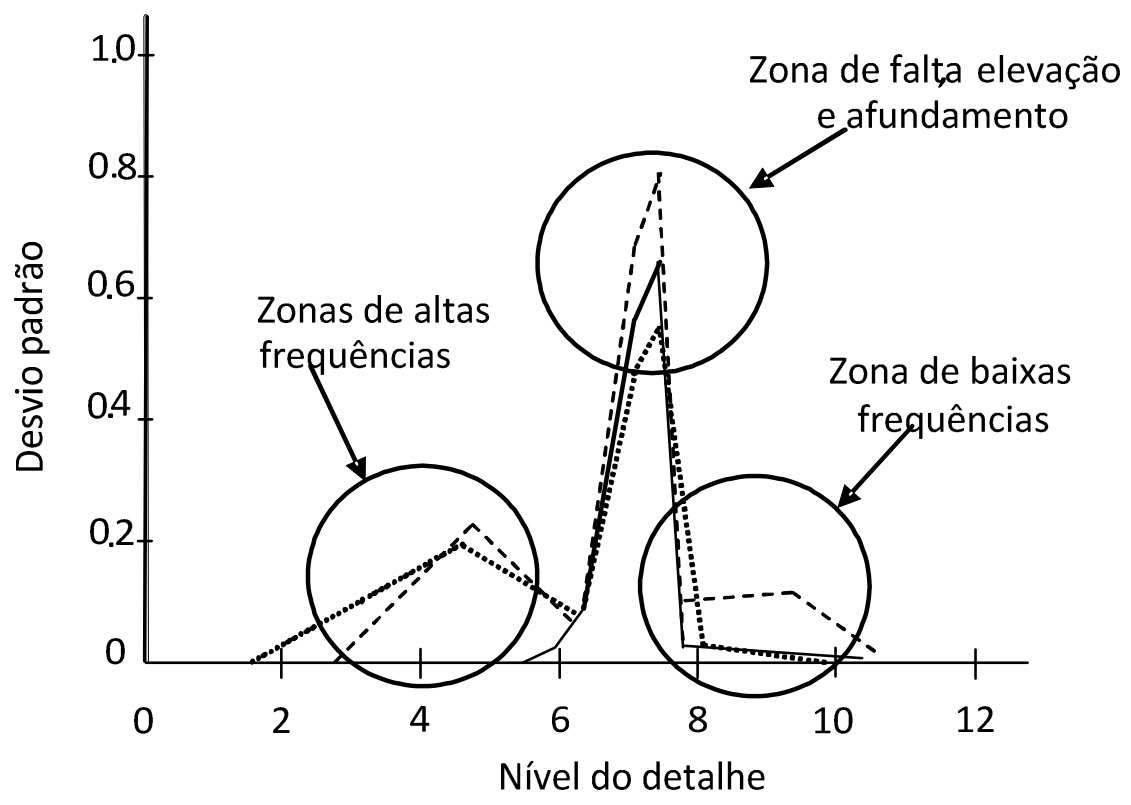

Figura 19 - Espectro wavelet. Detalhes característicos das faixas de frequência, utilizados na classificação dos diferentes tipos de distúrbios [6], [84].

Propõe-se, assim, por meio de análises repetidas e, considerando-se diversas posições fixas do sensor, determinar o desempenho e o comportamento eletromagnético resultante para as faltas, de forma a também permitir identificar a fase em que ocorreu a falha e seu tipo. 


\section{4 - RESULTADOS}

\section{1 - Introdução}

A fim de ilustrar a metodologia proposta, apresentam-se, a seguir, alguns resultados relativos a simulações numéricas de falta fase-terra, em um sistema de distribuição de energia elétrica, utilizando dados existentes na literatura [84].

A mesma metodologia é aplicada visando confrontar resultados teóricos (simulados) e os experimentais (obtidos em uma bancada experimental), cujos detalhes são apresentados no decorrer deste trabalho.

Nos resultados a seguir usar-se-á, para analisar os sinais, a TW 4-nível 10, juntamente com a $A M R$, quando for necessário e conveniente.

\section{2- Aplicação da metodologia em simulações numéricas}

A metodologia proposta será aplicada em simulações numéricas utilizando dados teóricos e experimentais.

\subsection{1 - Aplicação da metodologia em simulações numéricas utilizando dados teóricos}

\subsubsection{1 - Análise das correntes na linha}

As formas de onda das correntes de faltas aqui consideradas são resultantes de simulações de um sistema de distribuição real [16], [17] e [84]. O sistema analisado constitui-se de uma linha de distribuição típica de energia elétrica em 13,8 kV, onde as fases são condutores 1/0 AWG, com distância entre elas de $600 \mathrm{~mm}$, e a altura útil dos postes é de $10 \mathrm{~m}$. A freqüência de amostragem utilizada nas simulações foi de $7680 \mathrm{~Hz}$. O solo foi considerado como condutor perfeito. Assim a influência da resistividade do solo sobre a densidade de fluxo magnético não é contemplada nesta primeira abordagem do tema de pesquisa.

A Figura 20 apresenta as formas de onda das correntes nas três fases. A fase 1 , sujeita à falta, é a que apresenta maior variação de amplitude. 

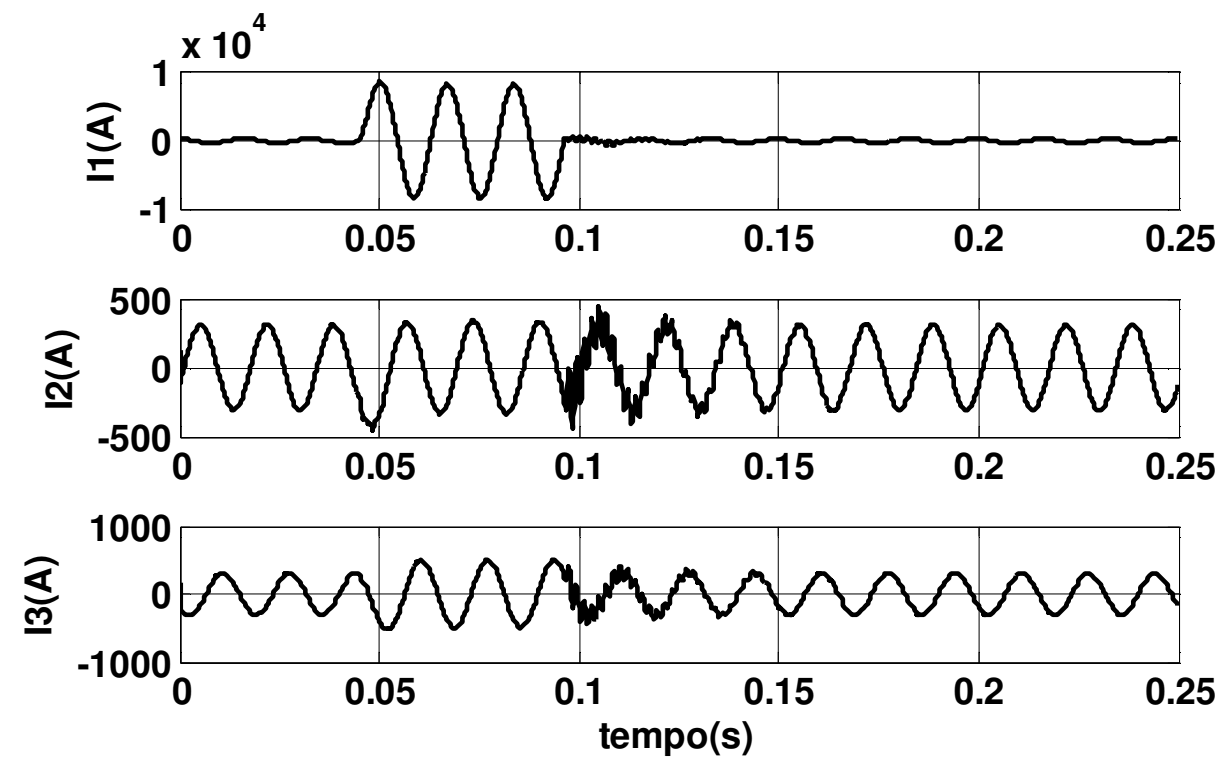

Fig. 20 - Formas de ondas das correntes para curto F1T simulado

A Figura 21 apresenta, em destaque, a forma de onda da corrente $\mathrm{I}_{1}$

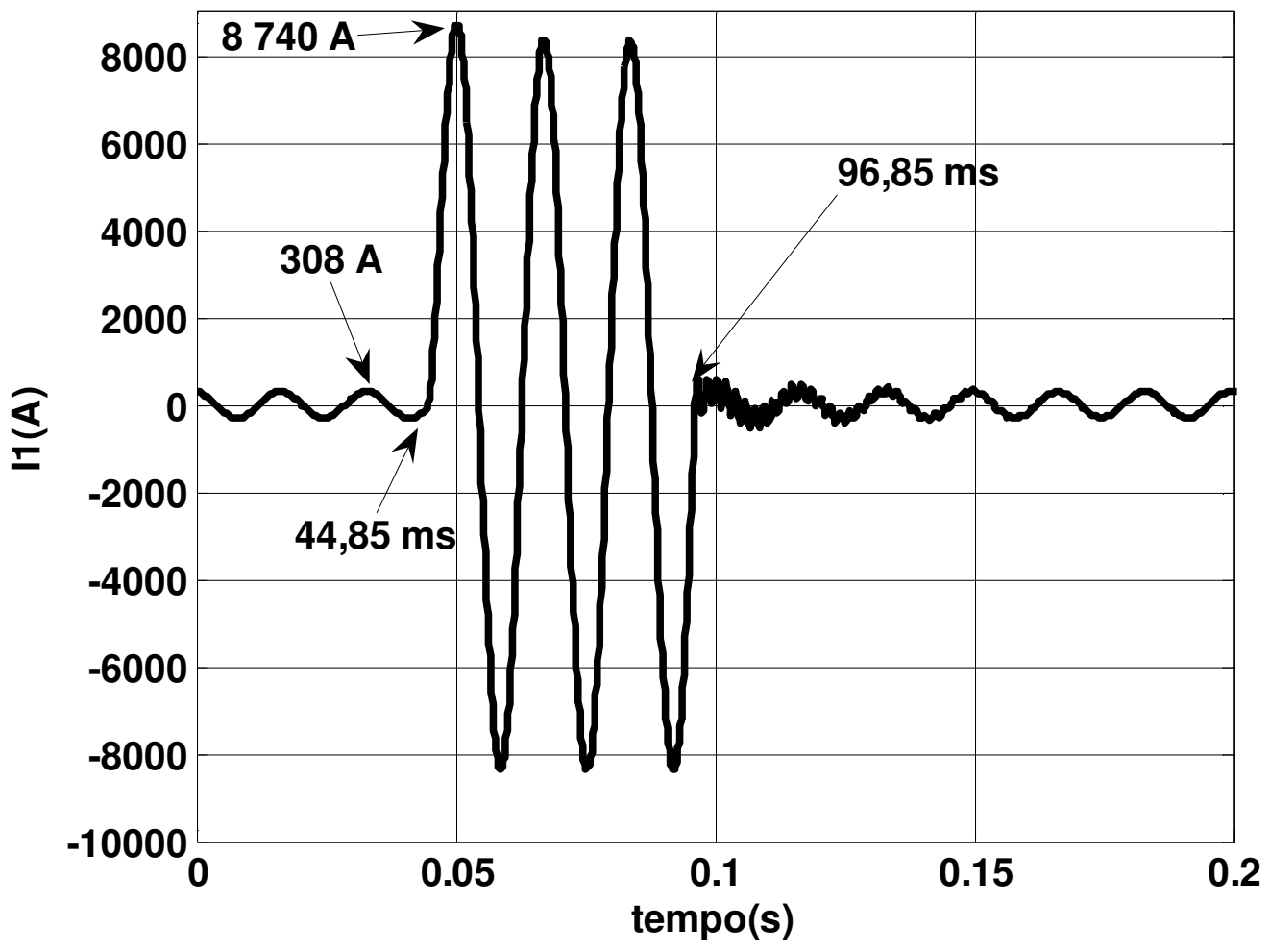

Figura 21- Corrente $\mathrm{I}_{1}$ curto monofásico F1T - simulado 
Com base nas informações colhidas na Figura 21, pode-se estimar a duração do curto-circuito, $\Delta t=96,85-44,85=52 \mathrm{~ms}$ e a variação da corrente $\Delta I=8740-308=8432 \mathrm{~A}$, características da falta curto-circuito fase-terra analisada.

\subsubsection{1 - Análise espectral da corrente $I_{1}$ simulada, através da Transformada Rápida de Fourier}

Com a finalidade de se obter o espectro de frequências da forma de onda da corrente $I_{1}$, representada na Figura 21, aplicou-se a Transformada Rápida de Fourier (TRF ou FFT). A Figura 22 apresenta estes detalhes. $O$ espectro obtido destaca a frequência fundamental $60 \mathrm{~Hz}$.

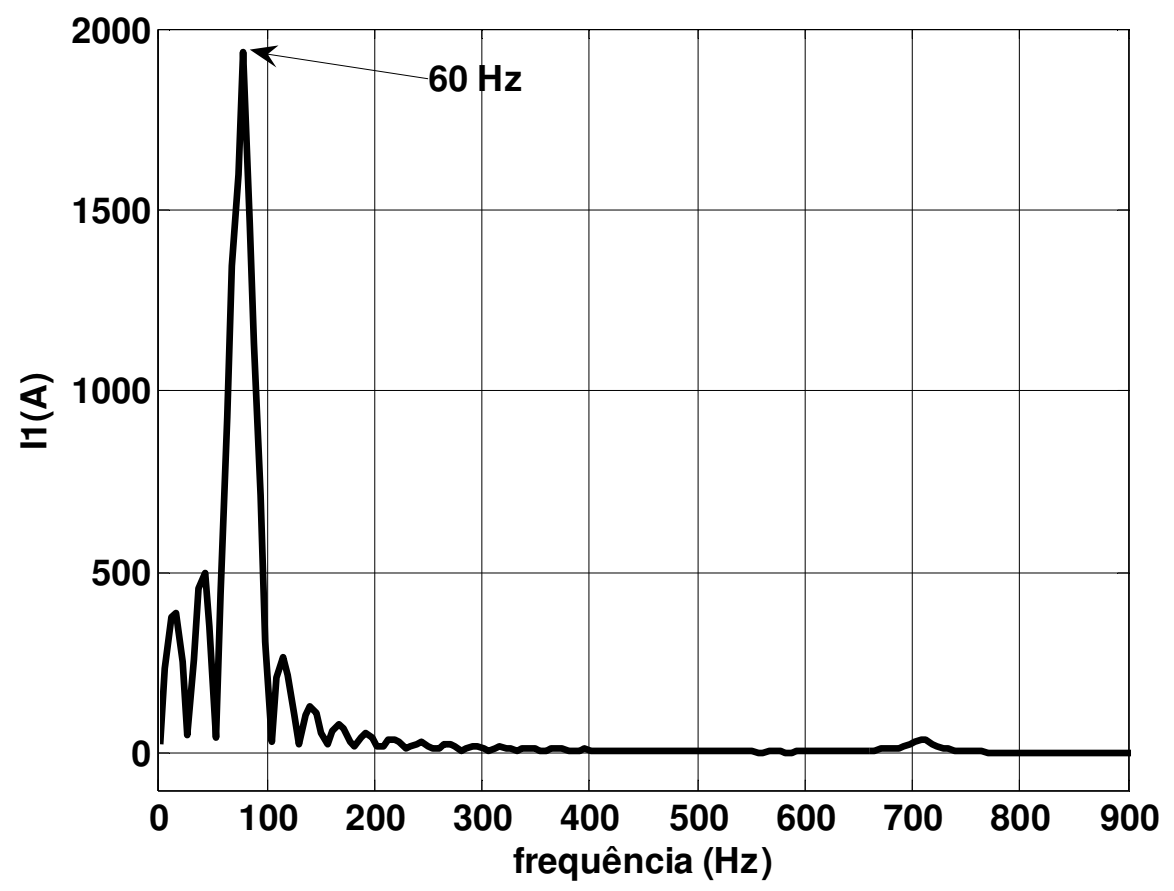

Figura 22 - Espectro de frequências da corrente $I_{1}$ para curto F1T simulado

A Figura 23 mostra este espectro correspondente à Figura anterior, porém, com as amplitudes representadas em $\mathrm{dB}_{\mathrm{A}}$. A TF em $\mathrm{dB}$ mostra mais detalhes da forma de onda. 


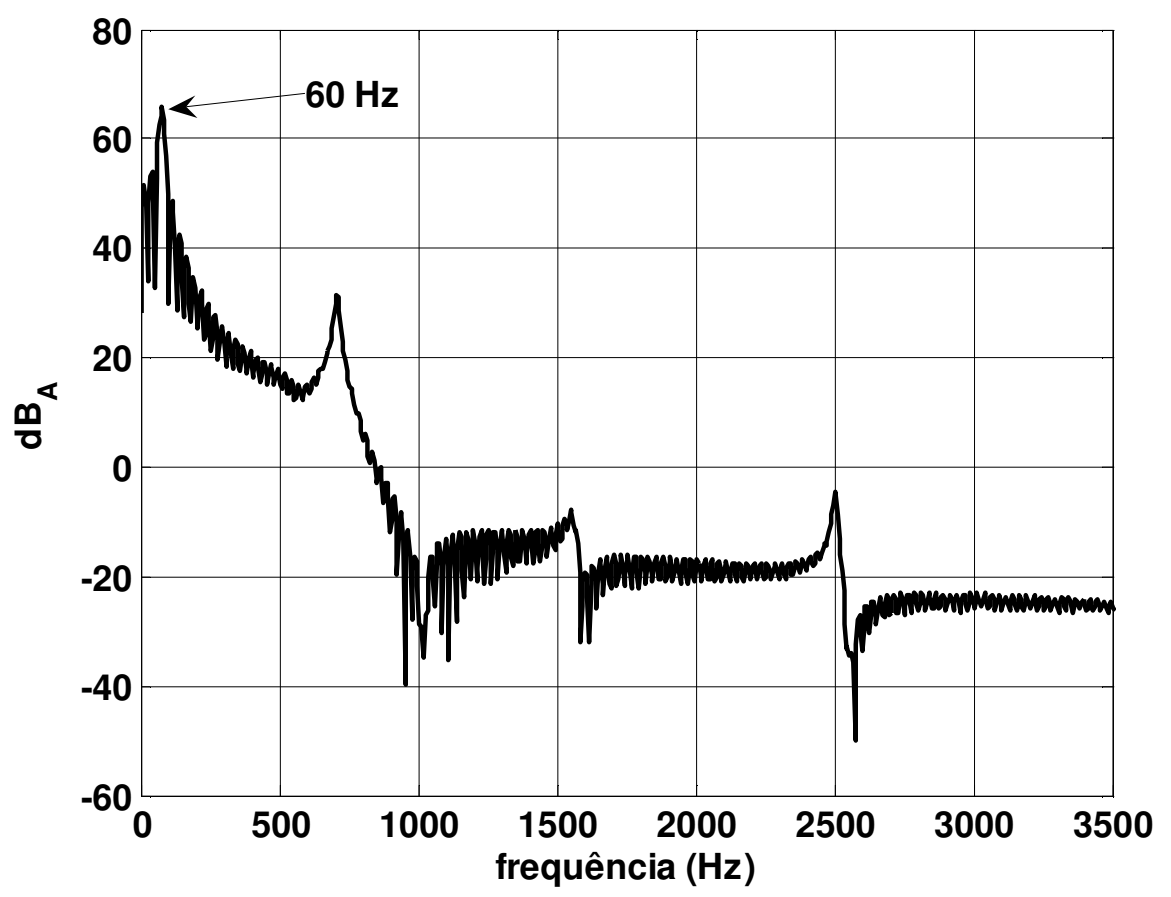

Figura 23 - Espectro de frequências em $\mathrm{dB}_{\mathrm{A}}$ de $\mathrm{I1}$ - simulado

Quando considerado, apenas, o detalhe de $I_{1}$ correspondente ao intervalo de tempo do curto-circuito, a amplitude e o espectro deste podem ser observados nas Figuras 24 e 25. A amplitude da FFT na Figura 24 coincide com a amplitude máxima de 11.

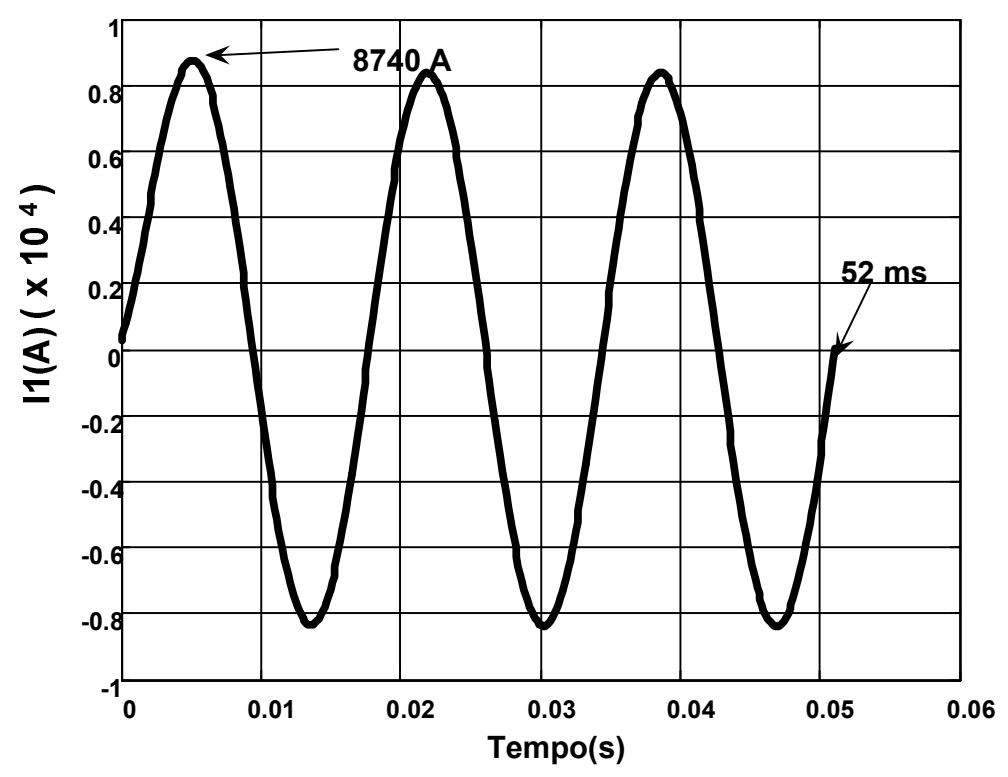

Figura 24 - Corrente 11 em função das amostras no intervalo da falta simulado 


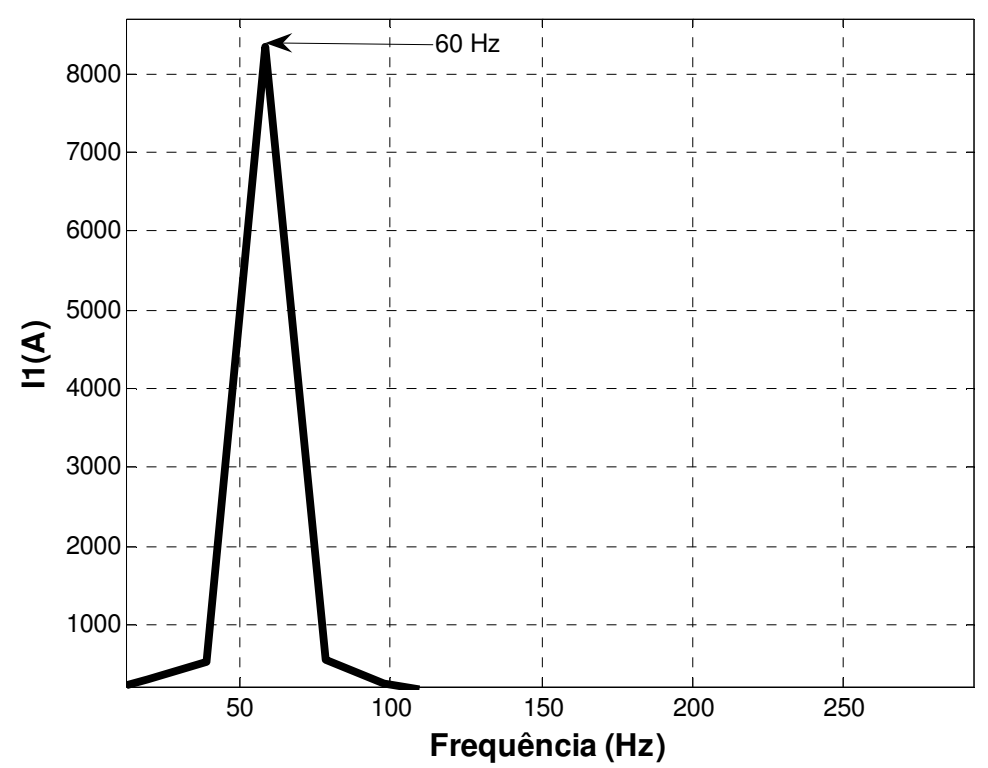

Figura 25 - Espectro de frequências do detalhe de $I_{1}$ usando FFT- simulado

\subsubsection{2- Transformada Wavelet aplicada à forma de onda da corrente $I_{1}$ e curva da variância}

Apresentam-se, neste item, os resultados resultantes de aplicação da TW Discreta (TWD) e $A M R$, que fornecem informações no domínio do tempo e da frequência. A Figura 26 apresenta os sinais $d_{1}$ a $d_{10}$, que correspondem aos detalhes de alta frequência do sinal, e a aproximação a ${ }_{10}$, que corresponde ao coeficiente de menor frequência do sinal. $O$ componente $S$ representa o sinal analisado.

Observa-se que o número de amostras do sinal está representado no eixo horizontal, sendo a taxa de amostragem correspondente de $7680 \mathrm{~Hz}$. Tal valor foi utilizado por existirem instrumentos de medição com frequência de amostragem similar, como por exemplo, o BMI (Basic Measurement Instrument) Modelo 7100, que apresenta um valor em torno de $7680 \mathrm{kHz}$ [8], [85]. Assim, segundo o critério de Nyquist, a maior frequência do sinal amostrado deve ser a metade desta frequência, isto é, $3840 \mathrm{~Hz}$. Os detalhes $d_{1}, d_{2}, d_{3}, d_{4}, \ldots, d_{10}$ fornecem a decomposição do sinal nos seguintes intervalos de frequências $(\mathrm{Hz}): d_{1}(1920 \mathrm{a}$ 3840), $d_{2}\left(960\right.$ a 1920), $d_{3}(480$ a 960$), d_{4}(240$ a 480$), d_{5}$ (120 a 240$), d_{6}(60$ a 120), $d_{7}(30$ a 60$), d_{8}(15$ a 30$), d_{9}\left(7,5\right.$ a 15) e $d_{10}(3,75$ a 7,5$)$. A frequência fundamental, $60 \mathrm{~Hz}$, está nos detalhes 6 e 7 . 
Decomposiçăo até nível $10: s=a 10+d 10+d 9+d 8+d 7+d 6+d 5+d 4+d 3+d 2+d 1$.
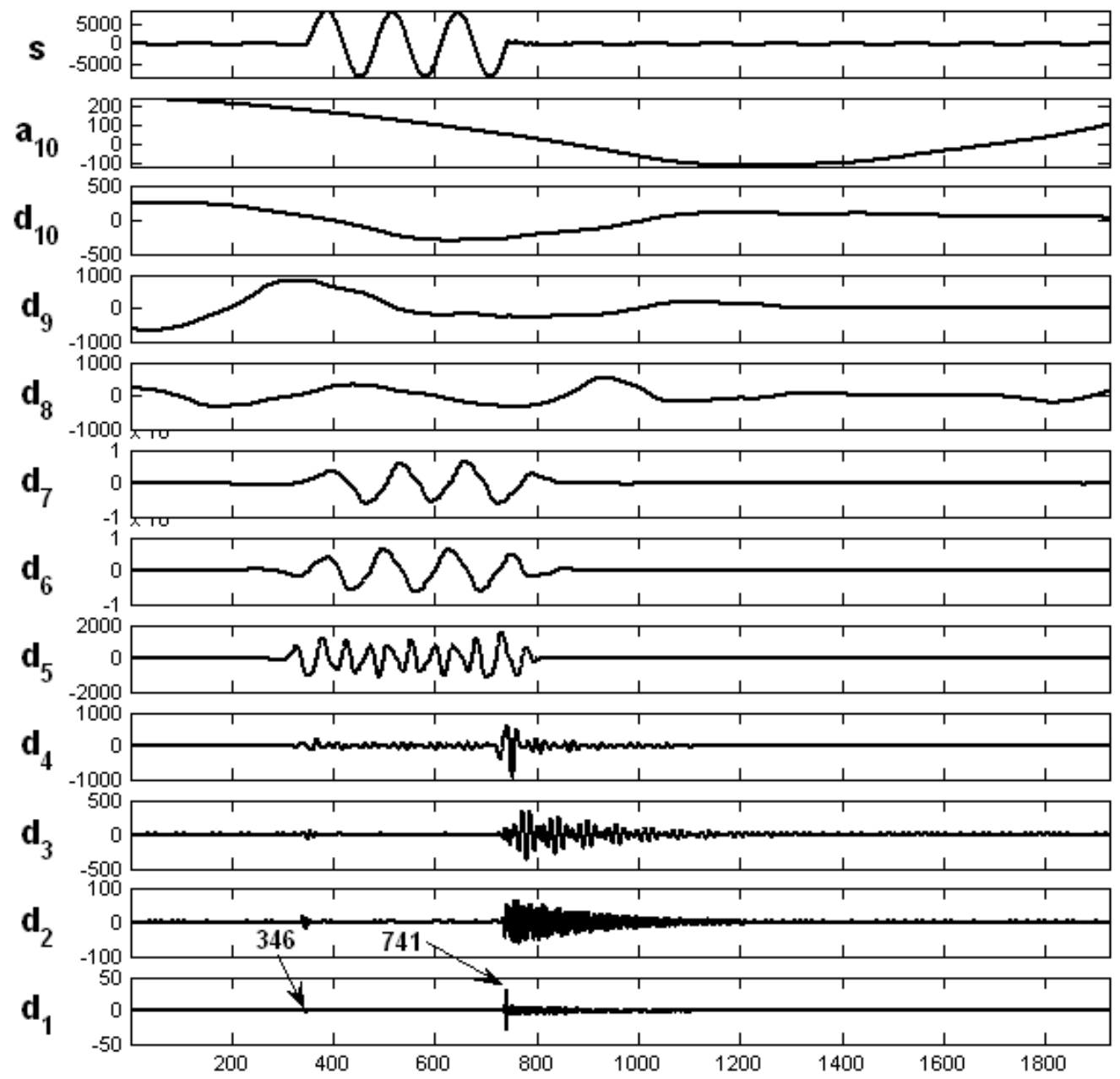

Figura 26- TW Daubechies 4- nível 10 (db4-10)

aplicada à corrente $\mathrm{I}_{1}$ - simulado

A Figura 26 mostra a TW aplicada à forma de onda, por exemplo, da corrente $I_{1}$, permitindo a determinação, através do nível de decomposição d1, da duração do curto-circuito. Como a taxa de amostragem é $7680 \mathrm{~Hz}$, o inverso deste valor fornece o tempo de amostragem 0,130 ms. Assim, o intervalo de tempo do curto-circuito, obtido pelo detalhe $d_{1}$ da Figura 26 , é dado por $\Delta t=(741-346) \times 0,130=51,35 \mathrm{~ms}$.

A Figura 27 mostra, em destaque, o detalhe $d_{1}$, permitindo, também, avaliar o intervalo de tempo do curto-circuito $\Delta t=(741-343) x 0,130=51,74 \mathrm{~ms}$. 
Observe-se a avaliação do intervalo de tempo do curto-circuito, que também poderia ser feita usando-se os detalhes $d_{2}$ ou $d_{3}$.

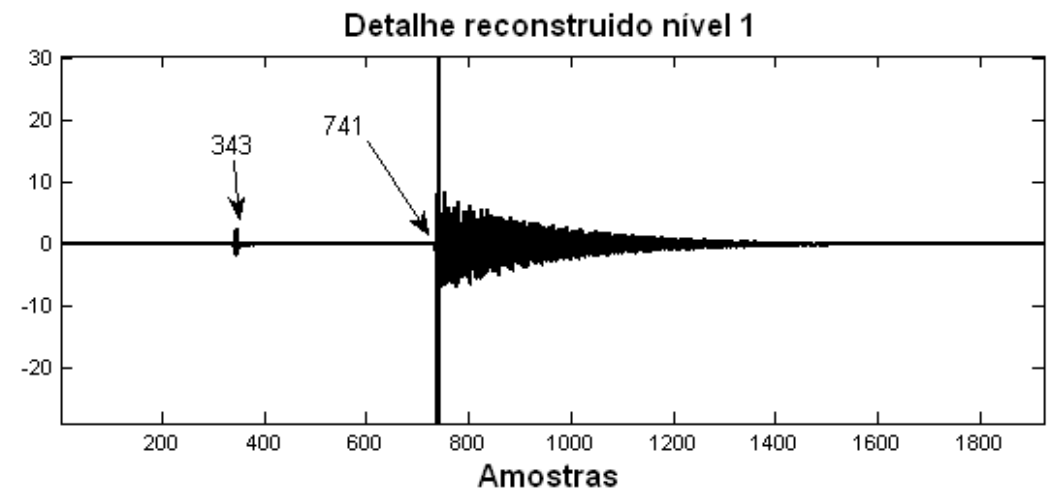

Figura 27 - Detalhe d1 da corrente $I_{1}$

Com relação ao espectro de energia do sinal, este pode ser observado por meio da curva da variância em função do nível do detalhe, apresentada na Figura 28. Observa-se nesta que a máxima concentração de energia do sinal decomposto está no detalhe 7 , correspondendo ao intervalo de frequência de $60 \mathrm{~Hz}$.

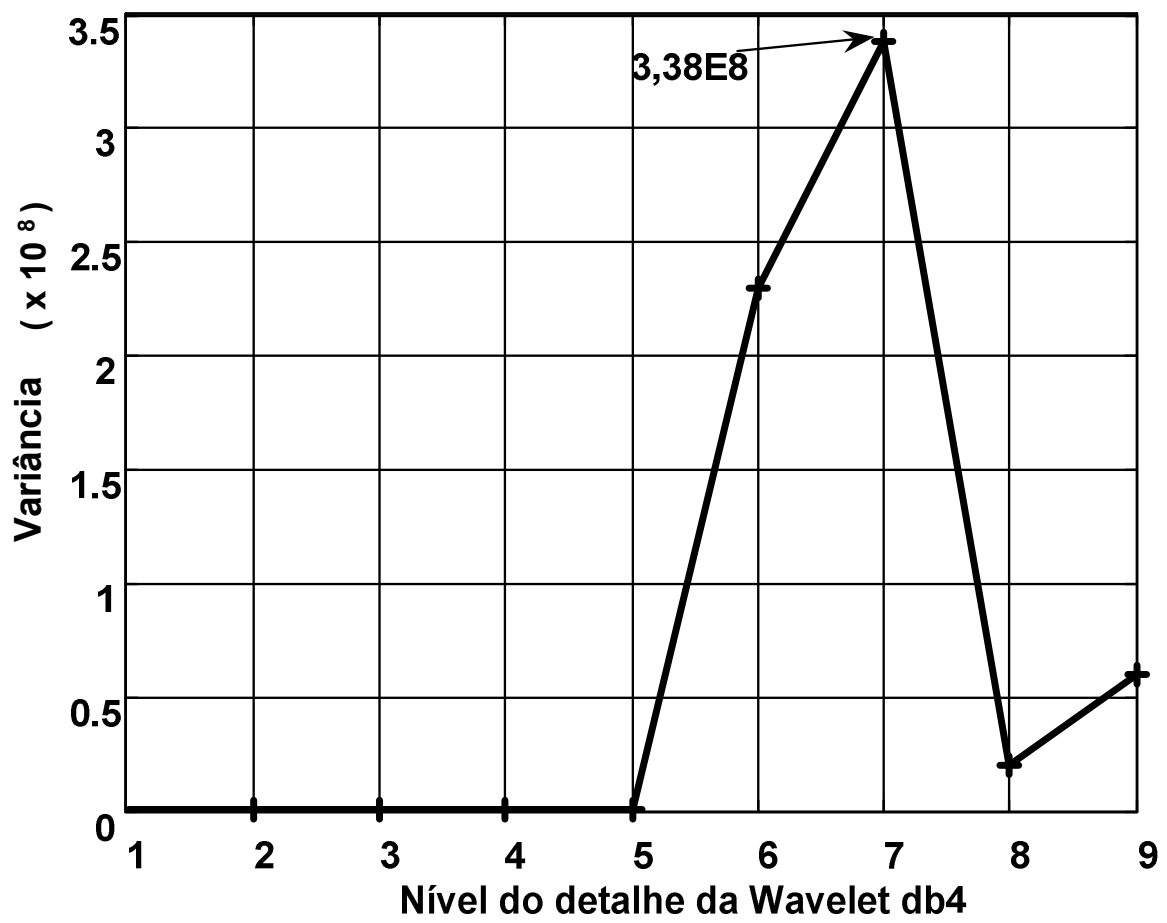

Figura 28- Curva da variância em função do nível do detalhe 


\subsubsection{3- Densidade de fluxo magnético e Transformada Wavelet}

A Figura 29 apresenta o circuito equivalente utilizado na simulação da densidade de fluxo magnético, no qual os valores das correntes das fases das linhas estão associados a um arquivo de dados. Os fluxogramas das Figuras 11 e 12 apresentam os detalhes destes procedimentos de cálculo.

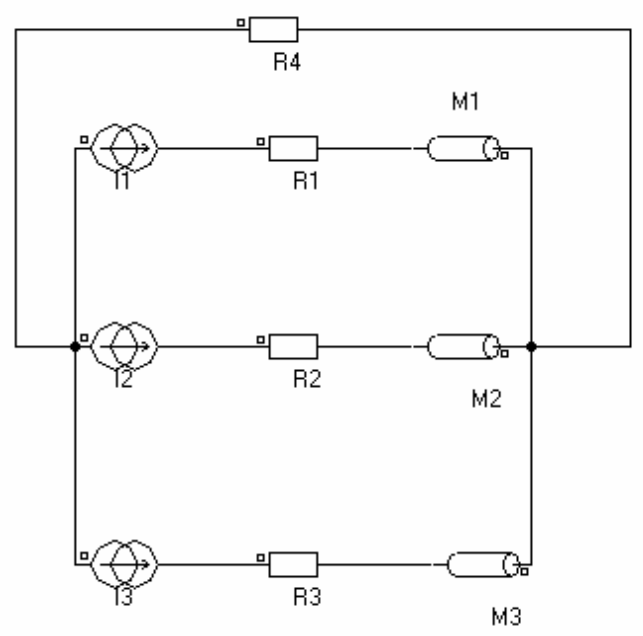

Fig. 29 - Circuito elétrico utilizado no Flux-2D para modelagem do problema

Assim, os valores disponíveis das correntes nas fases foram inseridos como fontes de correntes, de acordo com os recursos disponíveis nos softwares utilizados [17], [18] e [58]. Os valores "Ri" indicados nestes circuitos correspondem às necessidades específicas do software, necessárias para representar as conexões com as cargas "Mi".

A Figura 30 representa o componente na direção " $x$ " da densidade de fluxo magnético resultante no ponto $P(500 ;-500) \mathrm{mm}$. 


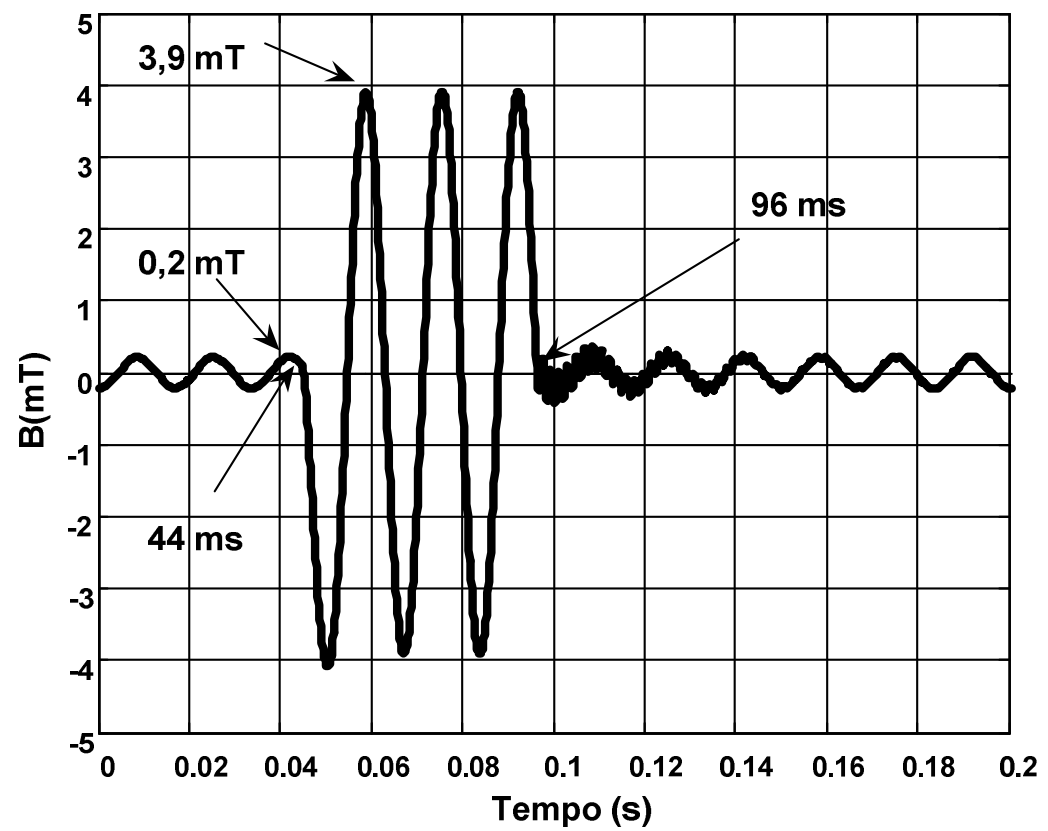

Figura 30 - Componente na direção "x" do campo magnético resultante $P(500,-500) \mathrm{mm}$

Pela inspeção da Figura 30, pode-se avaliar o intervalo de tempo da falha $\Delta t=96-44=52 \mathrm{~ms}$, o mesmo valor encontrado para a forma de onda da corrente. Observa-se que a forma de onda da densidade de fluxo magnético é semelhante à forma de onda da corrente, a menos da amplitude.

Aplicando-se à forma de onda da Figura 30 a TW Daubechies 4 nível 10, db4 - 10, obtém-se a decomposição da forma de onda da densidade de fluxo magnético em dez detalhes (altas frequências do sinal) e a aproximação $a_{10}$ (menor frequência do sinal). Com relação à detecção da falta, o intervalo de tempo medido através dos detalhes $\mathrm{d} 1$ ou $\mathrm{d} 2$ também é de, aproximadamente 52 ms, como pode ser visto nas Figuras 31, 32 e 33. Este resultado é similar que se obtém pela aplicação da $T W$, na forma de onda da corrente. 


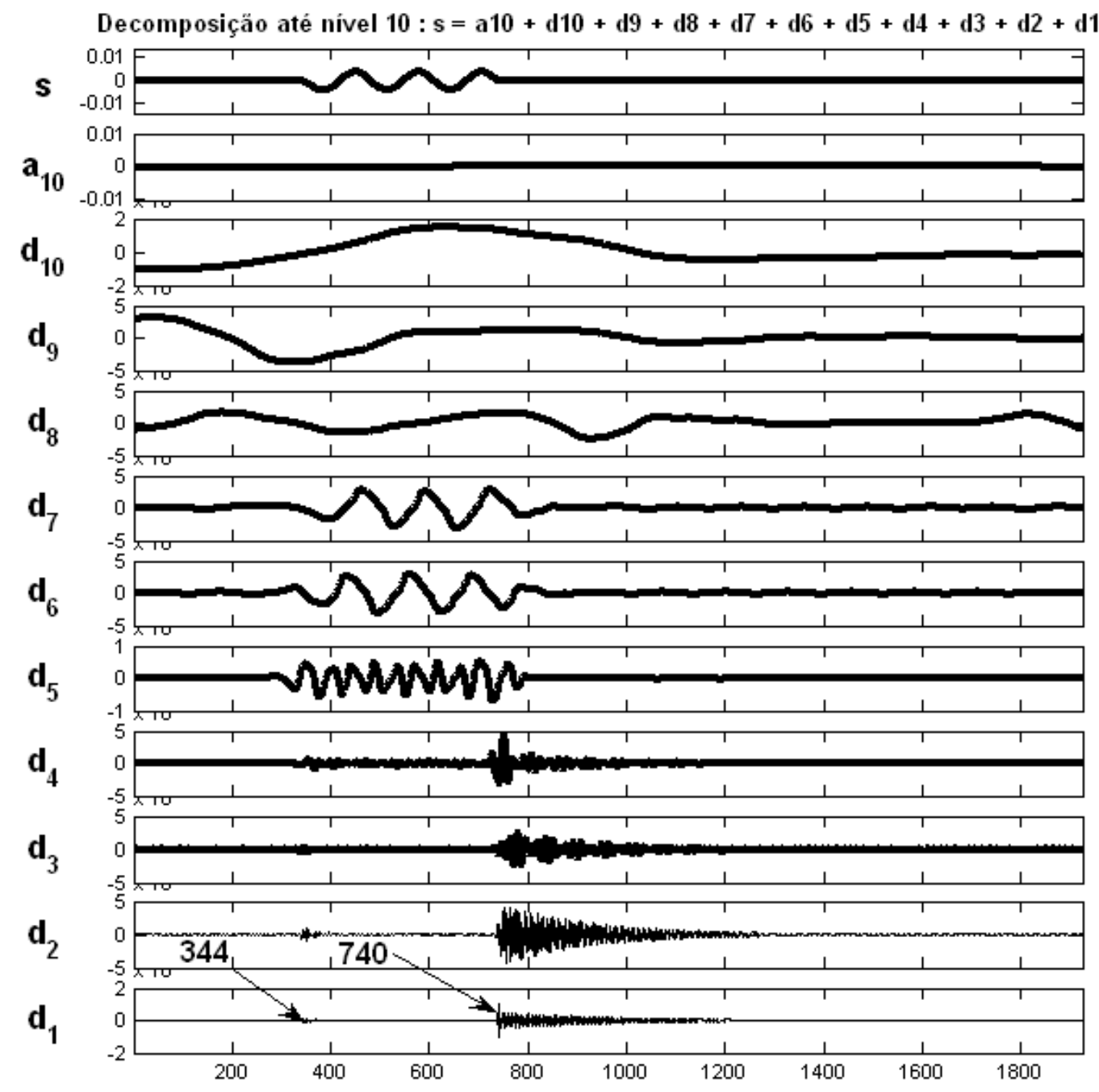

Figura 31 - Decomposição através da TW do componente " $x$ " da densidade de fluxo magnético

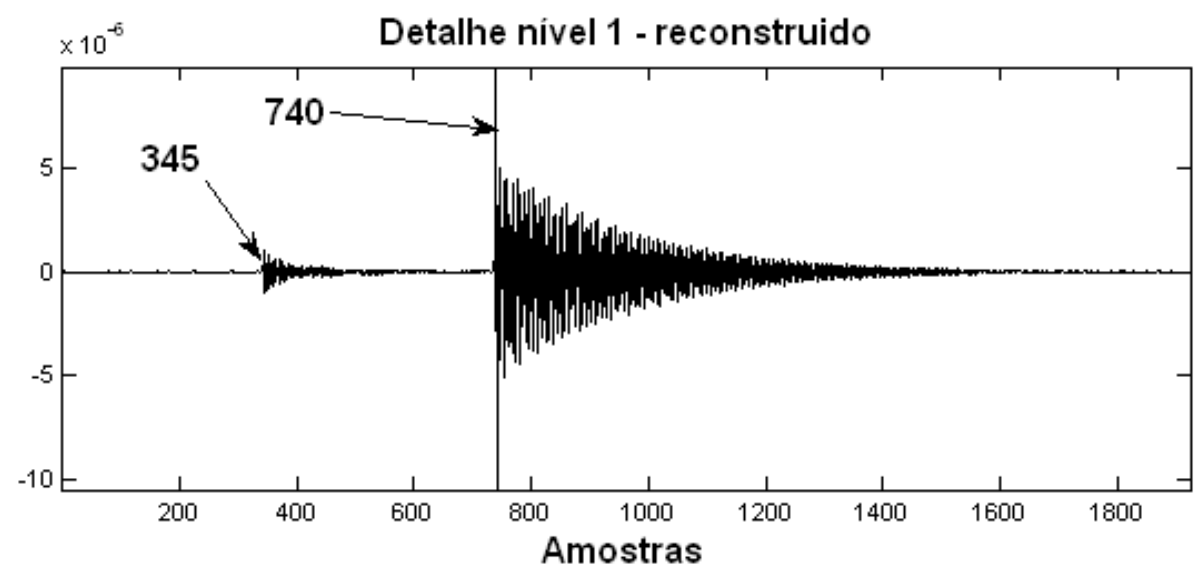

Figura 32- Detalhe $d_{1}$ da densidade de fluxo magnético 


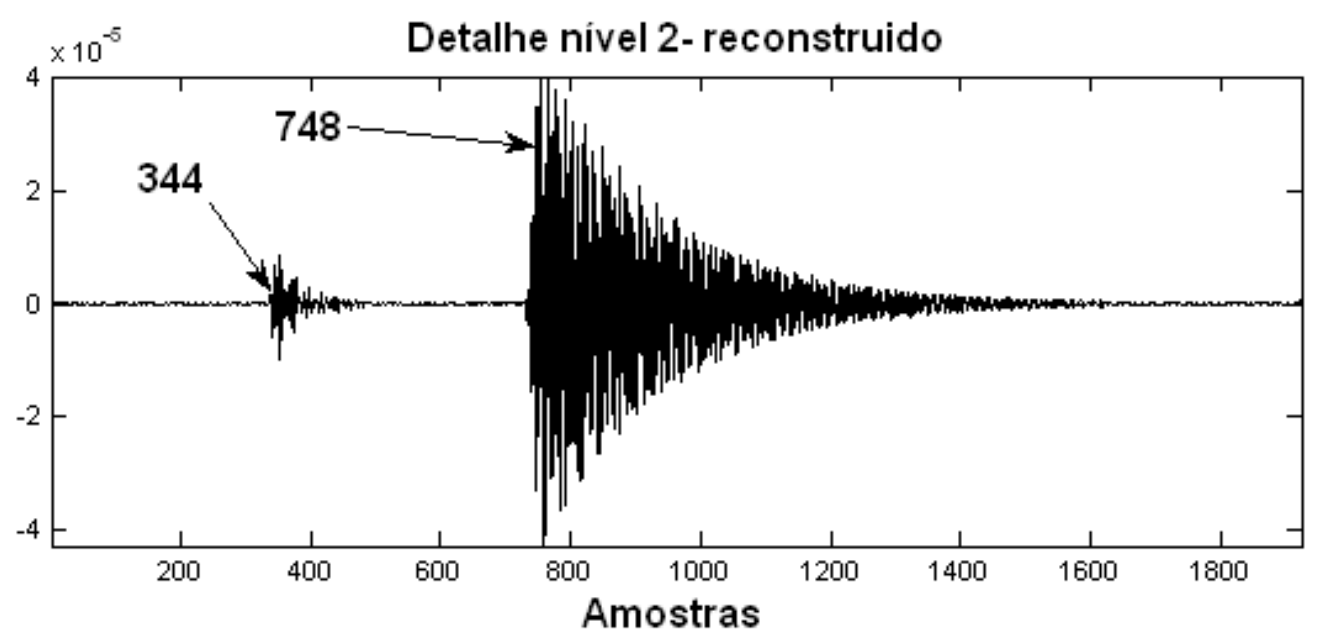

Figura 33- Detalhe $\mathrm{d}_{2}$ da densidade de fluxo magnético

\subsection{2 - Aplicação da metodologia em simulações numéricas com dados experimentais}

Conforme descrito na metodologia, usando-se a montagem experimental, cujo esquema é mostrado nas Figuras 13 e 14, foram considerados dez tipos de transitórios (curtos-circuitos), compreendendo os curtos Fase-Terra (3), DuplaFase (3), Dupla- Fase-Terra (3) e o Trifásico (1). Isto resultou em mais de 50 pontos de medições, onde foram obtidas as formas de onda das correntes e das densidades de fluxo magnético, por meio de sensores apropriados.

As formas de ondas foram obtidas através de um sensor de densidade de fluxo magnético acoplado a um osciloscópio, posicionado em vários pontos, cujas coordenadas são aquelas apresentadas na Tabela 1, referentes ao sistema de coordenadas da Figura 34. A taxa de amostragem utilizada foi $10 \mathrm{kHz}$ e 2000 amostras, características do modelo de osciloscópio utilizado. Os dados foram coletados em disquetes e tratados via softwares, Matlab e Flux 2D, [18] e [58]. Os resultados mais significativos serão apresentados a seguir: 


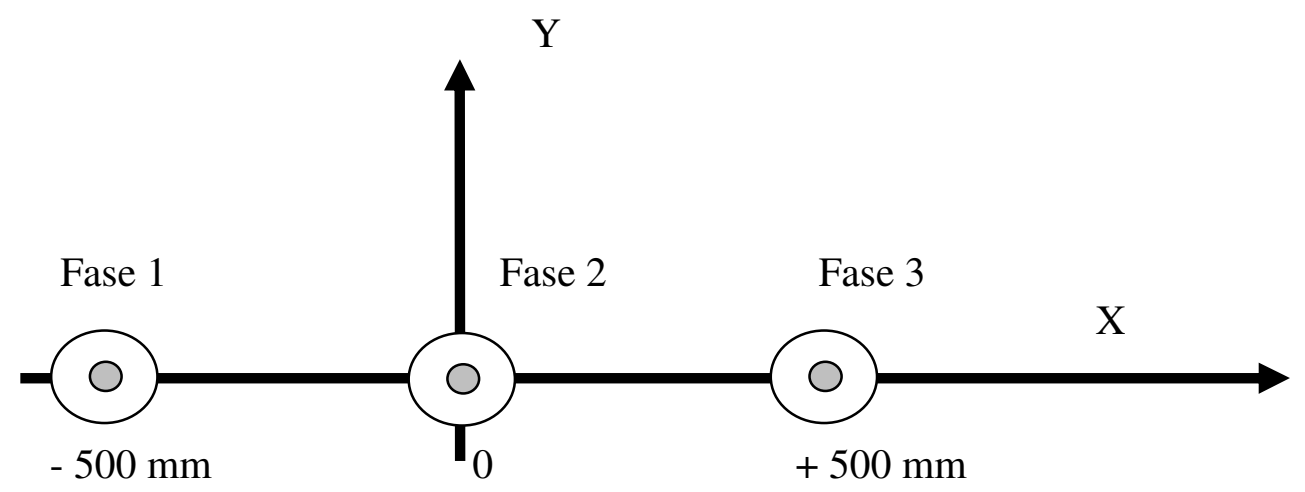

Figura 34 - Sistema de coordenadas utilizado.

Tabela 1 - Pontos onde foram realizadas as medições, em milímetros

\begin{tabular}{|c|c|c|c|c|c|c|c|}
\hline & Fase 1 & & Fase 2 & & Fase 3 & & \\
\hline & $-500,-250$ & & $0,-250$ & $100,-250$ & $500,-250$ & $700,-250$ & $1500,-250$ \\
\hline & $-500,-450$ & & $0,-450$ & & $500,-450$ & & $1500,-450$ \\
\hline \multirow[t]{2}{*}{$-690,-520$} & & & $0,-520$ & & $470,-520$ & & \\
\hline & $-500,-650$ & & $0,-650$ & & $500,-650$ & $810,-740$ & $1500,-650$ \\
\hline$-950,-740$ & $-500,-850$ & $-80,-740$ & $0,-850$ & & $500,-850$ & & $1500,-850$ \\
\hline$-1004,-730$ & $-500,-950$ & $-100,-950$ & $0,-950$ & $250,-950$ & $500,-950$ & $700,-950$ & $1500,-950$ \\
\hline \multirow[t]{4}{*}{$-1650,-950$} & $-500,-1050$ & $-250,-950$ & $0,-1050$ & & $500,-1050$ & $1180,-950$ & $1500,-1050$ \\
\hline & $-500,-1250$ & & $0,-1250$ & & $500,-1250$ & & $1500,-1250$ \\
\hline & $-500,-1350$ & & $0,-1350$ & & $500,-1350$ & & $1500,-1350$ \\
\hline & $-500,-1450$ & & $0,-1450$ & & $500,-1450$ & & $1500,-1450$ \\
\hline
\end{tabular}




\subsubsection{1- Medições das correntes na linha para curto F1T}

As formas de onda das correntes $I_{1}, I_{2}, I_{3}$, para um curto-circuito $F 1 T$, foram medidas e estão representadas na Figura 35.
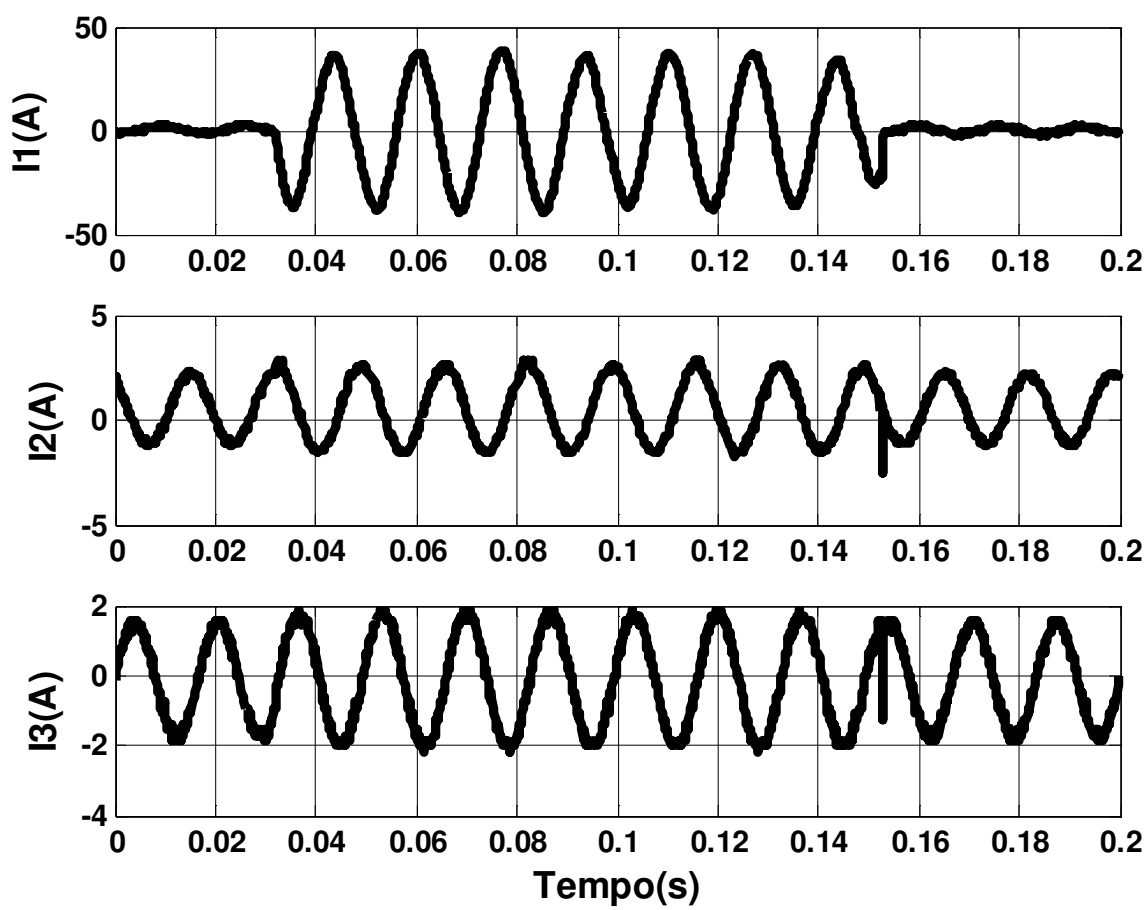

Figura 35 - Correntes $\mathrm{I}_{1}, \mathrm{I}_{2}$ e $\mathrm{I}_{3}$ para curto $\mathrm{F} 1 \mathrm{~T}$. Valores experimentais

A corrente da fase1, $l_{1}$, sofreu variação brusca na sua forma de onda; já as correntes das fases 2 e 3 sofreram pequenas variações. Ao analisar a forma de onda da corrente $\mathrm{I}_{1}$, que está representada na Figura 36, percebe-se que 0 curto-circuito Fase1- Terra está caracterizado, pois a corrente da fase1 variou de 2,5 A para 38,2 A. O transitório teve início em 31,2 ms e término em 153,2 ms. A duração do transitório foi de 122,0 ms. Estes valores foram obtidos com o auxílio do cursor disponibilizado no software utilizado [18]. 


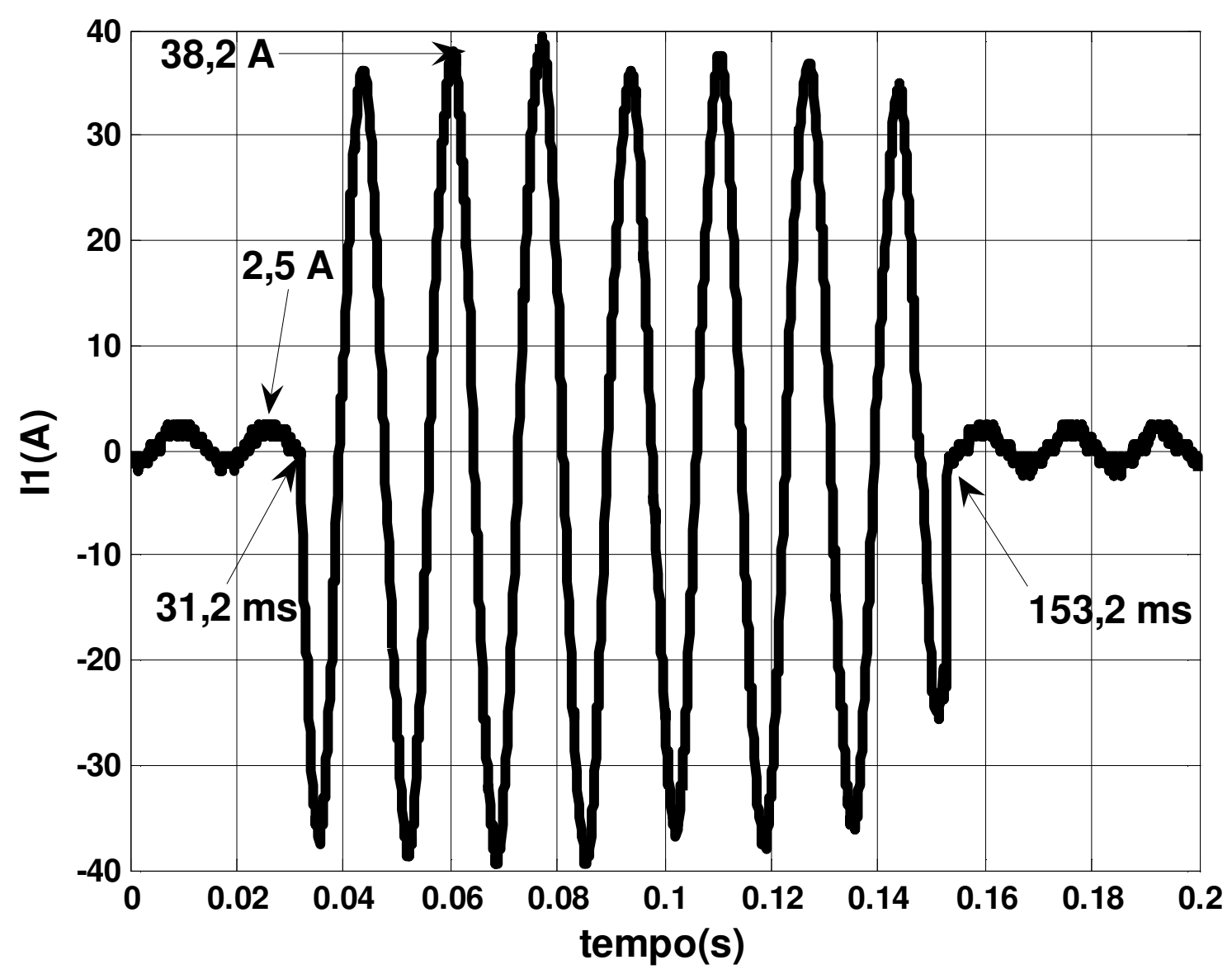

Figura 36 - Corrente $\mathrm{I}_{1}$ - curto F1T - Valores experimentais

4.2.2.2 - Análise espectral da corrente $I_{1}$ usando a Transformada Rápida de Fourier

As Figuras 37 e 38 mostram os espectros de frequências da corrente $I_{1}$ através da aplicação da Transformada Rápida de Fourier (TRF ou FFT) em Ampère e $\mathrm{dB}_{\mathrm{A}}$. Ambas mostram a maior concentração da energia do sinal em 60 $\mathrm{Hz}$. O espectro em $\mathrm{dB}_{\mathrm{A}}$ fornece mais detalhes do sinal do que o espectro em Ampère. 


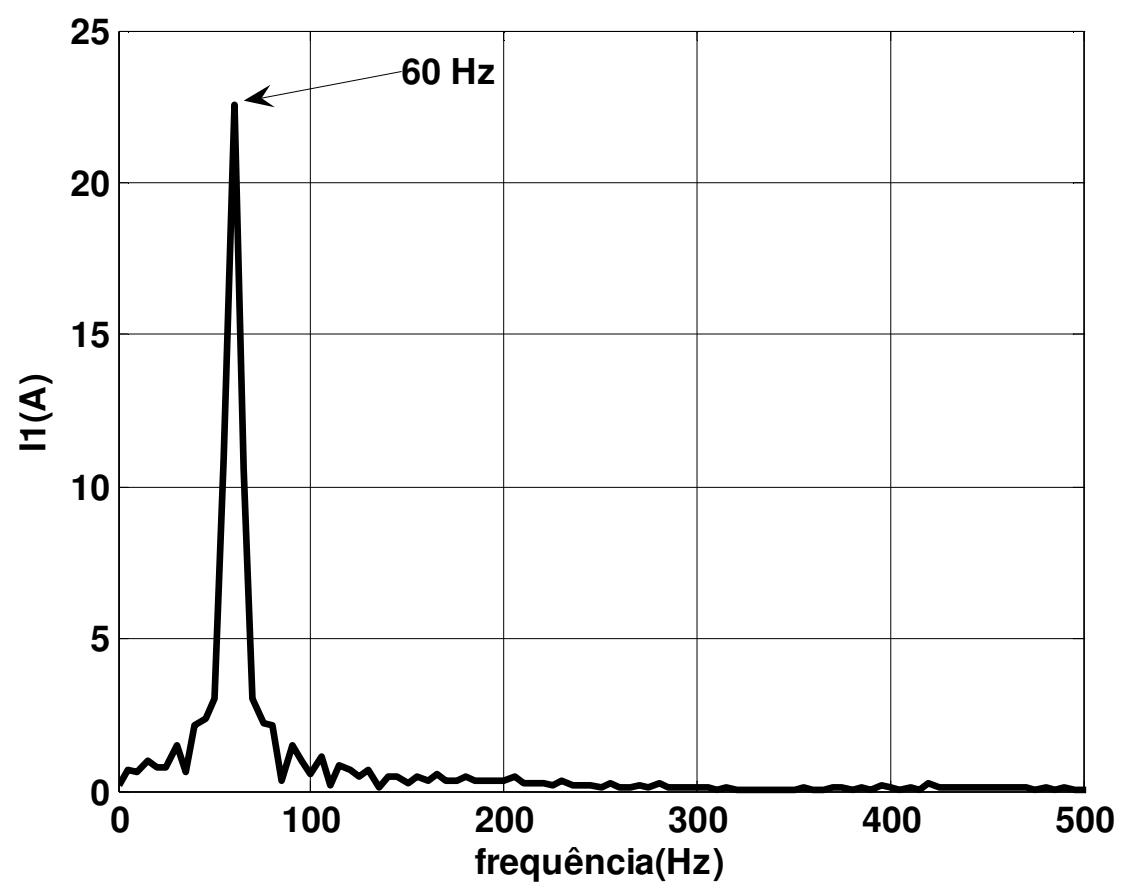

Figura 37 - Espectro de frequências da corrente $I_{1}(F F T)-$ Valores experimentais

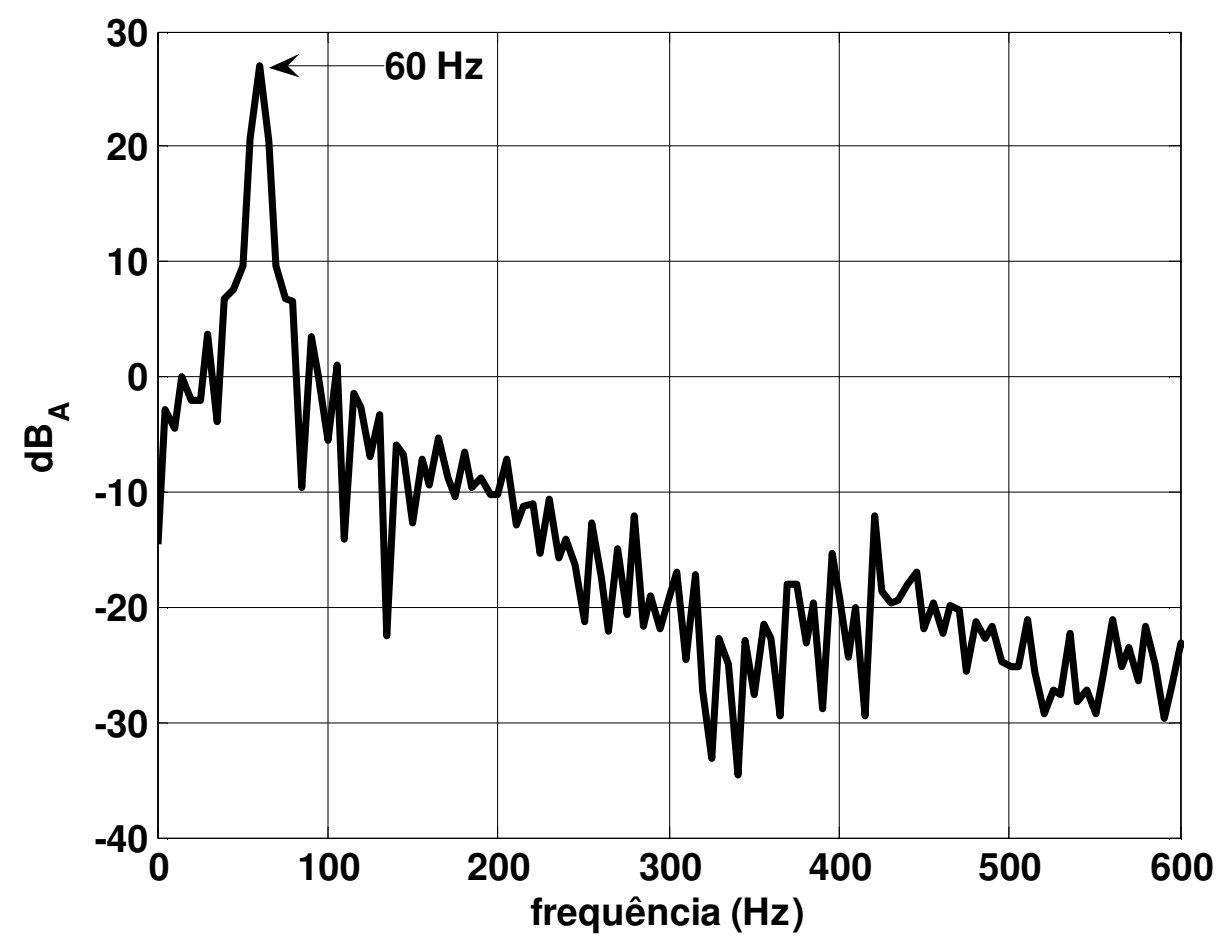

Figura 38 - Espectro de frequências da corrente $\mathrm{l}_{1} \mathrm{em} \mathrm{dB}_{\mathrm{A}}$. Valores experimentais 


\subsubsection{3 - Transformada Wavelet aplicada à forma de onda da corrente $\mathrm{I}_{1}$}

A TW Discreta (TWD) e a $A M R$ foram utilizadas como ferramentas de análise da forma de onda da corrente. Conforme descrito anteriormente, observase que estas fornecem informações no domínio do tempo e da frequência. A Figura 33 apresenta os coeficientes $d_{1}$ a $d_{10}$, que correspondem aos detalhes de alta frequência, e a aproximação $a_{10}$, que corresponde ao coeficiente de menor frequência do sinal analisado.

Assim, tem-se no eixo horizontal o número das amostras do sinal. A taxa de amostragem do sinal em estudo é de $10000 \mathrm{~Hz}$. Desta forma, segundo o critério de Nyquist, a frequência de um sinal de informação a ser amostrado, para que possa posteriormente ser reconstruído sem erro, deve ser igual ou menor que o dobro da maior frequência desse sinal. Portanto, para frequência de amostragem de $10000 \mathrm{~Hz}$, o máximo que pode ser amostrado e recuperado, sem erro, é $5000 \mathrm{~Hz}$ [82],[83]. Os detalhes $d_{1}, d_{2}, d_{3}, d_{4}, \ldots, d_{10}$ fornecem a decomposição do sinal nos seguintes intervalos de frequências, em $\mathrm{Hz}, d_{1}(2500$ a 5000$), d_{2}(1250$ a 2500$), d_{3}(625$ a 1250$), d_{4}(312,5$ a 625$), d_{5}(156,25$ a 312,5$)$, $d_{6}(78,125$ a 156,25$), d_{7}(39,06$ a 78,125$), d_{8}\left(19,53\right.$ a 39,06), $d_{9}(9,76$ a 19,53) e $d_{10}(4,88$ a 9,76). Note que a frequência fundamental, $60 \mathrm{~Hz}$, relaciona-se ao detalhe 7 .

Aplicando a $T W$ db4-10 no sinal da corrente $I_{1}$, obtém-se a Figura 39. A duração do curto-circuito obtida através do detalhe $d_{2}$ da Figura 33 vale $\Delta t=t_{2}-t_{1}=(1530-320) \cdot 0,1 \cdot 10^{-3}=121 \mathrm{~ms}$. 


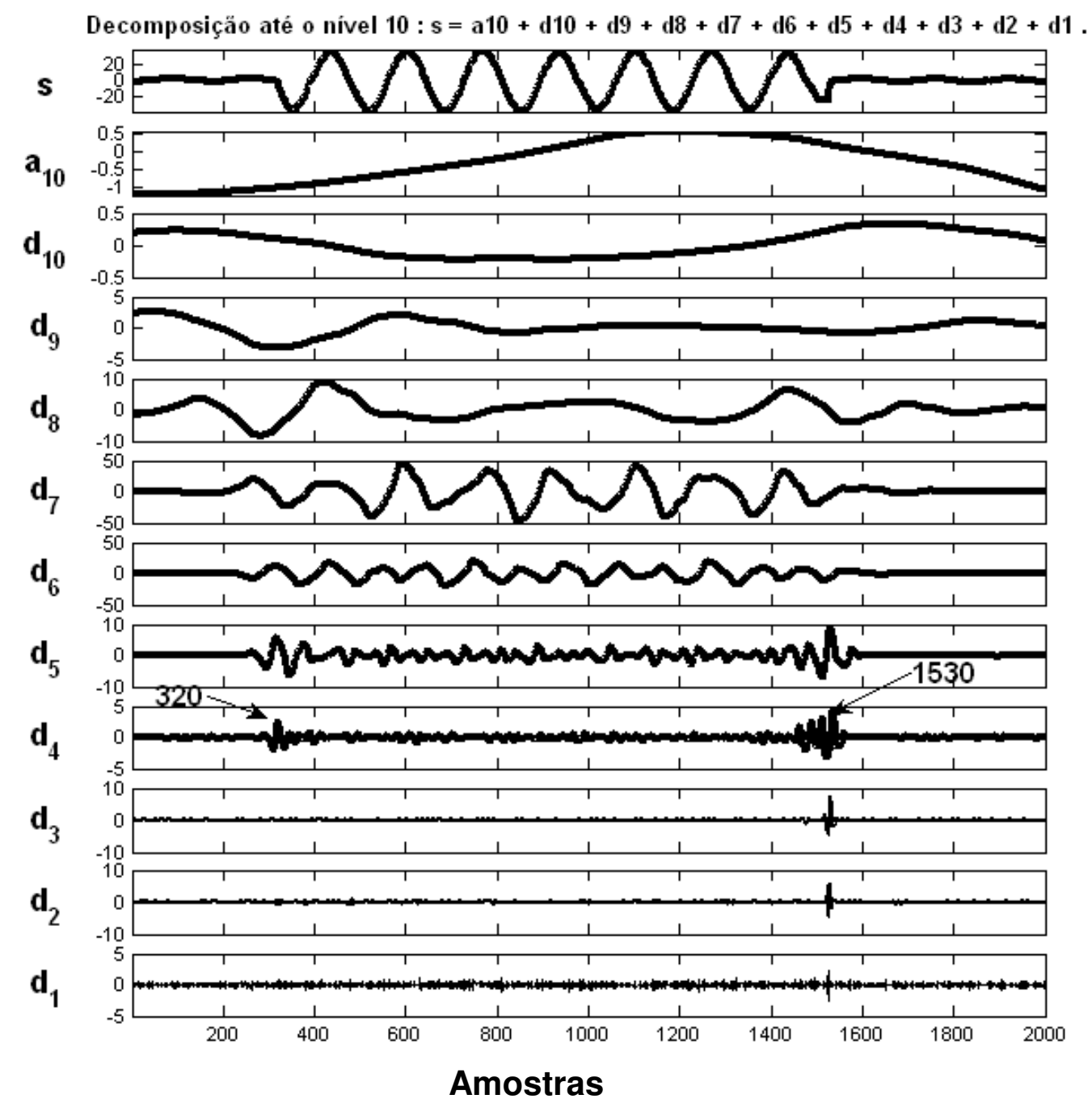

Figura 39- Decomposição da corrente $I_{1}$ através da Transformada Discreta Wavelet db4 - nível 10, em função do número de amostras. Valores experimentais

Separando-se o detalhe 4, obtém- se a Figura 40. A duração do curtocircuito medido pelo detalhe de nível 4 vale :

$$
\Delta t=t_{2}-t_{1}=(1538-321) \cdot 0,1 \cdot 10^{-3}=121,7 \mathrm{~ms} .
$$




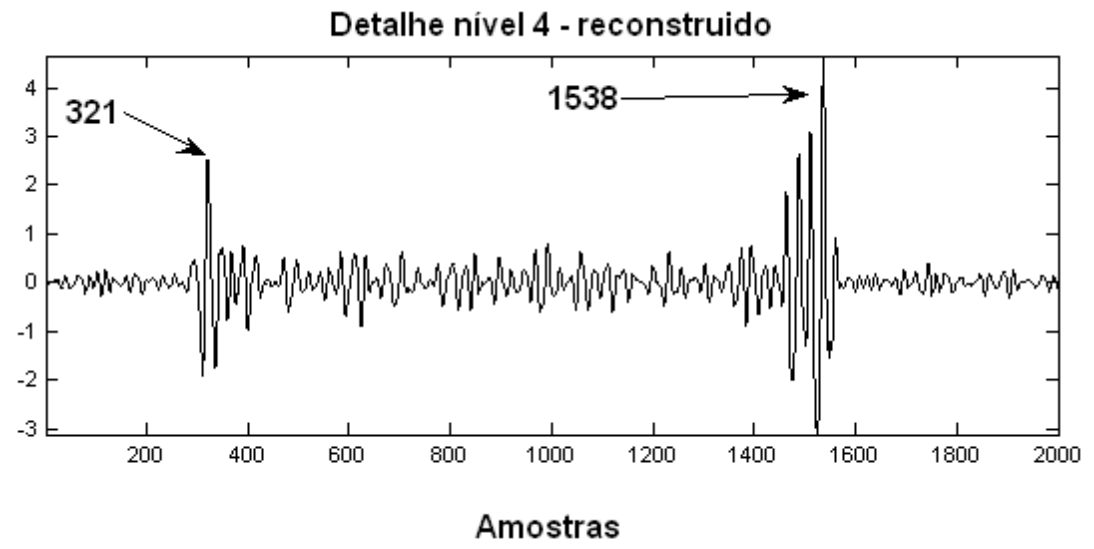

Figura 40- Decomposição da corrente $l_{1}$ através da Transformada Discreta Wavelet db4 - nível 4, em função do número de amostras. Valores experimentais.

Estas correntes, medidas na bancada experimental, serão os dados de entrada para o FLUX 2D simular a densidade fluxo magnético correspondente. As simulações estão apresentadas mais a frente juntamente com os valores medidos.

\subsubsection{4 - Densidade de fluxo magnético}

\subsubsection{1 - Forma de onda do curto fase-terra}

A corrente $I_{1}$ obtida na bancada experimental através de um curto-circuito fase 1 terra (F1T) e mostrada na Figura 36 , foi introduzida no software comercial [58] para simular a densidade de fluxo magnético na direção $x$, no ponto $P(-500$, -250) mm. A Figura 41 foi obtida via software [18] e [58]. 


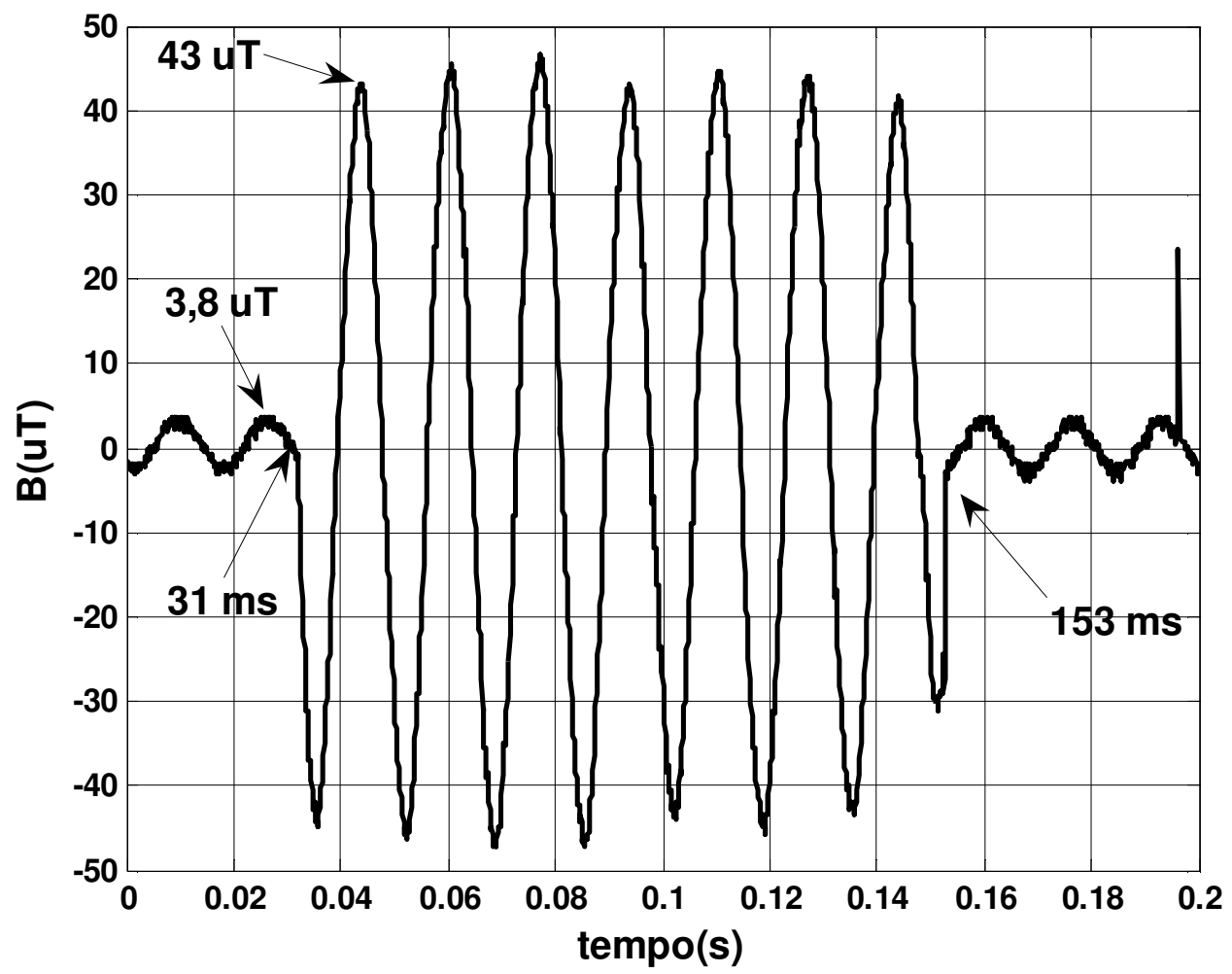

Figura 41- Densidade de fluxo magnético. Curto F1T no ponto $\mathrm{P}(-500,-250)$ $\mathrm{mm}$. Valores simulados [58].

O curto-circuito teve duração de $\Delta t=(153-31)=122 \mathrm{~ms}$ e a amplitude da densidade de fluxo magnético teve variação $\Delta B=(43-3,8)=39,2 \mu T$. 
4.2.2.4.2 - Espectro de freqüências da forma de onda da densidade de fluxo magnético.

O espectro de frequências, em $\mu T$, está apresentado na Figura 42 , sendo $60 \mathrm{~Hz}$ a frequência fundamental .

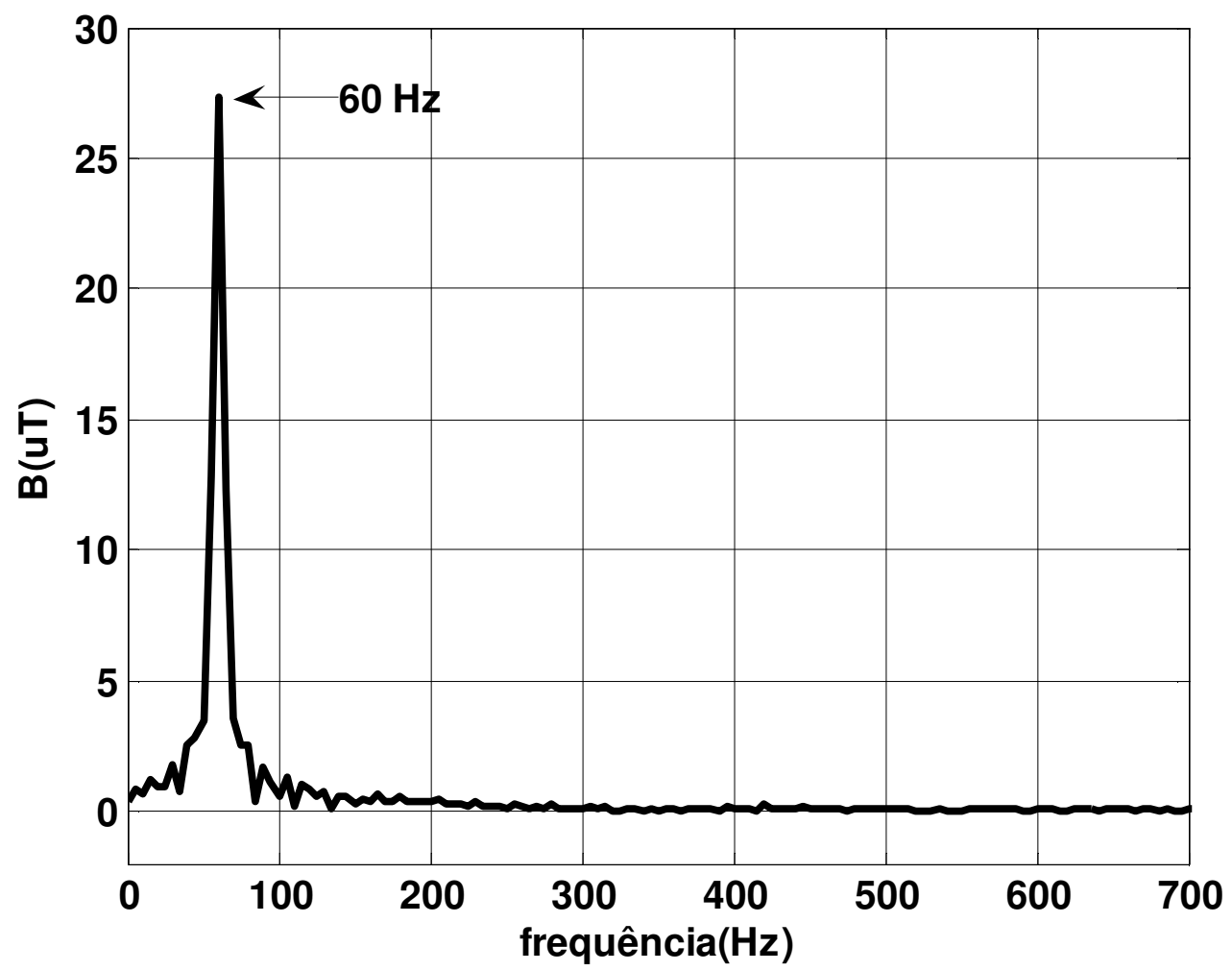

Figura 42 - Espectro de frequências da densidade de fluxo magnético B (UT). Curto F1T no ponto $\mathrm{P}(-500,-250) \mathrm{mm}$. Valores simulados.

O espectro de frequências em dB uT mostra, também, que a frequência fundamental é $60 \mathrm{~Hz}$ e mostra vários detalhes do espectro de frequências, como mostrado na Figura 43. 


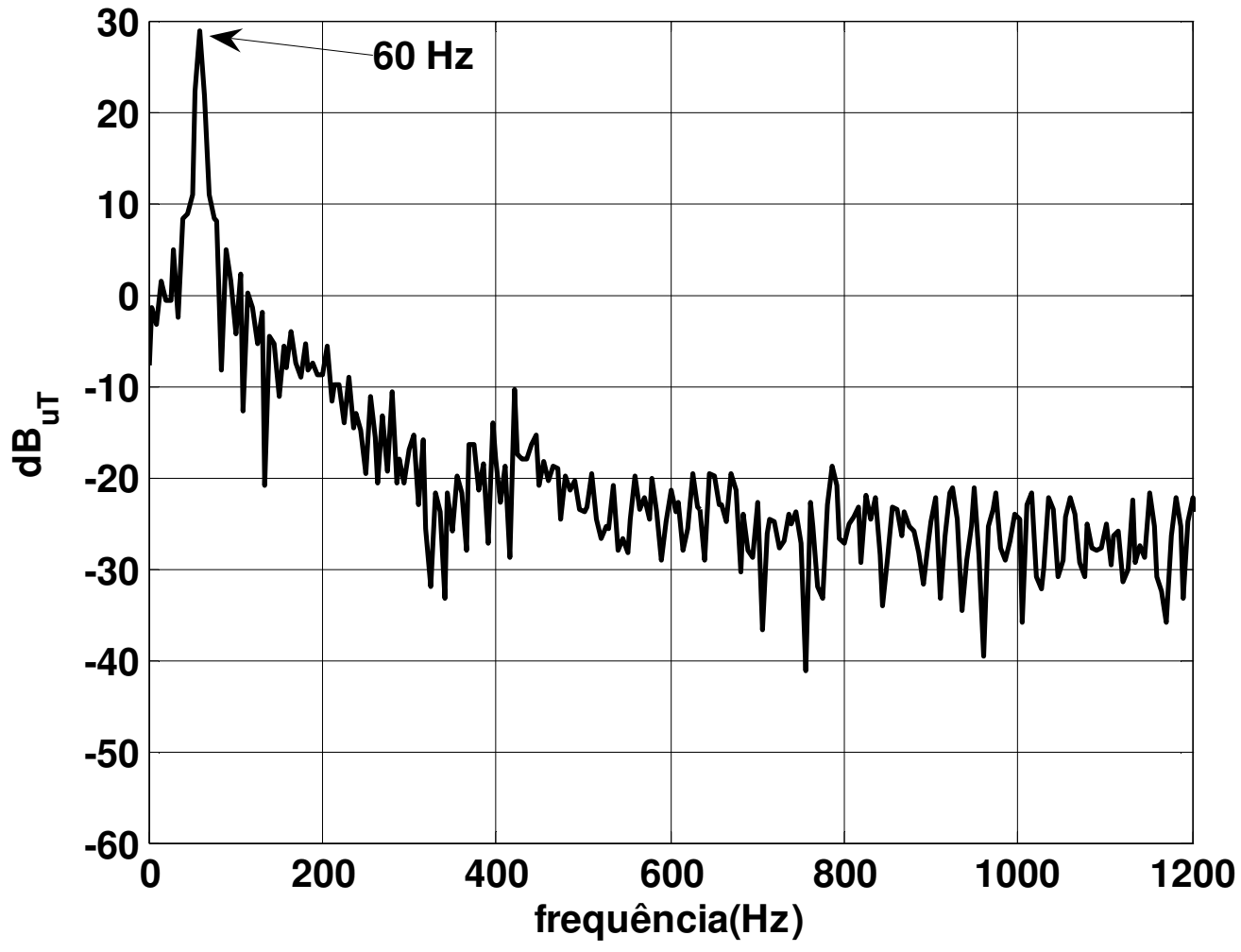

Figura 43 - Espectro de frequências em $\mathrm{dB}_{\mathrm{ut}}$ da densidade de fluxo magnético. Curto F1T no ponto $P(-500,-250) \mathrm{mm}$. Valores simulados

4.2.2.4.3 - Transformada Wavelet da forma de onda da densidade de fluxo magnético

A Figura 44 é obtida pela aplicação da TW na forma de onda da Figura 41, indicando que a duração do curto-circuito é $\Delta t=(1540-320) \cdot 0,1 \cdot 10^{-3} \mathrm{~s}=122 \mathrm{~ms}$. 


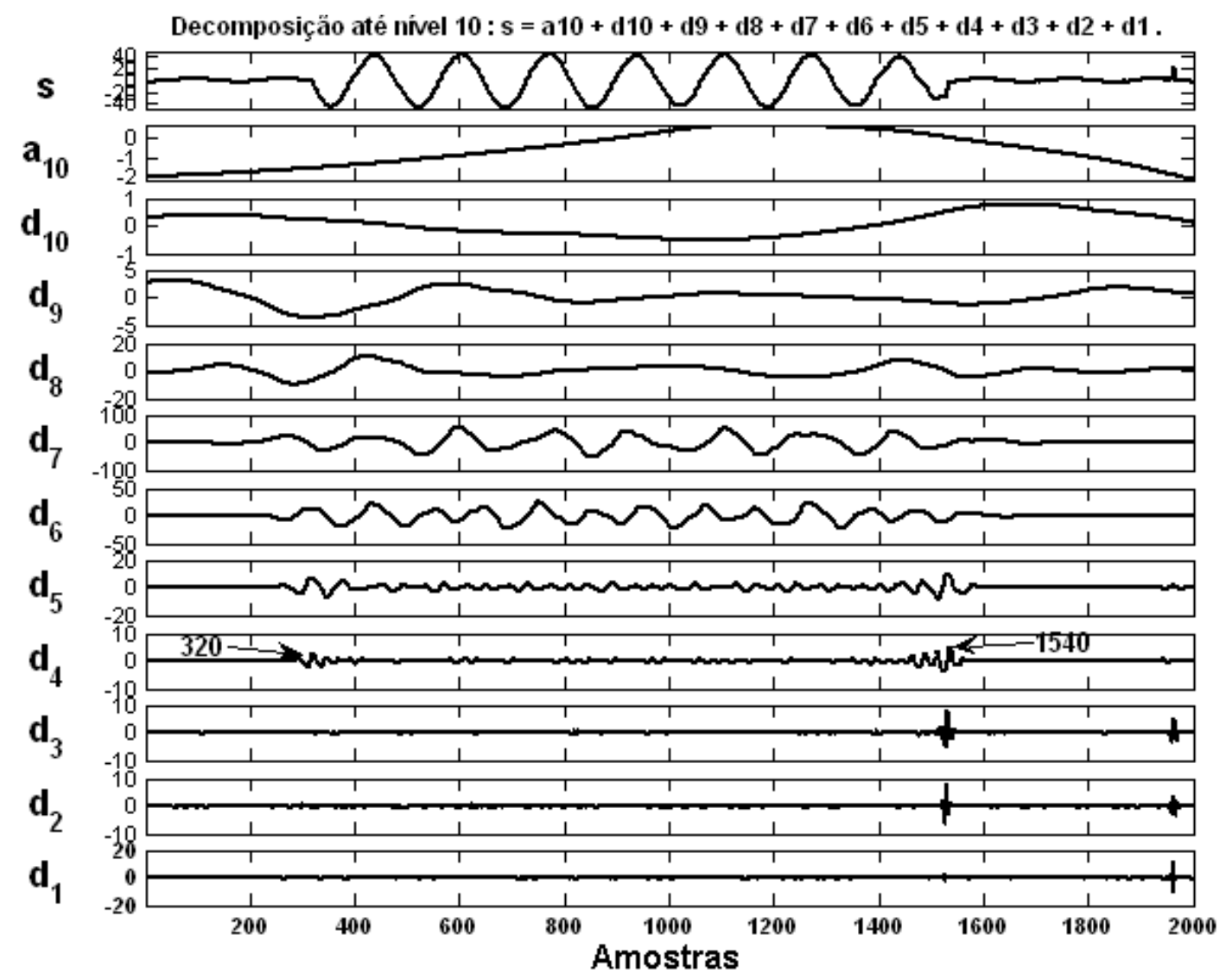

Figura 44- TW da Densidade de fluxo magnético. Curto-circuito F1T no ponto $P(-500,-250) m m$. Valores simulados.

Detalhe d4 - reconstruido - db4-10

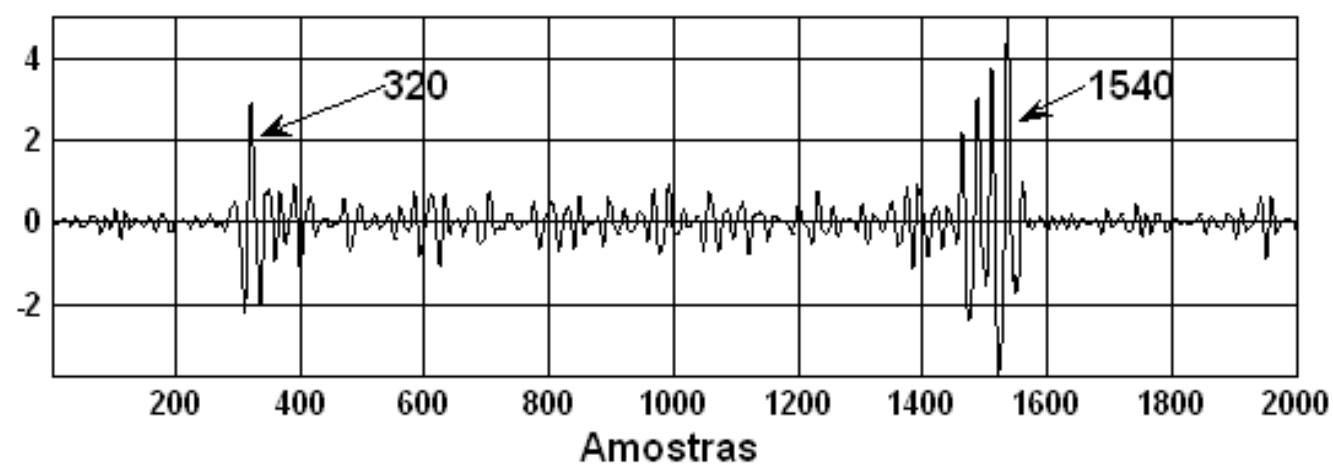

Figura 45- Detalhe 4 reconstruído da $T W$ da Densidade de fluxo magnético. Curto-circuito F1T no ponto $\mathrm{P}(-500,-250) \mathrm{mm}$. Valores simulados. 
A duração do curto na Figura 51 é $\Delta t=(1540-320) \cdot 0,1 \cdot 10^{-3} \mathrm{~s}=122 \mathrm{~ms}$, sendo igual ao obtido na Figura 50.

4.2.2.4.4 - Variância do sinal simulado no ponto $P(-500,-250) \mathrm{mm}$.

A Figura 46 mostra a variância do sinal simulado no ponto indicado.

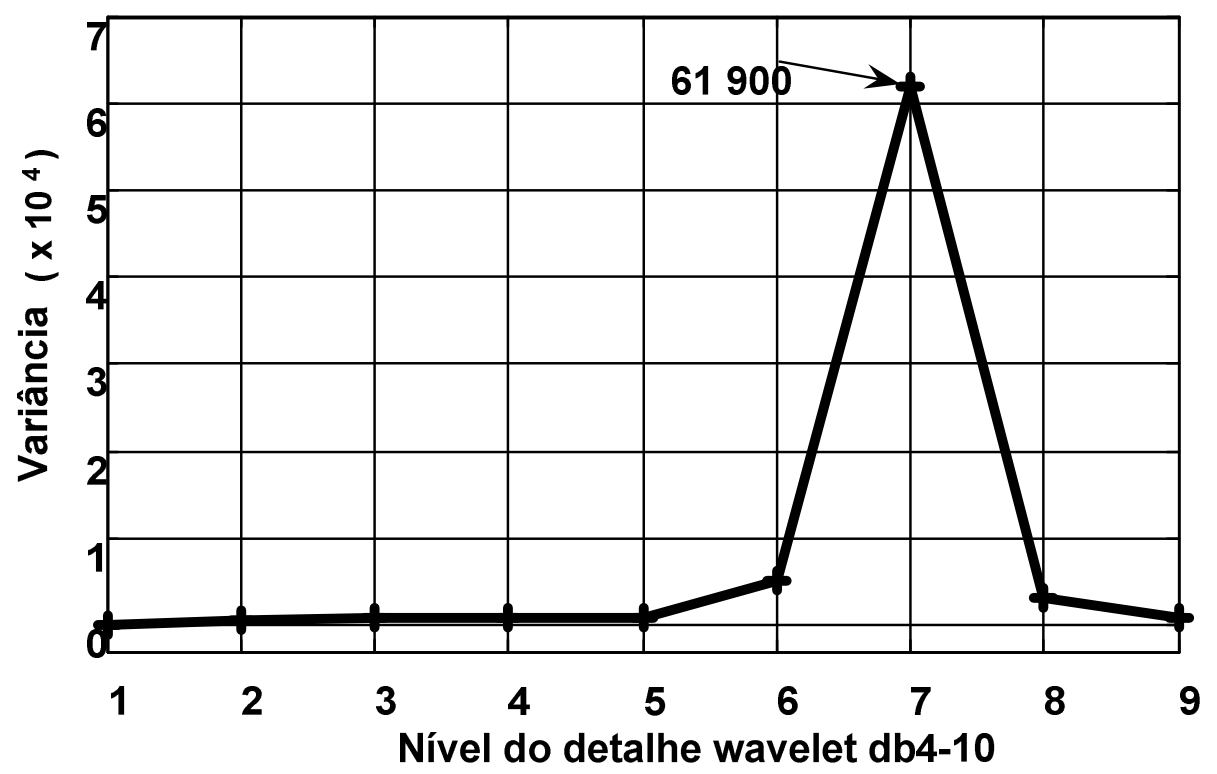

Figura 46- Variância para o ponto $\mathrm{P}(-500,-250) \mathrm{mm}$, curto F1T. Valores simulados. 


\section{3 - Aplicação da metodologia em dados experimentais.}

\subsection{1 - Medições das densidades de fluxo magnético através de sensor de campo magnético}

Visando obter os resultados experimentais, utilizou-se um sensor de campo magnético (cujos detalhes relativos à calibração encontram-se no Apêndice A) e mediu-se a densidade de fluxo magnético resultante de vários curtos-circuitos. Foram selecionados pontos significativos próximos aos condutores da bancada experimental. Inicialmente mediu-se a densidade de fluxo magnético residual, isto é, sem correntes na linha. Este valor, então, foi subtraído dos valores resultantes globais obtidos.

\subsubsection{1 - Forma de onda da densidade de fluxo magnético em um ponto $\mathrm{P}(-500,-250) \mathrm{mm}$ para curto.}

A Figura 47 permite observar a densidade de fluxo magnético decorrente do curto-circuito Fase1-Terra. Nota-se uma variação de 37,5 $\mu$ T na densidade de fluxo magnético, valores de pico. A duração do curto-circuito foi de $\Delta t=163-42=121 \mathrm{~ms}$. 


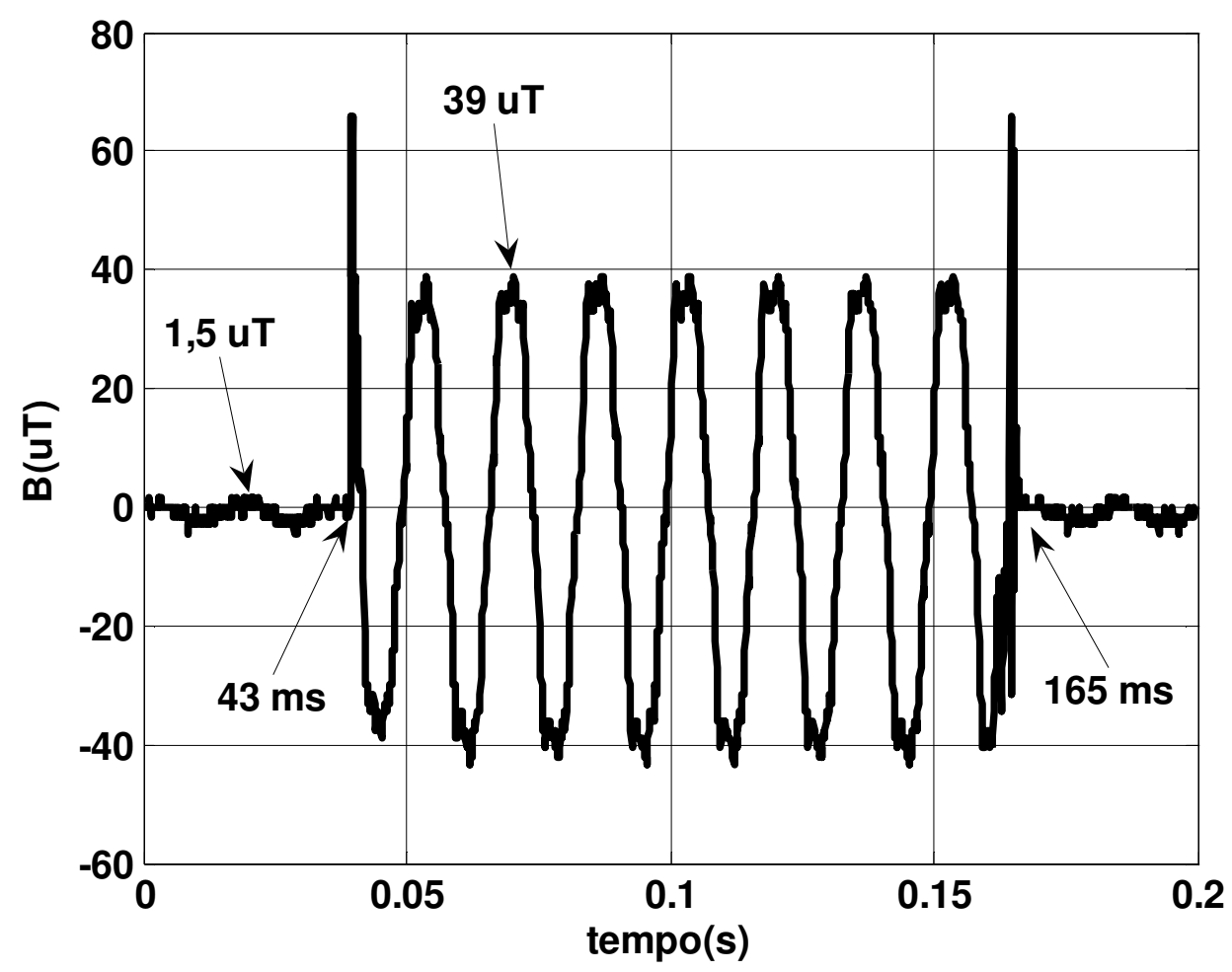

Figura 47- Densidade de fluxo magnético para curto F1T no ponto $\mathrm{P}(-500,-250) \mathrm{mm}$. Valores experimentais

Comparando-se a forma de onda da densidade de fluxo magnético da Figura 47, com a forma de onda da corrente $I_{1}$, da Figura 36, percebe-se similaridade entre eles e que a duração do curto-circuito é a mesma, aproximadamente $122 \mathrm{~ms}$. Justificam-se os picos no início e fim do transitório e observados na forma de onda da densidade de fluxo magnético como decorrentes de faiscamentos gerados quando do chaveamento experimental dos curtos-circuitos. 
4.3.1.1.1 - Análise espectral da densidade de fluxo magnético usando a Transformada Rápida de Fourier.

Para obter-se a informação do espectro de frequências da densidade de fluxo magnético, aplicou-se a Transformada Rápida de Fourier no sinal. Aplicouse a Transformada em B $(\mu \mathrm{T})$ e em dB $\mathrm{dT}_{\mathrm{uT}}$. Os resultados estão nas Figuras 48 e 49.

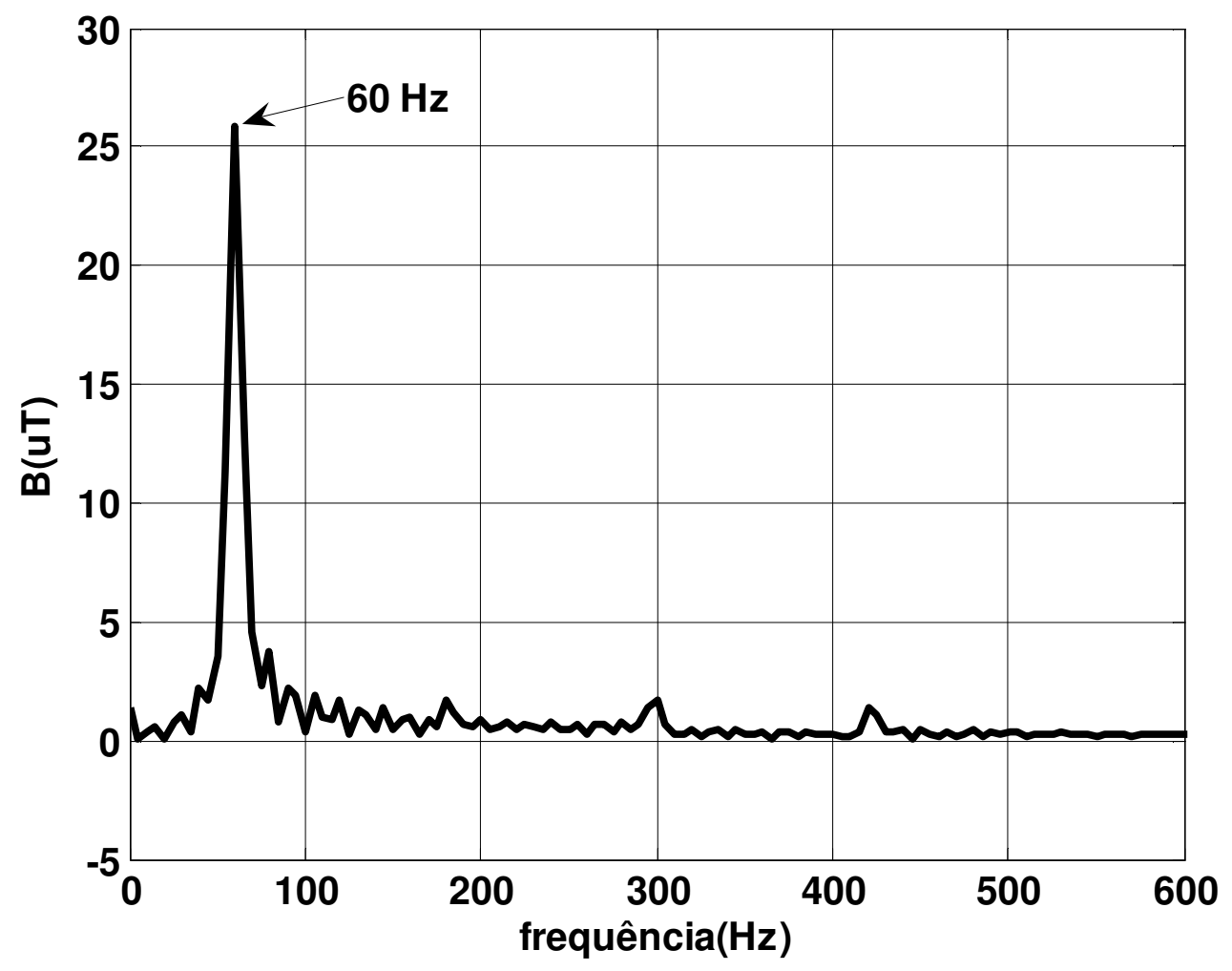

Figura 48- Espectro de frequências da densidade de fluxo magnético através da aplicação da FFT, com amplitude em $\mathrm{B}(\mu T)$. Valores experimentais 


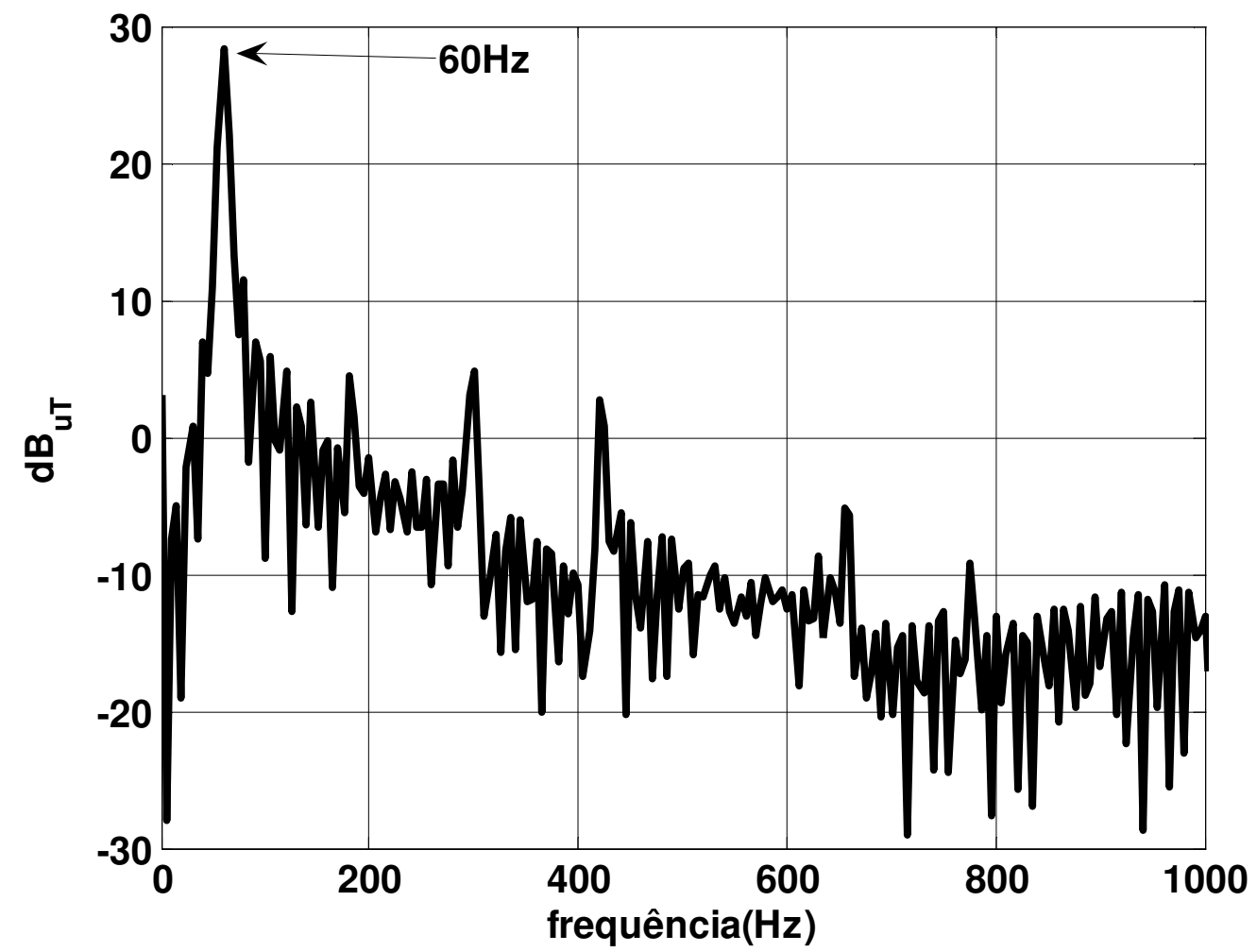

Figura 49- Espectro de frequências da densidade de fluxo magnético obtido através da aplicação da FFT, com amplitude em dB uT $_{\text {. }}$ Valores experimentais.

Os espectros de frequências nas Figuras 48 e 49 mostram a frequência fundamental $(60 \mathrm{~Hz})$ e outros detalhes. 


\subsubsection{2 - Transformada Wavelet aplicada à forma de onda da densidade de fluxo magnético para curto F1T no ponto $\mathrm{P}(-500,-250) \mathrm{mm}$.}

Como anteriormente apresentado, a aplicação da TW permite determinar a duração do curto-circuito, como mostrado nas Figuras 50 e 51.

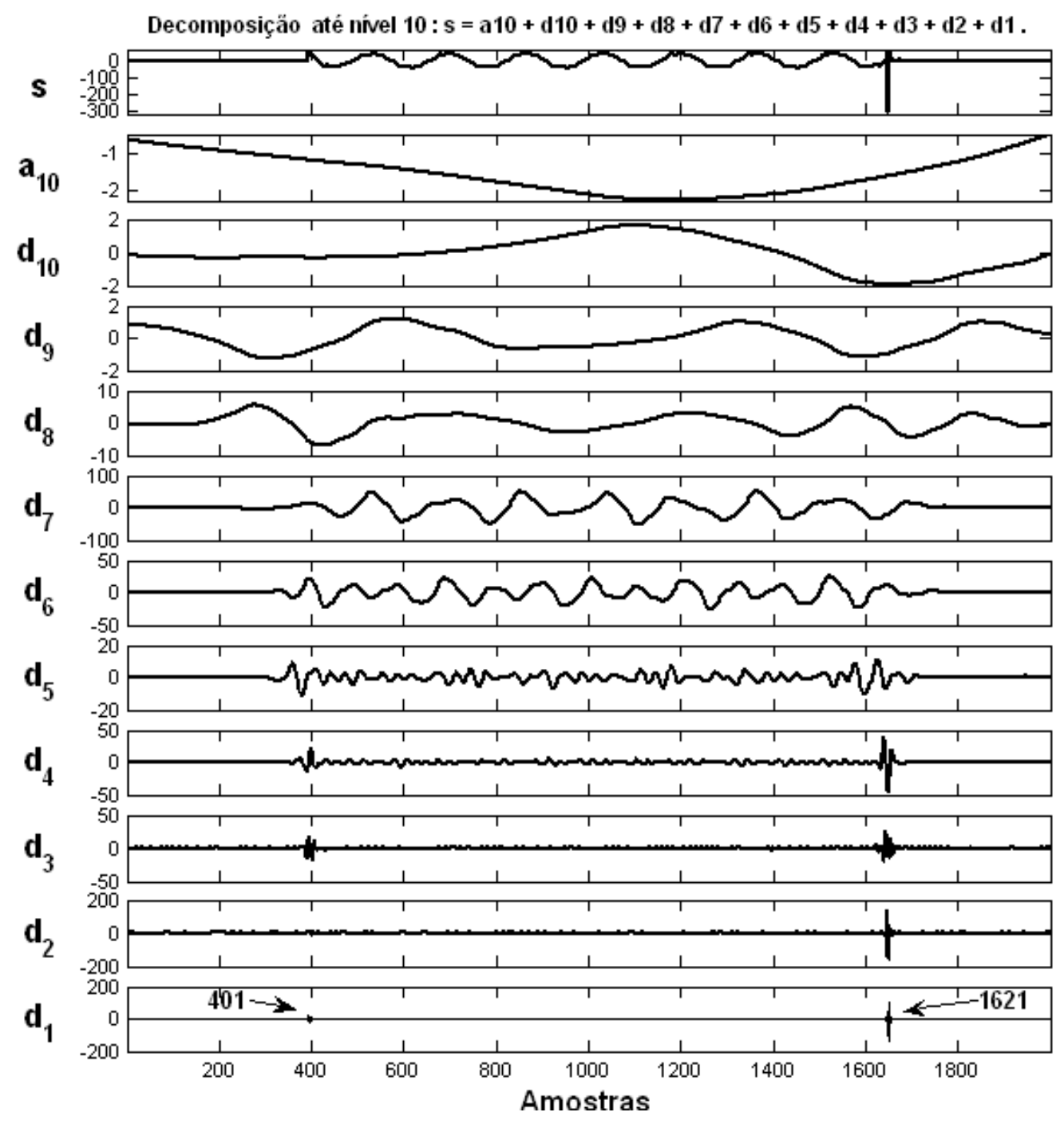

Figura 50 - TW Discreta db4, nível 10, aplicada para curto $\mathrm{F} 1 \mathrm{~T}$, medido no ponto $\mathrm{P}(-500,-250) \mathrm{mm}$. Valores experimentais. 
Assim, para o sinal em análise tem-se: $\Delta t=(1621-401) \cdot 0,1 \cdot 10^{-3}=122 \mathrm{~ms}$. Este valor é praticamente o mesmo daquele obtido através das formas de onda da corrente e da densidade de fluxo magnético.

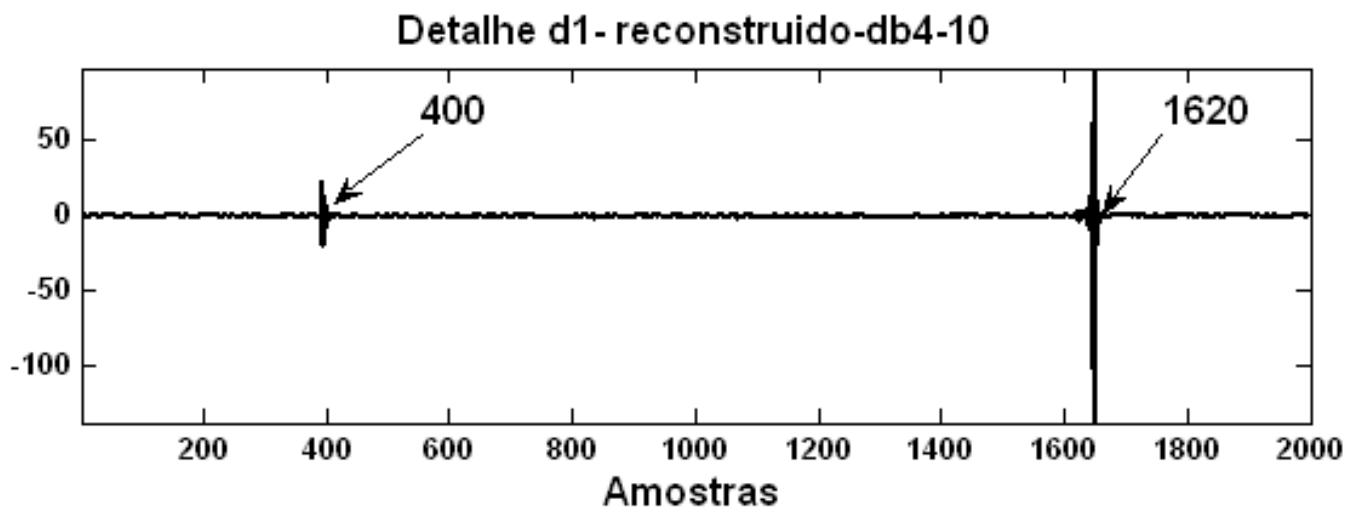

Figura 51 - TW Discreta db4, nível 10, aplicada para curto

F1T, medido no ponto $\mathrm{P}(-500,-250) \mathrm{mm}$

Através do detalhe $d_{1}$, obtém-se o mesmo valor para a duração do curtocircuito $\Delta t=(1620-400) \cdot 0,1 \cdot 10^{-3}=122 \mathrm{~ms}$. 
4.3.1.1.3 - Variância do sinal em função do nível de detalhe wavelet para curto F1T no ponto $\mathrm{P}(-500,-250) \mathrm{mm}$.

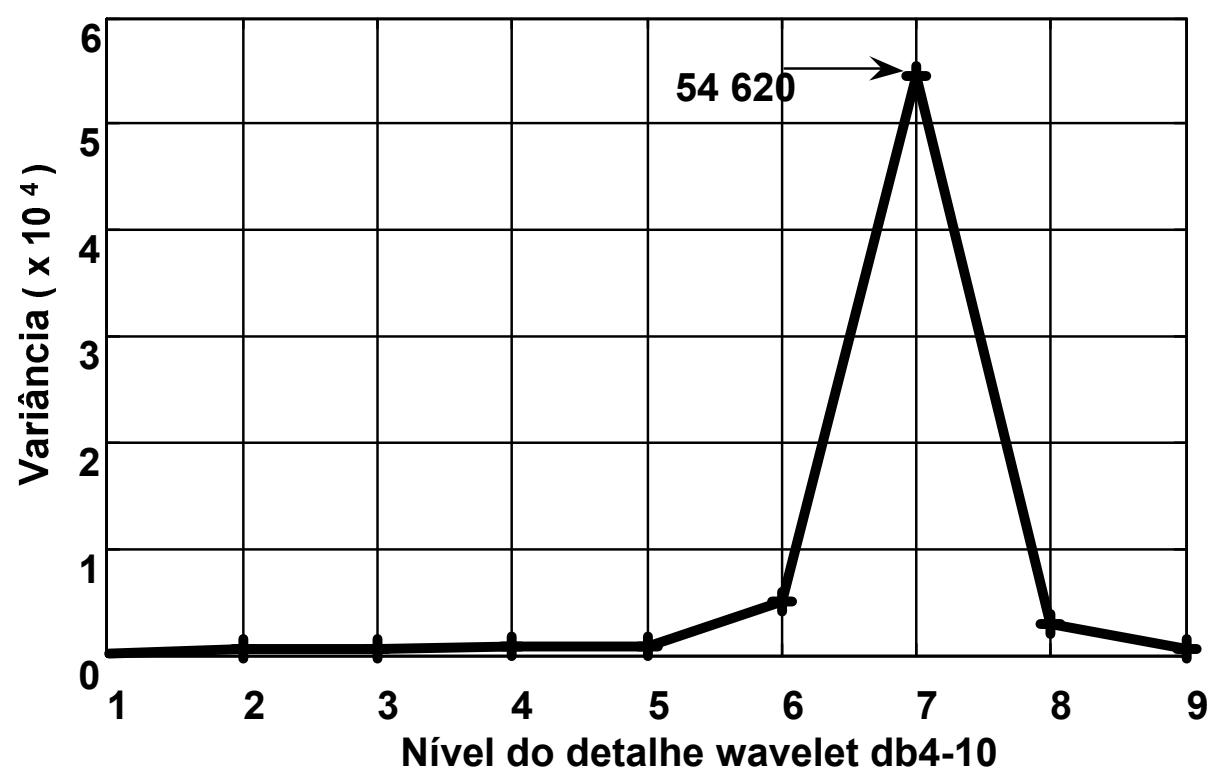

Figura 52 - Variância em função do nível de detalhe.

Valores Experimentais.

Na Figura 52 é mostrada a variância dos coeficientes wavelets relacionada à energia do sinal em função do nível do detalhe. O valor máximo da variância ocorre no nível de detalhe $d_{7}$, onde se encontra a frequência de $60 \mathrm{~Hz}$.

\subsection{2 - Influência da densidade de fluxo magnético presente no laboratório}

Com a finalidade de verificar qual a densidade de fluxo magnético existente no laboratório, fez-se a medição da densidade de fluxo magnético com a linha desligada. 


\subsubsection{1- Densidade de fluxo magnético no laboratório}

Os valores obtidos estão na Figura 53. O valor de pico medido foi da ordem de $0,56 \mu T$.

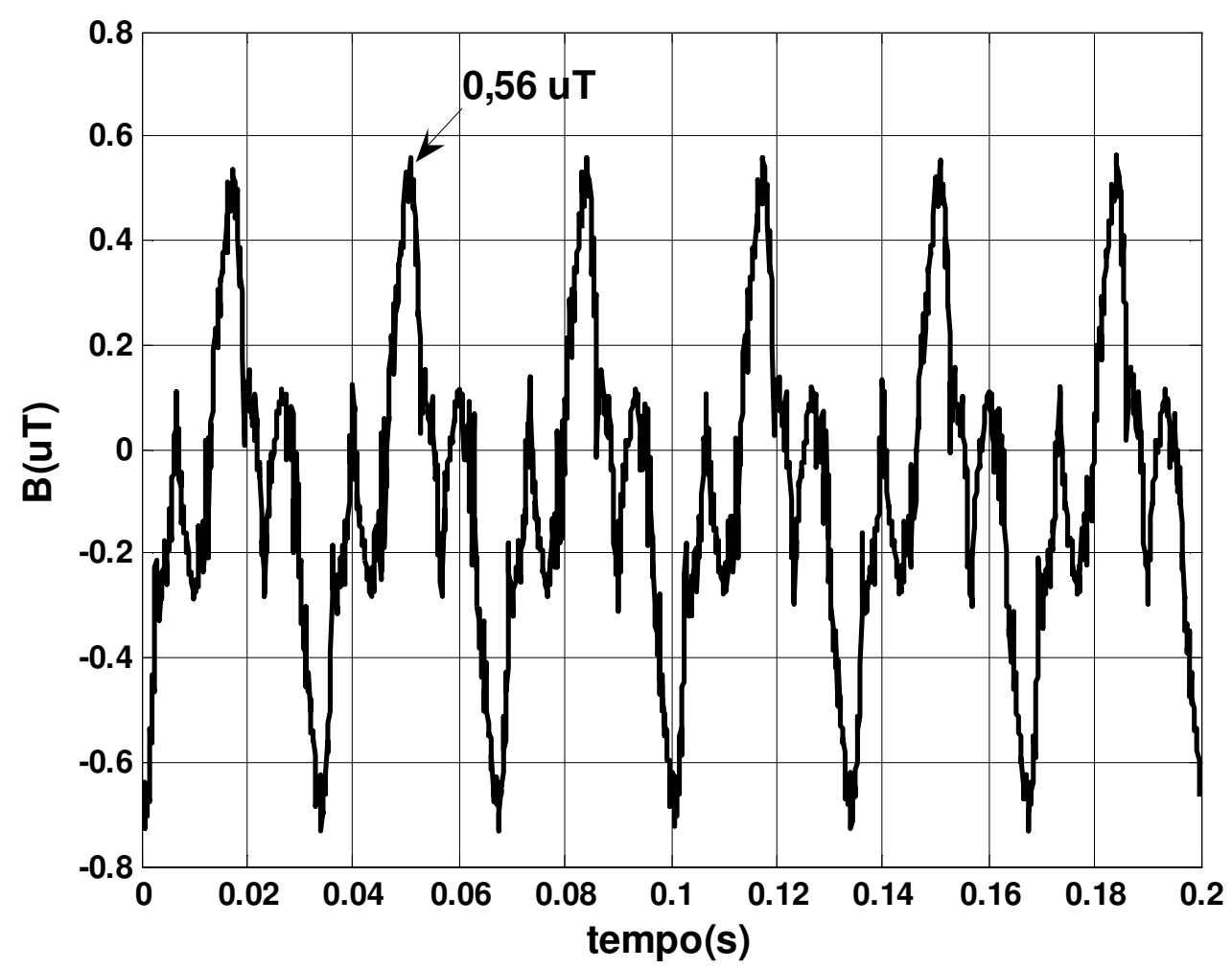

Figura 53- Ruido de fundo no laboratório - valores experimentais

\subsubsection{2- Densidade de fluxo magnético bruto}

Visando obter a densidade de fluxo magnético bruto, não se descontou a densidade de fluxo magnético residual. Os resultados para curto-circuito Fase1Terra no ponto $\mathrm{P}(-500,-950) \mathrm{mm}$ estão apresentados na Figura 54. 


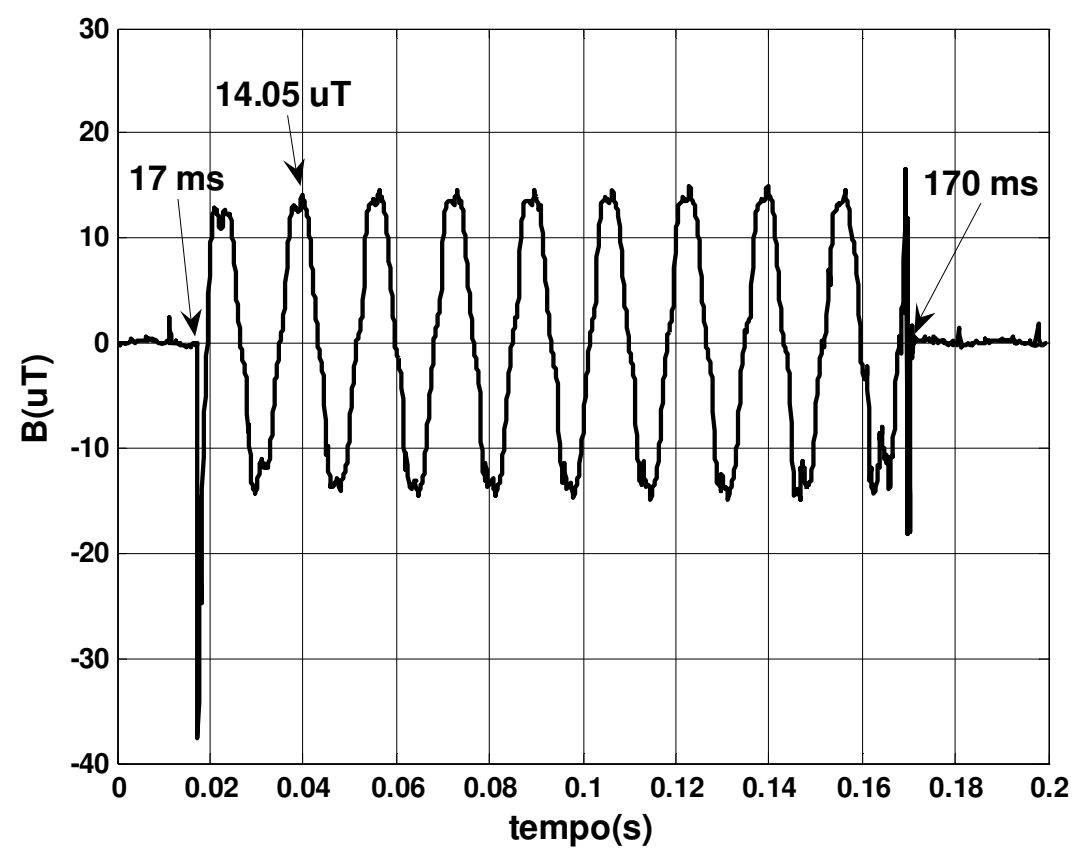

Figura 54- Densidade de fluxo magnético bruto para curto-circuito F1T no ponto $P(-500,-950) \mathrm{mm}$. Valores experimentais.

\section{4 - Comparação entre densidades de fluxo magnético simulado e medido para vários pontos.}

\subsection{1 - Introdução}

Neste item são apresentados os resultados referentes à comparação entre as densidades de fluxo magnético medido pela bobina e o simulado pelo software Flux 2D. A duração dos curtos-circuitos, em todos os casos apresentados, é de $122 \mathrm{~ms}$, ressaltando-se a semelhança entre as formas de onda. O software utilizado fornece os componentes $\mathrm{x}$ e y da densidade de fluxo magnético, em cada ponto. O sensor foi posicionado, em cada medição, transversalmente à linha, visando obter o valor máximo, correspondente à direção "x" simulada.

A seguir valores pré-selecionados serão avaliados aplicando-se a metodologia proposta, Figuras 55 a 63. 


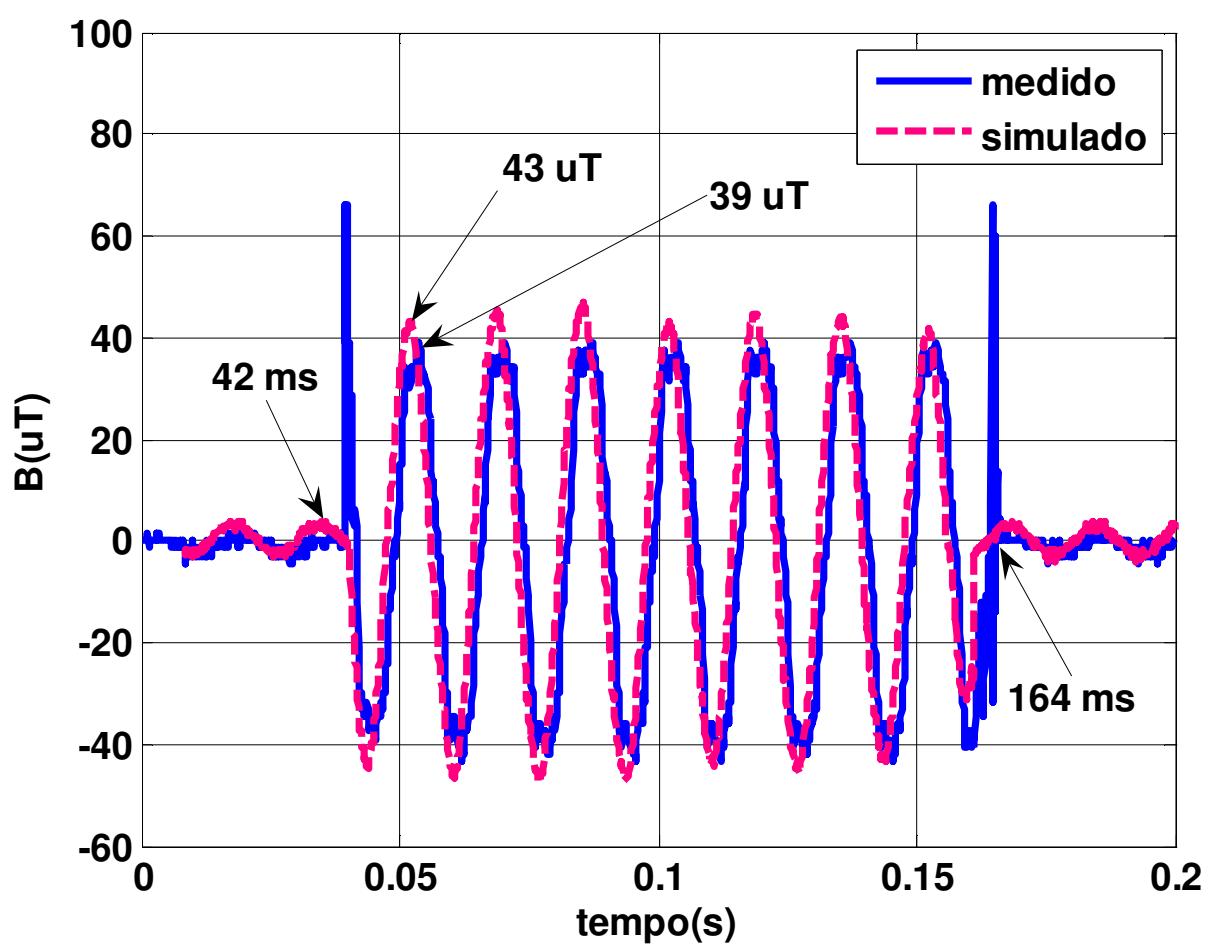

Figura 55 - Comparação entre as densidades de fluxo magnético, medido e simulado, para curto F1T, no ponto $\mathrm{P}(-500,-250) \mathrm{mm}$.

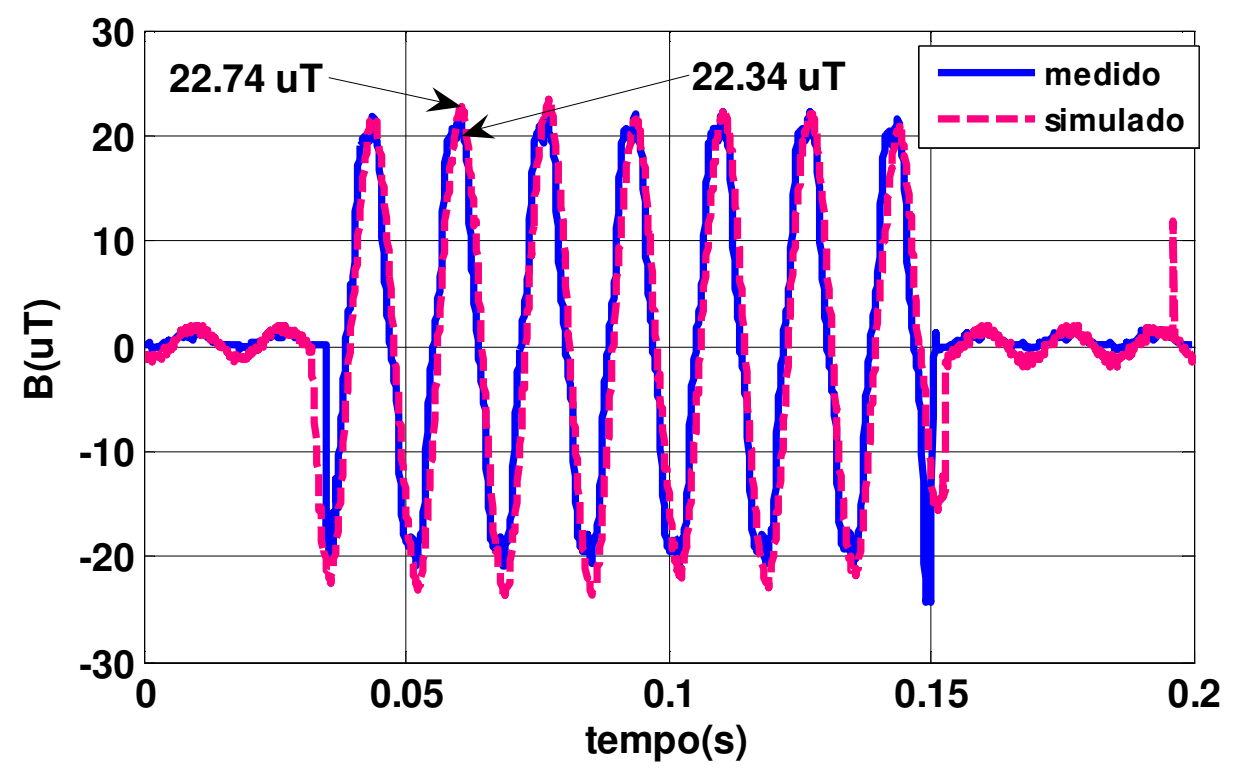

Figura 56- Comparação entre as densidades de fluxo magnético, medido e simulado, para curto $\mathrm{F} 1 \mathrm{~T}$, no ponto $\mathrm{P}(-500,-450) \mathrm{mm}$. 


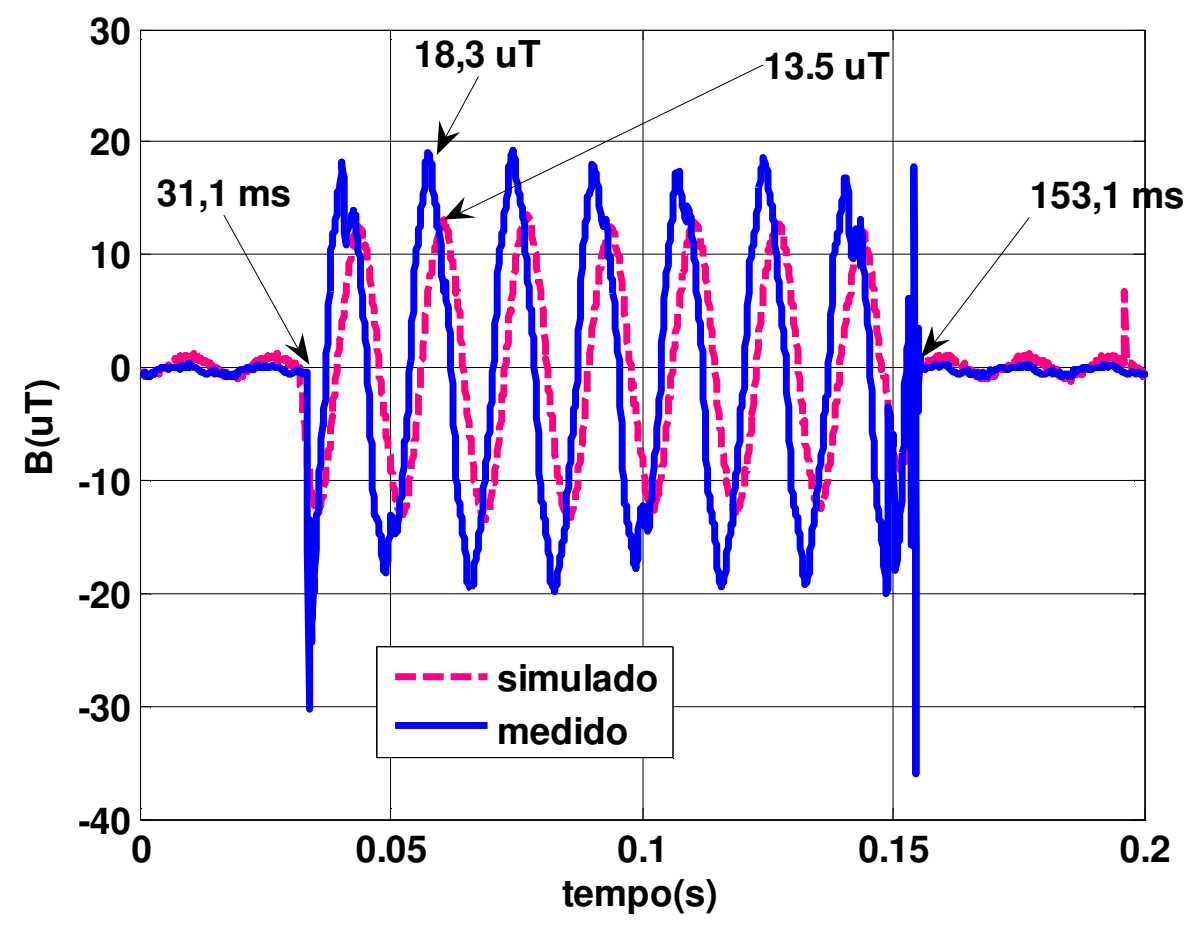

Figura 57 - Comparação entre as densidades de fluxo magnético, medido e simulado, para curto $\mathrm{F} 1 \mathrm{~T}$, no ponto $\mathrm{P}(-500,-650) \mathrm{mm}$.

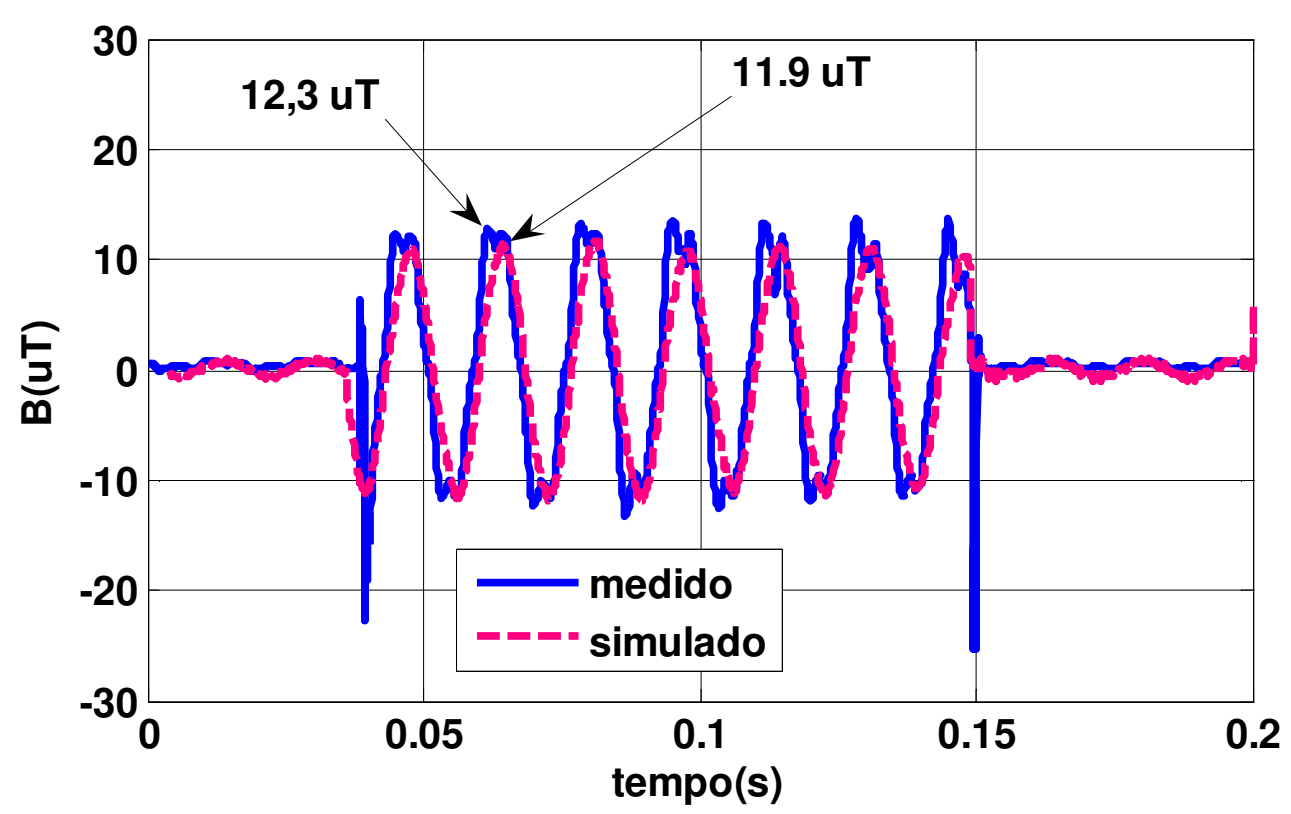

Figura 58- Densidades de fluxo magnético, simulado e medido, para curto F1T no ponto $P(-950,-740) \mathrm{mm}$. 


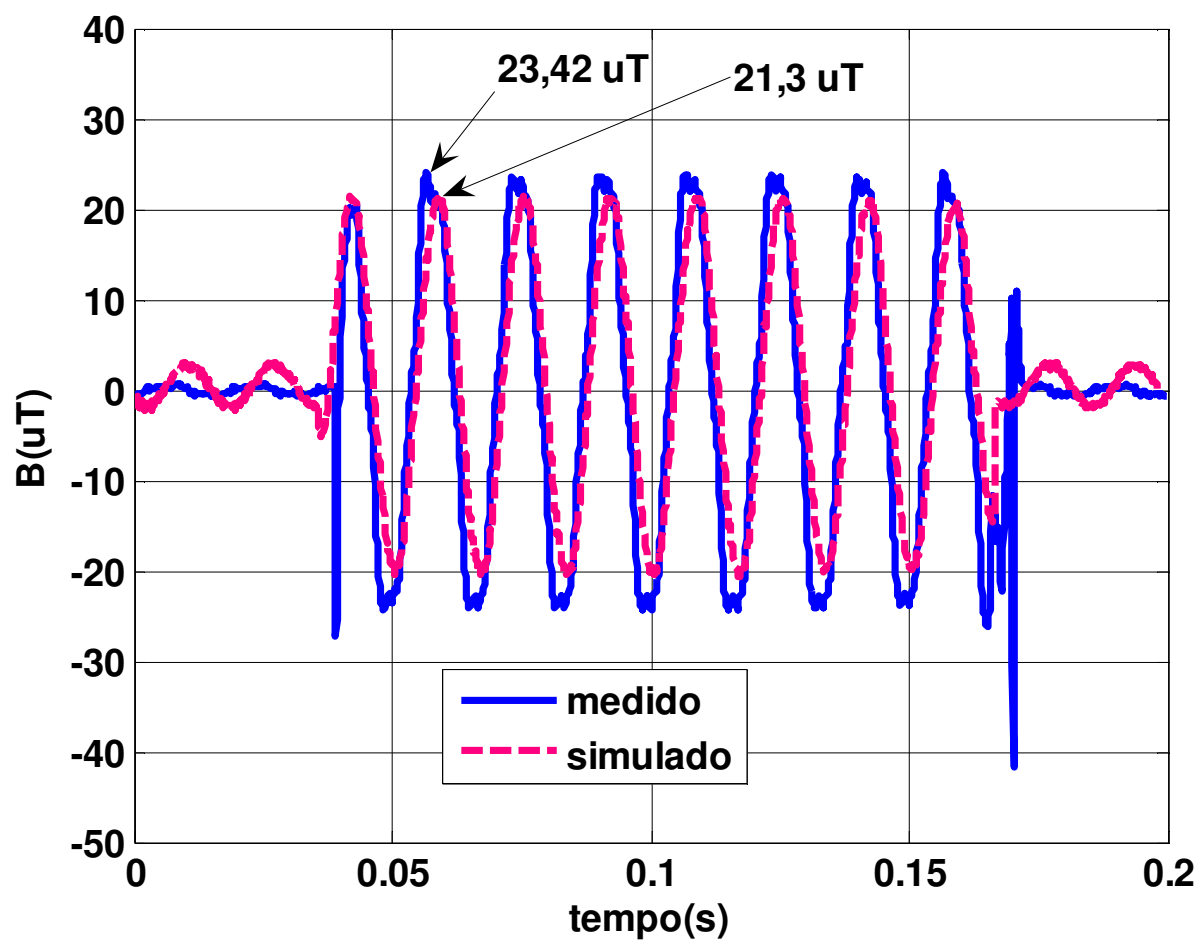

Figura 59- Densidades de fluxo magnético, simulado e medido, para curto F2T, no ponto $\mathrm{P}(0,-450) \mathrm{mm}$.

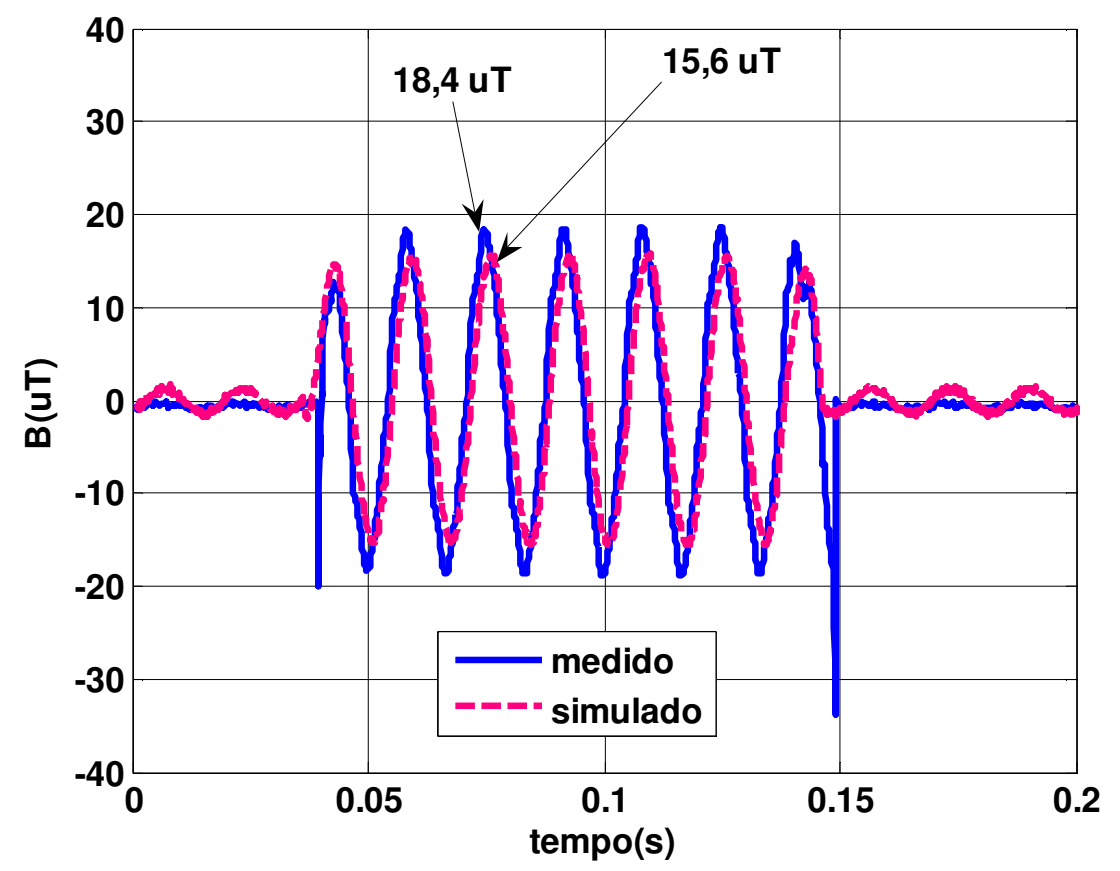

Figura 60 - Densidades de fluxo magnético, simulado e medido, para curto F3T, no ponto $\mathrm{P}(500,-650) \mathrm{mm}$. 


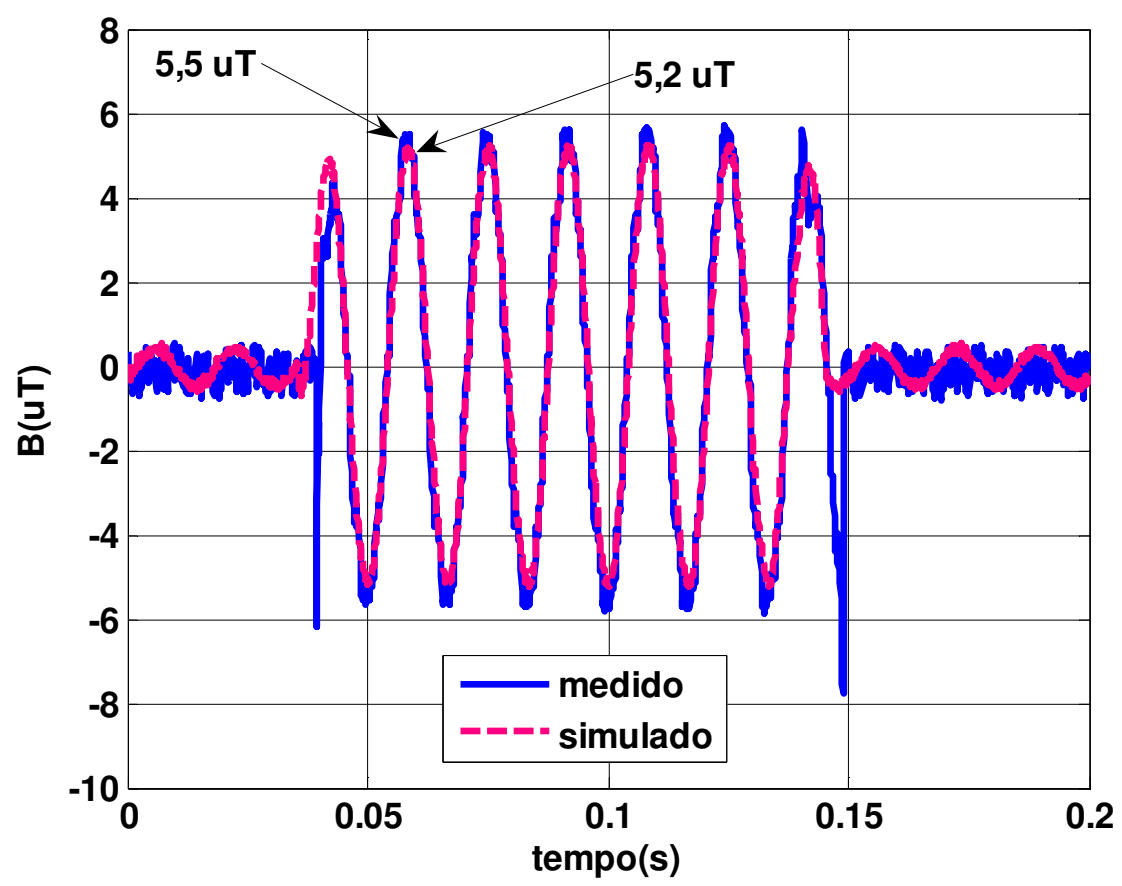

Figura 61- Densidades de fluxo magnético, simulado e medido, para curto F3T, no ponto $\mathrm{P}(1500,-650) \mathrm{mm}$.

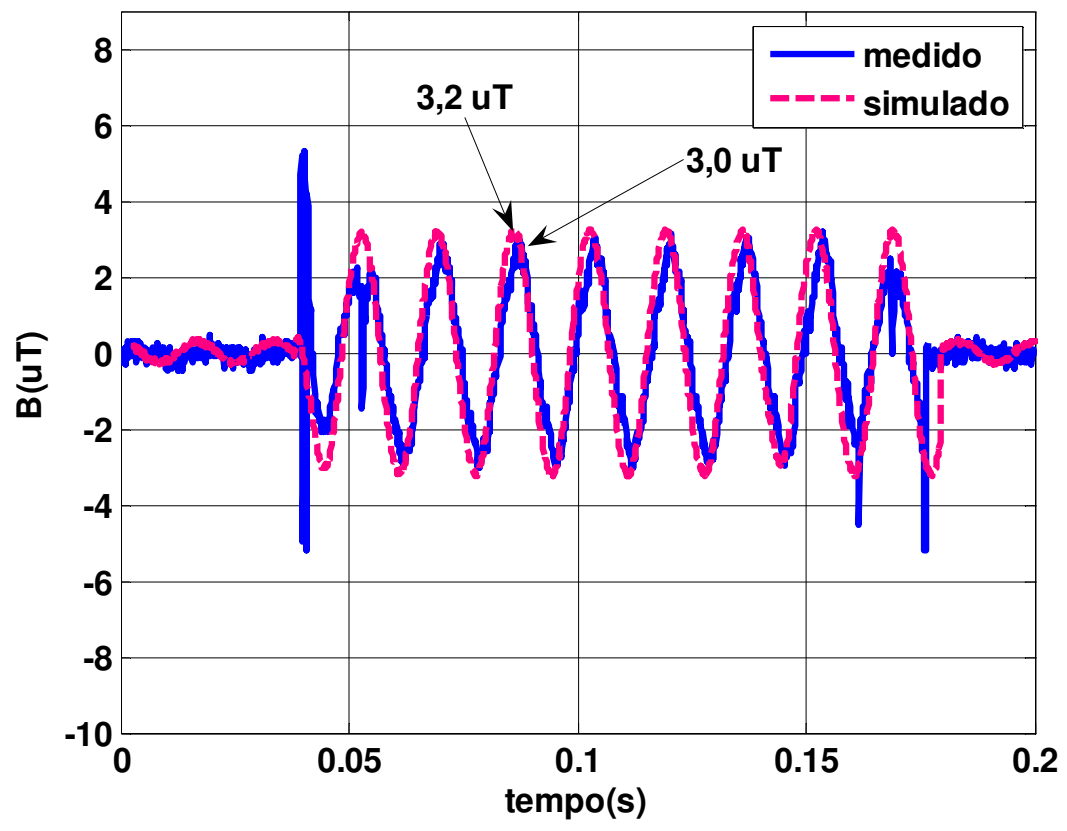

Figura 62- Densidades de fluxo magnético, simulado e medido, para curto F3T, no ponto $\mathrm{P}(500,-1450) \mathrm{mm}$. 


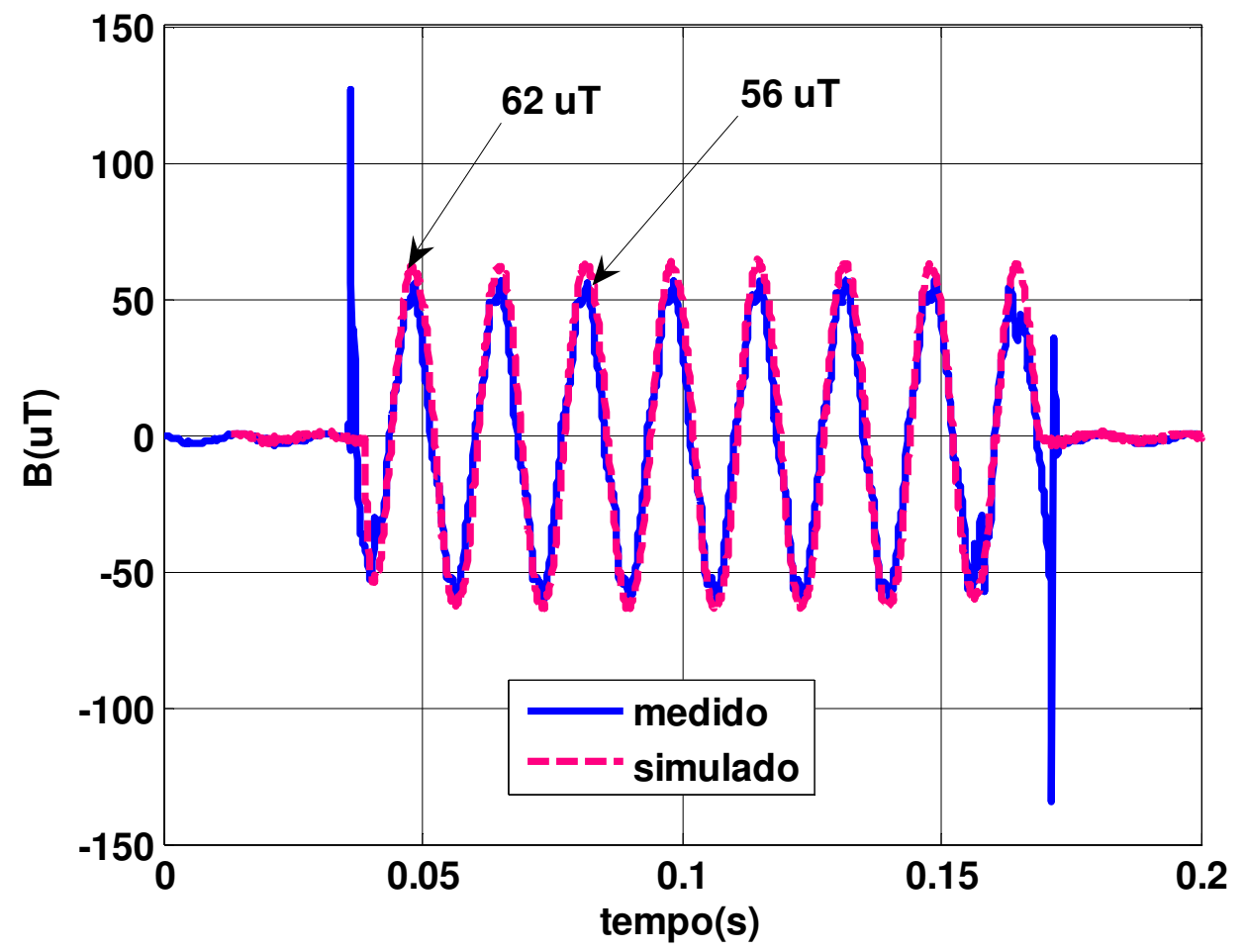

Figura 63- Densidades de fluxo magnético, simulado e medido, para curto bifásico, $\mathrm{F} 1 \mathrm{F3}$, no ponto $\mathrm{P}(500,-250) \mathrm{mm}$.

4.5 - Determinação da fase com falta por meio da comparação entre as curvas de variâncias para vários tipos de curtos.

\subsection{1- Introdução}

Apresentam-se, a seguir, as curvas das variâncias wavelets experimentais para os curtos-circuitos monofásicos, bifásicos-terra, bifásicos e trifásico em alguns pontos. Em cada medição, o sensor fica fixo no ponto indicado, para os vários tipos de curtos, Figuras de 64 a 70. 


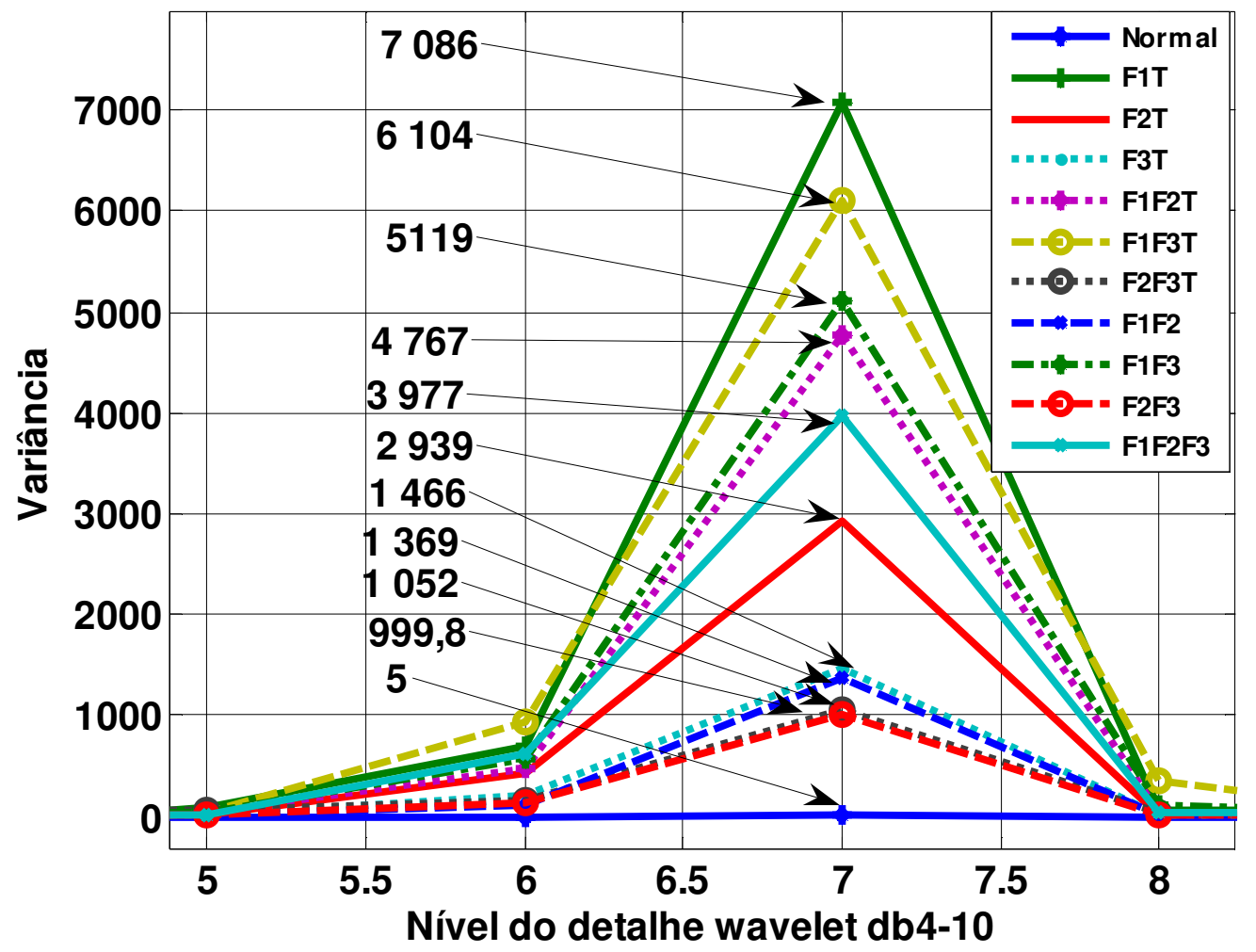

Figura 64- Variância da densidade de fluxo magnético, no ponto $P(-500,-650) \mathrm{mm}$, em função do nível de detalhe wavelet, para todos os tipos de curtos-circuitos. Valores experimentais. 


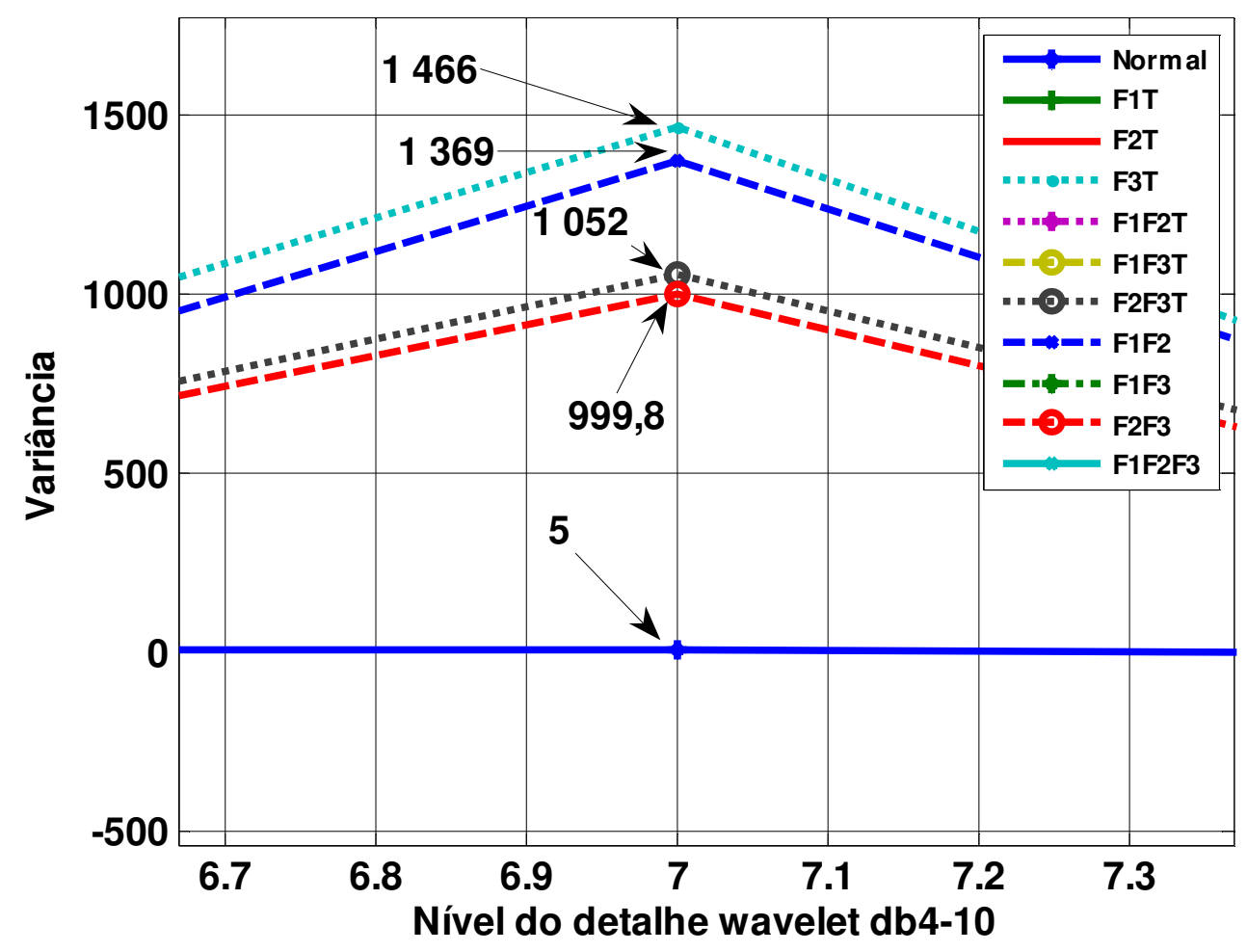

Figura 65- Detalhe das curvas de variância da densidade de fluxo magnético, no ponto $P(-500,-650) \mathrm{mm}$, em função do nível de detalhe wavelet, para todos os tipos de curtos-circuitos. Valores experimentais. 


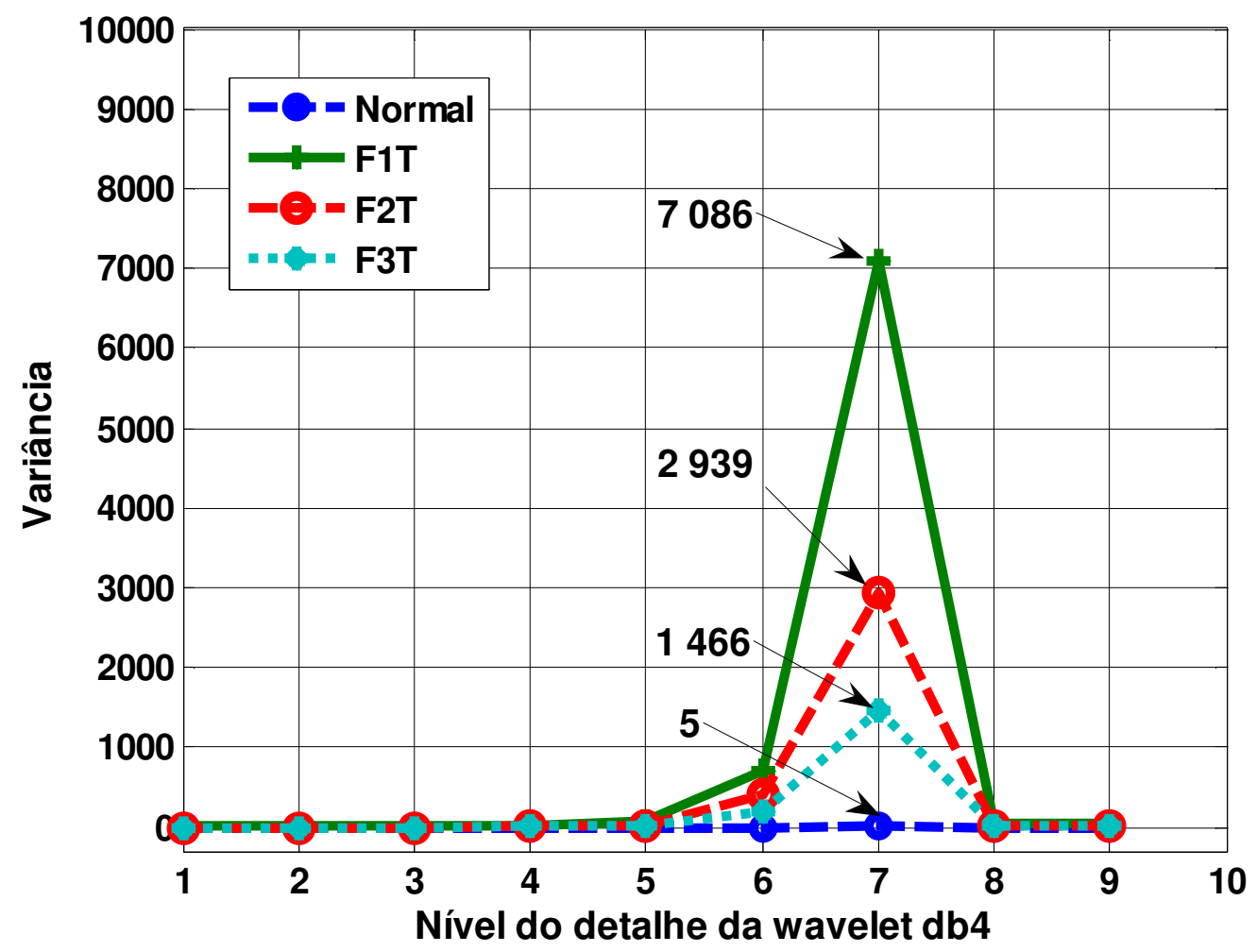

Figura 66- Variância da densidade de fluxo magnético, no ponto $\mathrm{P}(-500$, - 650) mm, em função do nível de detalhe wavelet, para curtos-circuitos monofásicos. Valores experimentais. 


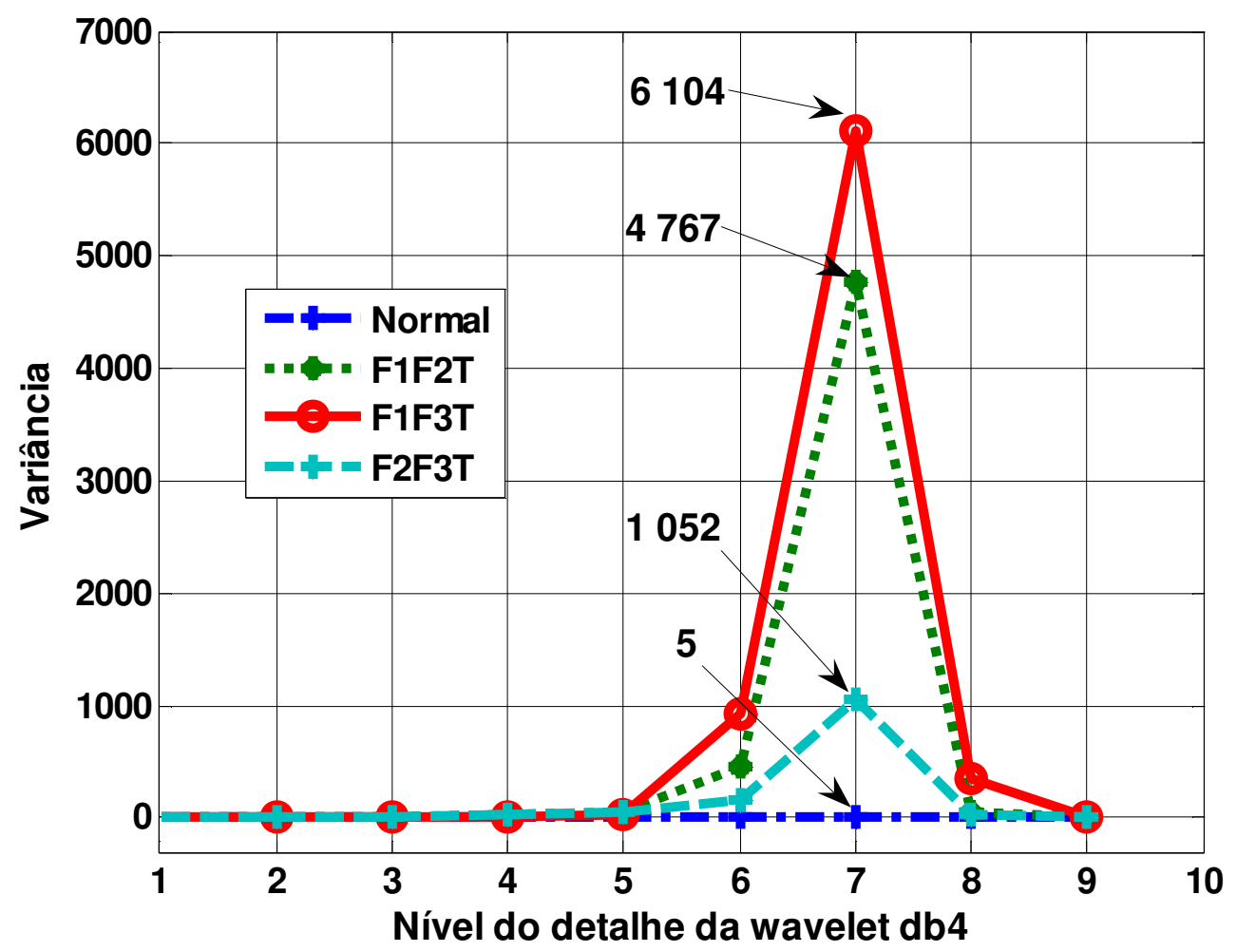

Figura 67 - Variância da densidade de fluxo magnético, no ponto $\mathrm{P}(-500,-650) \mathrm{mm}$, em função do nível de detalhe wavelet, para curtos-circuitos bifásicos- terra. Valores experimentais. 


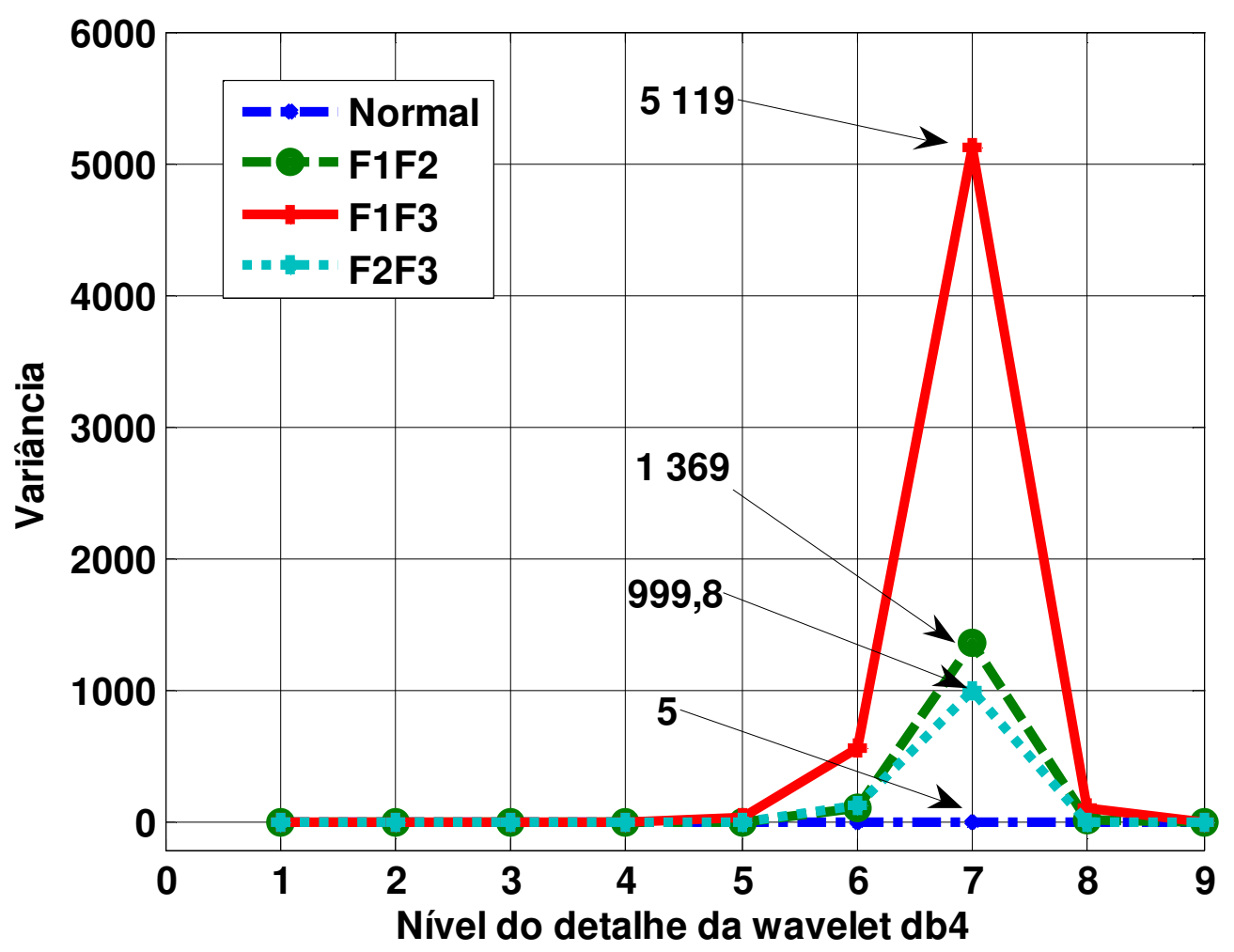

Figura 68 - Variância da densidade de fluxo magnético, no ponto $P(-500,-650) m m$, em função do nível de detalhe wavelet, para curtos bifásicos. Valores experimentais. 


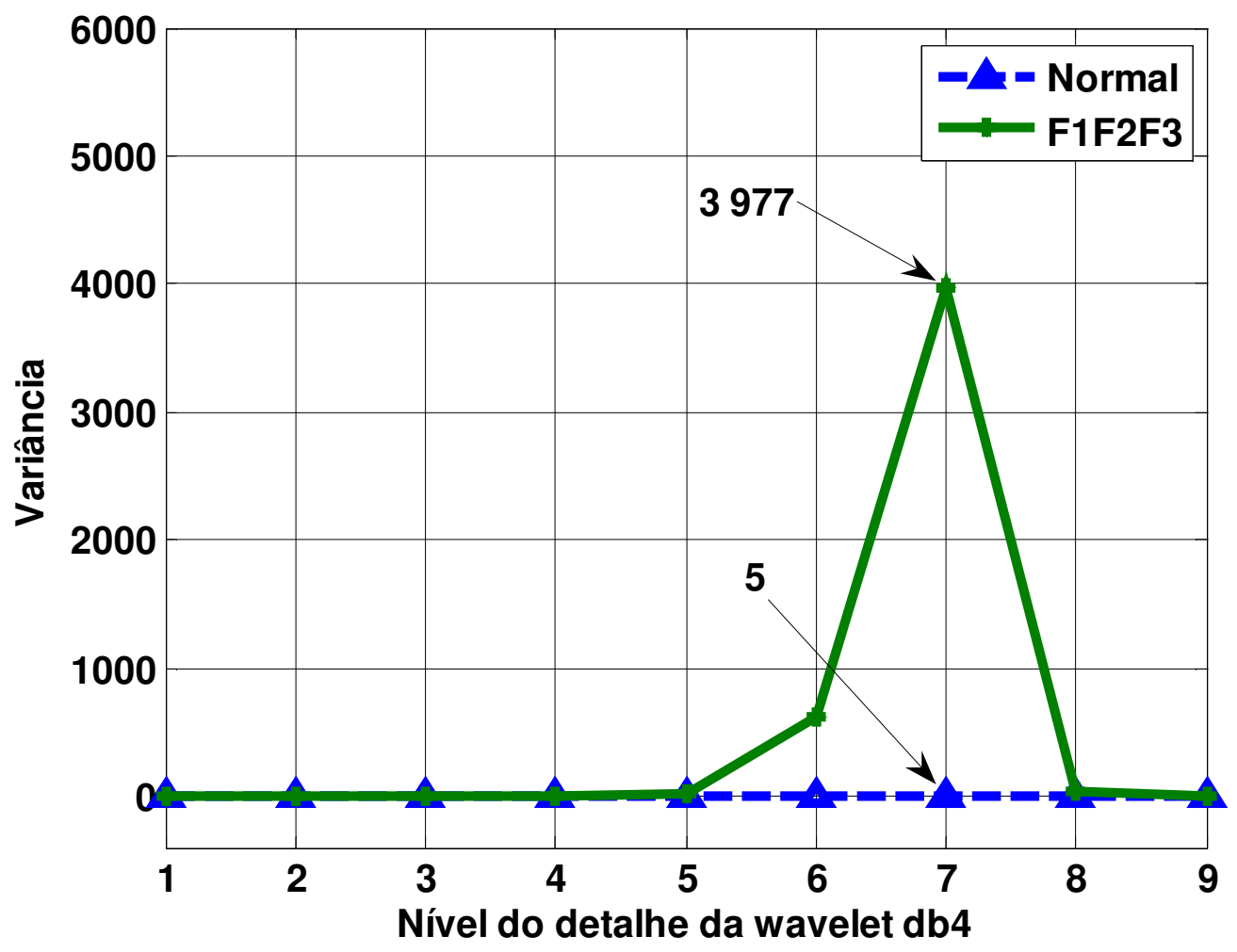

Figura 69 - Variância da densidade de fluxo magnético, no ponto $\mathrm{P}(-500,-650) \mathrm{mm}$, em função do nível de detalhe wavelet, para curto-circuito trifásico. Valores experimentais. 


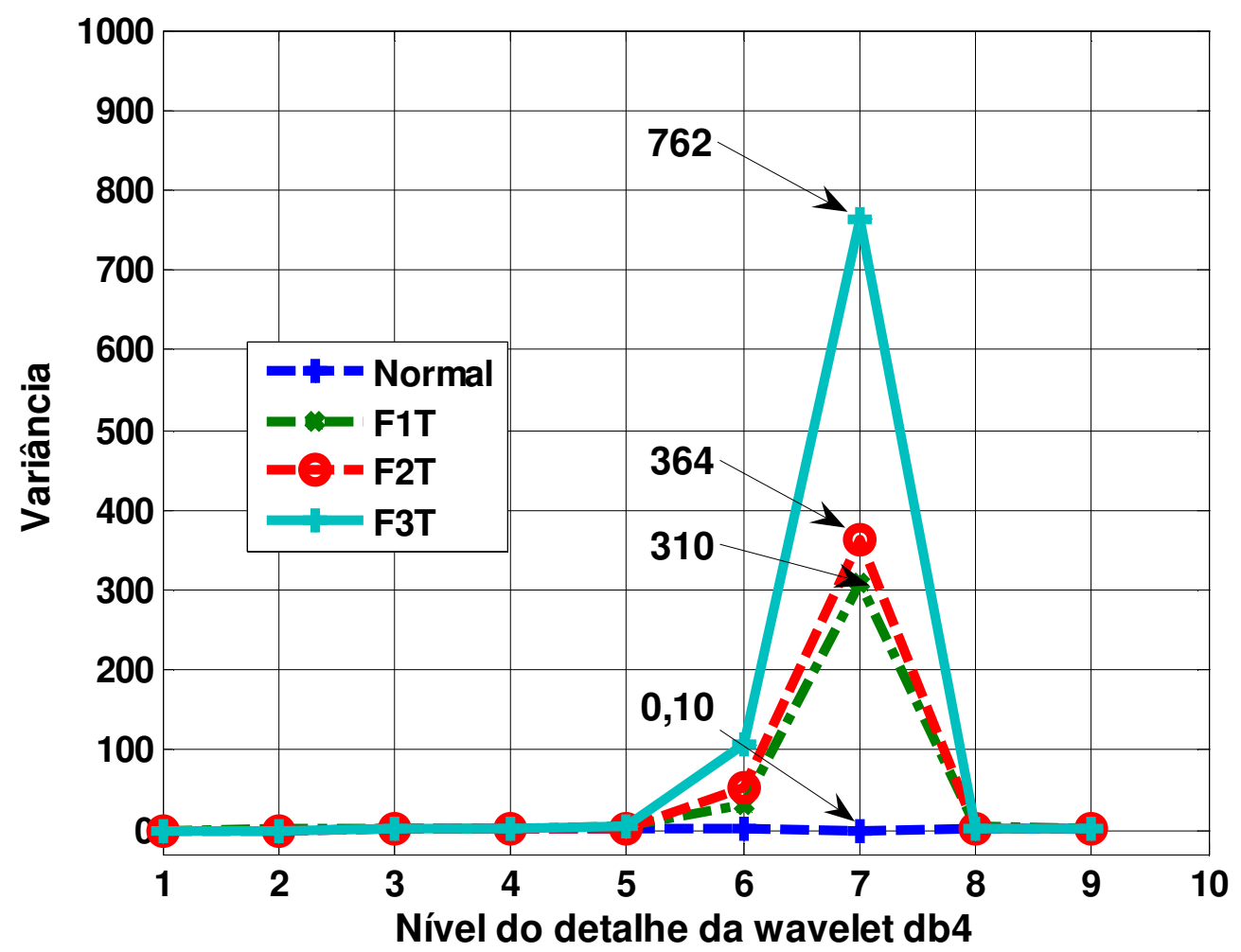

Figura 70 - Variância da densidade de fluxo magnético, no ponto $P(1500$, - 650) mm, em função do nível de detalhe wavelet, para curtos-circuitos monofásicos. Valores experimentais.

\section{6- Determinação da fase com falta através da amplitude da densidade de fluxo magnético em função do tempo}

\subsection{1- Introdução}

A fim de exemplificar a análise da determinação da fase em que ocorreu a falta, apresentam-se, a seguir, as curvas das densidades de fluxo magnético em função do tempo para curtos-circuitos monofásicos.

Estes resultados, Figuras 71 a 73, visam proporcionar uma análise comparativa entre a avaliação considerando-se a decomposição no domínio do tempo e via $T W$, apresentando a potencialidade de cada método. 


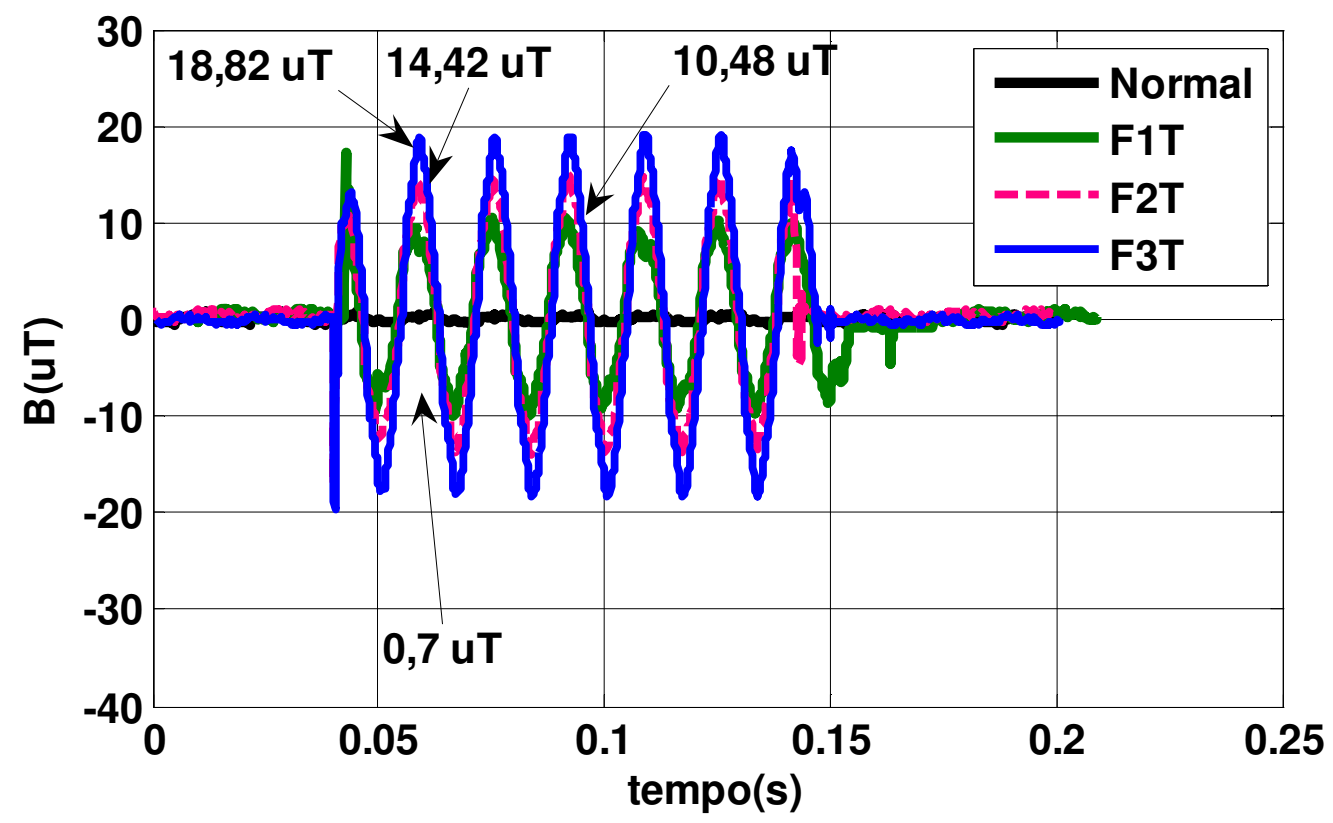

Figura 71 - Comparação entre as amplitudes da densidade de fluxo magnético medido para curtos-circuitos monofásicos e em regime permanente (normal) no ponto $P(500,-650) \mathrm{mm}$

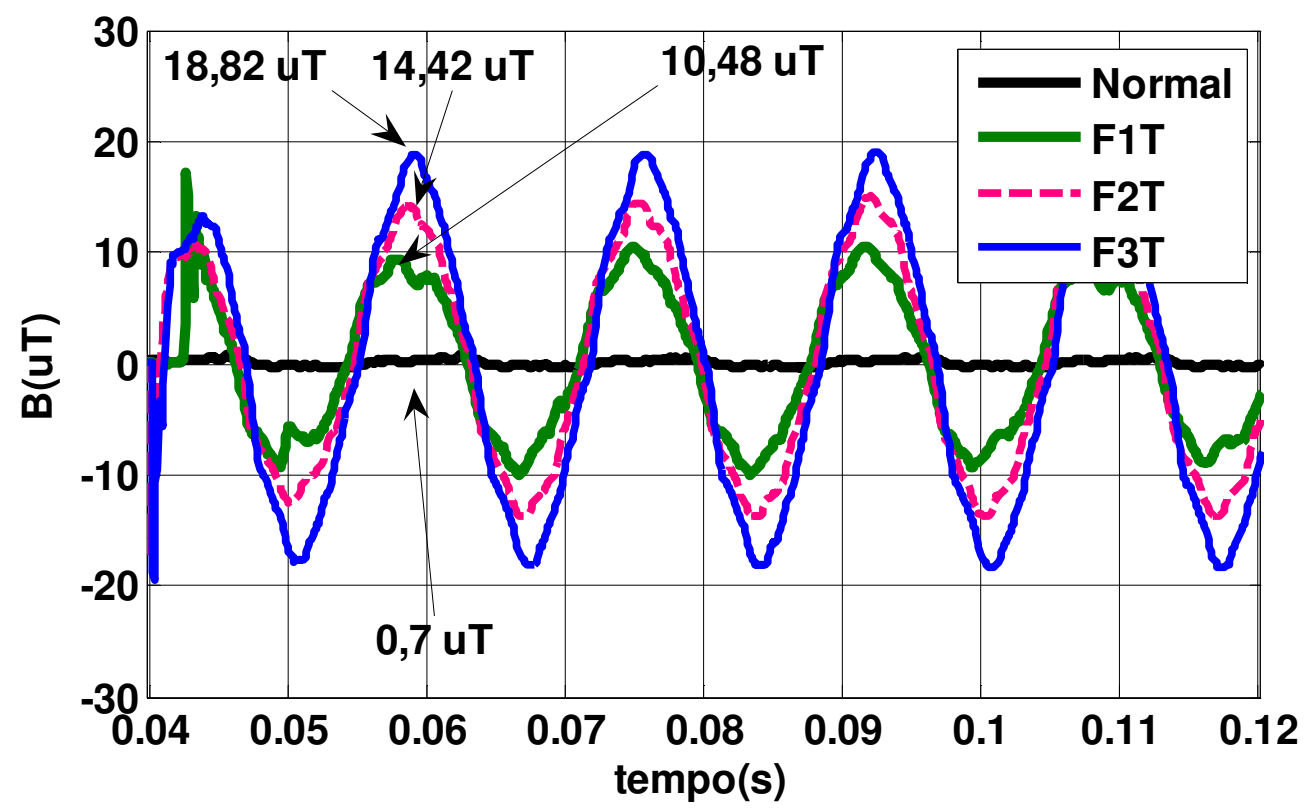

Figura 72 - Detalhe da comparação entre as amplitudes das densidades de fluxo magnético medidos para curtos-circuitos monofásicos e em regime permanente, no ponto $P(500,-650) \mathrm{mm}$ 


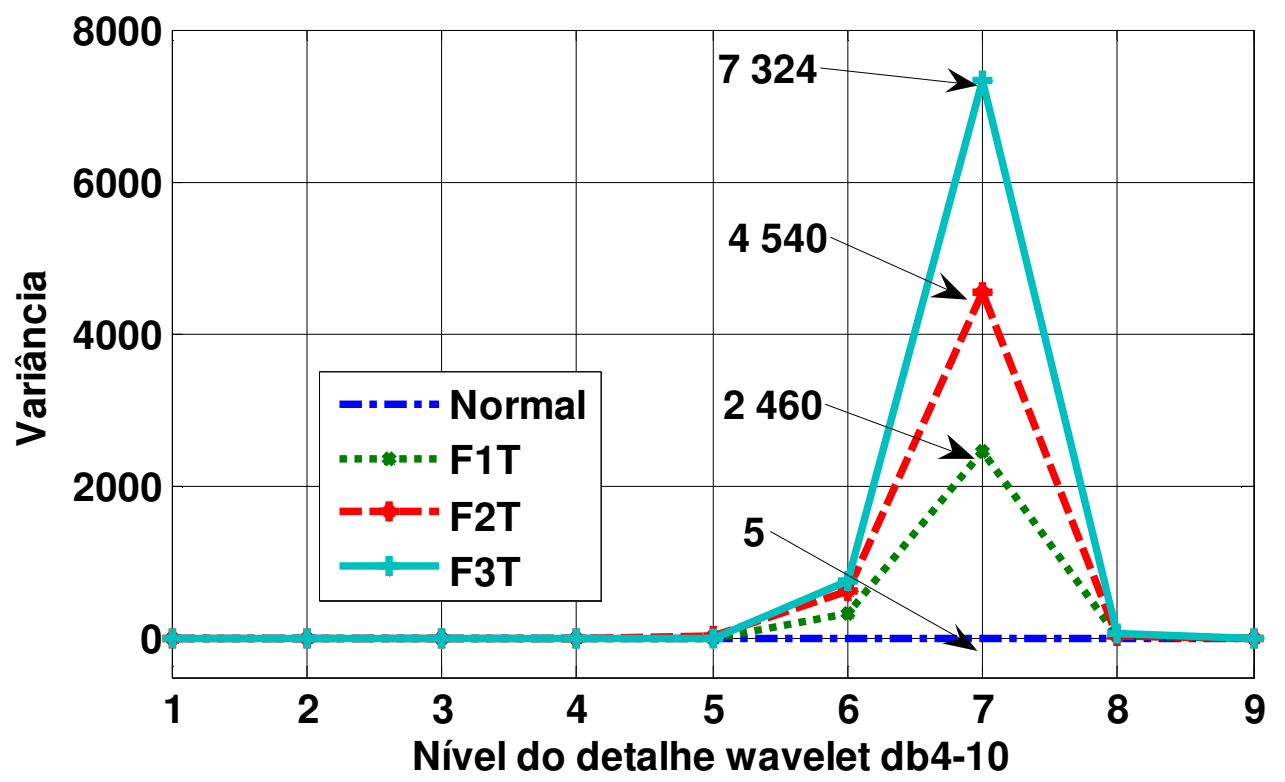

Figura 73 - Variância da densidade de fluxo magnético medido no ponto $P(500,-650) \mathrm{mm}$, para curtos-circuitos monofásicos e em regime permanente. 


\section{5 - DISCUSSÃO}

Este item tem por objetivo apresentar uma avaliação geral dos resultados obtidos via metodologia proposta com base nos tópicos e resultados durante o desenvolvimento deste trabalho.

\section{1- Análise dos resultados}

\subsection{1- Resultados simulados}

A análise dos resultados apresentados mostra a abrangência da metodologia proposta, bem como a importância das grandezas estudadas na análise de faltas.

As correntes utilizadas nas simulações visando obter a densidade de fluxo magnético, foram geradas pelo software ATP, denominadas correntes teóricas ,e, também, por meio de medidas experimentais em bancada. A Tabela 2 mostra uma síntese das formas de ondas obtidas, em cada caso, e a análise através das Transformadas de Fourier, Wavelet e da curva da variância.

Assim, nota-se que a corrente teórica tem sua forma de onda representada na Figura 21 e a duração do curto-circuito Fase1-Terra é de 52ms. O espectro de freqüência, obtido por meio da aplicação da TFestá mostrado nas figuras 22 e 23, indicando que a frequência fundamental é $60 \mathrm{~Hz}$. Analisando-se a forma de onda pela $T W$ obtém-se as Figuras 26 e 27 e através do detalhe d1 tem-se a duração do curto-circuito que é, também, 52ms. A energia do sinal é dada pela curva da variância wavelet, Figura 28, e seu valor máximo ocorre no detalhe d7, confirmando que a freqüência fundamental é $60 \mathrm{~Hz}$.

A corrente experimental, obtida através da bancada experimental, está representada na Figura 36, sendo a duração do transitório $122 \mathrm{~ms}$. Aplicando-se a TF a esta forma de onda, ontem os espectros de freqüência nas Figuras 37 e 38, mostrando que a frequêencia fundamental é $60 \mathrm{~Hz}$, confirmando o resultado teórico. Analisando a forma de onda da corrente experimental com a TW, obtémse as figuras 39 e 40 que mostram uma duração de transitório 122 ms.

A forma de onda da densidade de fluxo magnético obtida por simulação via Flux 2D, utilizando-se os dados da corrente teórica é apresentada na Figura 30, 
com duração de 52ms. Através da TW chega-se às figuras 31, 32 e 33 que também confirmam a duração do curto em $52 \mathrm{~ms}$, através do detalhe d1 e d2.

Tabela 2 - Valores simulados via FLUX 2D

\begin{tabular}{|c|c|c|c|c|}
\hline & $\begin{array}{c}\text { Corrente } \\
\text { Teórica } \\
\mathbf{I}_{\text {Teo }}(\mathrm{A})\end{array}$ & $\begin{array}{c}\text { Corrente } \\
\text { Experimental } \\
I_{\text {Exp }}(A)\end{array}$ & $\begin{array}{l}\text { Dens. de } \\
\text { fluxo mag } \\
\text { para I I } \\
\text { (uT) }\end{array}$ & $\begin{array}{c}\text { Dens. de } \\
\text { fluxo mag } \\
\text { para } \mathrm{I}_{\text {Exp }}(\mathrm{UT})\end{array}$ \\
\hline $\begin{array}{l}\text { Forma de } \\
\text { onda }\end{array}$ & Fig21 & Fig36 & Fig30 & Fig41 \\
\hline $\begin{array}{l}\text { Transformada } \\
\text { Fourier }\end{array}$ & Fig22, Fig23 & Fig37, Fig38 & & Fig42, Fig43 \\
\hline $\begin{array}{l}\text { Frequência } \\
\text { para Fourier }\end{array}$ & $60 \mathrm{~Hz}$ & $60 \mathrm{~Hz}$ & & $60 \mathrm{~Hz}$ \\
\hline$T W$ & Fig26, Fig27 & Fig39, Fig40 & $\begin{array}{c}\text { Fig31, } \\
\text { Fig32, Fig33 }\end{array}$ & Fig44, Fig45 \\
\hline $\begin{array}{c}\Delta t(m s) \\
\text { para TW }\end{array}$ & $52 \mathrm{~ms}$ & $122 \mathrm{~ms}$ & $52 \mathrm{~ms}$ & $122 \mathrm{~ms}$ \\
\hline Variância & Fig28 & & & Fig46 \\
\hline $\begin{array}{l}\text { Detalhe para } \\
\text { variância }\end{array}$ & $\mathrm{d} 7$ & & & $\mathrm{~d} 7$ \\
\hline $\begin{array}{l}\text { Frequência } \\
\text { da variância }\end{array}$ & $60 \mathrm{~Hz}$ & & & $60 \mathrm{~Hz}$ \\
\hline
\end{tabular}

Por outro lado, a forma de onda simulada da densidade de fluxo magnético da corrente experimental, via FLUX 2D, é apresentada pela Figura 41. As Figuras 42 e 43 mostram o espectro de freqüências quando se aplica a TF e confirmam, a freqüência fundamental de $60 \mathrm{~Hz}$. Já a TW, aplicada à mesma forma de onda, resulta nas Figuras 44 e 45 . A análise é feita por meio do nível de detalhe d4, pois este permite analisar melhor, o início e o fim do transitório. O valor da duração do transitório é de $122 \mathrm{~ms}$. A curva de variância wavelet mostra o espectro de energia wavelet contida no sinal, Figura 46 e confirma 0 detalhe $d_{7}$ como o de maior energia, indicando que a freqüência é $60 \mathrm{~Hz}$. 
A Figura 29 apresenta o circuito equivalente utilizado na simulação de densidade de fluxo magnético. O fluxograma da Figura 11 mostra detalhes deste procedimento.

Comparando-se a forma de onda da densidade de fluxo magnético simulado com a forma de onda da corrente medida, nota-se, sua similaridade.

\subsection{2 - Resultados experimentais}

Segundo a metodologia proposta foram ensaiados em bancada experimental dez tipos de curtos-circuitos e realizadas as medições da corrente elétrica, usando "probe" de corrente e a densidade de fluxo magnético, através de sensor magnético, em várias posições, Tabela 1.

A forma de onda da corrente $I_{1}$ medida para curto-circuito Fase1-Terra, no ponto $\mathrm{P}(-500,-250) \mathrm{mm}$, está representada na Figura 36 . O valor de pico da corrente em regime permanente é 2,5 A e, durante o transitório, assume o valor de 38,2 A, caracterizando o curto-circuito. No mesmo ponto, a forma de onda da densidade de fluxo magnético, medida pelo sensor magnético, está representada na Figura 47. O valor de pico da densidade de fluxo magnético varia de $1,5 \mu \mathrm{T}$, no regime permanente, para $39 \mu \mathrm{T}$, durante o transitório. Observando-se as formas de ondas da corrente e da densidade de fluxo magnético, Figuras 36 e 47, nota-se a semelhança entre elas. A duração do curto-circuito é $122 \mathrm{~ms}$ para ambas.

A forma de onda da Figura 47 foi analisada pela TF e TW, resultando as Figuras de 48 a 51 . Os resultados obtidos confirmam que a freqüência fundamental é $60 \mathrm{~Hz}$ e a duração do curto circuito, $122 \mathrm{~ms}$, através do detalhe $\mathrm{d}_{1}$ da TW.

A energia do sinal da densidade de fluxo magnético foi avaliada através da curva da variância em função do nível do detalhe, Figura 52, sendo seu valor máximo obtido no nível d7. Este nível contém a frequência fundamental $60 \mathrm{~Hz}$.

A Figura 53 fornece a densidade de fluxo magnético existente no laboratório, sendo seu valor de pico $0,56 \mu \mathrm{T}$. Por outro lado, a densidade de fluxo magnético "bruto" no ponto $\mathrm{P}(-500,-950)$ mm está representada na Figura 54. 


\subsection{3 - Comparação entre valores simulados e medidos}

A comparação entre a densidade de fluxo magnético medido e simulado foi feita para algumas dezenas de pontos diferentes e para curtos-circuitos monofásicos, bifásicos-terra, bifásicos e trifásico. Estão sendo apresentados alguns pontos ilustrativos. As Figuras de 55 a 63 mostram estas comparações que estão agrupados na Tabela 3.

Verifica-se que as formas de ondas são similares, tendo o transitório a mesma duração, $122 \mathrm{~ms}$. As amplitudes, para os pontos selecionados nas figuras em análise, diferem de um percentual que varia de 1,7\% a $26,22 \%$. As causas destas diferenças podem ser atribuídas a imprecisões no posicionamento do sensor, linha trifásica não perfeitamente horizontal, tamanho do sensor, não horizontalidade do sensor e simulação que considera o solo perfeitamente condutor. Estas variações de amplitudes não afetam a metodologia proposta, pois a mesma não tem como foco o valor da amplitude. Existem pontos que tem uma ótima concordância entre o medido e o simulado e outros diferem um pouco. Como o ponto de instalação do sensor pode ser escolhido, procuram-se pontos mais convenientes para atingir os objetivos desejados. 
Tabela 3 - Valores simulados e medidos

\begin{tabular}{cccccc}
\hline Curto & $\begin{array}{c}\text { Posição } \\
(\mathbf{m m})\end{array}$ & Figura & $\begin{array}{c}\mathrm{B}(\mathbf{u T}) \\
\text { Medido }\end{array}$ & $\begin{array}{c}\mathrm{B}(\mathbf{u T}) \\
\text { Simulado }\end{array}$ & $\begin{array}{c}\text { Variação } \\
\%\end{array}$ \\
\hline F1T & $\mathrm{P}(-500,-250)$ & 55 & 39 & 43 & 9,3 \\
& $\mathrm{P}(-500,-450)$ & 56 & 22,34 & 22,74 & 1,7 \\
& $\mathrm{P}(-500,-650)$ & 57 & 18,3 & 13,5 & 26,22 \\
& $\mathrm{P}(-950,-740)$ & 58 & 11,9 & 12,3 & 3,5 \\
F2T & $\mathrm{P}(0,-450)$ & 59 & 23,42 & 21,3 & 8,8 \\
F3T & $\mathrm{P}(500,-650)$ & 60 & 18,4 & 15,6 & 15,22 \\
& $\mathrm{P}(1500,-650)$ & 61 & 5,5 & 5,2 & 5,45 \\
& $\mathrm{P}(500,-1450)$ & 62 & 3,0 & 3,2 & 6,25 \\
& $\mathrm{~F}(500,-250)$ & 63 & 56 & 62 & 9,68 \\
\hline
\end{tabular}

5.1.4 - Determinação da fase com falta através das curvas de variância e por meio da amplitude da densidade de fluxo magnético em função do tempo

A Tabela 4 sintetiza as curvas de variâncias para os vários tipos de curtos-circuitos estudados.

A Figura 66 mostra as curvas da variância da densidade de fluxo magnético para um curto-circuito Fase1-Terra, Fase2-Terra, Fase3-Terra e regime permanente (normal), com sensor magnético fixo no ponto $\mathrm{P}(-500,-650) \mathrm{mm}$. No intervalo de 2939 a 7086 tem-se curto-circuito Fase1Terra. A relação entre os valores máximos e mínimos da variância no intervalo considerado é da ordem de 2,41. Este intervalo é bastante amplo e 
permite detectar a fase em que ocorreu o curto-circuito Fase1-Terra, independente da incerteza da medição.

Se os valores da variância estiverem entre 1466 e 2939 tem-se curtocircuito Fase2-Terra e a relação entre os valores máximo e mínimo é da ordem de 2,00. Este fator permite classificar o curto-circuito como Fase2-Terra.

Tabela 4 - Comparação entre as Variâncias

\begin{tabular}{lcll}
\hline Curtos & $\begin{array}{c}\text { Variância } \\
\text { P(-500,-650)mm }\end{array}$ & Relação entre as fases & \multicolumn{1}{c}{$\begin{array}{c}\text { Relação com Estado } \\
\text { sem contingência }\end{array}$} \\
\hline Normal & 5 & & \\
F1T & 7086 & $\mathrm{~F} 1 \mathrm{~T} / \mathrm{F} 2 \mathrm{~T}=2,41$ & $\mathrm{~F} 1 \mathrm{~T} / \mathrm{N}=1417,20$ \\
F2T & 2939 & $\mathrm{~F} 2 \mathrm{~T} / \mathrm{F} 3 \mathrm{~T}=2,00$ & $\mathrm{~F} 2 \mathrm{~T} / \mathrm{N}=587,80$ \\
F3T & 1466 & $\mathrm{~F} 3 \mathrm{~T} / \mathrm{N}=293,2$ & $\mathrm{~F} 3 \mathrm{~T} / \mathrm{N}=293,2$ \\
F1F2T & 6104 & $\mathrm{~F} 1 \mathrm{~F} 2 \mathrm{~T} / \mathrm{F} 1 \mathrm{~F} 3 \mathrm{~T}=1,28$ & $\mathrm{~F} 1 \mathrm{~F} 2 \mathrm{~T} / \mathrm{N}=1220,80$ \\
F1F3T & 4767 & $\mathrm{~F} 1 \mathrm{~F} 3 \mathrm{~F} / \mathrm{F} 2 \mathrm{~F} 3 \mathrm{~T}=4,53$ & $\mathrm{~F} 1 \mathrm{~F} 3 \mathrm{~T} / \mathrm{N}=953,40$ \\
F2F3T & 1052 & $\mathrm{~F} 2 \mathrm{~F} 3 \mathrm{~T} / \mathrm{N}=210,40$ & $\mathrm{~F} 1 \mathrm{~F} 3 \mathrm{~T} / \mathrm{N}=210,4$ \\
F1F3 & 5119 & $\mathrm{~F} 1 \mathrm{~F} 3 / \mathrm{F} 1 \mathrm{~F} 2=3,74$ & $\mathrm{~F} 1 \mathrm{~F} 3 / \mathrm{N}=1023,80$ \\
F1F2 & 1369 & $\mathrm{~F} 1 \mathrm{~F} 2 / \mathrm{F} 2 \mathrm{~F} 3=1,37$ & $\mathrm{~F} 1 \mathrm{~F} 2 / \mathrm{N}=273,80$ \\
F2F3 & 999,8 & $\mathrm{~F} 2 \mathrm{~F} 3 / \mathrm{N}=199,96$ & $\mathrm{~F} 2 \mathrm{~F} 3 / \mathrm{N}=199,96$ \\
F1F2F3 & 3977 & $\mathrm{~F} 1 \mathrm{~F} 2 \mathrm{~F} 3 / \mathrm{N}=795,40$ & $\mathrm{~F} 1 \mathrm{~F} 2 \mathrm{~F} 3 / \mathrm{N}=795,40$ \\
\hline
\end{tabular}

Já para valores da variância entre 5 e 1466, tem-se curto-circuito Fase3-Terra e a relação entre os valores máximo e mínimo é da ordem de 293,2 .

De modo semelhante, a Figura 67 mostra as curvas da variância da densidade de fluxo magnético para curtos bifásicos-terra no ponto $P(-500,-650) \mathrm{mm}$. Com variâncias entre 4767 e 6104 tem-se curto-circuito Fase1-Fase3-Terra, sendo a relação entre os valores máximo e mínimo da ordem de 1,28, possibilitando identificar a fase citada.

De 1052 e 4767 tem-se curto-circuito Fase1-Fase2-Terra, com um fator de 4,53 . 
O curto-circuito Fase2-Fase3-Terra é detectado no intervalo de variâncias entre 5 e 1052 com fator de 210,40.

A Figura 68 ilustra as curvas da variância da densidade de fluxo magnético para os curtos bifásicos e em regime permanente (normal), em função do nível do detalhe, no ponto $P(-500,-650) \mathrm{mm}$. Estando os valores da variância entre 1369 e 5119 tem-se curto-circuito Fase1-Fase3. Este intervalo permite detectar a fase em que ocorreu o curto-circuito. A relação entre os valores máximo e mínimo da variância no intervalo considerado é da ordem de 3,74 .

Para valores da variância entre 1369 e 999,8 tem-se curto-circuito Fase2-Fase3 e a relação entre os valores máximo e mínimo é da ordem de 1,37 .

Com variâncias entre 5 e 999,8 tem-se curto-circuito Fase2-Fase3 e o quociente entre os valores máximo e mínimo é da ordem de 199,96.

A razão entre as variâncias de cada um dos dez curtos-circuitos com o regime permanente, estão apresentadas na Tabela 4.

Da mesma forma, pode-se identificar a fase que sofreu falta através da curva da variância, para pontos fora da linha. A Figura 69 fornece as curvas da variância da densidade de fluxo magnético para curtos-circuitos Fase1-Terra, Fase2-Terra, Fase3-Terra e regime permanente (normal) para um ponto externo à linha, $P(1500,-650) \mathrm{mm}$.

As análises das Figuras 64 a 70 demonstram que é possível determinar a fase em que ocorreu a falta através das curvas das variâncias, utilizando apenas um sensor. A posição do sensor pode ser definida através de estudos prévios visando otimizar e adequar a classificação e localização da falha.

Assim enfatiza-se a metodologia aplicada relacionando a utilização da $T W$ como uma ferramenta potencial na análise da assinatura magnética. 


\subsection{5- Determinação da fase com falta através da densidade de fluxo magnético em função do tempo.}

Um outro modo de identificar a fase que sofreu a falta é através das amplitudes das densidades de fluxo magnético em função do tempo. As Figuras 71 e 72 mostram as curvas experimentais das densidades de fluxo magnético para curtos-circuitos Fase1-Terra, Fase2-Terra, Fase3-Terra e regime permanente (normal) em função do tempo, medidos com o sensor magnético no ponto $P(500,-650) \mathrm{mm}$.

No intervalo 14,42 a 18,42 $\mu T$ tem-se curto-circuito Fase1-Terra, sendo 1,27, a relação entre os valores máximo e mínimo do intervalo.

Da mesma forma de 10,48 a $14,42 \mu T$ ocorre o curto-circuito Fase 2-Terra com fator de 1,37.

Para valores entre 0,7 e 10,48 $\mu T$ tem-se curto-circuito Fase1-Terra e a relação entre o valor máximo e o mínimo é da ordem de 14,97.

Para comparar os algoritmos, levantaram-se as curvas da variância para o mesmo ponto. A Figura 72 mostra as curvas da variância da densidade de fluxo magnético para o ponto $P(500,-650) \mathrm{mm}$, para curtoscircuitos Fase1-Terra,Fase2-Terra, Fase3-Terra e regime permanente (normal).

Para valores da variância entre 4540 e 7324 tem-se curto-circuito Fase3-Terra e a relação entre estes valores é de 1,61.

Para valores da variância entre 2460 e 4540 tem-se curto-circuito Fase2-Terra e a relação é de 1,84.

Para valores da variância entre 5 e 2460 tem-se curto-circuito Fase1Terra e a relação é 492.

Comparando-se as curvas da variância da densidade de fluxo magnético em função do nível do detalhe wavelet para a identificação da fase, com as curvas da densidade de fluxo magnético em função do tempo, nota-se que os fatores da variância são maiores do que os fatores da 
densidade de fluxo magnético, permitindo uma melhor caracterização da fase que sofreu a falta.

\subsection{6- Resultados adicionais}

Visando avaliar a aplicabilidade da metodologia proposta, quando relacionada a fenômenos distintos, alguns resultados relativos ao chaveamento de banco de capacitores são apresentados no Apêndice D.

Embora não seja o foco deste trabalho, a comparação destes com os apresentados anteriormente relacionados a falhas em sistemas elétricos, possibilita afirmar que a caracterização destas podem ser diferenciadas através dos níveis de detalhes. 


\section{6 - CONCLUSÕES}

O estágio atual de desenvolvimento deste trabalho mostra que os objetivos inicialmente propostos relacionados à análise da assinatura magnética do sistema elétrico apresentam-se como uma potencial ferramenta para monitorar a qualidade de energia de sistemas elétricos.

Desta forma, a metodologia constitui-se em uma alternativa atraente e bastante útil para monitorar o sistema elétrico. Considere-se que este trabalho apresenta uma metodologia inovadora para detecção de transitórios em sistemas elétricos. A base desta metodologia é a análise da densidade de fluxo magnético resultante de faltas, visando monitorar a qualidade de energia do sistema elétrico e sua proteção. A detecção de faltas foi realizada à distância, sem contato físico com o sistema, de modo não invasivo, através de sensores magnéticos que medem a densidade de fluxo magnético originada pelas correntes de faltas. Esta metodologia é diferente da utilizada atualmente para a detecção de faltas que usa equipamentos conectados ao sistema.

Para validar a metodologia proposta, os resultados teóricos e experimentais foram comparados. Os resultados teóricos foram obtidos via Flux 2D. Com relação aos resultados experimentais foi montada uma bancada experimental trifásica com a finalidade de obter faltas na linha. Analisaram-se diversos tipos de intensidades de faltas tais como, curtos-circuitos monofásicos, bifásicos- terra, bifásicos e trifásico.

A obtenção das formas de ondas da densidade de fluxo magnético foi feita por meio de um sensor magnético, constituído por bobina e amplificador, conectada a um osciloscópio, calibrada através da bobina de Helmholtz. Foram medidos mais de 500 formas de ondas da densidade de fluxo magnético para 10 tipos curtos-circuitos avaliados, em diversos pontos.

A análise das formas de ondas foi realizada pela $T W, T F$ e a curva de variância wavelet. As análises destas formas de ondas pela $T W$ db-4, nível 10, permitiu a detecção dos tipos de faltas através dos coeficientes $d_{1}$ e $d_{2}$, que são os coeficientes que apresentam as frequências mais elevadas do sinal. 
Comparando-se as formas de ondas experimentais das densidades de fluxo magnético com as formas de ondas das correntes, verifica-se que elas são similares, diferindo apenas na amplitude.

A densidade de fluxo magnético foi medida e comparada com o valor obtido por simulação numérica, usando o método dos elementos finitos. Os resultados obtidos apresentam uma boa concordância. Alguns pontos apresentam desvios maiores, cujas causas podem ser atribuídas a imprecisões no posicionamento do sensor, linha trifásica não perfeitamente horizontal, tamanho do sensor, não horizontalidade do sensor e simulação que considera o solo perfeitamente condutor. Estas variações de amplitudes não afetam a metodologia proposta, pois a mesma não tem como foco avaliar o valor da amplitude. Como o ponto de instalação do sensor pode ser escolhido, procuram-se pontos mais convenientes para atingir os objetivos desejados.

Foi desenvolvido uma metodologia de classificação de transitórios baseado no Teorema de Parseval, onde a variância da densidade de fluxo magnético é expressa em termos de seus coeficientes wavelets. Como a variância do sinal da densidade de fluxo magnético é uma medida de sua energia, a variância do sinal decomposto, em seus diferentes níveis de resolução, é proposta como índice de mérito a ser utilizada na classificação de faltas. Através da $A M R$, decompõe-se o sinal em diferentes níveis de resolução (detalhes), sendo que o número de níveis selecionado visa cobrir a faixa de frequência de interesse. Em seguida, obtém-se a variância de cada versão de detalhe para diferentes níveis de resolução do sinal com distúrbio, e constrói-se a curva da variância em função dos níveis de detalhe. A classificação é feita pela diferença entre a curva de um determinado distúrbio e a curva referente ao sistema em regime permanente. Foram construídas curvas de variância da densidade de fluxo magnético para curtos-circuitos monofásicos, bifásicos- terra, bifásicos e trifásicos e através delas determina-se a fase na qual ocorreu o transitório. Verifica-se que a maior variância ocorre para o nível de detalhe 7, para transitórios relacionados a curtos-circuitos. 
Este trabalho apresenta vários tópicos que poderão ser explorados e que estão sendo apresentados para continuidade desta pesquisa. Dentre eles pode-se sugerir:

a) Desenvolvimento de sensores e aplicação da metodologia proposta na localização de faltas em sistema elétricos.

b) Aplicação de algoritmos computacionais que automatizem a detecção, duração e localização de faltas, atualmente disponíveis na literatura.

c) Desenvolvimento de pesquisas relacionadas à influência de diferentes sensores na avaliação da densidade de fluxo magnético.

d) No trabalho atual, o solo foi considerado como condutor perfeito.

Assim a consideração do efeito do solo em medidas experimentais e nos estudos teóricos, pode ser também, um tema a ser considerado nas pesquisas futuras. 


\section{7 - REFERÊNCIAS}

[1] INTERNATIONAL ELECTROTECHNICAL COMMISSION. 61000-4-30 (2003-02). Electromagnetic compatibility (EMC)- Part 4-30: Testing and measurement tecnicques-Power quality measurement methods.

[2] AGÊNCIA NACIONAL DE ENERGIA ELÉTRICA. Resolução № 24. Jan. (2000).

[3] DAUBECHIES, I. Ten lectures on Wavelet. (SIAM).5 ed. Monpelier: Capital City Press, 1997.

[4] CHAARI, O.; MEUNIER, M.; BROUAYE, F. Wavelets: a new tool for the resonant grounded Power distribution systems relaying. IEEE Transactions on Power Delivery, Vol11, No.3, Page(s): 1301-1308, July 1996.

[5] ROBERTSON, D.C.; CAMPS, O.I.; MAYER, J.S.; GISH, W.B. Wavelets and electromagnetic power system transients. IEEE Transactions on Power Delivery, Vol. 11, No. 2, Page(s): 1050-1058, April 1996.

[6] GAOUDA, A.M.; SALAMA, M.M.A.; SULTAN, M.R.; CHIKHANI, A.Y. Power quality detection and classification using wavelet-multiresolution signal decomposition. IEEE Transactions on Power Delivery, Vol. 14, No. 4, Page(s): 1469-1476, October 1999.

[7] SANTOSO, S.; POWERS, E.J.; GRADY, W.M.; HOFMANN, P. Power quality assessment via wavelet transform analysis. IEEE Transactions on Power Delivery, Vol. 11, No. 2, Page(s): 924-930, April 1996. 
[8] DELMONT FILHO, O. Um algoritmo para detecção, localização e classificação de distúrbios na qualidade de energia elétrica utilizando a TW. São Carlos 209 p. Tese (doutorado) - EESC, Universidade de São Paulo, 2007.

[9]DUGAN, R.C., MCGRANAGHAN, M.F., BEATY, H.W. Electrical Power Systems Quality. New York: McGraw-Hill, xv, 265 p. 1996.

[10] International Electrotechnical Commission. IEC 61000-4-11 (2004-03). Electromagnetic compatibility (EMC)- Part 4-11: Testing and measurement tecniques- Voltage dips, short interruptions and voltage variations immunity tests.

[11] International Electrotechnical Commission. IEC 61000-4-13 (2002-03). Electromagnetic compatibility (EMC)- Part 4-13: Testing and measurement tecniques- harmonics and interharmonics including mains signalling at a.c. power port, low frequency immunity tests.

[12] European Norm - EN 50160 (2000). Power Quality Standard.

[13] Institute of Electrical and Electronics Engineers - IEEE 519 (1992-05). IEEE Recommended practices and Requirements for Harmonic Control in Electric Power Systems.

[14] Institute of Electrical and Electronics Engineers - IEEE 1159 (1995-11). IEEE Recommended practice for Monitoring Electric Power Quality.

[15] Agência Nacional de Energia Elétrica- ANEEL: Resolução № 505. Nov (2001). 
[16] Electromagnetic Transient Program - EMTP - Rule Book and user's Guide, Eletrotek Concepts INC., November 1992.

[17] Alternative Transient Program - ATP - Rule Book and user's Guide, Leuven EMTP Center, Herverlee, Belgium, July 1987

[18] HANSELMAN, D., LITTLEFIELD,B. Mastering Matlab 7. Pearson Higher Education, 2004.

[19] PSCAD/EMTDC Power Systems Simulation Software Manual: Manitoba HVDC Research Center.

[20] KIM, C.H.; AGGARWAL, R. Wavelet transforms in power systems: Part 1 General introduction to the wavelet transforms. Power Enginneering Journal, v.14, n.2, p. 81-87, Apr.2000.

[21] KIM, C.H.; AGGARWAL, R. Wavelet transforms in power systems: Part 2 Examples of application to actual power system transients. Power engineering Journal, p. 193-202, Aug. 2001.

[22] JOAQUIM, B.M; SARTORI, J.C. Análise de Fourier. Escola de Engenharia de São Carlos. USP - São Carlos - SP, 2003. 1 CD ROM.

[23] OLESKOVICZ,M.; COURY,V.D.; CARNEIRO,A.A.F.M.; ARRUDA, E.F.; DELMONT Fo-O.; SOUZA A. S. Estudo comparativo de ferramentas modernas de análise aplicadas à qualidade da energia elétrica. Revista Controle \& Automação/ vol. 17 № 3/ julho, agosto e setembro 2006.

[24] ARRUDA, E.F., FILHO, O.D, COURY, D.V., CARNEIRO, A.F. Um estudo das famílias Wavelets no Estudo da Qualidade de Energia Elétrica. CBA 2002, 6p., Natal, RN, 2002. 
[25] SANTOSO, S., POWERS, E.J., GRADY, W.M. Electric Power Quality Disturbance Detection Using Wavelet Transform Analysis. IEEE International Symposium, p.166-169. Oct. 1994.

[26] HUANG, S. J., HSIEH, C.T. and HUANG, C.L.. Application of wavelets to classify power system disturbances. Electric Power Systems Resarch, n.47, p. 87-93, March, 1998.

[27] SHIN, Y.J., at al. Power Quality Indices for Transient Disturbances. IEEE Transactions on Power Delivery, v.21, n.1, Jan. 2006.

[28] KARIMI, M; MOKHTARI, H.; IRAVANI, M.R. Wavelet Based Online Disturbance Detection for Power Quality Applications. IEEE Transactions on Power Delivery, v.15, n.4, p. 1212-220, oct .2000

[29] PILlay, P. ; BHATtAChARJEE, A. Application of Wavellets to Model Short-Term Power System Disturbances. IEEE Transactions on Power Systems. v.11, n.4, November 1996.

[30] POISSON, O.; RIOUAL, P.; ASSEF Y.; BASTARD, P. .Advanced Techniques for Power Quality Analysis: A real case study. IEEE PES, Oct 1998.

[31] ZHENG, T., MAKRAM ,E.B.; GIRGIS A.A. Power System Transient and harmonic studies using wavelet transform. IEEE Transactions on Power Delivery, v.14, no 4, October 1999.

[32] YANG, H. T. and LIAO, C. C.. A De-Noising Scheme for Enhancing Wavelet-Based Power Quality Monitoring System. IEEE Transactions on Power Delivery, v.16, n.3, p.353-360, july 2001. 
[33] MOKHTARI, H.; KARIMI-GHARTEMANI, M.; IRAVANI, M.R. Experimental performance evaluation of a wavelet-based on-line voltage detection method for power quality applications. Page(s): 161-172 IEEE Transactions on Power Delivery, vol. 17, no. 1, January 2002

[34] TARASIUK, T. Hybrid Wavelet-Fourier Method for Harmonics and Harmonic Subgroups Measurement - Case Study. IEEE Transactions On Power Delivery, Vol. 22, no. 1, January 2007.

[35] SANTOSO, S.; GRADY, W.M.; POWERS, E.J.; LAMOREE, J.; BHATT, S.C. Characterization Of Distribution Power Quality Events With Fourier And Wavelet Transforms. IEEE Transactions On Power Delivery, Vol. 15, No. 1 , Page(s): 247-254 January 2000.

[36] POISSON, O., RIOUAL,P. and MEUNIER, M.. Detection and Measurement of Power Quality Disturbances Using Wavelet Transform. IEEE Transactions on Power Delivery, v.15, n.3, p.1039-1044, july 2000.

[37] POISSON, O., RIOUAL, P. and MEUNIER,M.. New Signal Processing Tools Applied to Power Quality Analysis .IEEE Transactions on Power Delivery, v.14, n.2, p.561-566, April 1999.

[38] BORRÁS, D. et al. Wavelet and Neural Structure: A new tool for diagnostic of power system disturbances. IEEE Transactions on Industry Applications, v.37, n.1, p.184-190, Jan. 2001.

[39] MONEDERO, I. et al. Classification of Electrical Disturbances in Real Time Using Neural Networks. IEEE Transactions on Power Delivery, vol.22, ํo. 3, July 2007.

[40] BUCCELLA, C.; ORLANDI, A. Diagnosing Transmission Line Termination Faults by Means of Wavelet Based Crosstalk Signature 
Recognition. IEE Transactions On Component and Packaging Technology, v.23, n. 1, march 2000.

[41] ANGRISANI, L., DAPONTE, P., D'APUZZO, $M$ and TESTA,A. A Measurement Method Based on the Wavelet Transform for Power Quality Analysis. IEEE Transations on Power Delivery, v.13, n.4, p. 990-998, October 1998.

[42] REIS FILHO, F. A. Uma Proposta de Algoritmo Digital para Proteção da Interligação Concessionária e Indústria Operando em Sistemas de Cogeração. São Paulo. 135p. Tese (Doutorado) - Escola Politécnica, Universidade de São Paulo, 2002.

[43] DUCK.J.L. et al. Signal Processing Technology for fault Location System in Underground Power Cable.PES TD 2005/2006 pg.839-842.

[44] MAGNAGO, F. H.; ABUR, A. Fault location Using Wavelets. IEEE Transactions on Power Delivery, New York, v.13, n.4, p. 1475-1480, October 1998.

[45] SILVEIRA, P.M. Identificação e localização de faltas utilizando análise por decomposição wavelet para relés de linhas de transmissão. 2001. 218p. Tese (Doutorado) - Universidade Federal de Santa Catarina. Florianópolis, 2001.

[46] SILVA, M. Localização de faltas em linhas de transmissão utilizando a teoria de ondas viajantes e TW. 2003. 231p. Dissertação (Mestrado) Escola de Engenharia de São Carlos, Universidade de São Paulo. São Carlos, 2003. 
[47] MICHALIK, M. et al. High- Impedance Fault Detection in Distribution Networks Whith Use of Wavelet- Based Algoritm. IEEE Transactions On Power Delivery, vol. 21, № 4, October 2006.

[48] SILVA, M. et al. Uma nova ferramenta baseada na TW para localização digital de faltas. Revista Controle \& Automação. Vol. 16, no 3, julho, agosto e setembro 2003.

[49] SHANG, L. et al. High-speed fault identification and protection for HVDC line using wavelet technique. IEEE Porto Power Tech Conference, Porto, Portugal, 2001.

[50] PEREIRA, C.E; ZANETTA, L.C. Fault location in transmission lines using one- terminal postfault voltage data. IEEE Transactions on Power Delivery, vol.19, № 2, April 2004.

[51] KANDA M. An Electromagnetic Near- Field Sensor for Simultaneous Electric and Magnetic- Field Measurements.IEEE Transactions on Electromagnetic Compatibility, vol. EMC-26, № 3, August 1984.

[52] KAUNE, W.T.; ZAFFANELLA, L.E. Analysis of magnetic Fields produced far from Electric Power Lines. IEEE Transactions on Power Delivery, vol. 7, no 4, October 1992.

[53] OLSEN, R.G.; WONG, P.S. Characteristics of Low Frequency Electric and Magnetic Fields in the Vicinity of Electric Power Lines. IEEE Transactions on Power Delivery, vol. 7, n 4, October 1992.

[54] DAHAB, A.A. et al. Comparison of Magnetic-Field Distribution of Noncompact and Compact Parallel Transmission-Line ConFigurations. IEEE Transactions on Power Delivery, vol. 20, no 3, July 2005. 
[55] GARRIDO, C.; OTERO, A.F.; CIDRÁS, J. Low- frequency Magnetic Fields From Electrical Appliances and power Lines. IEEE Transactions on Power Delivery, vol. 18, № 4, October 2003.

[56] FARIA, B.J.; ALMEIDA, M.E. Accurate Calculation of magnetic-Field Intensity Due to overhead Power Lines With or Without Mitigation Loops With or Without Capacitor Compensation. IEEE Transactions on Power Delivery, vol. 22, № 2, April 2007.

[57] ÁVILA. L. S.; CHADEBEC, 0.; RAISON.B.; VERNAU.G. Currents Identification in Overhead Lines from Radiated Magnetic Field Knowledge. In: Proceedings of the $16^{\text {th }}$ Conference on the Computation of Electromagnetic Fields. PB2-17, p. 437- 438. COMPUMAG 2007, Aachen, Germany, 2007.

[58] Flux 2D User's Guide, Vol. 3, "Physical Properties, Parametrization solving and Results". CEDRAT, France, 2001.

[59] BJERKAN.E. and VENSETH. Locating earth-faults incompensated distribution networks by means of fault indicators. In: Proceeding of International conference Power Systems Transients. Montreal, 2005.

[60] IEEE MAGNETIC FIELD TASK FORCE. Magnetic fields from electric power lines theory and comparison to measurements. IEEE Transactions On Power Delivery, 3(4): 2127 - 2136, 1988.

[61] ANSI/IEEE STd 644-1994. IEEE Standard Procedures for Measurement of Power Frequency Electric and magnetic Fields from AC Power Lines.

[62] Email: nortroll@nortroll.no Web: www.nortroll.no, NORTROLL AS Havneveien 17, N-7600 Levanger, Norway. 
[63] PELEGRINA, M. G., SARTORI, C.F.A., SEVEGNANI, F.X. "A Hybrid fault detection approach based on the resulting magnetic signature and wavelets". COMPUMAG 2007 - 16th International Conference on the Computation of Electromagnetic Fields - Aachen - Alemanha, 2007.

[64] PELEGRINA, M. G., SARTORI, C.F.A., SEVEGNANI, F.X. "Análise de Assinatura Magnética Resultante de faltas em sistemas elétricos via wavelets". MOMAG 2006 - 12ํㅗ SBMO - Simpósio Brasileiro de Microondas e Optoeletrônica; $7^{\circ}$ CBMAG - Congresso Brasileiro de Eletromagnetismo Belo Horizonte, 2006.

[65] KWAKERNAAK, H., SILVAN, R. Modern signals and Systems. Englewood Cliffs, NJ: Prentice Hall, 1991.

[66] HARRIS,F.J. On the Use of Windows for Harmonic Analysis with the Discrete Fourier Transform. Proceedings of IEEE, New York, v.66, n.1, p.51-83, January 1978.

[67] DAUBECHIES, I. The Wavelet Transform, Time-Frequency Localization and Signal Analysis. IEEE Transactions on Information Theory, New York, v.36, n.5, p.961-1005, july 1990.

[68] WICKERHAUSER, M.V. Adapted Wavelet Analysis from theory to Software. 10.ed. Wesllesley: AK Peters Ltda., 1994, pág. 24-25.

[69] OPPENHEIM, A.V.; SCHAFER,R.W. Discrete-Time Signal Processing. 20 ed. Englewood Cliffs,NJ: Prentice Hall, 1989.

[70] CHUI, K.Charles . An Introduction to Wavelets, Academic Press, San Diego, 1992, ISBN 0585470901 
[71] DAUBECHIES, I. Orthonormal Bases of Wavelets whith Finite Suport Connection with Discrete Filters. In: International Conference On TimeFrequency Methods And Phase Space (December 1987, Marseille,France). Proceedings. Marseille, 1987. p.38-66

[72] Haar, Alfred; Zur Theorie der orthogonalen Funktionensysteme. (German) Mathematische Annalen 69 (1910), no. 3, 331--371.

[73] GRAPS, A. An introduction to wavelets. IEEE Computational Science and Engineering, 1995, v.2, p.50-61, summer.

[74] LIMA, P.C. Wavelets: Teoria, Algoritmos e Aplicações. Belo Horizonte : Departamento de Matemática- ICEX-UFMG, 2002.

[75] DAUBECHIES, I. Where Do Wavelets Come From? - A Personal Point of View. Proceedings of the IEEE, v.84, n.4, p. 510-513, Apr. 1996.

[76] SCHIMIDT, R.F. Detecção e rastreamento de faces utilizando Gabor wavelet networks. Dissertação (Mestrado), Instituto de Matemática e Estatística, 2000, Universidade de São Paulo.

[77] MALLAT, S. A Theory for Multiresolution Signal Decomposition: The Wavelet Representation. IEEE Transaction on Pattern Analysis and Machine Intelligence, New York, v.11, n.7, p.674-693, july 1989

[78] MORETTIN A. P.(1999). Ondas e Ondaletas: Da Análise de Fourier à Análise de Ondaletas. São Paulo: Editora da Universidade de São Paulo, 1999. 272p.

[79] MISITI, M., MISITI, Y., OPPENHEIM, G.and POGGI, J.M. Wavelet Toolbox: User's Guide. Natick, MA: The Math Works, 626 p., 1997. 
[80] ADDISON S. PAUL. The Illustrated Wavelet Transform Handbook. Institute of Physics Publishing, Bristol and Philadelphia, 2002.

[81] PERCIVAL, D.B., WALDEN, A.T. Wavelet Methods for Time Series Analysis. CAMBRIDGE UNIVERSITY PRESS, 2000.

[82] LATHI, B.P. Modern Digital and Analog Comunication System. Third Edition, Oxford University Press, New York Oxford, 1998.

[83] GIROD, B. ; RABENSTEIN R.; STENGER A. Sinais e Sistemas. Editora

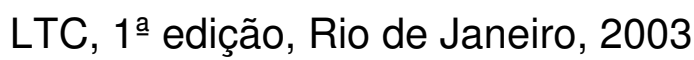

[84] ARRUDA, E. F. Análise de distúrbios Relacionados com a Qualidade de Energia Elétrica Utilizando a TW. São Carlos. 114p. Dissertação (Mestrado) - Escola de Engenharia de São Carlos, Universidade de São Paulo, 2003.

[85] HANDBOOK of Power Signatures. Santa Clara, CA: Basic Measuring Instruments, 2ª Ed. 1993.

[85] HAYT, JR., WILLIAM H.; BUCK, JOHN A. Eletromagnetismo. $7^{\mathrm{a}}$ edSão Paulo: McGraw-Hill, 2008 


\section{8 - APÊNDICE - A}

\section{SENSOR DE TRANSITÓRIOS ELETROMAGNÉTICOS}

\section{1- Sensor de Transitórios Eletromagnéticos}

Com o objetivo de medir a densidade de fluxo magnético criado por transitórios em sistemas de distribuição de energia elétrica construiu-se um sensor composto de uma bobina de exploração, ou sonda, e um circuito amplificador. $O$ sensor foi projetado para medir transitórios com frequências de $60 \mathrm{~Hz}$ a $7,2 \mathrm{kHz}$. O funcionamento do sensor baseia-se na lei de Faraday. A força eletromotriz induzida na bobina é igual à variação do fluxo magnético com o tempo, na bobina. Depende, também, diretamente do número de espiras $\mathrm{N}$ da bobina. Esta força eletromotriz induzida na bobina será a tensão de entrada do amplificador integrador $V_{\text {in }}$.

$$
V_{i n}=-N \frac{d \phi}{d t}
$$

Sendo $V_{\text {in }}$ a força eletromotriz induzida na bobina, $N$ o número de espiras da bobina, $\phi$ o fluxo magnético. O fluxo magnético $\phi$ é definido por

$$
\phi=\int_{S} \vec{B} \cdot d \vec{S}
$$

Onde, na equação (2), $\vec{B}$ é a densidade de fluxo magnético e $d \vec{S}$ é a área na direção de um vetor unitário $\vec{n}$, perpendicular à secção de área da bobina. Portanto, pode-se escrever $V_{\text {in }}$ em função de $B$ e $S$.

$$
V_{i n}=-N \frac{d}{d t} \int_{S} \vec{B} \cdot d \vec{S}
$$


Considerando constante em relação à posição, $\vec{B}=B_{\max } \cos \omega t \vec{k} \quad \mathrm{e}$ substituindo na equação (3), tem-se:

$$
\begin{aligned}
V_{i n} & =-N \int_{S} \frac{\partial}{\partial t}\left(B_{\text {max }} \cos \omega t\right) \vec{k} \cdot d S \vec{k} \\
V_{\text {in }} & =N \omega B_{\text {max }} \operatorname{sen} \omega t \int_{S} d S \\
V_{\text {in }} & =N \omega S B_{\text {max }} \operatorname{sen} \omega t
\end{aligned}
$$

Verifica-se pela equação (5) que a força eletromotriz induzida na bobina é diretamente proporcional ao número de espiras $\mathrm{N}$ da bobina, à área da secção transversal $S$ da bobina e à frequência angular $\omega$.

A tensão de saída $V_{\text {out }}$ do circuito integrador do fluxímetro é dada por

$$
V_{\text {out }}=\frac{1}{R C} \int_{0}^{t} V_{\text {in }} d t
$$

Substituindo a equação (5) na equação (6) vem

$$
\begin{aligned}
V_{\text {out }} & =\frac{1}{R C} \int_{0}^{t} N S \omega B_{\max } \operatorname{sen} \omega t d t \\
V_{\text {out }} & =\frac{\omega N S B_{\max } \int_{0}^{t} \operatorname{sen} \omega t d t}{R C} \\
V_{\text {out }} & =-\frac{\omega N S B_{\max } \cos \omega t}{R C \omega} \\
V_{\text {out }} & =-\frac{N S B_{\text {max }}}{R C} \cos \omega t
\end{aligned}
$$

A amplitude do fluxo de indução magnética é dada por:

$$
B_{\max }=\frac{R C}{N S} \cdot V_{\text {out }}
$$




\section{2- Circuito do amplificador do sensor de transitórios eletromagnéticos}

Como a bobina sonda produz uma tensão baixa, da ordem de milivolts, foi construído um circuito amplificador integrador, adequado ao tipo de sinal medido, conforme Figura 3.

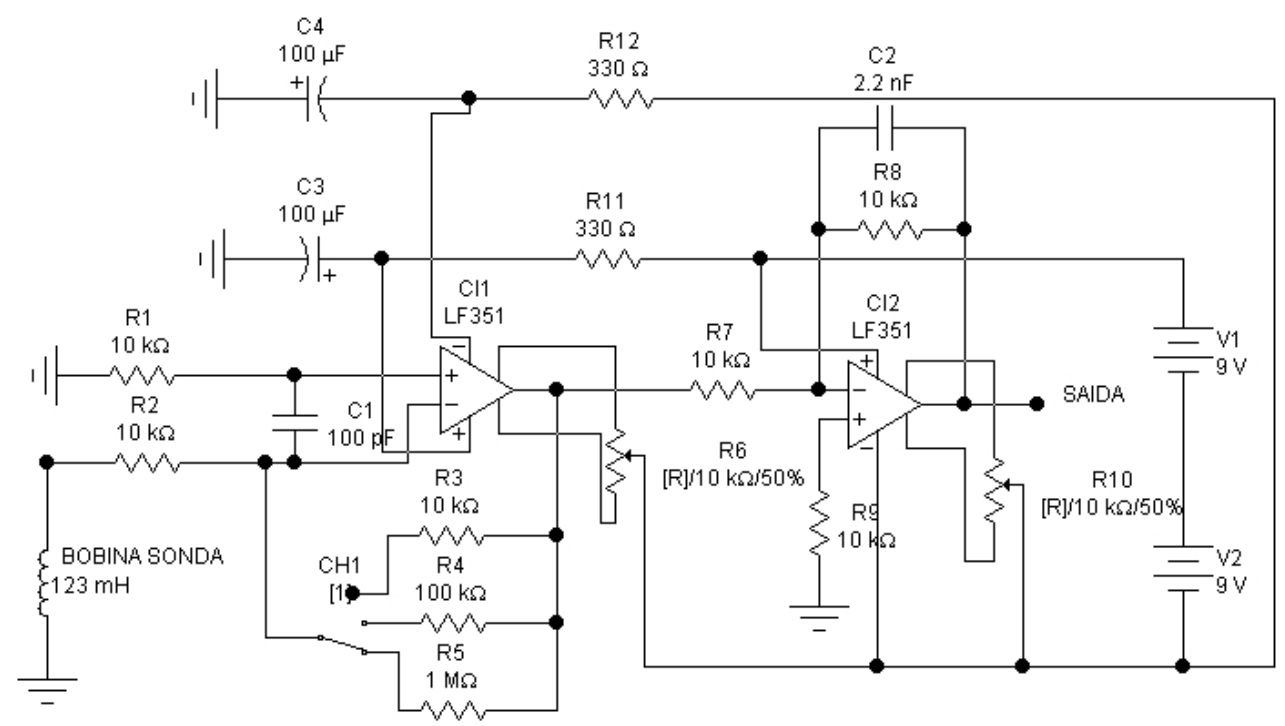

Figura 1 - Circuito do amplificador de ganho ajustável, com integrador.

A bobina sonda aplica o sinal ao primeiro estágio. $O$ amplificador apresenta ganho ajustável de um, dez e cem vezes. A seguir o sinal é filtrado por um circuito integrador, com pólo definido por valores que permitam medir uma faixa de frequências suficientemente grande para avaliar as harmônicas da frequência da rede que possivelmente existirão no transitório. Considerando que são encontradas várias harmônicas e que a frequência de corte do filtro deverá estar bem acima daquela do maior sinal 
a ser medido (pois a amplitude se reduz em $3 \mathrm{~dB}$ foi estabelecido o valor em torno de $7200 \mathrm{~Hz}$ para obter-se uma resposta adequada.

A frequência de corte $f_{c}$ é dada pela equação (9)

$$
\begin{gathered}
f_{c}=\frac{1}{2 \pi R_{7} C_{2}} \\
f_{c}=\frac{1}{2 \pi \times 10 \times 10^{3} \times 2,2 \times 10^{-9}}=7234 \mathrm{~Hz}
\end{gathered}
$$

O capacitor $\mathrm{C}_{1}$ apresenta baixa impedância para sinais de radiofrequência de modo a reduzir a interferência. Também os filtros da alimentação constituídos por $R_{11}-C_{3}$ e $R_{12}-C_{4}$, evitam possíveis realimentações através de $+V_{c c}$ e de $-V_{c c}$. Os circuitos integrados foram escolhidos em função de suas características adequadas a este tipo de sinal. O ajuste de off-set garante tensão de saída nula sem sinal aplicado.

A placa de circuito impresso foi fixada em uma caixa metálica (ferro) para oferecer blindagem a sinais externos. $O$ equipamento foi alimentado por baterias de 9 volts para possibilitar sua portabilidade. A bobina sonda foi interligada através de fio blindado. O sinal de saída do amplificador foi conectado a um osciloscópio digital AGILENT 4 canais, modelo 54624A. 


\section{3- Resposta em frequência do amplificador}

O circuito da Figura 1 foi simulado e produziu a resposta em frequência apresentada na Figura 2.

A resposta em frequência também foi medida em laboratório, aplicando-se na entrada do amplificador um sinal senoidal de frequência variável e medindo-se a razão entre as tensões de saída e de entrada para cada frequência. Os dados medidos estão na Tabela 2 e também representados na Figura 2, considerando o ganho unitário.

Tabela 2- Resposta em frequência do amplificador (dB)

\begin{tabular}{ccc}
\hline$f(\mathrm{~Hz})$ & Vout/Vin & 20log(Vout/Vin) $(\mathrm{dB})$ \\
\hline 60 & 1 & 0 \\
120 & 1 & 0 \\
600 & 1 & 0 \\
840 & 1 & 0 \\
1200 & 1 & 0 \\
1800 & 1 & 0 \\
2400 & 1 & 0 \\
3000 & 1 & 0 \\
3600 & 0,90 & $-0,84$ \\
4800 & 0,89 & $-1,0$ \\
6000 & 0,81 & $-1,8$ \\
6600 & 0,79 & $-2,0$ \\
7200 & 0,75 & $-2,4$ \\
7800 & 0,73 & $-2,66$ \\
8400 & 0,71 & $-2,9$ \\
9000 & 0,68 & $-3,36$ \\
9600 & 0,66 & -38 \\
10200 & 0,60 & \\
\hline
\end{tabular}




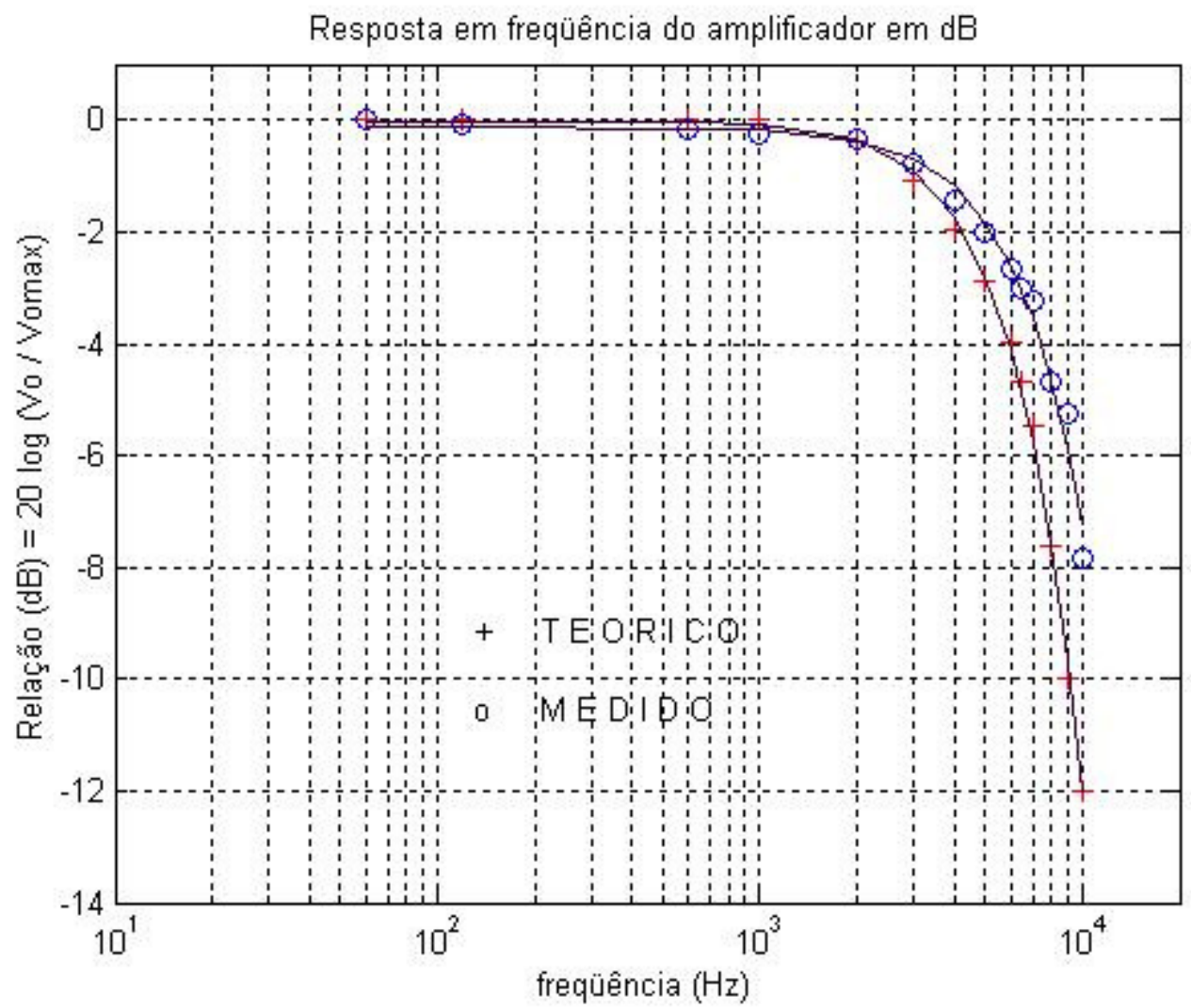

Figura 2 - Resposta em frequência do amplificador com integrador, para os dados medidos e simulados.

Pode-se observar, na Figura 2, que os valores obtidos no ensaio da resposta em frequência produziu resultados próximos aos simulados por software. A banda passante, isto é, o ponto de $-3 \mathrm{~dB}$ corresponde a uma frequência de aproximadamente $8 \mathrm{kHz}$. Este valor está acima da maior harmônica da rede elétrica $\left(50^{\mathrm{a}}\right)$ utilizada para fins práticos para analisar sistemas de potência e àquelas relacionadas aos fenômenos de curtocircuito [9]. Deste modo o amplificador é adequado para efetuar medições de transitórios oriundos de faltas no sistema elétrico. 


\section{4 - Calibração da bobina sonda}

A calibração da bobina sonda foi realizada para estabelecendo-se uma relação entre o valor medido em um osciloscópio e o campo de indução magnética uniforme produzido pelas bobinas de Helmholtz. Este conjunto é constituído por duas bobinas circulares, planas, cada uma contendo $N$ espiras com correntes no mesmo sentido. A separação entre estas bobinas é igual ao raio $R$ comum a ambas. O campo de indução magnética $B$ é calculado pela equação (10), [85]:

$$
B=\frac{8 \mu_{0} N}{5 \sqrt{5} R} . I
$$

$\mathrm{N}=$ Número de espiras da bobina de Helmholtz $=154$;

$R=$ Raio da bobina de Helmholtz $=0,2 \mathrm{~m}$

I = corrente na bobina de Helmholtz

$$
\mu_{0}=4 \pi \cdot 10^{-7} \frac{\mathrm{H}}{\mathrm{m}}
$$

Substituindo na equação (10) os valores numéricos, tem-se :

$$
B=6,92 \cdot 10^{-4} \text {. । }
$$

Para a calibração da bobina sonda usou-se o circuito da Figura 3, na frequência de $60 \mathrm{~Hz}$.

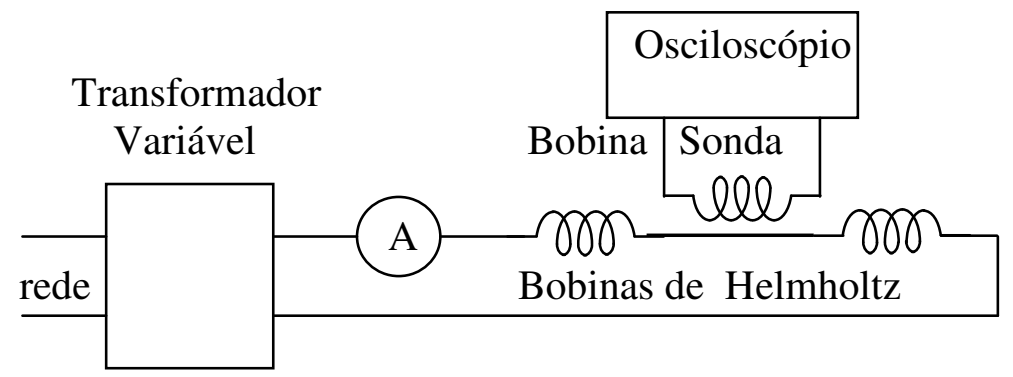

Figura 3- Circuito de calibração da bobina sonda - Helmholtz 


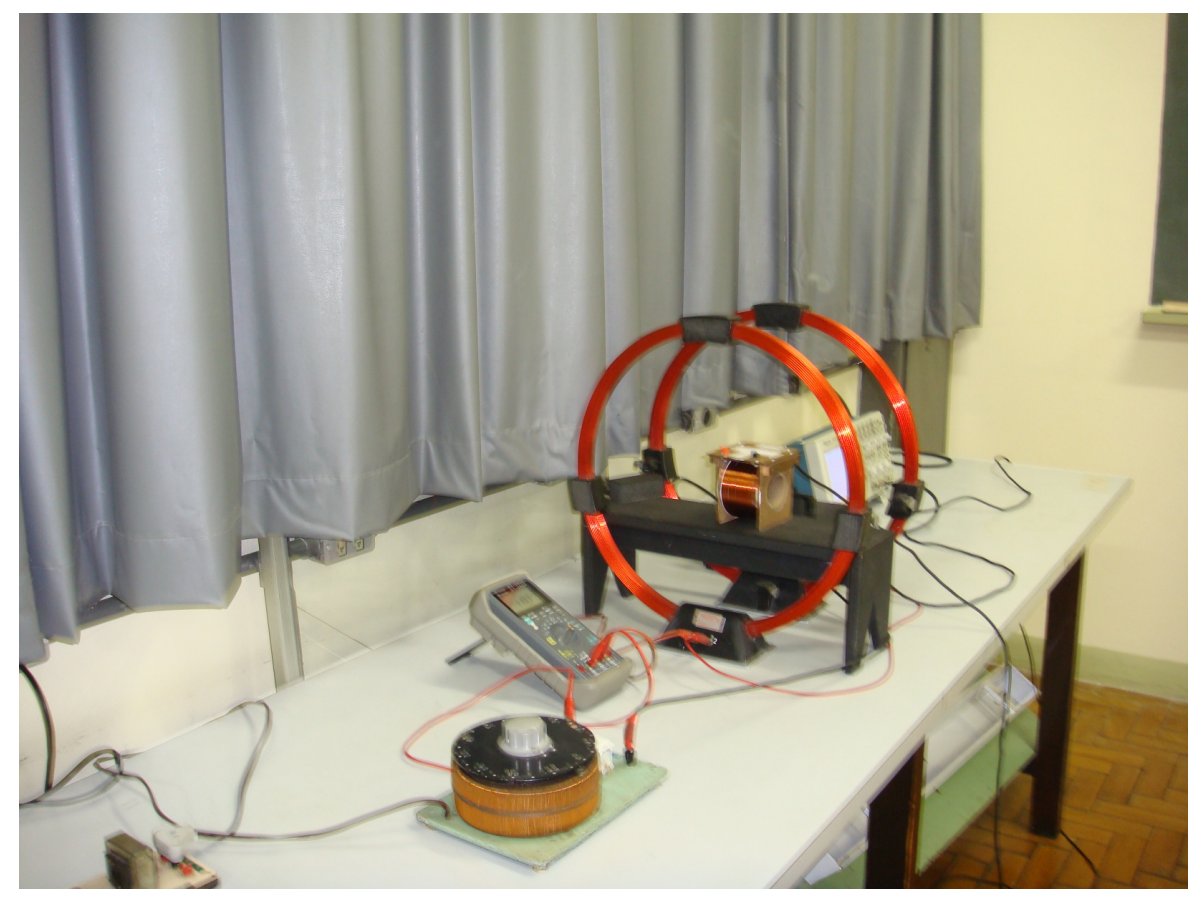

Figura 4 - Foto do circuito de calibração da bobina sonda

Variando-se a tensão através de um transformador variável, altera-se a corrente que circula nas bobinas de Helmholtz. Esta corrente é medida pelo amperímetro digital. A bobina sonda é colocada na região central, entre as duas bobinas de Helmholtz, onde a densidade de fluxo magnético é uniforme. A tensão induzida na bobina sonda é medida pelo osciloscópio. A densidade de fluxo magnético gerada corrente através das bobinas de Helmholtz é calculada pela equação (11). Os dados medidos e calculados estão na Tabela 3 . $O$ gráfico da Figura 5 fornece a constante de calibração da bobina sonda.

A densidade de fluxo magnético, em micro Tesla, medida pela bobina sonda é obtida pela multiplicação da tensão de pico a pico, em milivolts , pela constante de calibraçacão 0,42 , conforme equação (12).

$$
\mathrm{B}(\mu T)=0,42(\mathrm{mVpp})
$$


Tabela 3- Calibração da bobina sonda - Helmholtz

Calibração da bobina sonda utilizando as bobinas de Helmholtz em $60 \mathrm{~Hz}$

\begin{tabular}{llll}
\hline (mAef) & $\mathrm{I}(\mathrm{mApp})$ & $\left(\mathrm{B}=6.94 .10^{-4}\right.$ & $\mathrm{I})$ \\
$\mathbf{5 0}(\mathrm{mVpp})$ \\
$\mathbf{1 0 0}$ & 141.42 & 97.86 & 240 \\
$\mathbf{1 5 0}$ & 282.84 & 195.72 & 456 \\
$\mathbf{2 0 0}$ & 524.26 & 293.59 & 684 \\
$\mathbf{2 5 0}$ & 707.11 & 489.32 & 1140 \\
$\mathbf{3 0 0}$ & 848.53 & 587.18 & 1370 \\
$\mathbf{3 5 0}$ & 989.95 & 685.04 & 1620 \\
$\mathbf{4 0 0}$ & 1131.37 & 782.91 & 1860 \\
$\mathbf{4 5 0}$ & 1272.79 & 880.77 & 2120 \\
$\mathbf{5 0 0}$ & 1414.21 & 978.63 & 2340 \\
$\mathbf{5 5 0}$ & 1555.63 & 1073.49 & 2540 \\
$\mathbf{6 0 0}$ & 1697.06 & 1174.36 & 2780 \\
$\mathbf{6 5 0}$ & 1838.48 & 1272.22 & 3020 \\
$\mathbf{7 0 0}$ & 1979.90 & 1370.09 & 3260 \\
$\mathbf{7 5 0}$ & 2121.32 & 1467.95 & 3480 \\
$\mathbf{8 0 0}$ & 2262.74 & 1565.82 & 3720 \\
$\mathbf{8 5 0}$ & 2404.16 & 1663.68 & 3950 \\
$\mathbf{9 0 0}$ & 2545.58 & 1761.54 & 4170 \\
$\mathbf{9 5 0}$ & 2687.00 & 1859.40 & 4380 \\
$\mathbf{1 0 0 0}$ & 2828.43 & 1957.27 & 4620 \\
\hline & & & \\
\hline
\end{tabular}




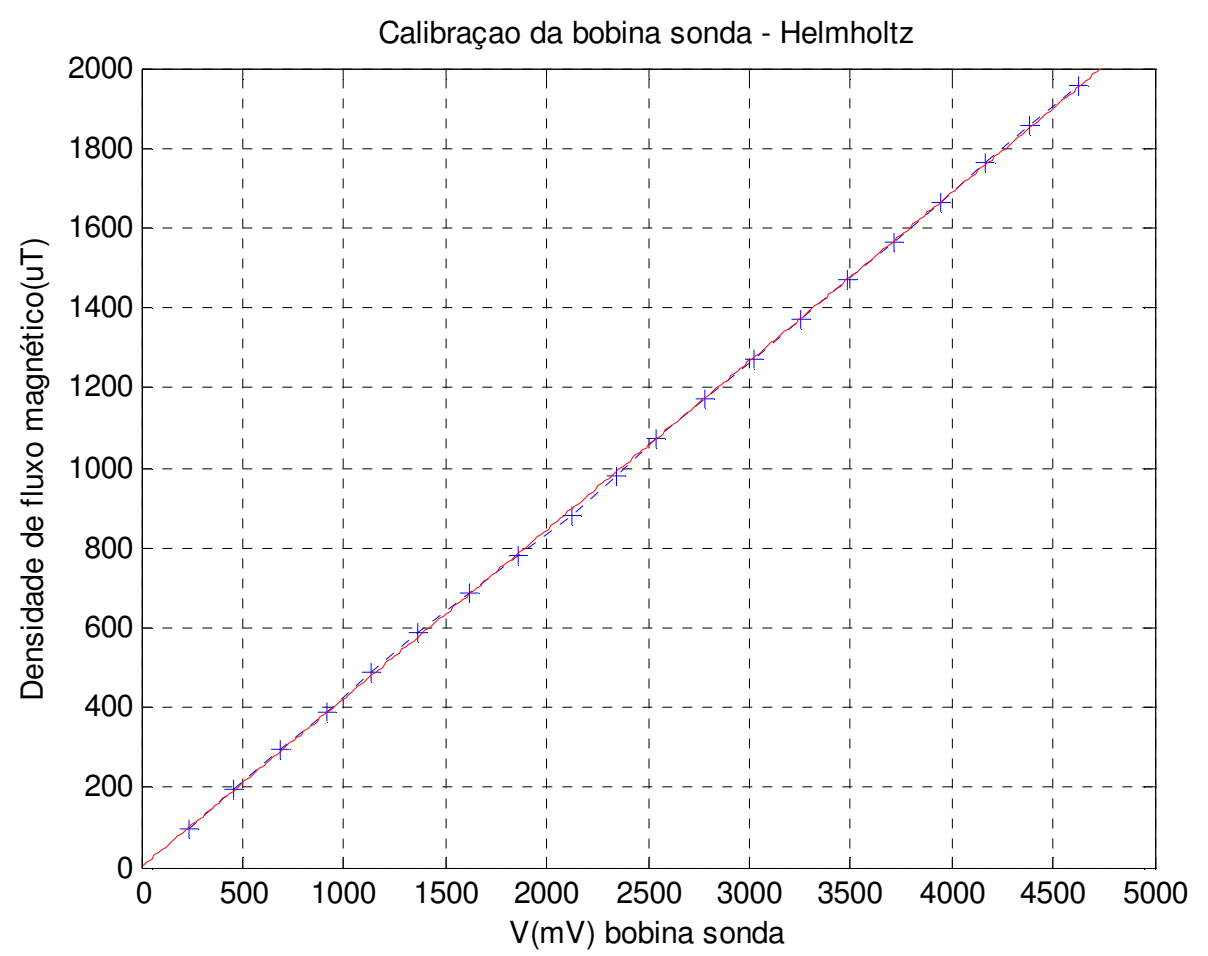

Figura 5- Calibração bobina sonda - Helmholtz $(60 \mathrm{~Hz})$

\section{5 - Resposta em frequência da Bobina sonda}

Mantendo-se constante a corrente através da bobina, teremos 0 mesmo valor para a densidade de fluxo magnético na bobina sonda. Foi ligada uma resistência em 0,33 ohms em série, para monitorar a corrente através da bobina de Helmholtz. 
Bobina de HELMHOLTZ Bobina Sonda Filtro
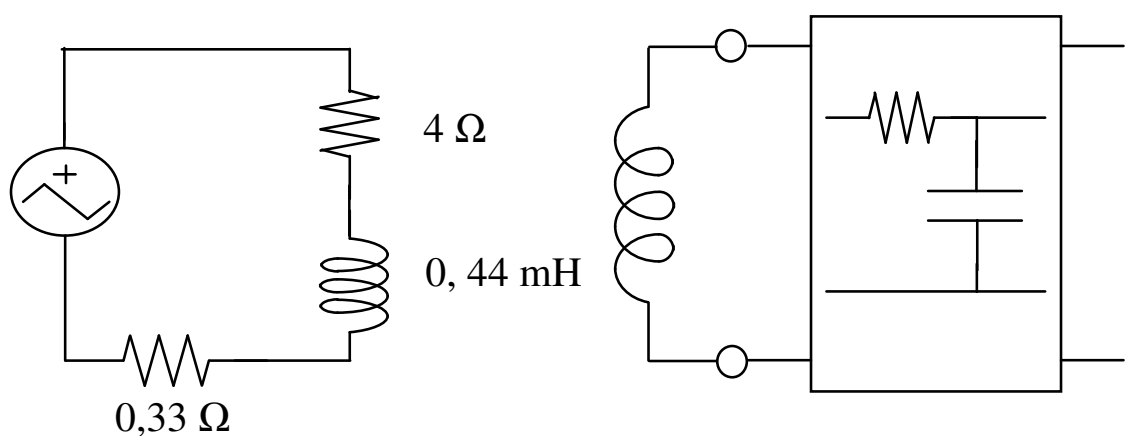

Figura 6 - Circuito de medição da resposta em frequência da Bobina Sonda.

A corrente foi mantida constante em 0,0303 App, obtendo-se pela equação (11) um fluxo de indução magnética $B=20,96 \cdot 10^{-6}$ (Tpp) e fluxo magnético $\Phi=B . S=69.6 \times 10^{-9} \quad(\mathrm{~Wb} \mathrm{pp})$

Substituindo-se na expressão (5), obtém-se a relação

$$
\text { Vsonda }(\mathrm{Vpp})=753,78.10^{-6} \mathrm{xf}
$$

Variando-se a frequência e medindo a tensão produzida pela bobina sonda, obtem-se a Tabela III abaixo.

Tabla III- Bobina de Helmholtz em função da frequência

\begin{tabular}{cc|ccc}
\hline $\mathrm{f}(\mathrm{Hz})$ & $\begin{array}{c}\text { V sonda (Vpp) } \\
\text { teórico }\end{array}$ & $\begin{array}{c}\text { Saída do filtro } \\
\text { passa baixas } \\
\text { Teórico (Vpp) }\end{array}$ & $\begin{array}{c}\text { Saída do filtro } \\
\text { passa baixas } \\
\text { Medido (Vpp) }\end{array}$ & \% erro \\
\hline 60 & 0.045 & 0.04 & 0.04 & 0 \\
120 & 0.090 & 0.09 & 0.09 & 0 \\
500 & 0.375 & 0.37 & 0.33 & 10.8 \\
1000 & 0.754 & 0.75 & 0.68 & 9.3 \\
2000 & 1.540 & 1.48 & 1.36 & 8.1 \\
3000 & 2.310 & 2,13 & 1.84 & 13.6 \\
4000 & 3.015 & 2.64 & 2.40 & 9.1 \\
5000 & 3.769 & 3.10 & 2.80 & 9.7 \\
6000 & 4.522 & 3.48 & 3.26 & 6.3 \\
7000 & 5.276 & 3.79 & 3.36 & 11.3 \\
8000 & 6.030 & 4.04 & 3.60 & 11.0 \\
\hline 9000 & 6.784 & 4.25 & 3.82 & 10.1 \\
\hline
\end{tabular}


Sabendo-se que a força eletromotriz induzida na bobina é diretamente proporcional à frequência angular $\omega$, obtem-se uma reta para a tensão de saída da bobina sonda. Após passar pelo filtro passa-baixas, obtem-se o valor teórico da saída. As curvas teóricas e medida estão indicadas na Figura 7 abaixo

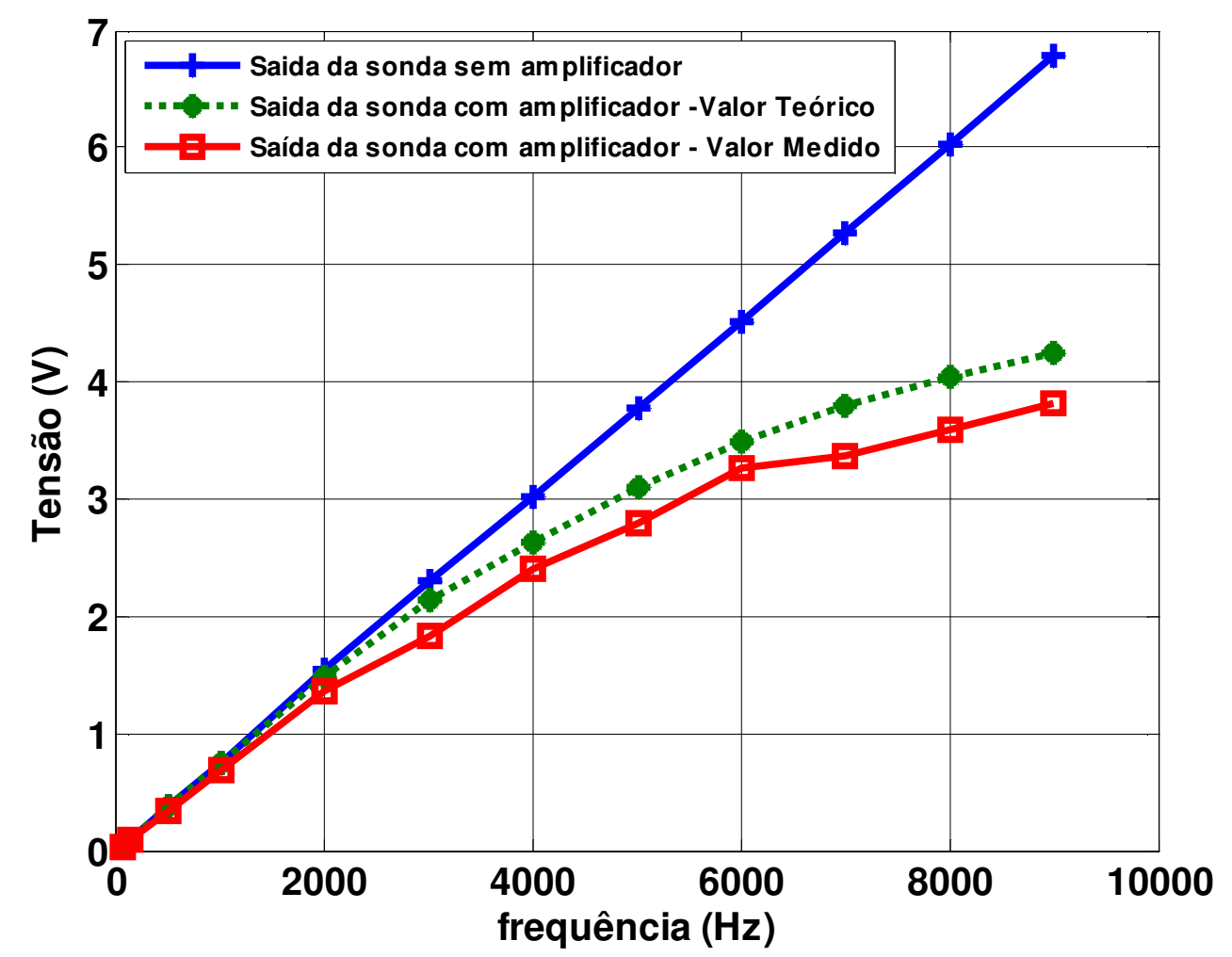

Figura 7- Resposta em frequência da bobina sonda, submetida ao campo de indução magnético uniforme da bobina de Helmholtz

O sensor magnético construído e calibrado, juntamente com o amplificador, foi utilizado para realizar todas as medições da densidade de fluxo magnético da bancada experimental. 


\section{9- APÊNDICE - B}

\section{MATLAB}

O software Matlab foi usado para analisar os dados deste trabalho.

1- Programa Matlab utilizado para obtenção dos transitórios no domínio do tempo

$\%$ Analise dos transistorios no MatLab

$A=[] ; \quad \%$ arquivo de dados da variável tempo

$\mathrm{B}=[\mathrm{j} ; \quad \%$ arquivo de dados da bobina 1, posicionado debaixo da Fase1

$\mathrm{C}=$ []; $\%$ arquivo de dados da bobina 2; posicionado debaixo da Fase2

$\mathrm{D}=$ []; $\%$ arquivo de dados da bobina 3; posicionado debaixo da Fase3

$\mathrm{E}=[\mathrm{]} ; \%$ arquivo de dados da bobina 4; afastada da linha

$B 20=B^{*} 480 ; \quad \%$ valores medidos $x$ fator de correção da bobina 1

$\mathrm{C} 20=C^{*} 480 ; \quad \%$ valores medidos $\times$ fator de correção da bobina 2

D20 $=D^{*} 480 ; \quad \%$ valores medidos $\times$ fator de correção da bobina 3

$\mathrm{E} 20=\mathrm{E}^{*} 420 ; \quad \%$ valores medidos $\mathrm{x}$ fator de correção da bobina 4

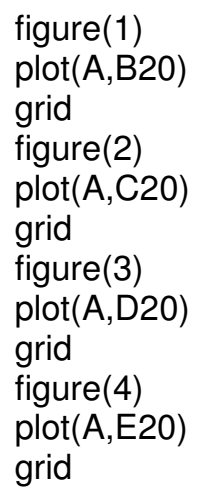

\section{2 - Programa Matlab para obtenção do Espectro - FOURIER}

$\% \mathrm{M}=$ arquivo de dados ;

[f,mag] = daqdocfft(M,10000,2000); \%calcula a fft de $\mathrm{M}$ usando freqüência de amostragem $\% 10000$

$\begin{array}{ll}x \mathrm{fft}=\mathrm{abs}(\mathrm{fft}(\mathrm{M})) ; & \% \text { modulo } \\ \mathrm{mag}=20^{*} \log 10(\mathrm{xft}) & \% \text { modulo em } \mathrm{dB} \\ \mathrm{mag}=\operatorname{mag}(1: 2000 / 2) ; & \end{array}$

$f=f(:)$;

$\operatorname{plot}(\mathrm{f}, \mathrm{mag})$;

grid on

ylabel('Amplitude (dB)')

xlabel('Frequencia $(\mathrm{Hz})$ ')

title('Espectro do sinal ')

axis([0 500 - 0 95]) 
3 - Roteiro para obter a TW

a) Salvar os dados a serem analisados através da $T W$, digitando o comando matlab Save B20.mat B20;

b) Chamar o toolbox wavelet, através do comando wavemenu;surge a Figura 1.

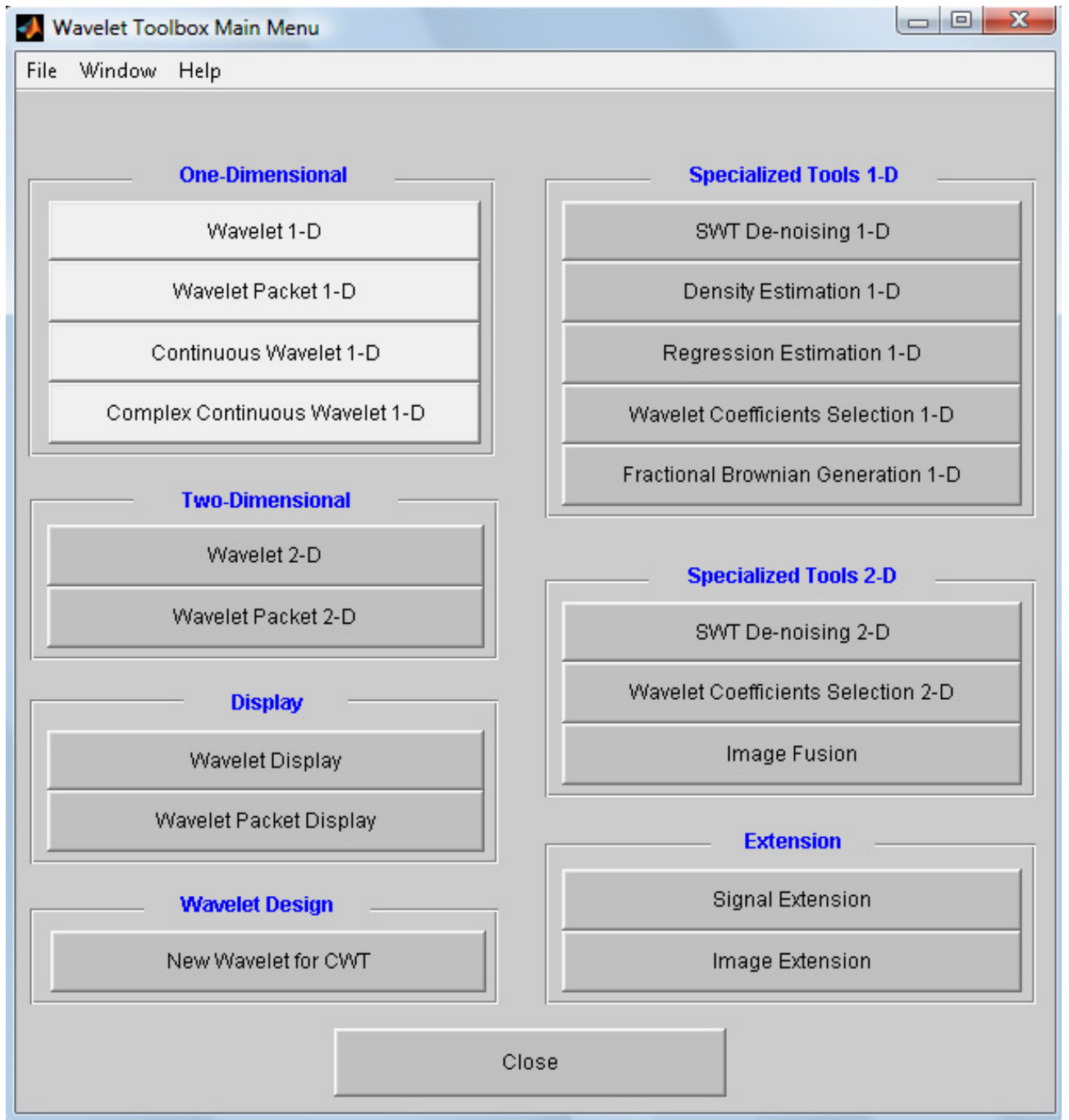

Figura 1 - tela inicial do toolbox wavemenu. 
c) Escolher wavelet 1-D, carregar o arquivo do sinal File, Load, Signal e escolher os dados a serem analisados.

d) Selecionar a família wavelet dB4 nível 10, analisar e selecionar o modo de apresentação. Figura 2.

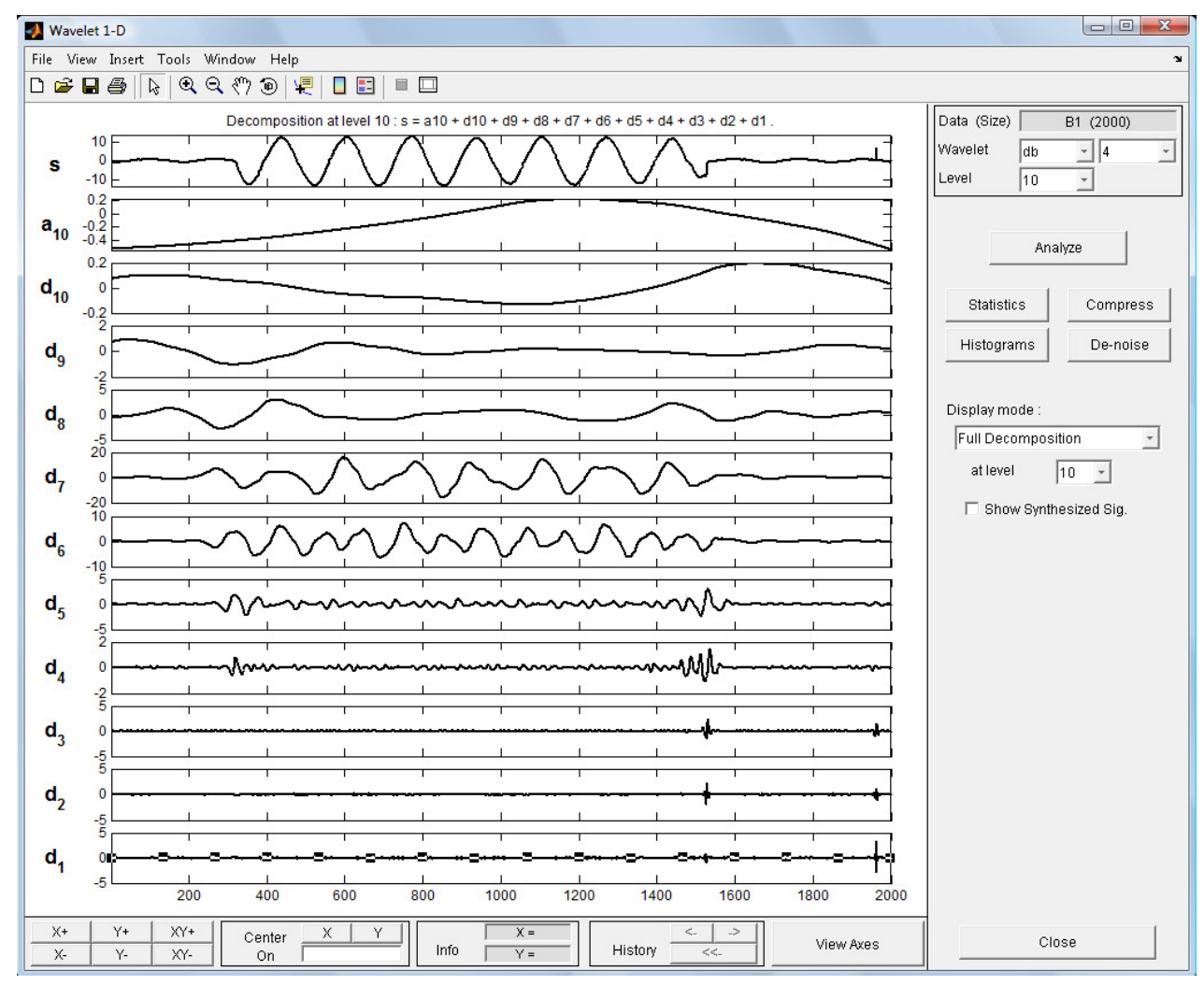

Figura 2 - wavelet dB4 nível 10, 
4 - Obtenção do desvio padrão e variância

Na tela wavelet 1D selecionar: Estatística, Detalhe, Detalhe no nível 1, Sinal Reconstruído. Nos dados estatísticos pode-se ler o valor do desvio padrão para cada nível do detalhe. Para obter a variância, eleva-se ao quadrado o valor do desvio padrão. Figura 3

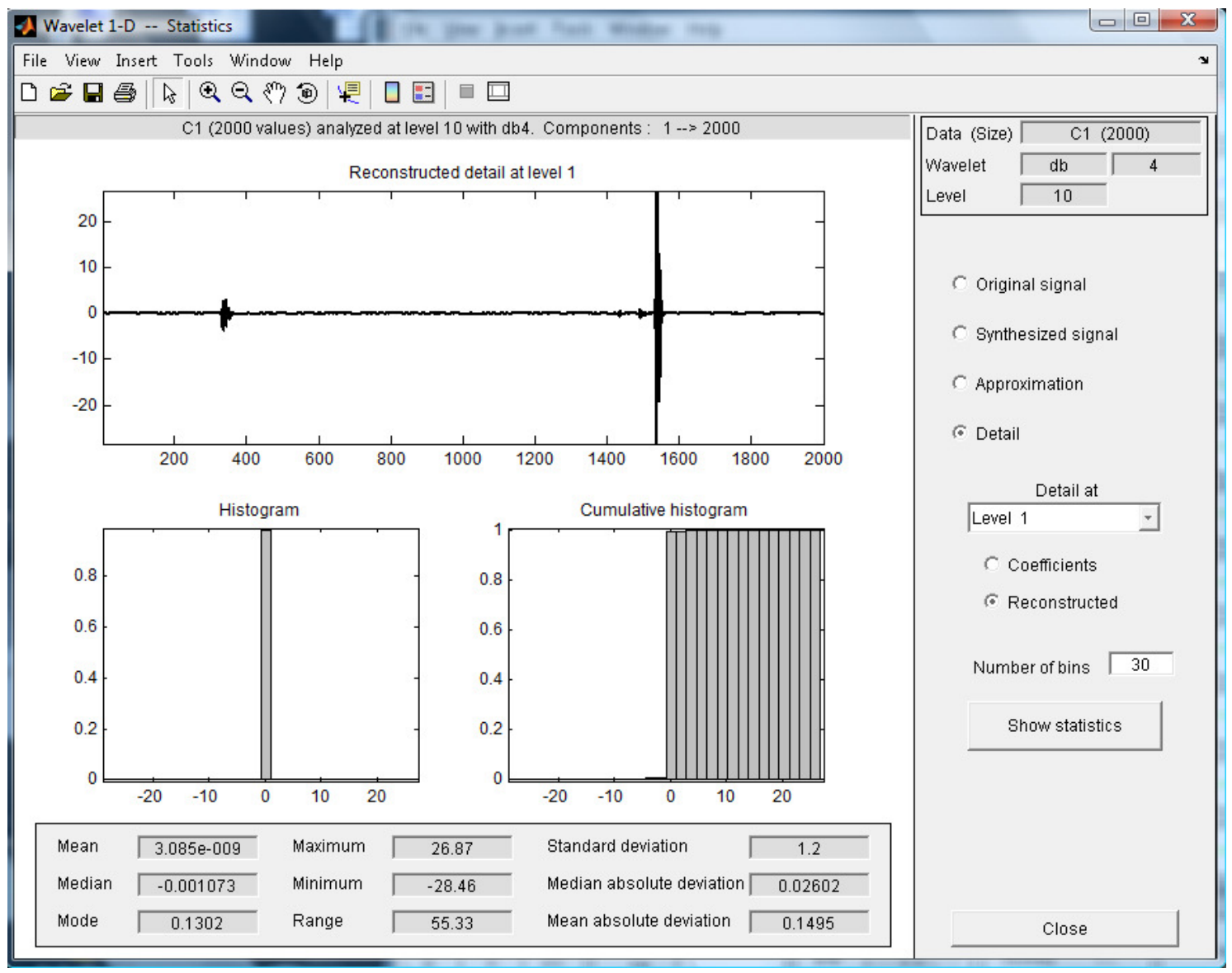

Figura 3 - Obtenção do desvio padrão e variância. 
5 - Obtenção de aproximações e detalhes

Na tela wavelet $1 \mathrm{D}$ selecionar: Display mode, Separate mode para obter a visualização das aproximações e detalhes conforme Figura 4.

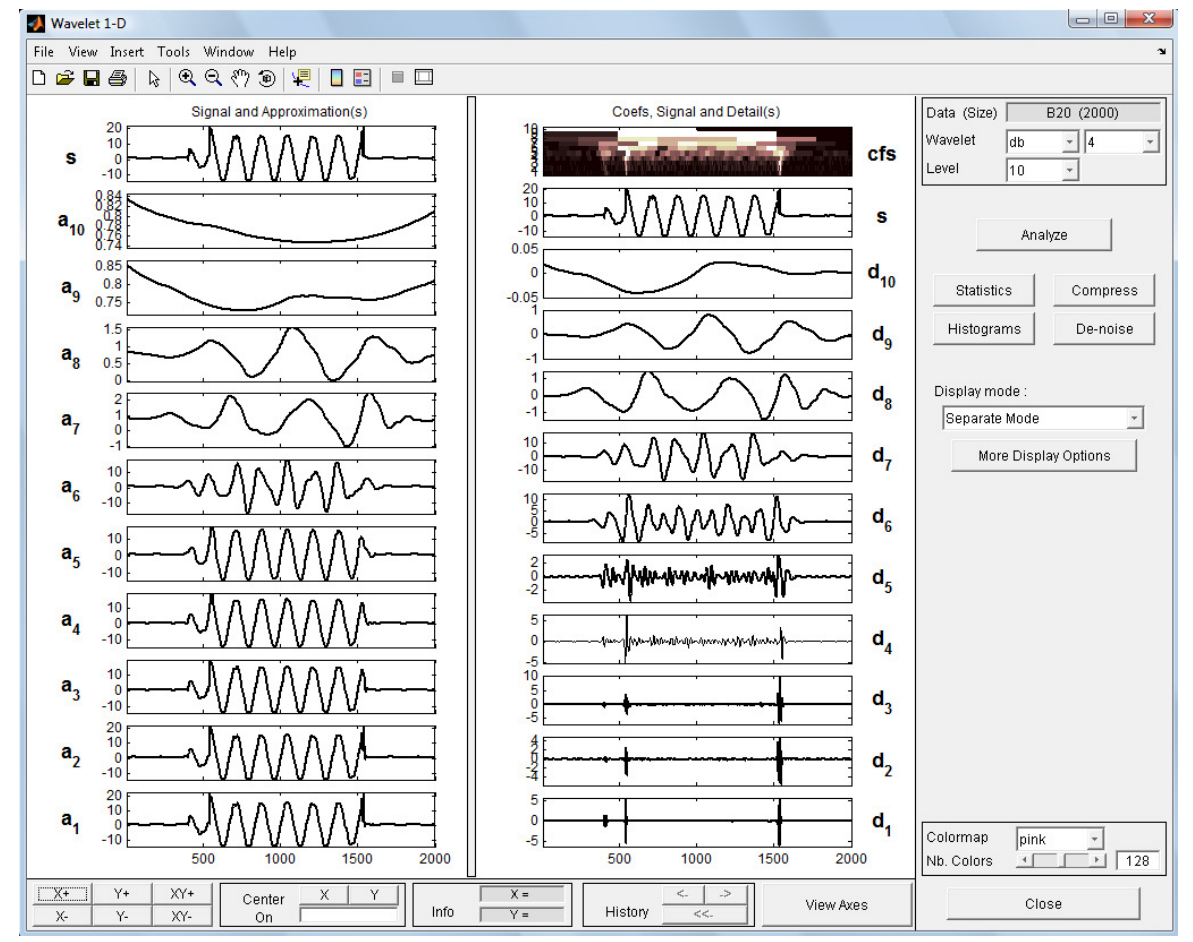

Figura 4 - Visualização das aproximações e detalhes.

6 - Programa MatLab utilizado na obtenção dos coeficientes dos detalhes e das aproximações e na reconstrução dos detalhes e das aproximações

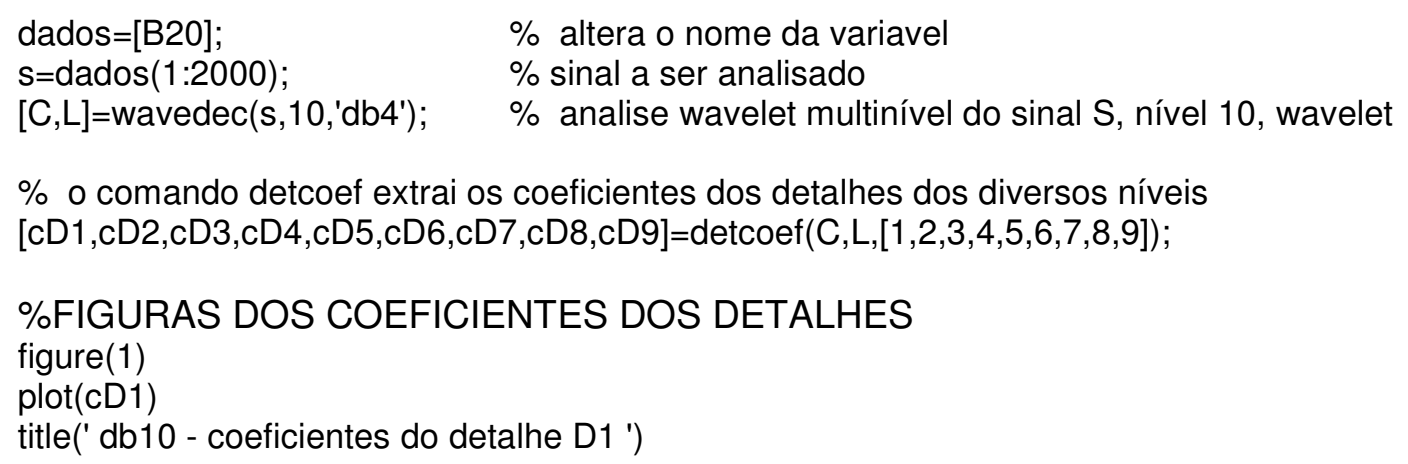


figure(2)

plot(cD2)

title(' db10 - coeficientes do detalhe D2 ')

figure(3)

plot $(\mathrm{cD} 3)$

title(' db10 - coeficientes do detalhe D3 ')

\%FIGURAS DA RECONSTRUCAO DOS DETALHES

$\%$ o comando wrcoef reconstrói um ramo à partir dos coeficientes da wavelet

$\%$ o argumento ' $d$ ' indica a reconstrução do detalhe

figure(4)

D5=wrcoef('d',C,L,'db4',5);

plot(D5)

title('db10 - Detalhe reconstruido - D5 ')

figure(5)

plot(A,D5)

title(' db10 - coeficientes do detalhe D5 COM TEMPO')

\%FIGURAS DOS COEFICIENTES DAS APROXIMAÇÕES

\% o comando appcoef extrai os coeficientes das aproximações dos diversos níveis

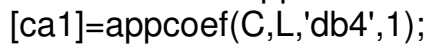

figure(6)

plot(ca1)

title('db10 - coeficientes da aproximação A1')

[ca2]=appcoef $(C, L, ' d b 4 ', 2)$;

figure(7)

plot(ca2)

title('db10 - coeficientes da aproximação A2')

[ca5]=appcoef $(C, L, ' d b 4 ', 5)$;

figure(8)

plot(ca5)

title('db10 - coeficientes da aproximação A5')

\%FIGURAS DA RECONSTRUCAO DAS APROXIMAÇÕES

$\%$ o comando wrcoef reconstrói um ramo à partir dos coeficientes da wavelet

\% o argumento 'a' indica a reconstrução da aproximação

figure(9)

A5=wrcoef('a',C,L,'db4',5);

plot(A5)

title('db10 - Aproximaçãoo reconstruida - A5 ')

figure(10)

A7=wrcoef('a',C,L,'db4',7);

plot(A7)

title('db10 - Aproximaçãoo reconstruida - A7 ') 
10 - APENDICE C

\section{FLUX 2 D}

As simulações numéricas deste trabalho, foram realizadas através do software FLUX 2D que utiliza o método dos elementos finitos.

1) Tela principal -

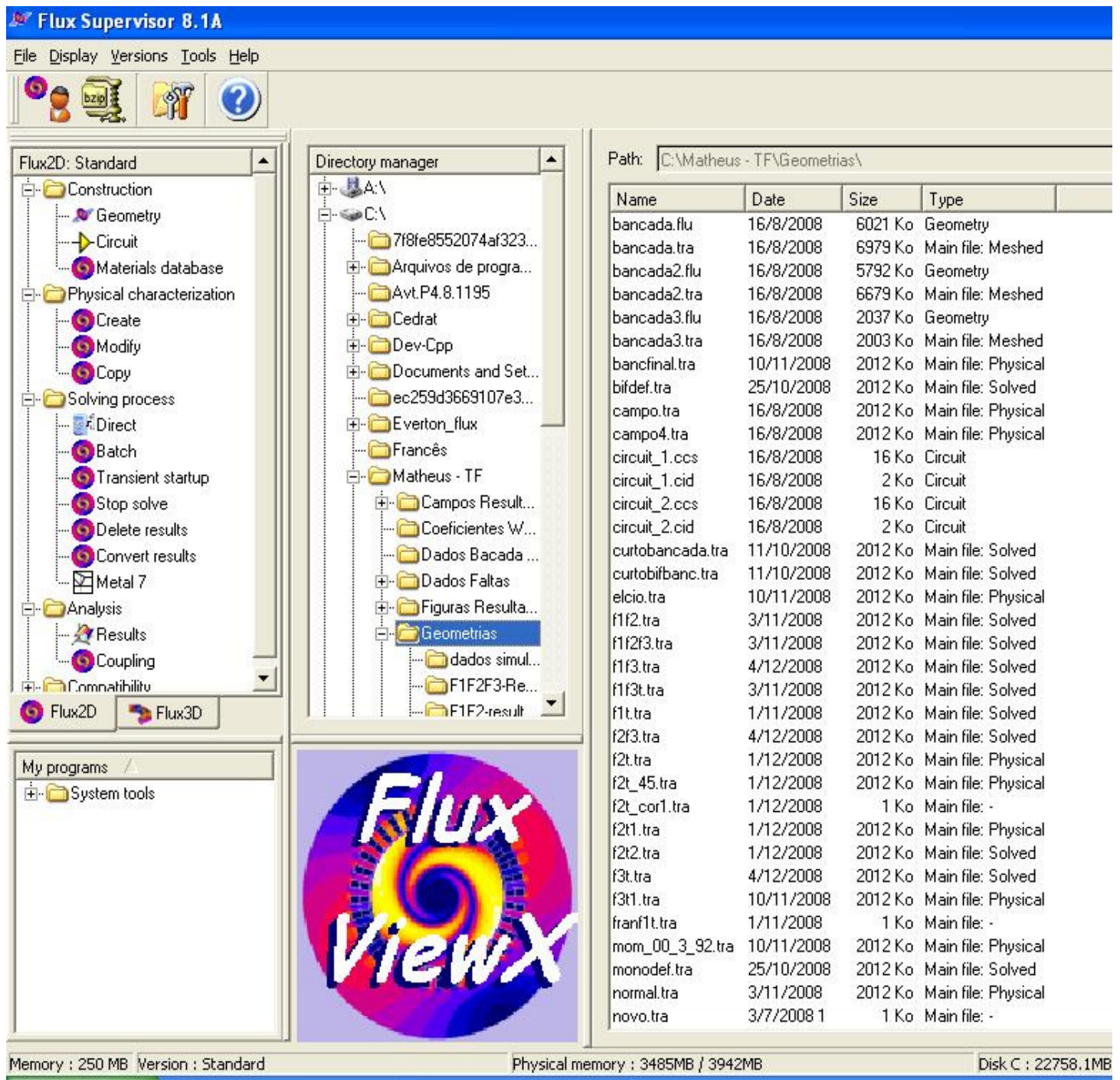

Figura 1 - Tela principal do FLUX 2D. 
2)Interface entre o MatLab e o FLUX 2D.

As correntes de faltas são introduzidas através de variáveis existentes na área de trabalho e transferidas para o FLUX 2D através do Simulink.

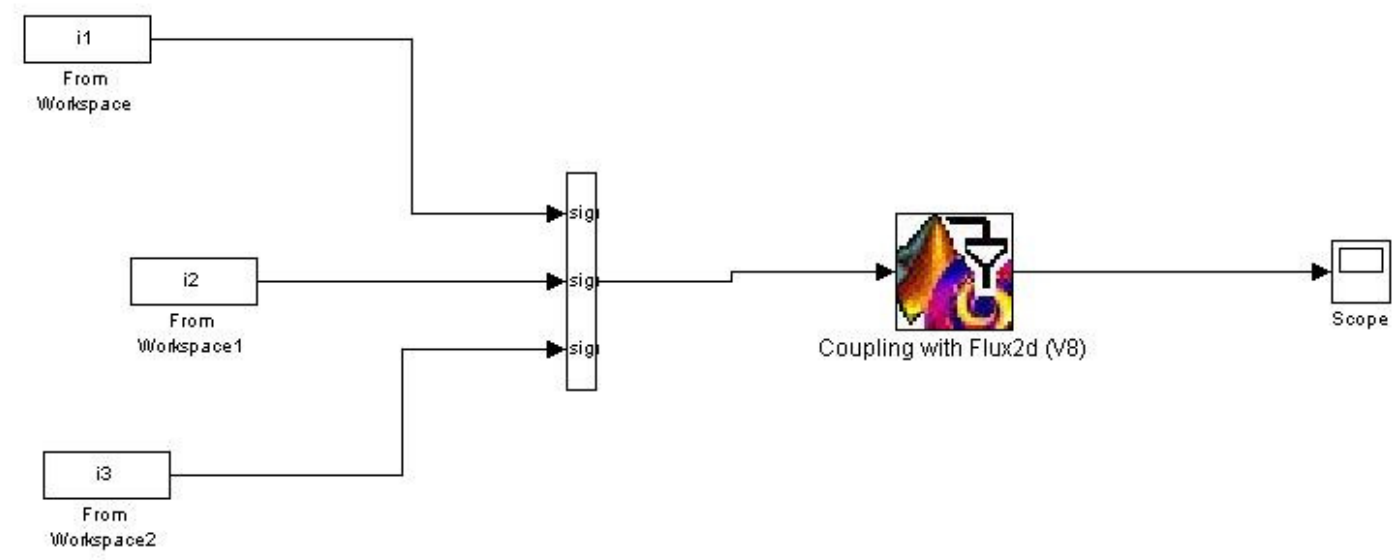

Figura 2 - Interface entre o MatLab e o FLUX 2D através do Simulink.

3)Malha da geometria

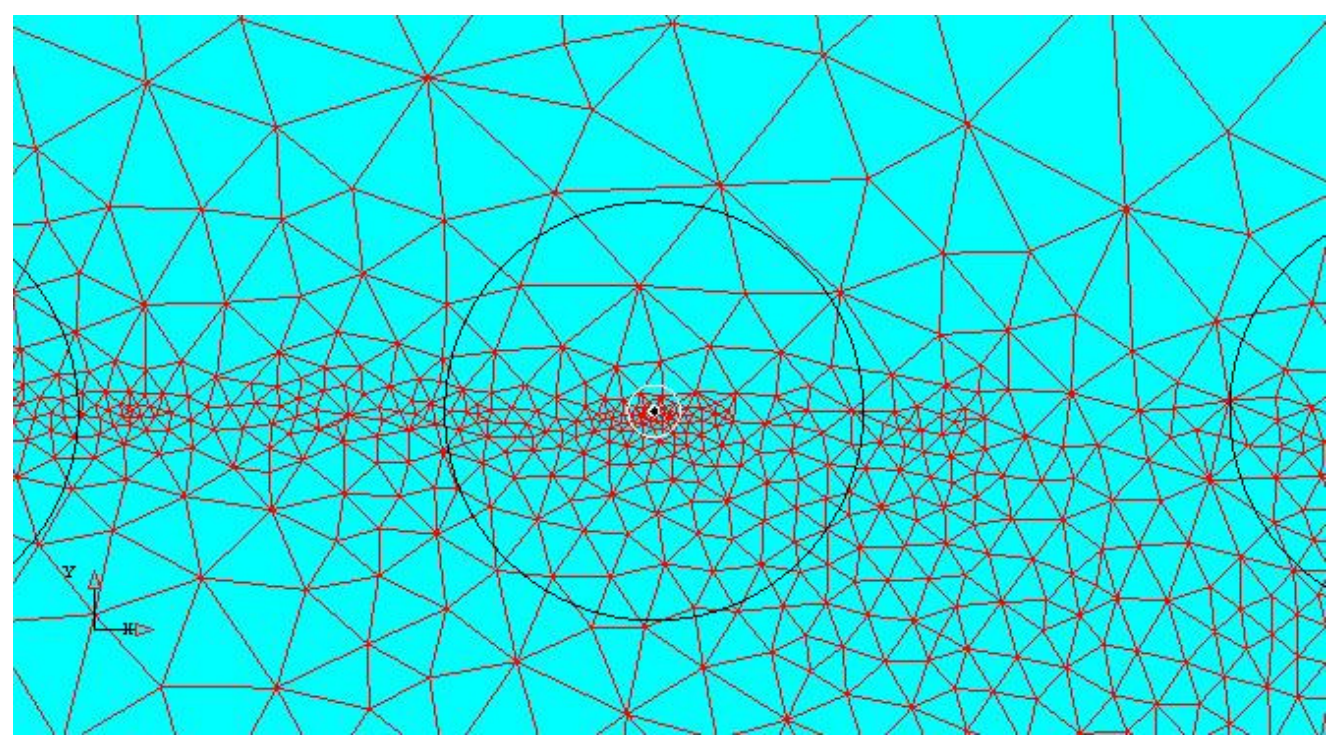

Figura 3 - Detalhe da malha utilizada 


\section{4)Tela do resultado}

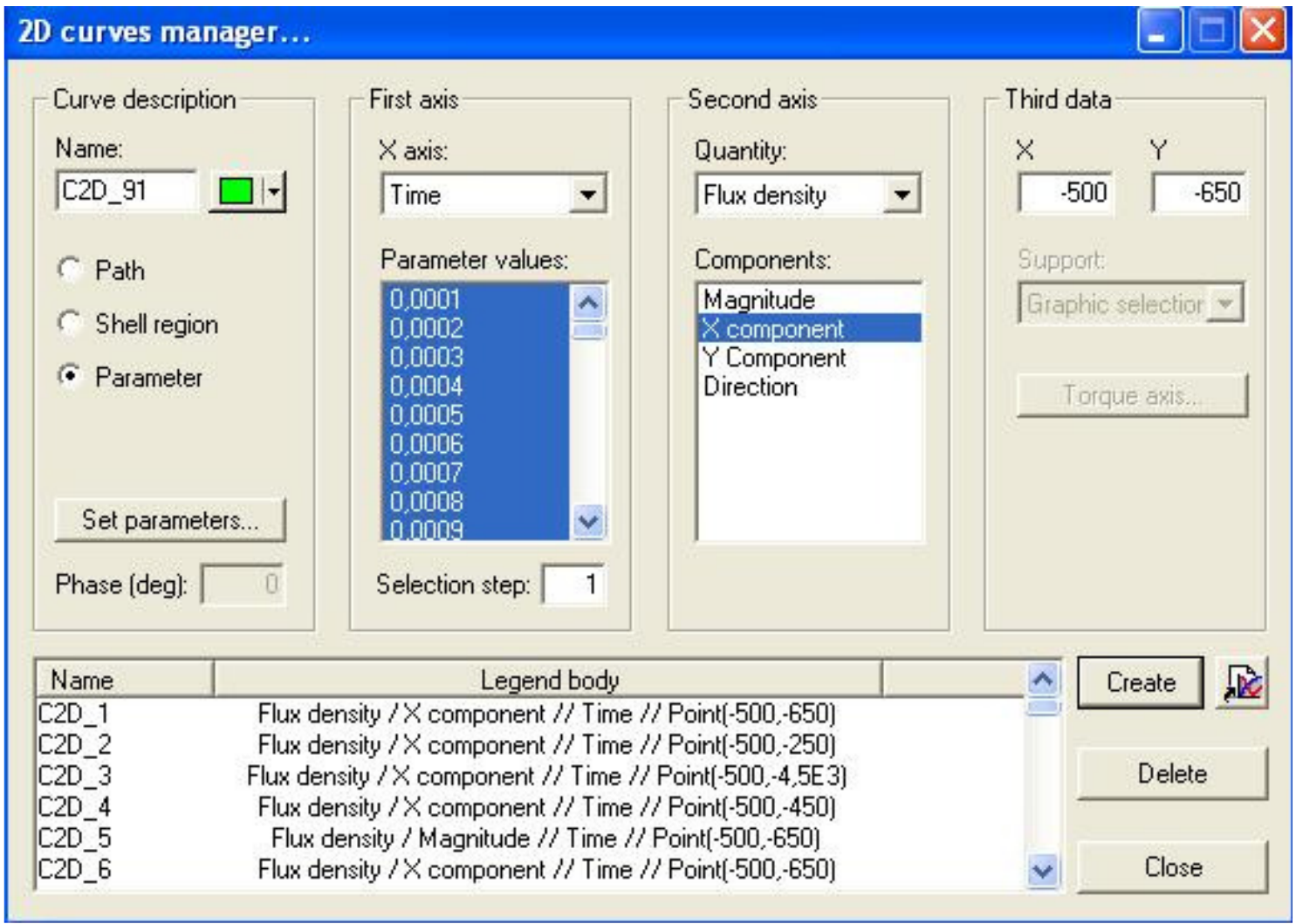

Figura 5 - Tela do resultado. 
11- APÊNDICE - D

\section{CHAVEAMENTO DE CAPACITORES}

\section{1- Introdução}

Apresentam-se, a seguir, as formas de onda da tensão, em função do tempo, resultantes da simulação, via ATP, do chaveamento de um banco de capacitores numa rede de distribuição de $13,8 \mathrm{kV}$, valor nominal. $\mathrm{O}$ valor de pico é dado por $V_{p}=(13,8 / \sqrt{3}) \cdot \sqrt{2}=11,26 \mathrm{kV}$. A freqüência de amostragem é $f_{s}=33,3 \mathrm{kHz}$. O objetivo é diferenciar o chaveamento de capacitores de um curto-circuito Fase-Terra.

2- Formas de ondas do chaveamento de um banco de capacitores das três fases A, B e C

As formas de ondas da Figura 1 mostram que durante o chaveamento a fase A sofreu maior alteração na tensão, $20,47 \mathrm{kV}$, em seguida a fase $\mathrm{C}$, $13,95 \mathrm{kV}$ e depois a fase $\mathrm{B}, 12,25 \mathrm{kV}$.

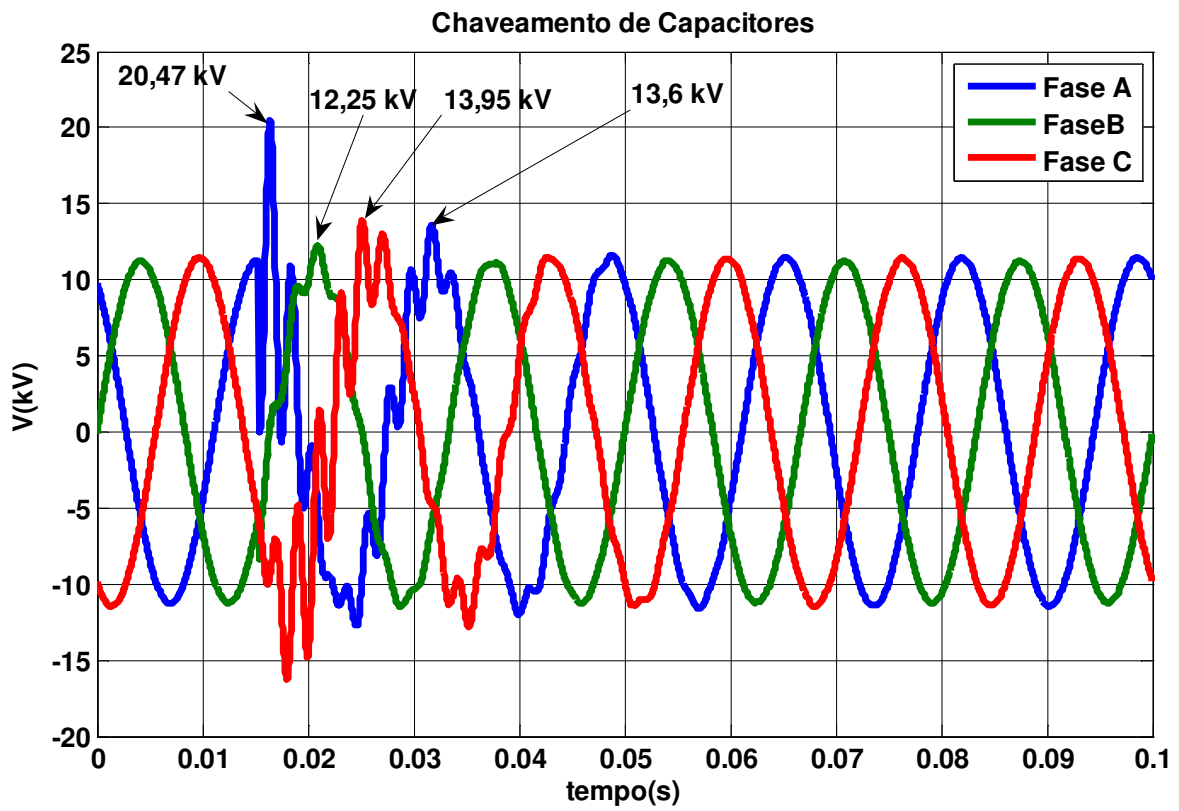

Figura 1- Chaveamento de banco de capacitores em rede de distribuição 13,8 kV. Transitórios nas fases A,B,C. Simulação ATP. 


\section{3 - Forma de onda da fase A}

A Figura 2 mostra a forma de onda do transitório na fase $A$.

O maior valor da tensão é de 20,47 kV e em regime permanente 11,6 kV. A duração transitório é de 18,72 ms.

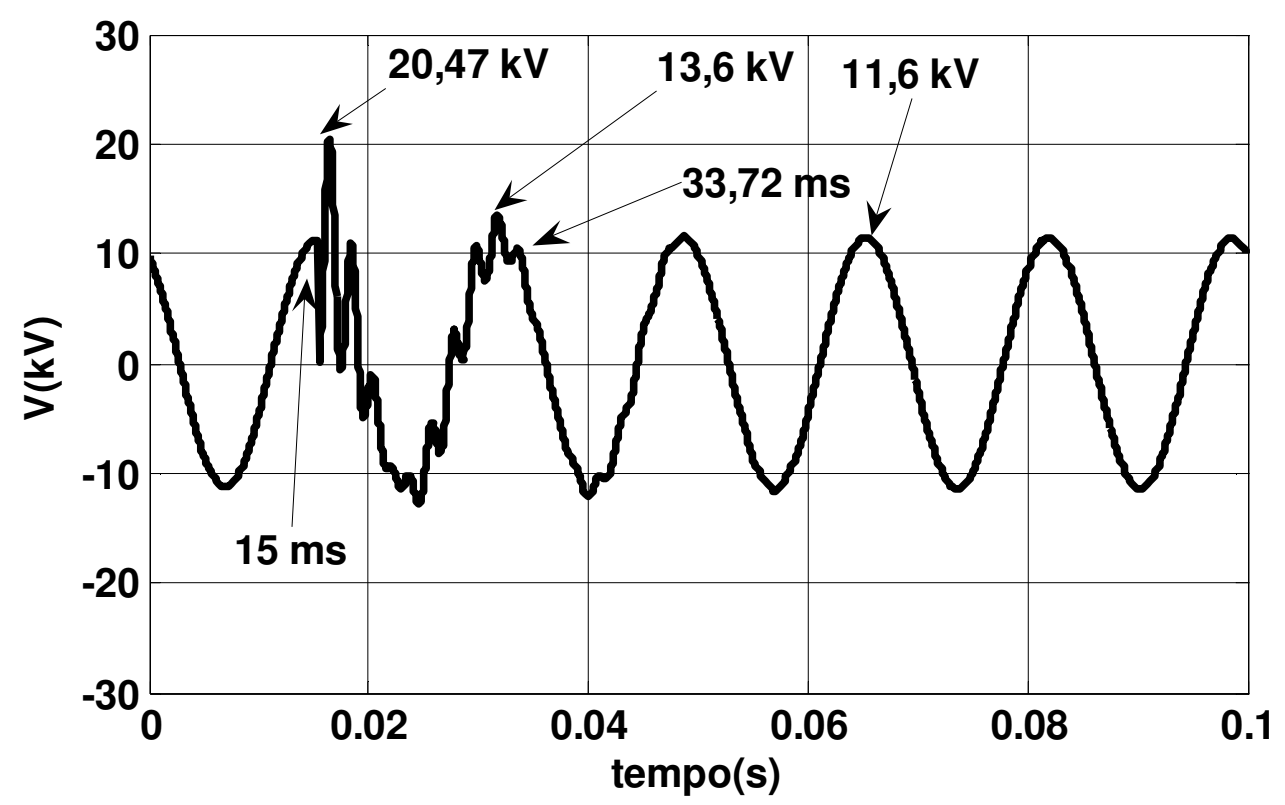

Figura 2- Chaveamento de capacitores em rede de distribuição 13,8 kV. Fase A

\section{4 - Forma de onda da fase B}

A Figura 3 fornece a forma de onda da fase B. Nota-se que a perturbação foi bem menor do que nas outras duas fases. A duração do transitório é da ordem de 7,41 ms. 


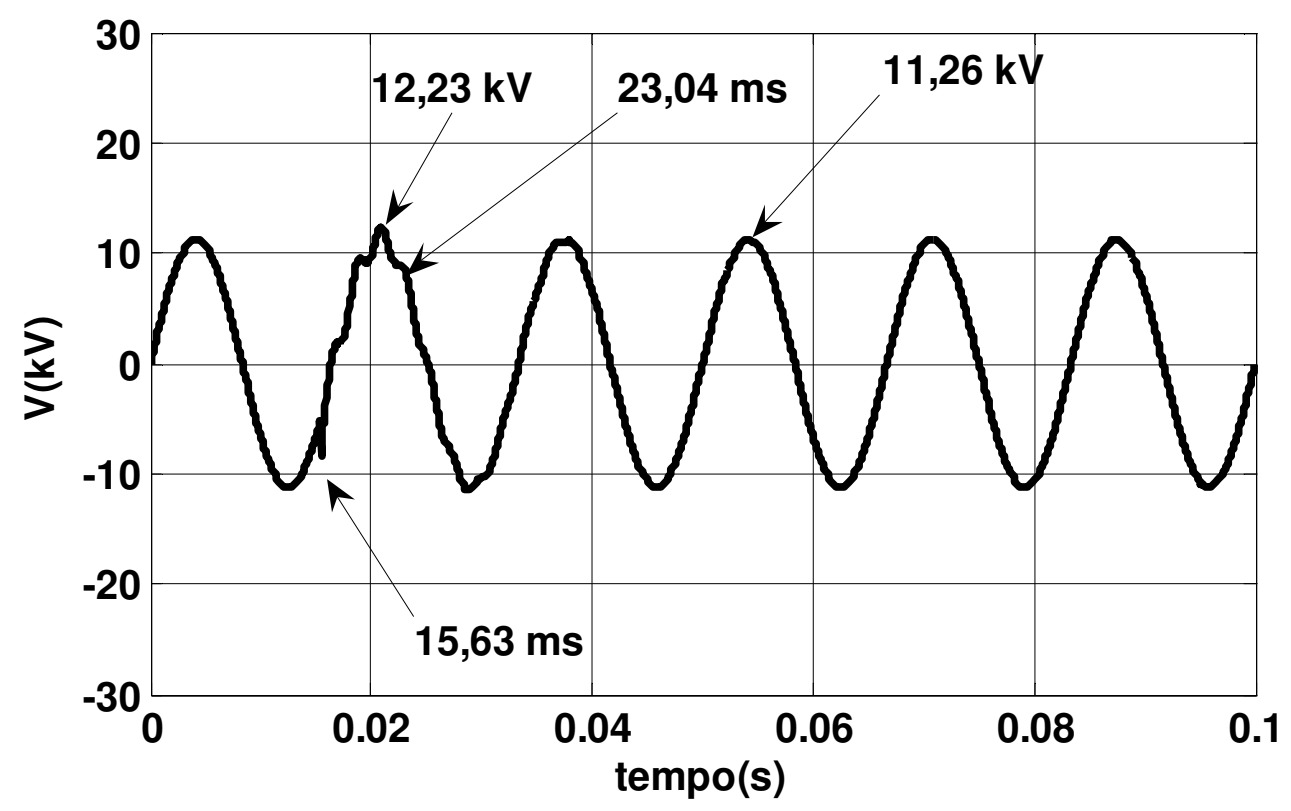

Figura 3- Chaveamento de capacitores em rede de distribuição 13,8 kV. Fase B

5 - Forma de onda da fase $C$

A forma de onda da fase $C$ está ilustrada na Figura 4. A duração do transitório é da ordem de 20,34 ms maior do que a fase $A$. 


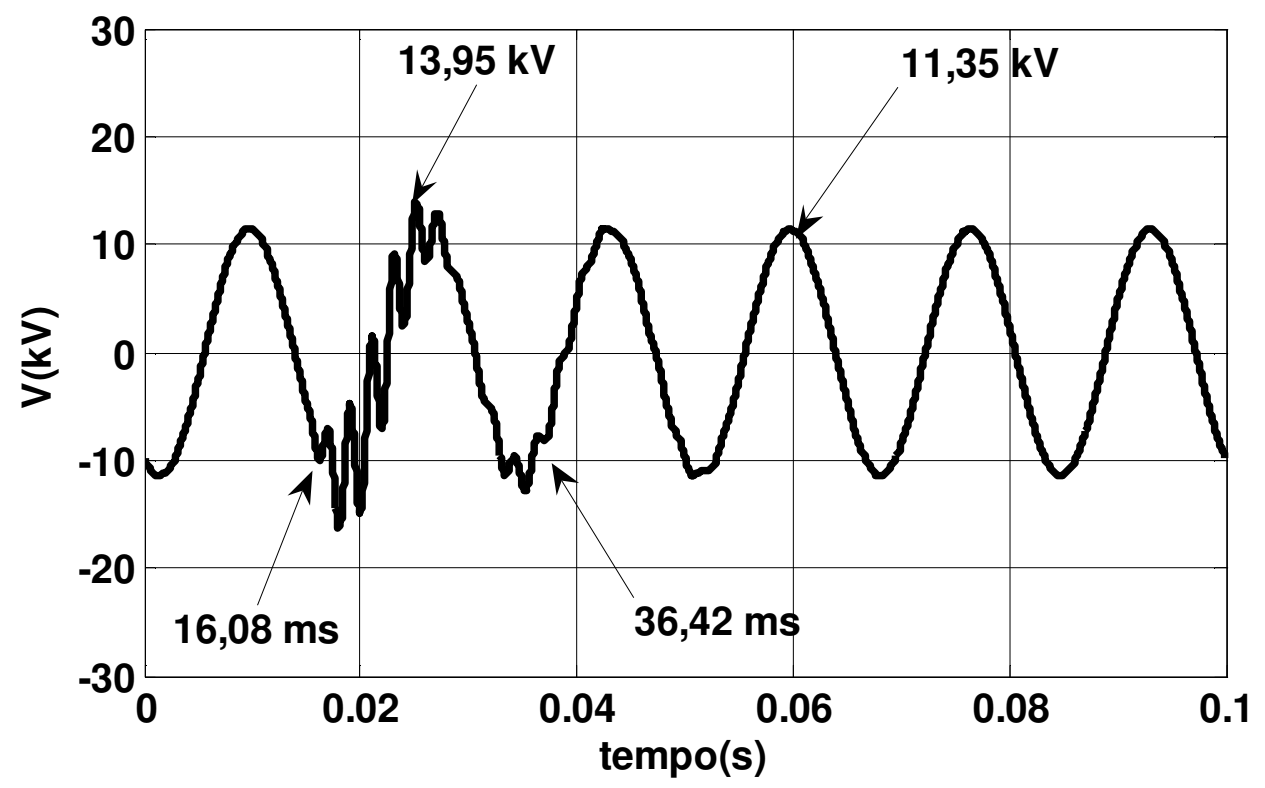

Figura 4 - Chaveamento de capacitores em rede de distribuição 13,8 kV. Fase C

6 - Análise espectral da tensão na fase A, através da Transformada Rápida de Fourier.

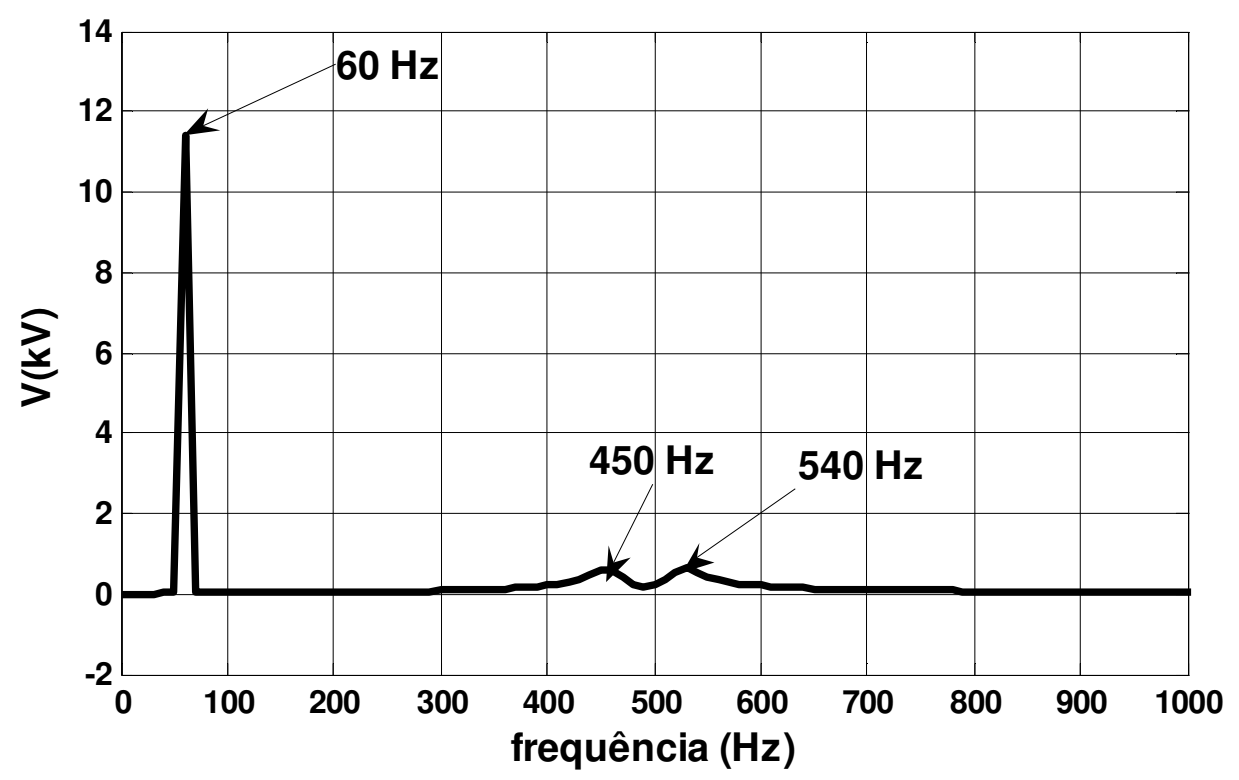

Figura 5 - Análise espectral da fase A por Fourier

A análise espectral mostra que a frequência fundamental é $60 \mathrm{~Hz}$ e possui o $9^{\circ}$ harmônico bem definido. 
7 - Análise espectral da tensão na fase A, através da Transformada Rápida de Fourier em dB.

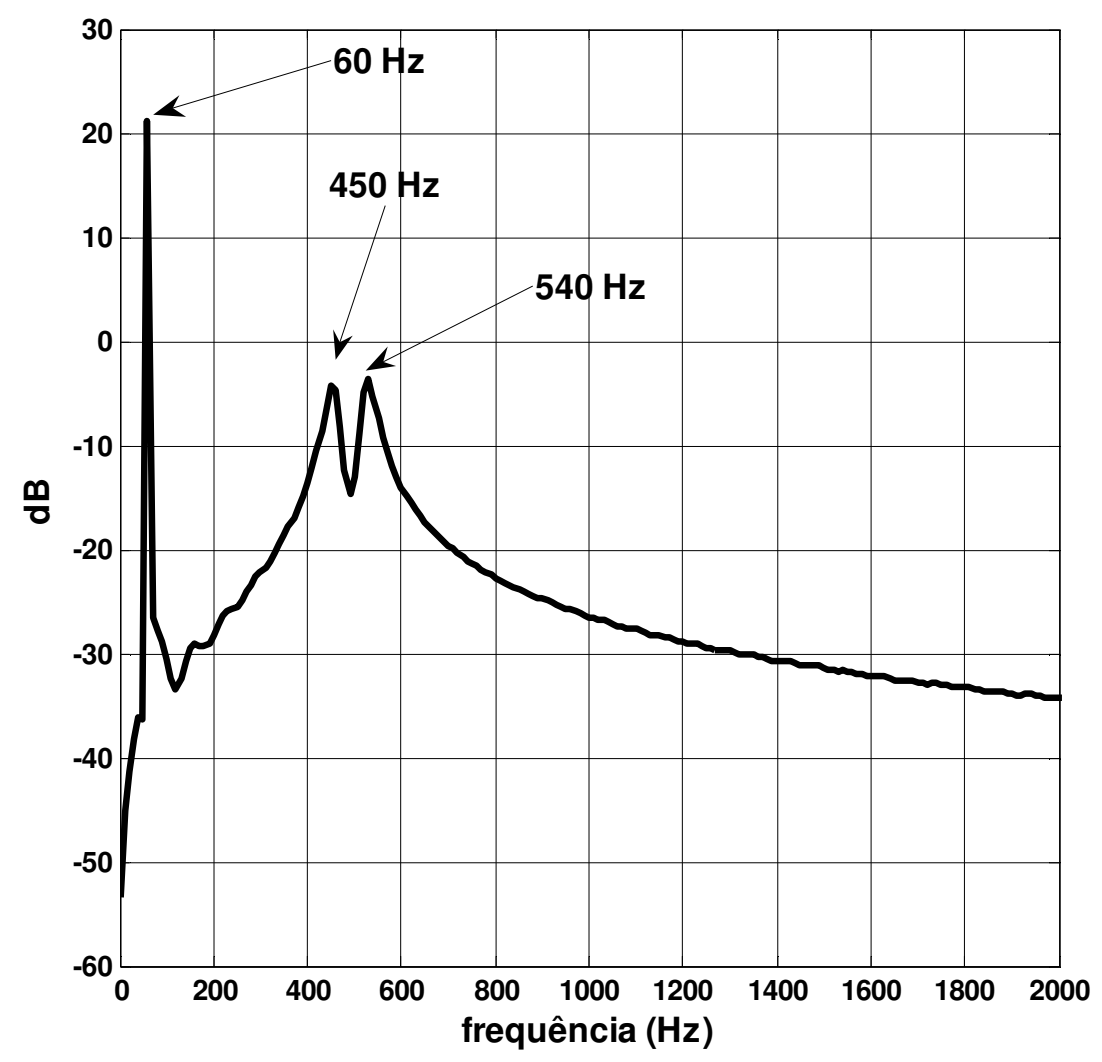

Figura 6- Análise espectral da fase A por Fourier em dB

A Figura 6 mostra 0 espectro de freqüências em $\mathrm{dB}$. A freqüência fundamental é $60 \mathrm{~Hz}$ e possui o 9 harmônico. 


\section{8 - TW aplicada à forma de onda da fase $\mathrm{A}$}

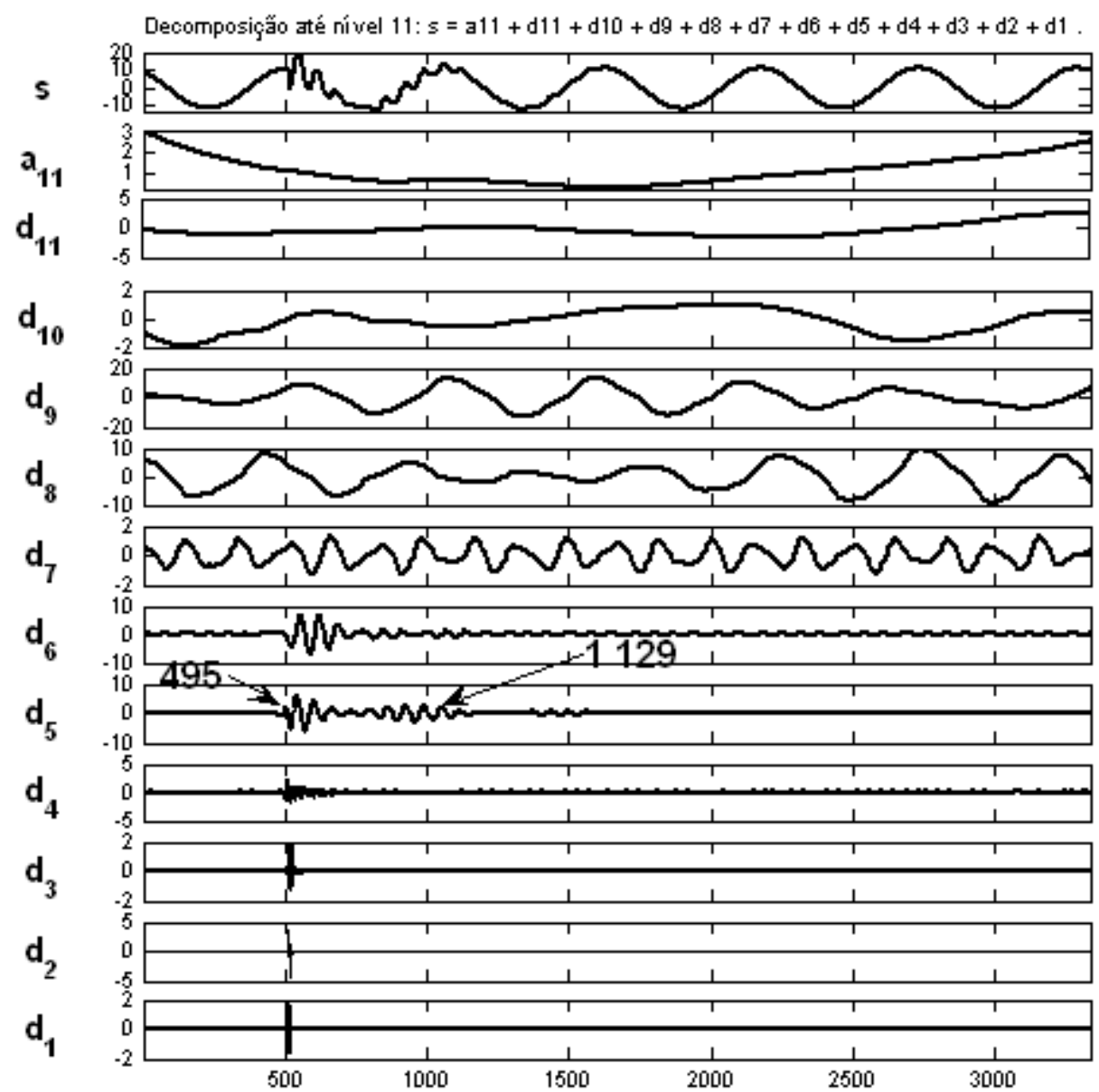

Figura 7 - TW db4-10 aplicada na forma de onda da fase A.

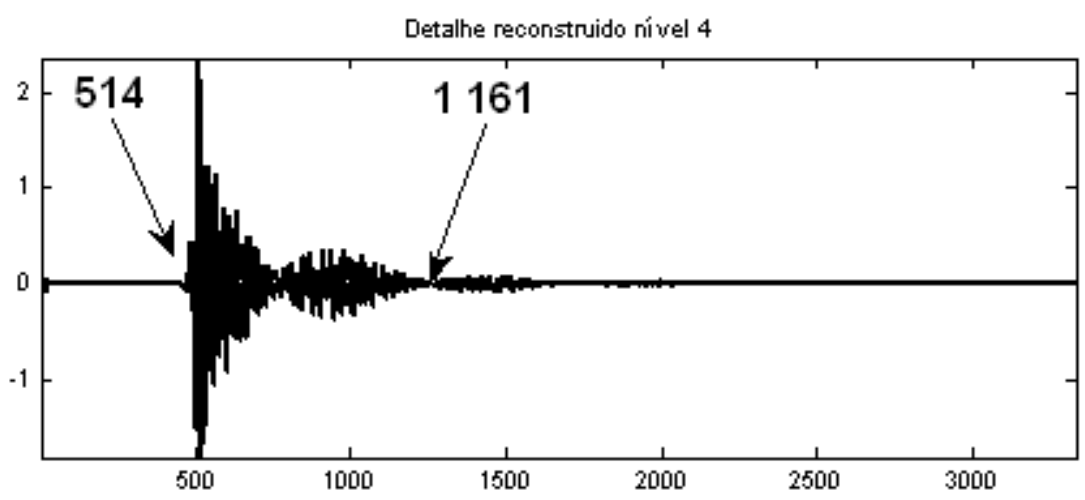

Figura 8- Detalhe d4 da $T W \mathrm{db} 4$ - 10 aplicada à forma de onda da fase $\mathrm{A}$ 
As Figuras 7 e 8 mostram o início e o fim do transitório através do detalhe 4. A duração do transitório é dado por

$$
\begin{aligned}
& \Delta t=(1129-495) \cdot 3 \cdot 10^{-5}=19,02 m s \\
& \Delta t=(1161-514) \cdot 3 \cdot 10^{-5}=19,4 m s
\end{aligned}
$$

\section{9 - TW aplicada à forma de onda da fase $\mathrm{A}$}

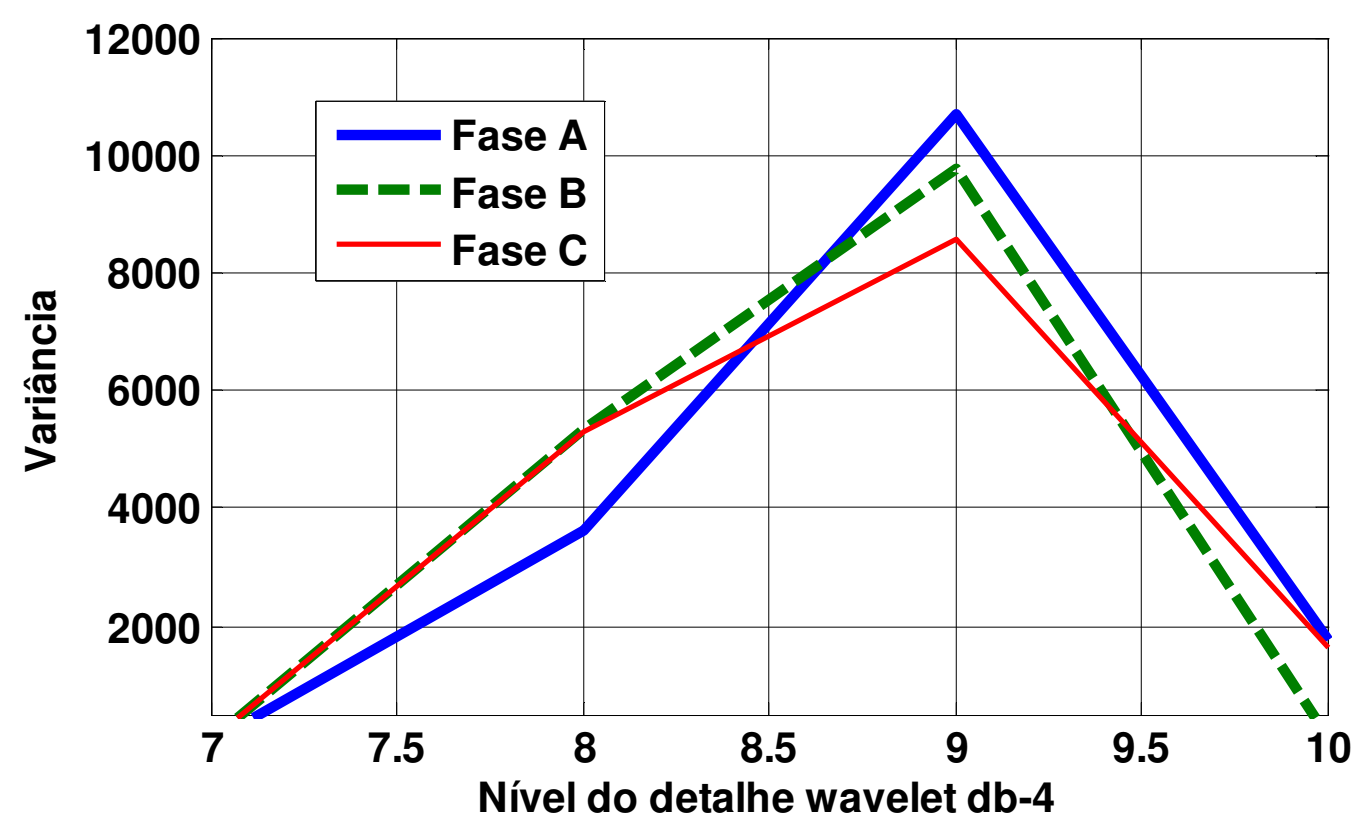

Figura 9 - Chaveamento de capacitores em rede de distribuição 13,8 kV. Fase C

A curva da variância mostra, Figura 9, que a maior energia do sinal ocorre no nível de detalhe $d_{9}$. Como a frequência de amostragem é $33,3 \mathrm{kHz}$, fazendo a decomposição pela AMR, determina-se que o detalhe $\mathrm{d}_{9}$ compreende a frequência de $60 \mathrm{~Hz}$. 